\title{
DEEP ENERGY RETROFITS: TORONTO'S URBAN SINGLE FAMILY HOUSING STOCK
}

\author{
By \\ Denver Jermyn \\ Bachelor of Engineering, University of Guelph, 2008
}

\author{
A thesis \\ presented to Ryerson University \\ in partial fulfillment of the requirements \\ for the degree of Master of Applied Science \\ in the program of Building Science
}

Toronto, Ontario, Canada, 2014

(C) Denver Jermyn 2014 


\section{Author's Declaration for Electronic Submission of a Thesis}

I hereby declare that I am the sole author of this thesis. This is a true copy of the thesis including any required final revisions, as accepted by my examiners.

I authorize Ryerson University to lend this thesis to other institutions or individuals for the purpose of scholarly research.

I further authorize Ryerson University to reproduce this thesis by photocopying or by other means, in total or in part, at the request of other institutions or individuals for the purpose of scholarly research.

I understand that my thesis may be made electronically available to the public. 


\title{
DEEP ENERGY RETROFITS: TORONTO'S URBAN SINGLE FAMILY HOUSING STOCK
}

Master of Applied Science 2014 - Denver Jermyn - Building Science Program Ryerson University

\begin{abstract}
There is a need to address the energy consumption of existing single family homes in the City of Toronto. This study outlines a process for developing and analyzing retrofit strategies for specific housing archetypes. The process was applied to Century, Century-Semi, and War Time Home archetypes. Housing data was collected and baseline energy models were prepared utilizing EnergyPlus software. Retrofit strategies were selected and analyzed for hygrothermal performance and cost. The process utilized a Brute Force method for retrofit selection considering the cost/benefit of each strategy and showed where in the process it was beneficial to upgrade each parameter. Furnace and air sealing parameters were typically upgraded early in the process as they showed an attractive cost/benefit. Basement walls and slab parameters were then upgraded, followed by exterior walls and roofs. Windows tended to be upgraded late in the process as they exhibited high capital costs compared to energy savings.
\end{abstract}




\section{Acknowledgements}

I would like to first and foremost thank my advisor Dr. Russell Richman for his dedicated guidance and support throughout this thesis. I would also like to thank Katarzyna Blaszak, Andrea Mucciarone, Ivo Markiel, and Hayes Zirnhelt whose research work inspired and laid the groundwork for my research. I would like to thank the homeowners who participated in my study for their generous support of my research and for opening their homes to me for the purpose of data collection. Finally, l'd like to thank my peers in the Building Science program who have provided ongoing insights, advice, and support during my research. 


\section{Table of Contents}

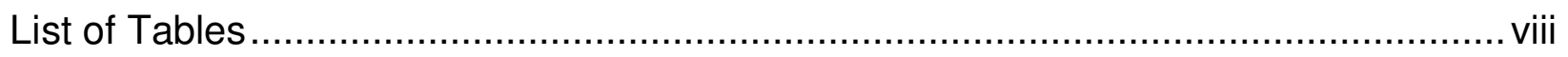

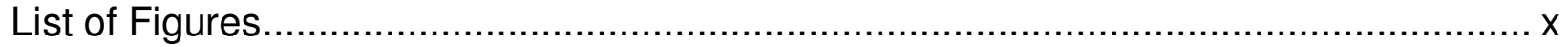

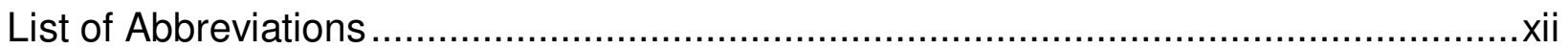

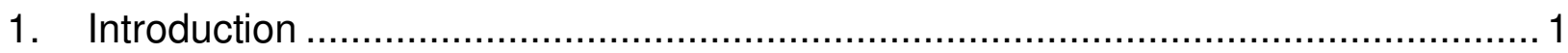

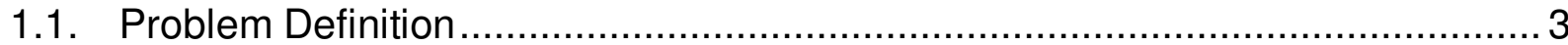

2. Background and Literature Review .............................................................. 4

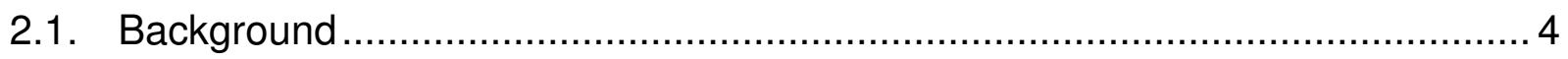

2.1.1. High Density Urban Areas of Toronto.................................................. 6

2.1.2. Existing Urban Housing Stock - Archetypes ........................................ 7

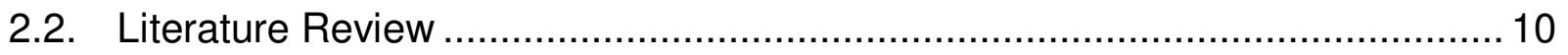

2.2.1. Deep Energy Retrofits ................................................................ 11

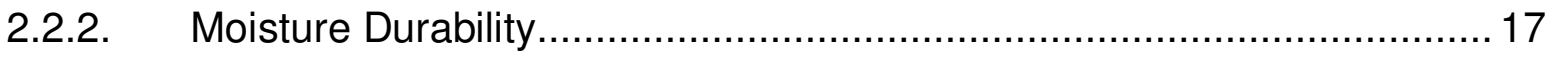

2.2.3. High Performance Buildings ............................................................... 19

2.2.4. Energy Modelling of Building Retrofit Strategies ................................. 20

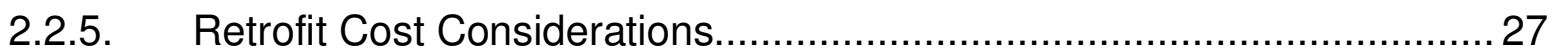

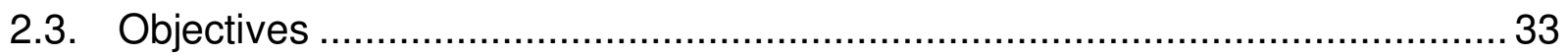

3. Methodology

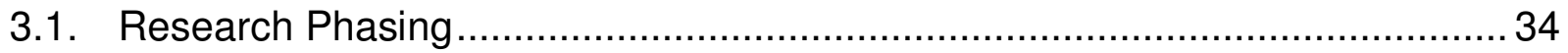

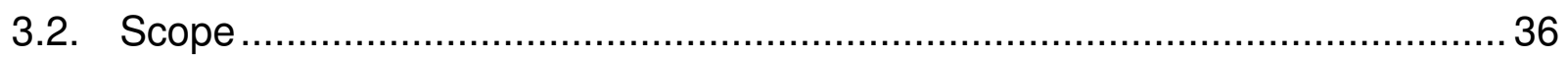

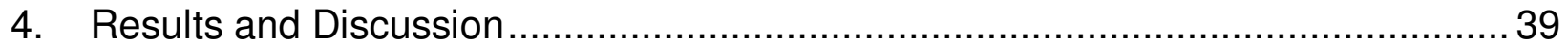

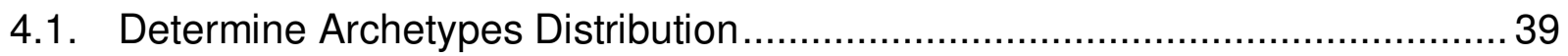

4.2. Estimate Neighbourhood Energy Intensities ............................................... 42

4.3. Considering Semi-Detached and Row Houses ........................................... 46

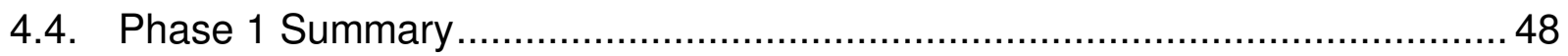

4.5. Data Collection for Baseline Energy Models .............................................. 50

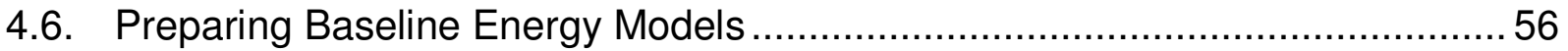

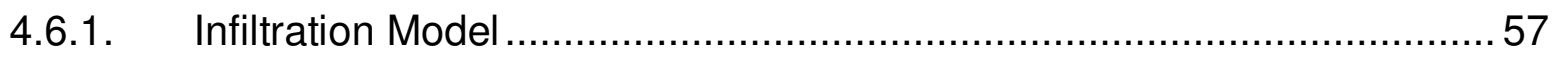

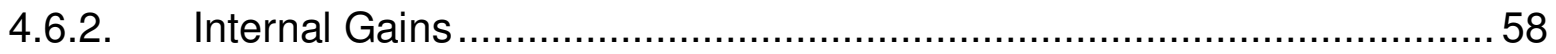

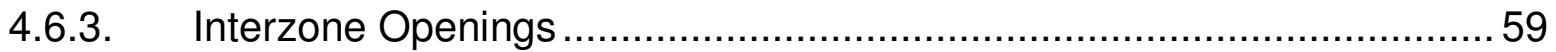




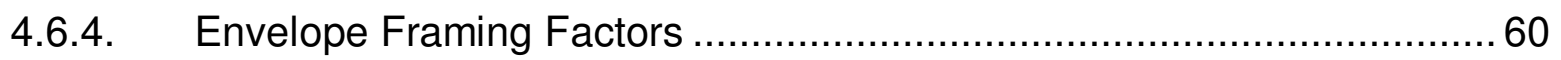

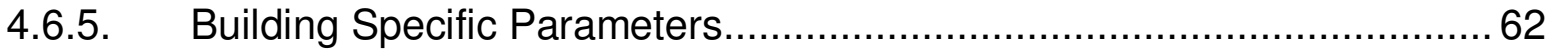

4.7. Validating the Baseline Energy Models ..................................................... 63

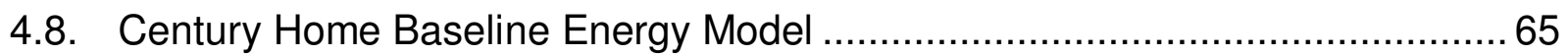

4.9. Century-Semi Home Baseline Energy Model ............................................. 67

4.10. War Time Home Baseline Energy Model ................................................. 68

4.11. Final Calibration of the Baseline Energy Models...................................... 71

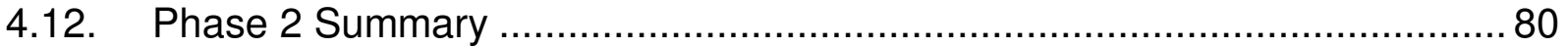

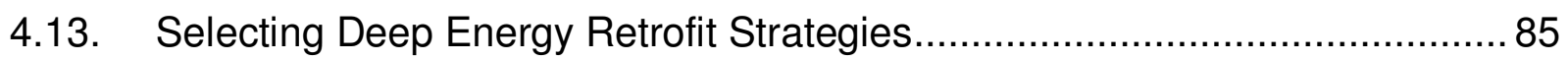

4.14. Hygrothermal Analysis of Retrofit Strategies ........................................... 94

4.15. Retrofit Capital Costs Estimations......................................................... 103

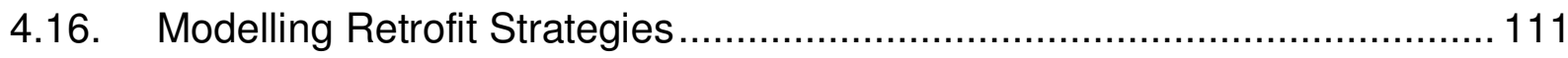

4.17. Estimating Capital Costs to Reach Energy Intensity Targets.....................119

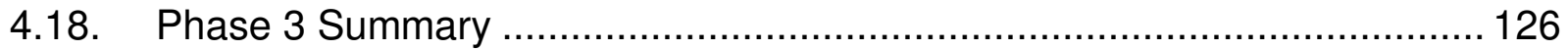

4.19. Summary of Process for Retrofit Development and Analysis.................... 130

4.19.1. Select Archetype for Study and Performance Target ......................... 130

4.19.2. Collect Representative Data for the Archetype.................................. 130

4.19.3. Prepare Baseline Energy Model..................................................... 131

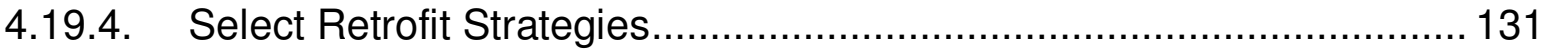

4.19.5. Perform Hygrothermal Analysis of Building Envelope Retrofits ........... 131

4.19.6. Perform Cost Estimation of the Retrofits ........................................ 131

4.19.7. Select "Rule" for Retrofit Decision Making .......................................... 132

4.19.8. Perform Modelling: Brute Force Sequential Search Method ................ 132

4.19.9. Quantify Overall Retrofit Costs to Reach Performance Target ............. 132

5. Contributions and Further Research .......................................................... 133

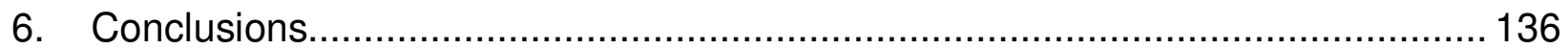

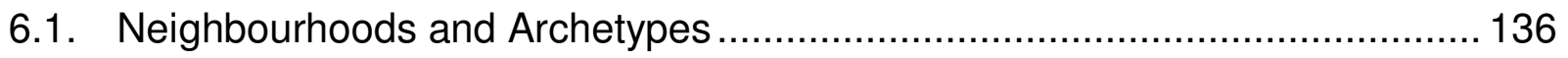

6.2. Baseline Energy Model Data Collection and Preparation............................. 136

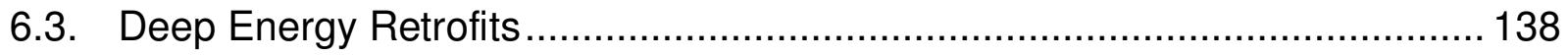

Appendix A: Toronto Neighbourhood Profile Sample ........................................... 141

Appendix B: Neighbourhood Data Compiled From Toronto Neighbourhood Profiles.. 144 
Appendix C1: Housing Inspection Data: Century Home .......................................... 145

Appendix C2: Housing Inspection Data: Century-Semi .......................................... 147

Appendix C3: Housing Inspection Data: War Time Home ....................................... 149

Appendix C4: Housing Inspection Data: Survey Results........................................ 151

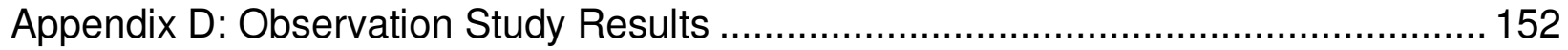

Appendix E1: Archetype Data: Century Home …….............................................. 153

Appendix E2: Archetype Data: Century-Semi ...................................................... 155

Appendix E3: Archetype Data: War Time Home ……........................................... 156

Appendix F: Baseline Energy Model Development ……......................................... 157

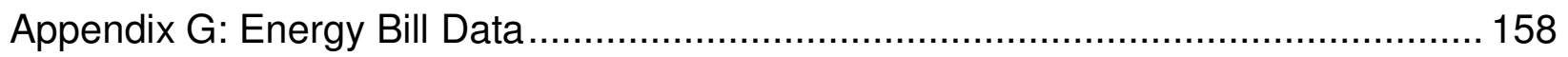

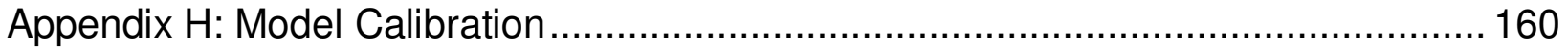

Appendix I: Normalized Energy Bill Data and Calibration Summary .......................... 165

Appendix J: Assemblies Updated Through Hygrothermal Analysis............................ 171

Appendix K: Retrofit Strategy Cost Estimations ..................................................... 173

Appendix L: Retrofit Strategy Cost Estimation Summary by Archetype ...................... 191

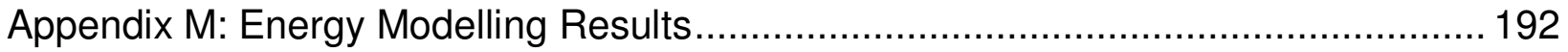

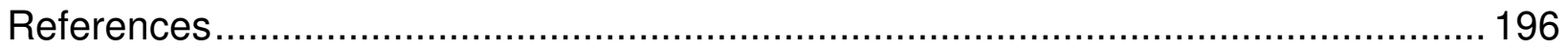




\section{List of Tables}

Table 1: Summary Description of the Four Housing Archetypes ................................... 9

Table 2: Yearly Baseline Energy Intensity of the Four Housing Archetypes.................... 9

Table 3: Number of Buildings by Housing Type and Number of Homes by Archetype in

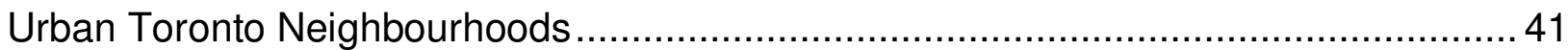

Table 4: Average Yearly Energy Intensity of Urban Toronto Neighbourhoods ............... 43

Table 5: Distribution and Energy Intensity Contribution of Archetypes in the Target

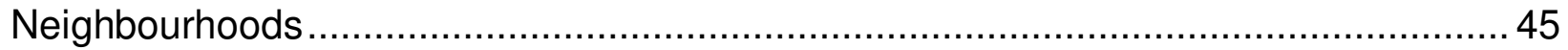

Table 6: Number of Buildings by Housing Type in the Target Neighbourhoods ............ 46

Table 7: Number of Homes Inspected by Neighbourhood and Archetype......................52

Table 8: Percentage of Total Single Family Homes Tallied by Neighbourhood..............55

Table 9: Tally and Percentages of Various Housing Types Observed in the

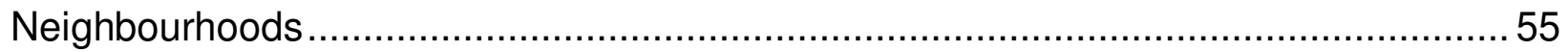

Table 10: Building Specific Parameters for Baseline Energy Models ..........................62

Table 11: Comparison of Initial Baseline and Geometry Testing Results....................... 70

Table 12: Energy Bill Normalization Example - Century Home 2, 2012...................... 72

Table 13: Energy Bill Normalization Example - Century-Semi Home 2, 2012 .............. 73

Table 14: MBE and CVRSME Results for Energy Model Calibrations .......................... 79

Table 15: Final Baseline Energy Use and Energy Intensity by Archetype...................... 80

Table 16: Century and Century-Semi Retrofit Strategies and Implementation Levels... 87

Table 17: War Time Retrofit Strategies and Implementation Levels .......................... 88

Table 18: Materials Utilized for WUFI Analysis ....................................................... 97

Table 19: Hygrothermal Analysis Moisture Trend Summary for Retrofit Envelope

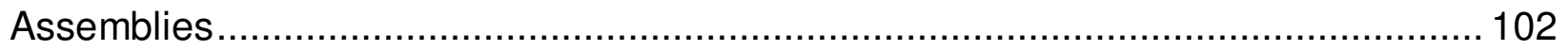

Table 20: Cost Summary for Wood Frame Wall Retrofit Level 1 Provided by Contractor

1

Table 21: Cost Summary for Cathedral Roof Retrofit Level 1 Provided by Contractor 1

104

Table 22: Take-off Quantities from the Three Archetypes - Area .............................. 105

Table 23: Take-off Quantities from the Three Archetypes - Linear Metres, Linear Feet

Table 24: Total Retrofit Cost Calculation Example - Level 1 Wall Retrofit - War Time

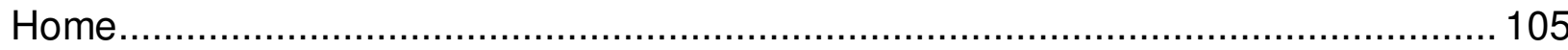

Table 25: Average Capital Cost for each Retrofit and Level of Implementation

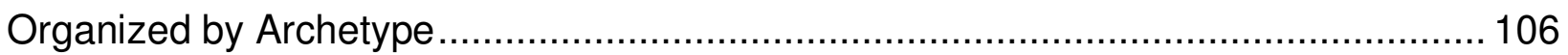

Table 26: Treated Floor Area Calculations for EnerPHit EQUiv ................................... 113

Table 27: Floor Areas for Wall Retrofits and Treated Floor Area for EnerPHit

Table 28: Century Home Energy Modelling Results by Round ................................ 115

Table 29: Century-Semi Home Energy Modelling Results by Round ..........................116

Table 30: War Time Home Energy Modelling Results by Round .............................. 116 
Table 31: Retrofit Level Required to Meet Performance Targets with Diminishing Return Point Highlighted ........................................................................................... 118

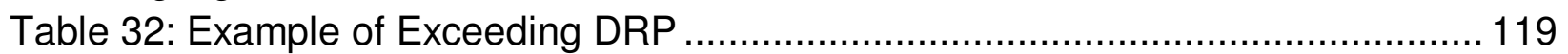

Table 33: Century Home Retrofit Cost Increments by Round .................................. 120

Table 34: Century-Semi Home Retrofit Cost Increments by Round ........................... 120

Table 35: War Time Home Retrofit Cost Increments by Round ................................ 121

Table 36: Capital Cost to Reach Performance Targets for Each Archetype................. 122

Table 37: Utility Cost Estimation for the Century Home over 25 Year Period at a Fuel

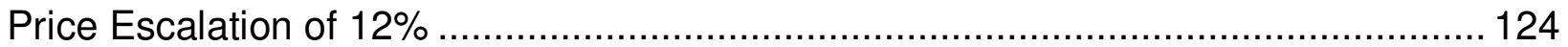

Table 38: 25 Year Cost Estimation with a Fuel Price Escalation of 8\%...................... 124

Table 39: 25 Year Cost Estimation with a Fuel Price Escalation of 12\%.................... 125 


\section{List of Figures}

Figure 1: Map of Toronto and Surrounding Suburbs ............................................... 2

Figure 2: Concentration of Single Family Homes in Urban Toronto Neighbourhoods ..... 7

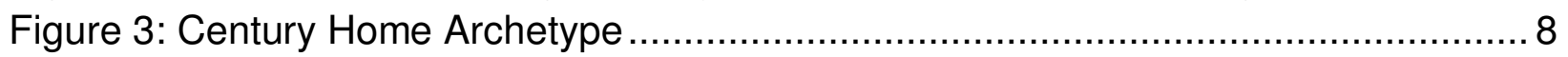

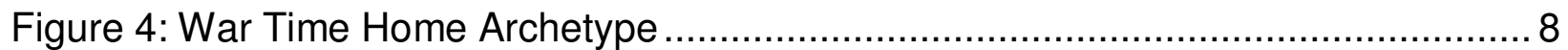

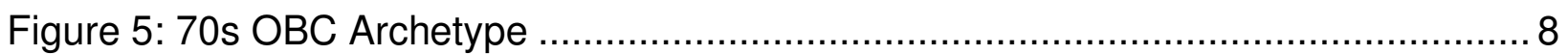

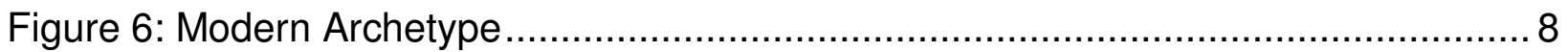

Figure 7: Map of Toronto Highlighting Target Neighbourhoods................................. 44

Figure 8: Geometry of Century Home Archetype Baseline Energy Model.....................66 66

Figure 9: Geometry of Century-Semi Home Archetype Baseline Energy Model ...........66 67

Figure 10: Geometry of War Time Home Archetype Baseline Energy Model.................69

Figure 11: Century Home 1, 2012, monthly calibration results................................... 75

Figure 12: Century Home 1, 2013, Monthly Calibration Results................................ 75

Figure 13: Century Home 2, 2012, Monthly Calibration Results................................ 76

Figure 14: Century Home 2, 2013, Monthly Calibration Results................................. 76

Figure 15: Century-Semi Home 1, 2012, Monthly Calibration Results ......................... 77

Figure 16: Century-Semi Home 1, 2013, Monthly Calibration Results ......................... 77

Figure 17: Century-Semi Home 2, 2012, Monthly Calibration Results ......................... 78

Figure 18: Century-Semi Home 2, 2013, Monthly Calibration Results .......................... 78

Figure 19: Masonry Walls (Century, Century-Semi) Level 1 - RSI 4 (R 22).................. 88

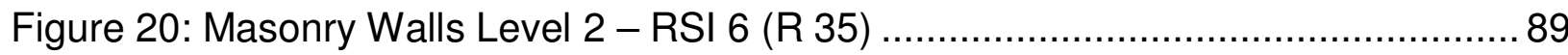

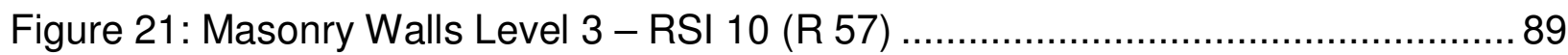

Figure 22: Wood Frame Walls (War Time) Level 1 - RSI 4 (R 22)............................. 89

Figure 23: Wood Frame Walls Level 2 - RSI 6 (R 35) ............................................ 90

Figure 24: Wood Frame Walls Level 3 - RSI 10 (R 57) ............................................ 90

Figure 25: Cathedral Roof (Century, Century-Semi) Level 1-RSI 9 (R 50) ................. 90

Figure 26: Cathedral Roof Level 2 - RSI 10.5 (R 60) ............................................ 91

Figure 27: Cathedral Roof Level 3 - RSI 13 (R 75) ............................................... 91

Figure 28: Attic Roof (War Time) Level 1 - RSI 9 (R 50) .......................................... 91

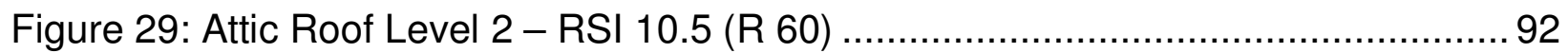

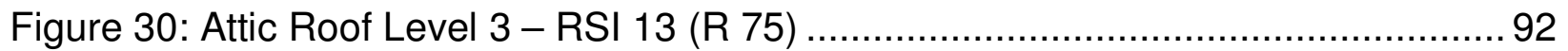

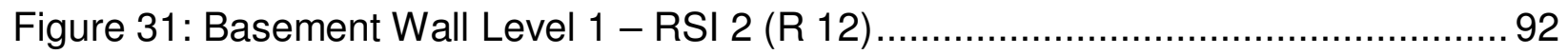

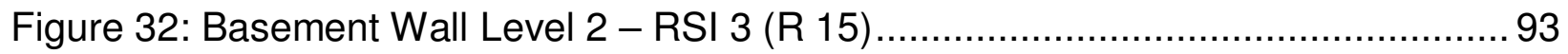

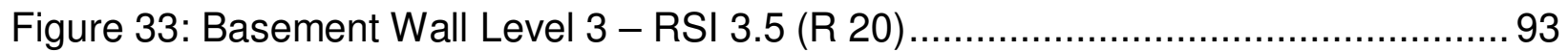

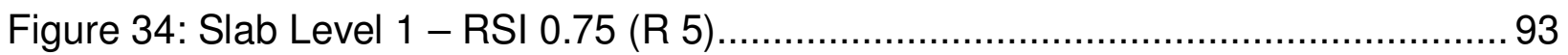

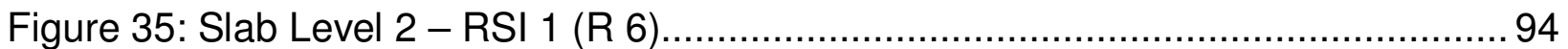

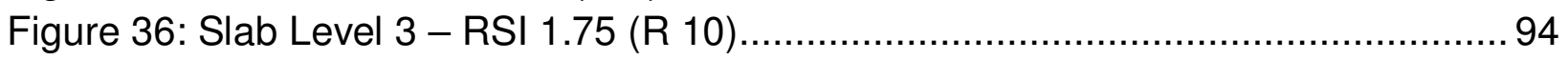

Figure 37: Condensation and Decay Hours in Initial and Final Wood Frame Wall

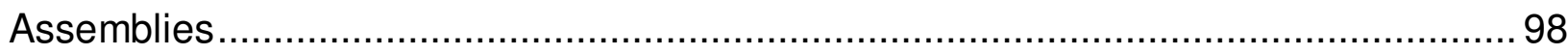


Figure 38: Condensation and Decay Hours in Initial and Final Level 1 Cathedral Roof Assembly

Figure 39: Condensation and Decay Hours in Century/ Century-Semi Home Baseline and Retrofit Assemblies

Figure 40: Condensation and Decay Hours in War Time Home Baseline and Retrofit Assemblies.

Figure 41: Example of Static Moisture Content Trend - Level 2 Masonry Wall Retrofit

Figure 42: Example of Static Moisture Content Trend - Level 3 Cathedral Roof Retrofit

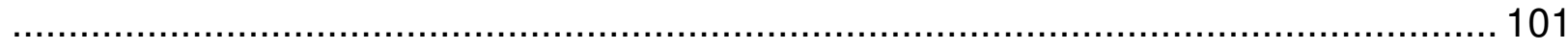

Figure 43: Example of Drying Moisture Content Trend - Level 2 Slab Retrofit ........... 102 Figure 44: Century Home Cost Estimate Comparison - Walls, Roof, Basement Walls, and Slab 108

Figure 45: Century Home Cost Estimate Comparison - Windows, Air Sealing, Furnace, HRV/ERV 108

Figure 46: Century-Semi Home Cost Estimate Comparison - Walls, Roof, Basement Walls, and Slab 109

Figure 47: Century-Semi Home Cost Estimate Comparison - Windows, Air Sealing, Furnace, HRV/ERV 109

Figure 48: War Time Home Cost Estimate Comparison - Walls, Roof, Basement Walls, and Slab 110

Figure 49: War Time Home Cost Estimate Comparison - Windows, Air Sealing, Furnace, HRV/ERV 110

Figure 50: Brute Force Sequential Search Method for Retrofit Determination 112

Figure 51: Building Floor Area Drawing Example. 113

Figure 52: Energy Modelling Results Example. 114 


\section{List of Abbreviations}

$\mathrm{ACH}-$ Air Changes per Hour

ASHRAE - American Society of Heating, Refrigeration, and Air Conditioning Engineers

BFSS - Brute Force Sequential Search

CMHC - Canada Mortgage and Housing Corporation

CVRMSE - Coefficient of Variation of the Root Mean Squared Error

DOE - United States Department of Energy

DRP - Diminishing Return Point

EGH - EnerGuide for Houses

ERV - Energy Recovery Ventilator

FF - Framing Factor

HDD - Heating Degree Days

HRV - Heat Recovery Ventilator

HVAC System - Heating Ventilation and Air Conditioning System

NMBE - Normalized Mean Bias Error

$\mathrm{RH}$ - Relative Humidity 


\section{Introduction}

Concerns surrounding climate change and the rising cost of energy have fuelled public interest in energy conservation and efficiency. Residential buildings are responsible for $17 \%$ of total energy consumed and $16 \%$ of total greenhouse gas emissions in Canada (CMHC, 2008). In the Canadian residential sector, singledetached dwellings have been shown to use 1.8 times more energy than apartment dwellings on a per capita basis (Norman, McLean, \& Kennedy, 2006). This is due to the greater number of exterior walls in detached dwellings compared to apartments, which typically have fewer exterior walls per unit. While it is generally accepted that new buildings are more energy efficient than their predecessors (VandeWeghe \& Kennedy, 2007), existing buildings have a long life span and a low rate of replacement (Foley, 2012). Therefore there is a need to address the high energy consumption of existing residential buildings, focusing on single family homes. Pitt, Randolph, St. Jean, and Chang (2012) stressed the need for building retrofits asserting that "evidence suggests that energy-efficiency retrofits to existing buildings represent the biggest, fastest, cheapest, cleanest, and most long-lasting opportunity to reduce energy use and greenhouse gas emissions in cities". With $57 \%$ of energy consumed in Canadian households being used for space heating (Centre for Energy, 2013), it is prudent to focus retrofits on reducing heat loss through building envelope upgrades and on improving mechanical systems to increase efficiency and to match the reduced heating requirements of a retrofitted envelope (CMHC, 2008). 
In the City of Toronto, urban residential buildings are the greatest contributor to greenhouse gas emissions (VandeWeghe \& Kennedy, 2007). In the high density, urban core of the city, Old Toronto (see Figure 1), greenhouse gas emissions from residential buildings are greater per capita than the surrounding lower density suburban areas. This is due largely to the older age of buildings in the core which were built at a time when energy efficiency was not a priority (VandeWeghe \& Kennedy, 2007).

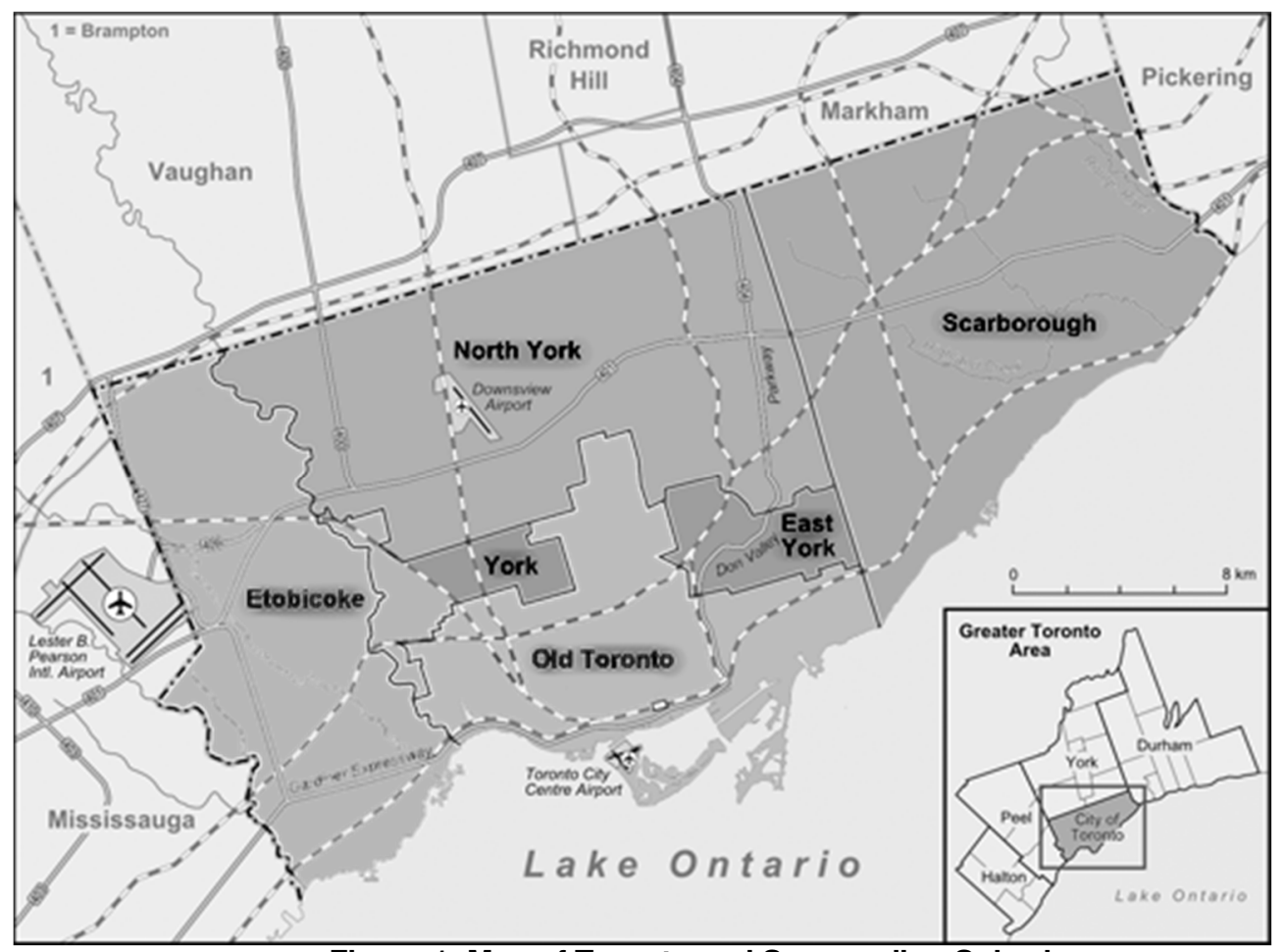

Figure 1: Map of Toronto and Surrounding Suburbs

(Toronto City Directory, 2010)

Additionally, the City of Toronto's Sustainable Energy Plan (2007) highlighted the need to "adopt a 'conservation first' energy strategy that positions conservation and demand management as the preferred first action". As the urban core of Toronto is the area responsible for the greatest greenhouse gas emissions and single family homes have 
been shown to consume the most energy (Norman et al., 2006), this housing sector shows great potential for energy use reduction through building retrofits.

\subsection{Problem Definition}

There is a need to address the high energy consumption of existing single family homes through energy efficient retrofits focused on building envelope and mechanical systems. Preliminary research has shown that most of the research to date addressing retrofits for urban single family homes in Toronto has been fragmented and has not formed a comprehensive process for studying retrofits that take into consideration the current state of Toronto's single family homes. Priority areas that present the greatest potential for energy use reduction through retrofitting have not been identified and retrofit strategies for Toronto homes have largely not been developed, tested, and priced for specific urban housing typologies. 


\section{Background and Literature Review}

\subsection{Background}

Procter (2011) stated that in Canada, the retrofit market is strong and continuing to grow as existing buildings become older and that new construction only accounts for a small proportion of the building stock on the market. Burleton and Petramala (2014) stated that new home sales make up $25 \%$ of housing sales in the greater Toronto area with the remaining $75 \%$ being existing homes. This figure includes cities outside of the City of Toronto; the proportion of new homes sales in urban Toronto is likely less. This highlights the importance of deep energy retrofits for Toronto homes as few efficient newer homes are being brought to market and many home buyers are purchasing older, inefficient homes which could be updated and rendered more efficient by applying deep energy retrofits.

In their study of Canadian residential energy efficiency programs, Hoicka and Parker (2011) outlined federal programs that had been implemented to address the efficiency of existing residential buildings. The Federal Government first implemented the EnerGuide for Houses (EGH) program in 1999. Under this program homeowners could pay a small fee to have a home energy evaluation performed to determine baseline energy consumption. Then a second evaluation, after an energy retrofit, could be scheduled to assess the energy improvements that were achieved. Initially the program offered no financial incentives for retrofitting, although in 2003 the program was amended to offer compensation for home retrofitting based on the actual measured efficiency improvement of the retrofit. In 2006 the EGH program was cancelled and in 2007 the Federal Government launched the EcoENERGY for Homes program which 
offered financial incentives for several listed retrofit options (Hoicka \& Parker, 2011). The EcoENERGY for Homes program was offered until March 2012 and at the time of writing was no longer operational.

Past research studies have begun to address the need for sustainable retrofits in urban Toronto. Blaszak and Richman (2013) identified neighbourhoods in urban Toronto with a large proportion of single family homes and proposed four archetypes to represent the housing stock in these neighbourhoods. Blaszak and Richman performed initial energy modelling on each archetype to determine the potential for energy efficient retrofits and to prioritize retrofit options to have the greatest impact on energy use. This study did not identify the proportion of housing archetypes in each neighbourhood, but did provide a framework to assess which neighbourhoods contained the largest proportion of high energy consuming archetypes and therefore which areas represent the greatest potential for energy use reduction through retrofitting. This study also did not consider the costs of implementing retrofits. Mucciarone (2011) developed a listing of existing building envelope assemblies in Toronto and proposed several retrofit assembly options to meet various performance targets. This study was limited in that it considered wood frame and load bearing masonry buildings to represent all of Toronto's homes and did not consider other differences such as geometry, air tightness, roof types, and foundation constructions which Blaszak and Richman (2013) had considered. While Mucciarone (2011) conducted a hygrothermal analysis of the proposed assemblies, the analysis was qualitative in nature and could be improved with a quantitative analysis utilizing specific moisture performance metrics. Markiel (2011) proposed a methodology for evaluating energy savings from building envelope retrofits 
in a Toronto climate and took into consideration the effects of geometry and shading on the overall performance. This study however was not applied to actual housing typologies in Toronto.

\subsubsection{High Density Urban Areas of Toronto}

Using information predominantly contained in the Toronto Neighbourhood Profiles (City of Toronto, 2013), Blaszak (2010) identified three areas of urban Toronto with a higher than average proportion of single family homes. These areas were described as the East, comprising the region between Riverdale and the Beaches, the West, comprising the High Park and Parkdale neighbourhoods north and south of Bloor Street, and the North, comprising the region along the east side of Yonge Street and north of Bloor Street. Each of these areas had a single family housing concentration of greater than 2000 units/neighbourhood (see Figure 2). These locations formed the boundaries of the urban areas that were considered in this research. 


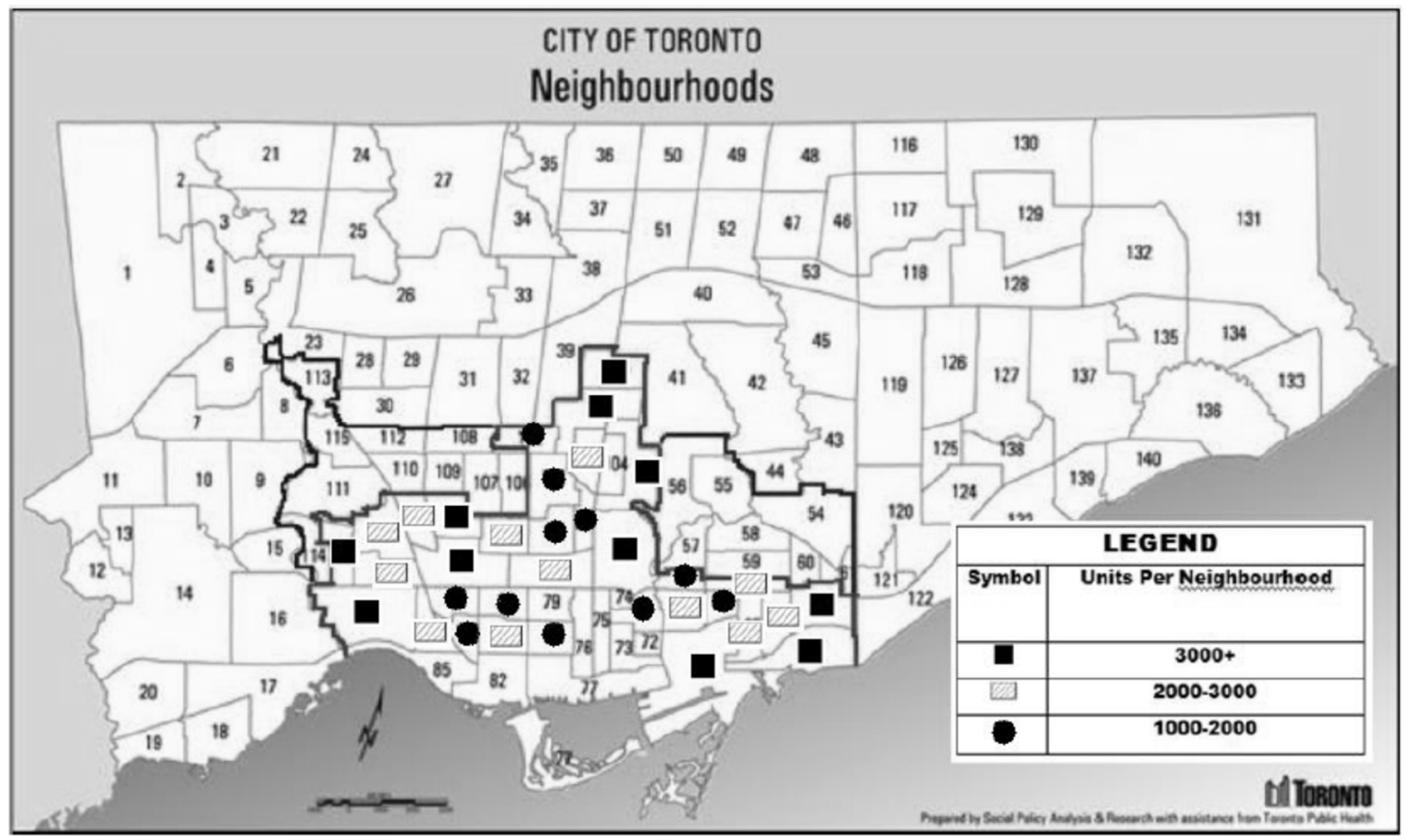

Figure 2: Concentration of Single Family Homes in Urban Toronto Neighbourhoods

(Adapted from Blaszak, 2010)

\subsubsection{Existing Urban Housing Stock - Archetypes}

By conducting a historical study of the development of housing in the locations described above, Blaszak and Richman (2013) were able to identify four housing archetypes that described a large portion of Toronto's urban housing stock; Century, War Time, 70s OBC, and Modern (see Figures 3 through 6). The four archetypes were described as follows:

"The first, Century, includes the solid masonry construction homes typical of the turn of the century and earlier. The second, Wartime, is representative of the small bungalows either built by the Wartime Housing Limited (WHL) or from the subsequent $\mathrm{CMHC}$ pattern books. The third, 70s OBC, shows the trend towards larger spaces and glazing areas and incorporates the first edition of the Ontario Building Code. The fourth and final archetype, Modern, includes the tall and narrow brick veneer homes with attached garages that are typically found in urban infill lots." 


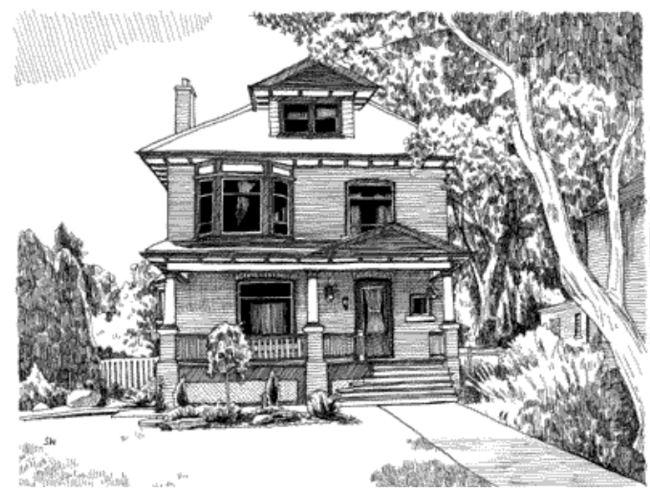

Figure 3: Century Home Archetype

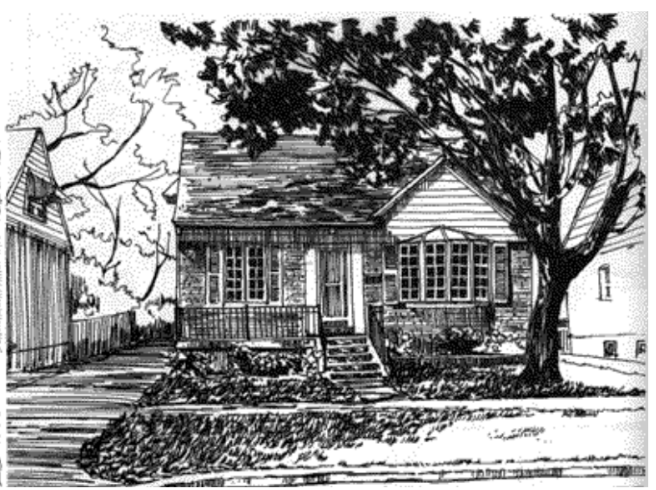

Figure 4: War Time Home Archetype

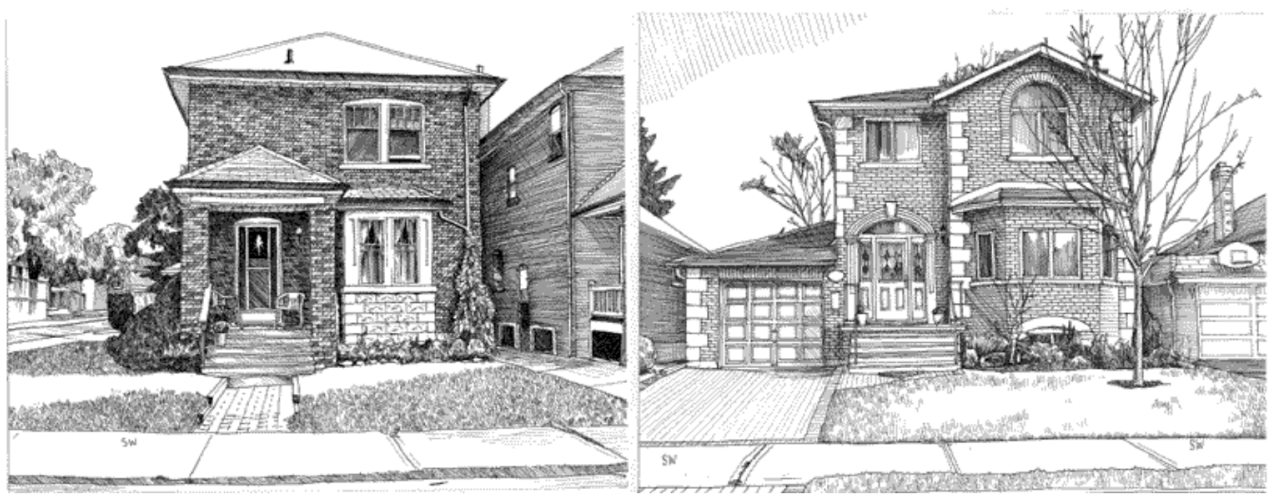

Figure 5: 70s OBC Archetype
Figure 6: Modern Archetype

(Adapted from Blaszak \& Richman, 2013)

Furthermore, data was collected for each archetype to identify their general characteristics in terms of construction, geometry, vintage, features, insulation levels, air tightness, and glazing. The collected data is summarized in Table 1 below: 
Table 1: Summary Description of the Four Housing Archetypes

\begin{tabular}{|c|c|c|c|c|}
\hline Archetypes & Century & War Time & $70 \mathrm{~s}$ OBC & Modern \\
\hline Heated Floor Area & $208 m^{2}$ & $182 \mathrm{~m}^{2}$ & $216 m^{2}$ & $239 m^{2}$ \\
\hline \multicolumn{5}{|l|}{ Building } \\
\hline \# Storeys & 2.5 & 1 & 2 & 3 \\
\hline Plan Shape & L-shape & Rectangular & Rectangular & L-shape \\
\hline Vintage & $<1940$ & 1940-60 & $1970 \mathrm{~s}$ & $>2000$ \\
\hline Lot Placement & $\begin{array}{l}\text { Adjacent to } \\
\text { Neighbours }\end{array}$ & Driveway on one side & $\begin{array}{l}\text { Adjacent to } \\
\text { Neighbours }\end{array}$ & $\begin{array}{l}\text { Adjacent to } \\
\text { Neighbours }\end{array}$ \\
\hline Features & $\begin{array}{l}\text { Finished attic, full- } \\
\text { width porch }\end{array}$ & Half-width porch & $\begin{array}{c}\text { Partly raised } \\
\text { basement, narrow } \\
\text { awning }\end{array}$ & $\begin{array}{c}\text { Attached garage, } \\
\text { narror porch }\end{array}$ \\
\hline Roof & Gable front, flat rear & Hip & Hip & Hip with gable accents \\
\hline Structure & Double-wythe brick & Light-wood frame & Light-wood frame & Light-wood frame \\
\hline Cladding & Brick & Brick & Brick & Brick \\
\hline \multicolumn{5}{|l|}{ Insulation (RSI) } \\
\hline Ceiling & 2.74 & 3.66 & 4.18 & 5.76 \\
\hline Walls & 1.11 & 1.41 & 1.71 & 5.9 \\
\hline Foundation & 0.52 & 0.74 & 1.16 & 2.01 \\
\hline Air Leakage $(\mathrm{ACH})$ & 11.24 & 7.5 & 5.75 & 3.42 \\
\hline \multicolumn{5}{|l|}{ Glazing (\%) } \\
\hline Front & 20 & 20 & 20 & 15 \\
\hline Side & 3 & 8 & 5 & 3 \\
\hline Rear & 20 & 15 & 25 & 25 \\
\hline
\end{tabular}

(Adapted from Blaszak \& Richman, 2013)

Finally, the typical energy consumption of each archetype was modelled utilizing HOT2000 software. The typical energy consumption is shown in Table 2 below:

Table 2: Yearly Baseline Energy Intensity of the Four Housing Archetypes

\begin{tabular}{|l|c|c|}
\hline Archetype & Energy Intensity & Energy Intensity (heating and cooling) \\
\hline Century Home & $408 \mathrm{kWh} / \mathrm{m}^{2}$ & $326 \mathrm{kWh} / \mathrm{m}^{2}$ \\
\hline Wartime Bungalow & $263 \mathrm{kWh} / \mathrm{m}^{2}$ & $171 \mathrm{kWh} / \mathrm{m}^{2}$ \\
\hline 70s OBC & $251 \mathrm{kWh} / \mathrm{m}^{2}$ & $172 \mathrm{kWh} / \mathrm{m}^{2}$ \\
\hline Modern Home & $231 \mathrm{kWh} / \mathrm{m}^{2}$ & $128 \mathrm{kWh} / \mathrm{m}^{2}$ \\
\hline
\end{tabular}

This preliminary study did not address significant aspects, such as: 1) what proportion of each archetype is present in each neighbourhood?, and 2) knowing the baseline energy intensity of each archetype and knowing the proportion of archetypes in each neighbourhood, which neighbourhoods are the most energy intensive and which 
archetypes are predominantly contributing to the energy intensity? These aspects are important and should be explored as they provide an indication of the existing single family housing stock of urban Toronto and also show where retrofit improvements should be prioritized in order to have the greatest reduction in energy use.

\subsection{Literature Review}

To understand the current conditions and knowledge base regarding deep energy retrofits for single family homes, several areas were explored in the literature. First, a review of the justification for deep energy retrofits was conducted followed by a review of building retrofits in a Canadian and Toronto context. Several building retrofits strategies were explored and compared to inform what types of retrofits should be focused on in this study. The relationship between the building envelope and the mechanical system was explored to determine how the systems should be retrofitted together to optimize performance and minimize energy consumption. The impacts of moisture on the building envelope were reviewed in order to inform appropriate targets and thresholds for hygrothermal performance and to ensure that the building envelope retrofit assemblies would not decrease the durability of the homes in which they were applied. A review of high performance buildings was also performed to inform and justify the performance targets of the deep energy retrofits that were striven for in the research. Typical methodologies for analyzing retrofit strategies utilizing building energy

models were uncovered and explored. Finally, methodologies for performing retrofit decision making and performing cost analyses were studied and considered. 


\subsubsection{Deep Energy Retrofits}

Existing buildings, on average, use more energy than buildings that were more recently constructed (Harvey, 2009). This is due to the fact that much of the existing building stock is aging and was not built to current standards of energy efficiency (Cooperman, Dieckmann, \& Brodrick, 2011). Foley (2012) of the Greater Philadelphia Innovation Cluster, whose mandate is to study building retrofits, added to this by explaining that buildings have a long useful life and therefore existing buildings that are underperforming will consume significant resources over their life unless retrofits are implemented. A case study by Parker and Bin (2012) of a century home in Kitchener, Ontario provided a quantitative example of this point. Parker and Bin (2012) studied the life cycle energy use of the home, built in 1910 and retrofitted for significant energy efficiency in 2010 , and found that the home consumed approximately $429 \mathrm{kWh} / \mathrm{m}^{2}$ per year during the first 100 years of its life and consumed only $71 \mathrm{kWh} / \mathrm{m}^{2}$ per year after retrofitting. The $140 \mathrm{~m}^{2}$ home had a remaining expected service life of 50 years, yielding an anticipated energy use of $500,000 \mathrm{kWh}$ over this period, compared to $3,000,000 \mathrm{kWh}$ of energy use for the 50 year period prior to the deep energy retrofit; a six-fold reduction after retrofitting.

Foley (2012) indicated that building retrofits should focus on a "threefold problem; increasing energy efficiency, decreasing environmental impact, and increasing indoor habitability". In an evaluation of 20 municipal plans to address climate change in the United States, Bassett and Shandas (2010) found that $70 \%$ of the plans included strategies to increase the energy efficiency of existing buildings. Globally, the Intergovernmental Panel on Climate Change (IPCC) in its fourth assessment report, 
outlined strategies for reducing energy use in buildings and realizing the great energy savings potential in buildings worldwide (Harvey, 2009). Finally Ma, Cooper, Daly, and Ledo, (2012) concluded in their study of the state of the art of building retrofits that the "retrofitting of existing buildings offers significant opportunities for reducing global energy consumption and greenhouse gas emissions" and that "this is being considered as one of the main approaches to achieving sustainability in the built environment".

Foley (2012) asserted that it has only been within the latter decades of this century that energy efficiency has come closer to the forefront in building design. Building retrofitting to reduce energy consumption traces its roots back to the energy crisis in the 1970s where significant attention was paid to insulating and air sealing buildings to reduce the energy required to heat and humidify, or cool and dehumidify ventilated and infiltrated air (Wagner, 2012). Despite these efforts to retrofit buildings and despite the advancement in energy efficiency of new building design, Foley (2012) claimed that building retrofits have not reached the level of rigour and sophistication required to achieve significant energy use reduction and to meet the performance expectations of building owners. This is because compared to design tools for automotive and chemical engineers, the design tools for buildings are rudimentary. This study mentioned EnergyPlus software as one of the most advanced building modelling tools, however noted that EnergyPlus is user-intensive and is therefore difficult to apply to building retrofits which are typically considered on a case by case basis. Despite the time constraint, in order to increase the rigour and effectiveness of building retrofits, advanced building modelling software should be utilized when developing and analyzing retrofits. 
According to Parker, Rowlands, and Scott (2003), Canada "exemplifies the problem of countries where energy demand is growing faster than gains in energy efficiency". However, to demonstrate the benefits of increasing energy efficiency Parker et al. (2003) outlined that energy efficiency gains in Canada reduced the growth of energy demand from 15\% to $9 \%$ between 1990 and 1998 and was responsible for avoiding a five billion dollar increase in national fuel bills. Many parties in Canada have called for building retrofit plans. The Toronto-Central Ontario Building Trades Council called for the Provincial and Federal governments to implement plans to renovate commercial, industrial, and residential buildings to consume less energy (Cameron, 1999). Also, a group of former Prime Ministers of Canada in the past had called on the government to implement a stimulus package in the federal budget to fund retrofits for existing homes and buildings with the goal of reducing energy consumption (Munro, 2009).

Hoicka and Parker (2011) studied what types of retrofits were carried out under past government incentive programs for retrofitting in Waterloo Region and found that homeowners were most likely to purchase efficient furnaces and to address air leakage through air sealing. The study found that homeowners were least likely to retrofit the building envelope to reduce heat loss through walls, windows, and doors. When envelope upgrades were made, they were typically not implemented to the levels recommended by government programs. Aydinalp, Ferguson, Fung, and Ugursal (2001) gave reasons for this stating that under the government programs homeowners generally chose to undertake the lowest cost retrofits, not the most economically attractive retrofits as outlined by the government programs. This highlights the need to 
identify retrofits with the lowest capital costs as homeowners are most likely to select and implement the lowest cost retrofits and are not as likely to select retrofits based on payback periods.

Several strategies for retrofitting are discussed in the literature. Building envelope upgrades include increasing insulation levels in foundations, walls, and roofs, as well as upgrading windows and doors (Hoicka \& Parker 2011, Cooperman et al. 2011, Foley 2012, Harvey 2009, CMHC 2008, Ma et al. 2012). Improving air tightness through air sealing was also discussed for building envelope retrofitting (Hoicka \& Parker 2011, Cooperman et al. 2011, Harvey 2009, Ma et al. 2012). For mechanical systems, strategies include increasing furnace efficiency (Hoicka \& Parker, 2011) and installing new high performance HVAC systems that are better suited to the heating and cooling needs of upgraded building envelopes (Harvey 2009, CMHC 2008). In addition to the above strategies that are focused on increasing efficiency and reducing energy inputs to buildings, retrofitting strategies can also include methods of alternative energy generation, such as installing photovoltaic panels (Cooperman et al. 2011, CMHC 2008, Ma et al. 2012). Ma et al. (2012) however stated that measures to reduce energy consumption generally require less cost and provide greater environmental benefits than retrofit measures that produce alternative energy. While the studies above listed many typical retrofit strategies many of them were informative only and did not analyze and compare strategies or discuss typical levels of implementation, for example insulation thickness. These studies also did not give indications of how the strategies perform as a system. 
It is possible to achieve energy savings by implementing any of the retrofit strategies mentioned above, however the total energy usage of buildings is not only a factor of the efficiency of individual building components (envelope, HVAC, lighting etc.), but also a factor of how the components are put together as a system (Harvey, 2009). Olgyay and Seruto (2010) argued that significant energy use reduction in buildings requires more than energy efficient components; a whole-building or whole-systems approach is required in which the energy reduction benefits are optimized and coordinated between the various systems and components in a retrofit. Harvey (2009) indicated that the energy savings possible at the whole-building or whole-systems level are "many times what can be achieved on the device level". Ma et al. (2012) indicated that building systems are highly interactive and that different retrofit measures may have different impacts on the various building systems and thereby affect the overall performance of the retrofit. Ma et al. (2012) therefore stated that a whole-building approach should be utilized to inform the best retrofit solutions. Olgyay and Seruto (2010) argued similarly that "whole-systems thinking" should be utilized to determine an array of retrofit measures to "optimize the whole building for resource efficiency" and to "maximize the benefits available in a retrofit project".

For deep energy retrofitting, implementing a high performance building envelope is often the most important factor when retrofitting homes to be low energy (Harvey, 2009). This is because a high performance envelope can reduce the amount of heating and cooling required of the HVAC system down to a level where internal gains (from people, lighting, and appliances) and passive solar heat gain can contribute the majority of the required heating (Harvey, 2009). An HVAC system needs to be sized only to 
make up the small remainder of heating required and therefore alternative, unconventional, and often more efficient heating and cooling systems can be employed (Harvey 2009). A case study by Badescu and Sicre (2003) found that a low energy house in Germany was able to reduce heating energy requirements tenfold by super insulating and air sealing the envelope. A database of low energy homes in cold climates compiled by Hamada, Nakamura, Ochifuji, Yokoyama, and Nagano (2003) found that low energy homes in Japan, Sweden, Finland, Canada, Austria, and Germany were able to achieve heating and cooling load reductions of $25-45 \%$ compared to typical homes in the same areas. As it has been over ten years since this database was developed and since building retrofit technology continues to advance, it is possible that greater heating and cooling load reductions are possible utilizing today's technology and retrofitting techniques. The studies above appear to indicate that optimizing the building envelope should be pursued first when retrofitting so that heating and cooling requirements can be reduced; however the studies do not take into consideration a whole-systems approach or cost. A whole-systems approach would indicate that the building envelope and HVAC system should be considered together to form a complementary system not one followed by the other. Additionally cost should be taken into consideration as building envelope upgrades may be many times greater in cost than HVAC system upgrades. Therefore a more balanced approach should be taken to maximize efficiency gains and minimize cost through retrofitting both the envelope and the HVAC system. 


\subsubsection{Moisture Durability}

While providing energy saving benefits, some low energy homes have been associated with durability issues. Smulski (1999) indicated that moisture concerns are increasing as homes become more insulated and air tight. In the past, natural infiltration and exfiltration of air through permeable building envelopes had removed moisture from buildings and decreased the likelihood of moisture accumulation and deterioration (Smulski, 1999). McNulty (2003) indicated that buildings must be designed to take moisture into account to ensure durability. Lstiburek (2002) listed several metrics to determine whether moisture deterioration will occur in buildings including moisture balance, moisture storage capacity, and drying time. Moisture balance in a building assembly refers to whether moisture is accumulating or dissipating over time. Moisture storage capacity refers to how much moisture a material in the building can absorb before mould can grow or deterioration will occur. Drying time refers to how quickly and easily a material can dry out once wet (Lstiburek, 2002).

To quantitatively assess the durability of building retrofits, specific performance metrics are required. Johansson, Ekstrand-Tobin, Svensson, and Bok (2012) indicated that wood building materials are the most susceptible to mould growth. When studying the effect of moisture on buildings, many authors considered wood to be the limiting factor in moisture durability (Hannu \& Viitanen 1997, Carll, TenWolde \& Munson 2007, Hukka \& Viitanen 1999). Therefore the hygrothermal performance testing of buildings generally considers the moisture thresholds for wooden materials. ASHRAE Standard 160P (ASHRAE, 2009a) stipulates that to avoid mould growth buildings surfaces should be kept at: 
- A relative humidity $(\mathrm{RH})$ of below $80 \%$ when the 30 day average surface temperature is between 5 and 40 degrees Celsius

- $\mathrm{RH}$ below $98 \%$ when the 7 day average surface temperature is between 5 and 40 degrees Celsius

- $\mathrm{RH}$ below $100 \%$ when the 24 hour average surface temperature is between 5 and 40 degrees Celsius

(Adapted from TenWolde, 2008)

Allinson and Hall (2010) indicated that the number of hours that a wall surface is kept above a relative humidity of $80 \%$ greatly increases the possibility of moisture related damage. Johansson et al. (2012) described in their study that the lowest surface $R H$ where mould appeared was $80 \%$ and that no mould growth was present at a surface $\mathrm{RH}$ of $75 \%$. Hukka and Viitanen (1999) stated a similar threshold for mould growth indicating that surfaces should be kept below an $\mathrm{RH}$ of $80 \%$ to inhibit mould growth and that no mould growth will occur at an $\mathrm{RH}$ of $75 \%$. Hannu and Viitanen (1997) outlined identical findings showing mould growth above $80 \%$ surface $\mathrm{RH}$ and no mould growth below $75 \%$ surface $\mathrm{RH}$. Other publications confirmed these thresholds (Krus, Sedlbauer, Zillig, \& Kunzel 2001). Additionally, Carll et al. (2007) outlined that wooden building components should be kept to a moisture content of $16 \%$ or less in order to avoid damage, decay, and deterioration. The studies outlined above highlight the need to model the hygrothermal performance of building envelope systems to ensure that moisture damage and deterioration potential is minimized. The studies provide quantitative moisture performance guidelines including minimizing the number of hours that the $\mathrm{RH}$ of wooden materials exceeds $80 \%$ and the number of hours that the 
moisture content of wooden materials exceeds $16 \%$. The studies also provide qualitative guidelines indicating that moisture accumulation and drying should be considered to ensure that a stable or drying trend is present.

\subsubsection{High Performance Buildings}

The question of what constitutes a high performance building is subjective and requires definition. For the purpose of this study, a high performance building has low energy use for heating and cooling. In order to normalize the energy use of buildings with different sizes, $\mathrm{kWh} / \mathrm{m}^{2}$ is often used as the annual unit of energy measurement (Wagner 2012, Blaszak \& Richman 2013).

Although Bassett and Shandas (2010) found that many American cities are implementing plans for a 30\% reduction in residential energy use, both Foley (2012) and Wagner (2012), advocated for a building retrofit goal of increasing overall building energy efficiency by $50 \%$. A similar target was utilized by Blaszak and Richman (2013) who set a yearly energy consumption target of $100 \mathrm{kWh} / \mathrm{m}^{2}$ for heating and cooling utilizing approximately a 50\% reduction from the Toronto average of $204 \mathrm{kWh} / \mathrm{m}^{2}$ contained in the EcoENERGY database produced by Natural Resources Canada. As a $50 \%$ reduction in energy use for Toronto homes was already attempted and shown to be possible by Blaszak and Richman (2013), more ambitious targets should be considered.

Another high performance standard for buildings is the Passive House standard. Started in Germany in 1996, the Passive House standard is a stringent performance standard for buildings requiring a maximum energy consumption of $15 \mathrm{kWh} / \mathrm{m}^{2} \mathrm{yr}$ of 
treated floor area (TFA) for both heating and cooling and a maximum air leakage rate of 0.6 ACH at $50 \mathrm{~Pa}$ (Passive House Institute, 2013a). Treated floor area is a calculation based on the floor area of a building to approximate the actual heated living space (Passive House Institute, 2013b). Achieving the Passive House standard in a retrofit however can be difficult to achieve (Passive House Institute, 2012). To ease the process the Passive House Institute in Germany created the EnerPHit standard which serves as a target for Passive House renovations and retrofits. The EnerPHit standard allows for a slightly less stringent heating and cooling maximum energy consumption of $25 \mathrm{kWh} / \mathrm{m}^{2} \mathrm{yr}$ of TFA and an air leakage rate of $1 \mathrm{ACH}$ at $50 \mathrm{~Pa}$ (Passive House Institute, 2012). As Passive House has been documented to be difficult to achieve and since the EnerPHit standard was designed specifically for retrofit applications, it provides an ambitious high performance target to be striven for in home retrofitting.

\subsubsection{Energy Modelling of Building Retrofit Strategies}

Various retrofit strategies were listed and discussed above as was the importance of considering how retrofit strategies are put together in a system. Rysanek and Choudhary (2012) expanded on this stating that in the building retrofit industry, professionals are tasked with recommending retrofit strategies from a wide array of possible options and that the best solution is not only dependent on the thermodynamic performance of each individual option, but also on co-related interactions between them. Questions remained however as to what methodology should be utilized to determine the most suitable retrofit strategies for a given building and to ensure that the chosen retrofits form a complementary system. Rysanek and Choudhary (2013) indicated that the optimal type of retrofit often cannot be determined solely by reference 
to economic analysis, reference to case studies, or by expert judgement. Every building is different either in architectural, construction, or operational characteristics and therefore retrofit options should be investigated for individual buildings on a case by case basis. To do this, Rysanek and Choudhary (2013) recommended building energy modelling and concluded in their review of building retrofit literature that building energy modelling is the benchmark by which researchers investigate the full range of retrofit strategies.

EnergyPlus is a computer simulation program developed by the United States Department of Energy and its partner agencies. EnergyPlus software is capable of highly detailed and accurate modelling and has undergone extensive testing and validation (Crawley 2004, Henninger \& Witte 2013). The study by Zirnhelt (2013) outlined a model development and calibration procedure utilizing EnergyPlus Software. This study prepared a calibrated energy model of an existing detached, single family research dwelling located in Ottawa and outlined the modelling techniques and parameters utilized to achieve the calibrated model. The strengths of this study are that it described in detail the steps outlined to develop a calibrated model in EnergyPlus for a single family dwelling and also compared and contrasted various modelling techniques. The weakness of the study is that, since it considered a research dwelling for model preparation, extensive building specific data was available from sensors located throughout the home. This level of information is typically not available for an average home.

Evaluating the large array of building retrofit strategies as well as the relationship between strategies presents a problem of multi-objective optimization (Diakaki, 
Grigoroudis, \& Kolokotsa, 2008). Several multi-objective optimization software programs have been developed as front end applications to building energy modelling software, for example BeOPT and OptEPlus for the EnergyPlus program (National Renewable Energy Laboratory 2010, National Renewable Energy Laboratory 2014). These programs perform an automated optimization utilizing a Brute Force method in which every retrofit possibility from a defined list is carried out and analyzed against the retrofitting goals. Both Eisenhower, O’Neill, Narayanan, Fonoberov, and Mezić (2012) and Asadi, da Silva, Antunes, and Dias (2012) indicated that these types of software become impractical when a large number of retrofit design variables are utilized due to the computational time required to carry out all of the building energy simulations. To render the optimization process more practical, design professionals and researchers have often limited the number of variables considered, simplified the building energy model by reducing the number of thermal zones or time steps, or simplified the heat balance and building physics calculations; all of which can lead to inaccuracies in the building energy models.

Many researchers have striven to avoid the impracticalities of multi-objective optimization by developing alternative multi-criteria decision making methodologies for retrofit design. Rysanek and Choudhary (2012) outlined a methodology using MATLAB and TRNSYS software in which a number of pre-selected retrofit strategies are applied in an iterative process. First the internal gains profile and the baseline greenhouse gas emissions of a building are determined. Then an iterative process begins where each retrofit strategy and combination of retrofit strategies are modelled using TRNSYS and the resulting greenhouse gas emissions are quantified. The best retrofit scenario is 
determined to be the one that results in the lowest greenhouse gas emissions compared to the baseline. The limitation of this methodology is that large numbers of model simulations are required to model all possible retrofit combinations. If a method was included to prioritize the retrofit strategies to first address the most inefficient areas of the building, the number of total retrofit combinations could be limited and therefore the number of simulations could be reduced.

Aste and Del Pero (2013) outlined a similar iterative strategy utilizing multicriteria analysis. First an energy audit is carried out on the building to be retrofitted to determine the building features and energy use distribution. An energy model of the building is then constructed and validated, utilizing the actual building data from the audit, and the baseline energy consumption is determined. Retrofit strategies are selected based on the typical strategies utilized in industry, the feasibility of the strategies given technical and context related constraints (budget compatibility and building regulations for example), and what areas of the building are significantly above average in terms of energy usage compared to similar buildings. The potential energy impact of each retrofit strategy is calculated utilizing the energy model and different scenarios are developed considering different levels of application of each strategy (for example different insulation thicknesses). The final retrofit scenarios are chosen based on meeting all technical constraints while providing an attractive cost/benefit. The strength of this methodology is that it limits the possible retrofit scenarios by considering technical, legal, and practical aspects, therefore limiting the number of simulations by only considering feasible solutions. The limitation however is that it appears to consider the retrofit strategies separately and not as a system. So while the level of 
implementation of each retrofit is studied, the relationship between the retrofits is not. Additionally it should be noted that the criteria for selecting the retrofit strategies to consider and employ are limited. The method relies on "typical strategies used in industry" which can vary considerably based on location and building type. Additionally this method of selecting initial strategies lacks rigour as the decision maker's bias is introduced and no metric for selection is employed. Finally, the selected retrofits need to be technically feasible and have an attractive cost/benefit; however no consideration is given to material type.

Flourentzou and Roulet (2002) outlined both a "typical methodology" for determining retrofit scenarios and also a proposed methodology. The "typical methodology" involves breaking a building down into a number of components and assessing the state of the component. A listing of retrofit works can then be determined considering the components that are in a poor state of repair. The limitation of this methodology, as described by Flourentzou and Roulet (2002) is that it does not consider co-relationships between the retrofit strategies and therefore a systematic and multi-criteria assessment is required. The methodology proposed by Flourentzou and Roulet (2002) considers an assessment of the building objects and relies on designer expertise to select appropriate retrofits and levels of implementation. Each strategy is applied to the building and tested utilizing building energy modelling software. Utilizing a database of typical interactions between retrofit strategies and again relying on designer expertise, the interrelations between the strategies are considered and if inconsistencies are observed by the designer, the retrofit strategies are refined and tested. Flourentzou and Roulet (2002) described this process as follows: 
"Looking at the effect of an action on the whole, [the designer] measures the coherence of that action with the objectives of the retrofit. From this point, he may come back on his decisions and alter his decisions to retrofit some objects or groups of objects."

Through an iterative process of applying retrofits on a detailed level and then considering the interactions from a global perspective, a suitable package of retrofit strategies is developed. The strength of this approach is that it considers the relationship between each chosen retrofit strategy and focuses on the effect of the complete retrofit package as opposed to only looking at the individual strategies. The limitation of this process is that it relies heavily on designer expertise and decision making and does not provide a metric for determining the most appropriate retrofit package.

Dembo (2011) utilized a Brute Force Sequential Search (BFSS) method to select potential upgrades to new residential buildings. A number of upgrade options were selected and each individually applied to the baseline home. The most appropriate upgrade option was then selected based on a "rule", defined by Dembo, which in this case was the lowest life cycle cost. The original baseline with the upgrade option applied became the new baseline and the remaining upgrade options were individually applied to the new baseline. This method is somewhat similar to the multi-objective optimization software programs, as outlined above, in that it carries out a Brute Force analysis although it differs in that it eliminates certain combinations of strategies utilizing the "rule". This method addresses many of the weaknesses of other studies outlined above. First, this method limits the total number of upgrade combinations by selecting the most appropriate upgrades first, based on the "rule", and eliminating combinations 
that don't include these upgrades. Also, this method considers the relationship between upgrades; once the first upgrade is selected, the subsequent upgrades are evaluated considering their relationship to the first. Once two upgrades are selected, the subsequent upgrades are evaluated considering their relationship to the first two. This process continues so that all upgrades are evaluated considering their relationship to the others. Finally, this method does not rely on designer expertise to select the most appropriate upgrade, but relies on a "rule" which can be set to take into consideration various criteria. The weakness of this method is that while reducing computation time by eliminating certain combinations, it is possible that some of the ruled out combinations may have been attractive options. Therefore while this method addresses the time constraint of other similar Brute Force methods, the rigour of strategy selection is reduced. Additionally identifying a "rule" to govern strategy selection is a limiting factor. While the "rule" is customizable to allow for a number of different retrofitting goals to be considered, setting the "rule" is somewhat arbitrary and identifying a "rule" that takes into consideration all of the complexities of retrofit decision making is difficult.

From the literature it appears that multi-objective optimization for building retrofit decision making often involves making concessions in modelling accuracy to assist in simplifying the simulations which can have a detrimental effect on modelling results. Many researchers have instead employed multi-criteria assessments for retrofit decision making and the strengths and limitations of a number of these studies have been outlined. 


\subsubsection{Retrofit Cost Considerations}

Determining the most appropriate retrofits for a building is not typically governed solely by building performance and energy use reduction. Rysanek and Choudhary (2013) indicated that evidence suggests the success of a building retrofit relies as much on accurately determining the economic conditions of a retrofit as determining postretrofit building performance. As such, retrofit decision making typically includes a cost/benefit analysis, or optimization, often focusing on energy use reduction and cost minimization (Rysanek \& Choudhary, 2013). Many studies listed above performed the cost/benefit analysis by comparing the capital cost of implementing a retrofit strategy to the expected operational cost savings from the resultant energy use reduction.

Rysanek and Choudhary (2013), in their case study of an office building retrofit, determined the cost/benefit of an array of feasible retrofit strategies to determine which strategies to employ. Cost savings due to reduced operational energy demand over the lifetime of each retrofit strategy were estimated and were compared to the capital cost of implementing the strategy. Cost savings estimates took into consideration future energy cost increases, determined through literature review, but did not take into consideration real estate value increases or potential changes in operation or occupancy over the lifetime of the building.

A case study conducted by Aste and Del Pero (2013) also included cost in the retrofit decision making process. The expected capital cost of various retrofits were calculated and compared to the expected energy savings or value of energy production (for renewable energy retrofits) to determine a payback period for the retrofits. Similar to 
above, cost savings took into consideration estimates of future energy cost increases, but did not take into consideration other economic uncertainties.

Similar studies were conducted by Pappas and Reilly (2011), who made retrofit decisions based on simple payback period, and Entrop, Brouwers, and Reinders (2010) who calculated the financial returns on energy savings investments by comparing capital costs to future energy cost savings.

Other studies, however discussed the limitations of these methods of estimating retrofit economic conditions due to the uncertainty of building and economic assumptions. Shonders and Im (2012) gave the example of changing weather conditions over time that will affect the heating and cooling loads of buildings and asked how accurately savings can be estimated considering future unknowns. Menassa (2011) listed further limitations indicating that it is impossible to accurately predict future energy use due to possible changes in building occupancy, hours of building and system operations, control set points, maintenance conditions, and weather conditions. Economic assumptions also include future energy costs, inflation rates, and discount rates (Menassa, 2011) all of which can vary significantly over time.

Another factor related to retrofit costing is investment period (Rysanek and Choudhary, 2013). This may be particularly true for residential buildings where the length of time occupants remain in the home varies and therefore determining an acceptable payback period is difficult. Additionally, as residential homes do not necessarily have an operations and maintenance budget and more likely rely on mortgage funding for home retrofits, investment time periods may vary considerably. 
Menessa (2011) concluded that the uncertainty in economic benefits of retrofitting creates a major risk factor in investment decisions. Shonders and Im (2012) indicated that estimates of savings from a retrofit depend on complicated statistical models and therefore the uncertainty of the parameters, as outlined above, is rarely considered. They also indicated that classical statistical models are difficult to apply to retrofit decision making as well as uncertainty, leading to complex models being required.

The studies reviewed above generally advocated against long term economic predictions to justify building retrofits due to inherent uncertainty in future financial, building, and energy parameters. The studies generally supported methods of quantifying energy use reduction through building energy modelling and also methods of estimating the capital costs of retrofitting through literature or through industry correspondence. Complicated statistical models to quantify the uncertainty of future economic conditions were discussed as a method for dealing with future uncertainty in financial estimations, however it was shown in a Canadian context that homeowners are likely to base retrofit decision making only on the lowest upfront capital cost regardless of the long term economic attractiveness of the retrofit (Aydinalp et al., 2001).

The background and literature review provided a context and understanding of the current conditions and knowledge base regarding deep energy retrofits for single family homes. The need for building retrofits in order to reduce energy use was established. As such, this study will aim to create a process to study building retrofits in order to increase the rigour and effectiveness of retrofits utilizing the most advanced building energy modelling tools. This process will aim to be applicable to specific 
building typologies or archetypes, which will provide the opportunity to develop retrofits for groupings of buildings instead of on a case by case basis. Additionally the process will aim to be repeatable and to allow different building typologies or archetypes to be considered.

The neighbourhoods of urban Toronto with a high proportion of single family homes as well as the archetypes developed by Blaszak and Richman (2013) provide a framework to assess which neighbourhoods contain the largest proportion of high energy consuming archetypes. This assessment will be undertaken in this study in order to focus retrofits on the most energy intensive neighbourhoods and archetypes in the City of Toronto. The wall assemblies proposed by Mucciarone (2011) provide an opportunity to model the performance of select wall assemblies utilizing the archetypes developed by Blaszak and Richman (2013) to determine how much energy usage can be reduced by installing the retrofit assemblies.

Strategies for building retrofitting were uncovered and discussed. Strategies to reduce energy consumption were found to be preferable to strategies that produce alternative energy and the importance of combining strategies in a complementary system was outlined. As such, this study will focus exclusively on retrofit strategies for increasing efficiency and reducing building energy usage. This study will also address gaps in the studies outlined above as it will analyze and compare retrofit strategies and levels of implementation considering energy efficiency, cost, and applicability to specific archetypes. The whole-building or whole-systems approach to retrofitting will be followed in this study taking into consideration the building envelope system and the HVAC system as well as the relationship between the various elements of each. 
The importance of moisture durability was explored in the literature and quantitative metrics were identified to ensure the risk of moisture damage and decay is minimized. This study will explore the effects of moisture on retrofit assemblies utilizing hygrothermal modelling to ensure that retrofitting will not decrease durability, but instead will maintain or increase the durability of the homes. Moisture performance will be assessed quantitatively considering the number of hours that the $\mathrm{RH}$ of wooden materials exceeds $80 \%$ and the number of hours that the moisture content of wooden materials exceeds $16 \%$ over the modelling period. Additionally, moisture accumulation and drying will be observed to ensure that a stable or overall drying trend is present as recommended by Lstiburek (2002).

High performance buildings were explored and it was determined that a $50 \%$ reduction in energy use is often targeted. This target was utilized by Blaszak and Richman (2013) when developing retrofits for the Toronto archetypes. Their study set a yearly energy consumption target of $100 \mathrm{kWh} / \mathrm{m}^{2}$ for heating and cooling utilizing approximately a $50 \%$ reduction from the Toronto average of $204 \mathrm{kWh} / \mathrm{m}^{2}$ contained in the EcoENERGY database produced by Natural Resources Canada. As a 50\% reduction in energy use for Toronto homes was already attempted and shown to be possible, this study will aim to improve on these results by setting a low end target of 75 $\mathrm{kWh} / \mathrm{m}^{2}$ for heating and cooling. As the EnerPHit standard was designed specifically for retrofit applications, it will provide a high performance target for this study. As certification is required to officially achieve the EnerPHit standard, this study will aim to achieve an estimated equivalency to the EnerPHit standard, denoted as "EnerPHit EQUIV" for the purpose of the research. 
Building energy modelling will be employed to develop and evaluate retrofit strategies as recommended by the literature. EnergyPlus software will be utilized and the calibrated model development procedure established by Zirnhelt (2013) will be utilized to guide model development. This study will aim to develop building retrofits taking into consideration both energy efficiency and cost and therefore multiple objectives, however a multi-objective optimization will not be utilized due to the computational time requirement. This study will aim to maximize the accuracy of the building energy models and therefore reducing the number of times steps and thermal zones or simplifying the heat balance and building physics calculations will be avoided.

The research will utilize a multi-criteria assessment process for retrofit decision making similar to the Brute Force Sequential Search method of Dembo (2011) taking into consideration the strengths and weaknesses of the methodologies proposed by Rysanek and Choudhary (2012), Aste and Del Pero (2013), and Flourentzou and Roulet (2002). The methodology will test retrofit strategies singularly and in combination, to varying levels of implementation to determine what retrofit packages will meet the energy efficiency targets.

This study will focus on present day energy use reduction, as calculated by building energy modelling, as well as capital costs, as ascertained by industry partners, for retrofit decision making. For each retrofit strategy, the cost per unit of energy saved will be determined. This will provide a quantification of the present day cost/benefit of each strategy while avoiding the inherent uncertainties, as outlined above, of long term cost/benefit analyses. Complicated statistical models to quantify the uncertainty of future economic conditions will be avoided as it was shown in a Canadian context that 
homeowners are likely to base retrofit decision making on the lowest upfront capital cost regardless of the long term economic attractiveness of the retrofit (Aydinalp et al., 2001).

\subsection{Objectives}

The main objective of this study is to outline a process through which to develop and analyze deep energy retrofits for specific housing archetypes or typologies. The process will be developed to include the selection of target housing archetypes for retrofitting, the establishment of the baseline energy consumption of the housing types, and a retrofit decision making process. The process is meant to be customizable and repeatable allowing it to be applied to a variety of housing types and allowing different retrofitting goals to be incorporated. The process is aimed at being applicable for researchers to study building retrofits with the aim of moving towards a process that can be utilized by homeowners to develop retrofits for their homes. The research questions that arose from the literature review and objectives were as follows:

1) What areas of urban Toronto, with a high concentration of single family homes, are the most energy intensive?

a. What proportion of each defined archetype is present?

b. Do the four defined archetypes describe the majority of single family homes in these areas?

c. Are more archetypes needed to define the majority of homes?

2) What characteristic data is required to develop baseline energy models of the Toronto archetypes?

a. Is the data collected by Blaszak and Richman (2013) sufficient?

b. What types of HVAC systems are currently in use in Toronto homes?

c. What types of internal gains can be presently expected? 
3) For each archetype what retrofits are required to achieve a target energy

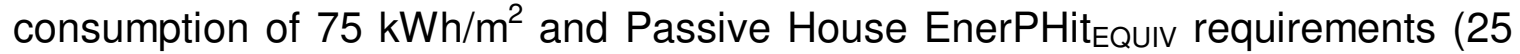
$\mathrm{kWh} / \mathrm{m}^{2}$ of Treated Floor Area for heating and cooling)?

a. How do the proposed retrofit envelopes perform hygrothermally?

b. What are the cost implications of achieving the target performance levels?

\section{Methodology}

In order to answer the research questions, this research will study the urban neighbourhoods considered and archetypes developed by Blaszak and Richman (2013) to determine neighbourhoods and archetypes that represent the greatest potential for energy use reduction. These neighbourhoods and archetypes will be utilized to create the process for developing and analyzing deep energy retrofits for specific housing typologies. For the purpose of this study, deep energy retrofits are defined as whole building retrofits including building envelope and HVAC retrofits. The research will conduct questionnaire surveys and inspect archetypal Toronto homes to collect data related to internal gains, HVAC systems, and characteristic housing dimensions and features which will be used to develop baseline energy models. Finally, the research will apply retrofit strategies to the baseline energy models and explore the performance and cost of the retrofits. Retrofits strategies will be combined in an iterative process to reach the target performance levels.

\subsection{Research Phasing}

The process will be developed over three phases with each phase corresponding to a research question as derived above: 
P1) Determine neighbourhoods and archetypes for retrofitting and whether the majority of homes in the neighbourhoods can be represented by the defined archetypes.

P2) Conduct housing inspections and questionnaire surveys to collect characteristic housing data. Build and calibrate baseline energy models.

P3) Develop retrofit strategies and estimate cost. Perform hygrothermal analyses on all envelope assemblies. Determine what retrofits are required to achieve an energy performance of $75 \mathrm{kWh} / \mathrm{m}^{2}$ and Passive

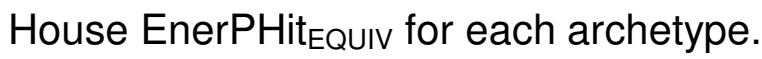

The research phases will be performed in linear order with each phase being dependent on the results of the previous phase.

Phase 1 will analyze the Toronto Neighbourhood Profiles to determine the distribution of the archetypes developed by Blaszak and Richman (2013) within the neighbourhoods outlined in the project scope. Phase 1 will also determine the energy intensity of the neighbourhoods and which archetypes predominantly contribute to the energy intensity. Phase 1 will conclude with the determination of target neighbourhoods and archetypes which will be utilized in the development of the process to develop and analyze deep energy retrofits for specific housing types.

Phase 2 will conduct housing inspections and questionnaire surveys to collect the data required to build baseline energy models for each of the archetypes selected in Phase 1. The baseline energy models will be prepared utilizing the calibrated 
methodology developed by Zirnhelt (2013). Phase 2 will then correlate the modelled baseline energy consumption of the archetypes to the baseline energy consumption determined by Blaszak and Richman (2013), as well as the Natural Resources Canada Urban Archetypes Project (NRCan - CanmetENERGY, 2009) and afterwards pursue further calibration of the models. Calibration will be conducted by comparing the energy models to energy bill data from a sample of archetypal homes and will be determined using ASHRAE Guideline 14 (ASHRAE, 2007),

Phase 3 will develop deep energy retrofits to meet the target energy performances for each archetype. The hygrothermal performance of the developed building envelope retrofit assemblies will be analyzed. The hygrothermal analysis will be quantitative in nature and will act as a comparison between the hygrothermal performances of the existing base building and the retrofit assemblies, as well as provide an indication of whether moisture damage and deterioration will be likely in the retrofitted buildings. Costs will be estimated through consultation with Toronto contractors and a long term cost analysis will be utilized to compare the capital and energy costs of the baseline home to the retrofits that met the performance targets. An iterative, multi-criteria assessment process will be utilized to guide retrofit selection, considering both energy use reduction and capital cost through an assessment of the cost/benefit of each retrofit strategy.

\subsection{Scope}

The scope of this study is limited by housing type, geographic area, and archetype, however the process is meant to be applicable to other geographical areas and building types. The housing type is limited to single family homes. The term "single 
family home" is not meant to denote the type of occupancy, but is meant to denote single-detached, semi-detached, and row housing and to exclude multi-unit residential buildings. The geographic area is broadly limited by the boundaries of the Old City of Toronto or "urban Toronto", and is also limited to areas with a higher than average proportion of single family homes as determined by Blaszak (2010). These areas were listed as the East, comprising the region between Riverdale and the Beaches, the West, comprising the High Park and Parkdale neighbourhoods north and south of Bloor Street, and the North, comprising the region along the east side of Yonge Street and north of Bloor Street. Within these areas, the housing archetypes which will be considered are those developed by Blaszak and Richman (2013).

The scope of the deep energy retrofits is limited to building envelope and mechanical systems and will focus exclusively on heating and cooling loads as $57 \%$ of energy consumed in Canadian households is used for space heating (Centre for Energy, 2013). This study is limited to developing a sampling of options for envelope retrofits and will not perform an optimization of various assembly choices. While there is a wide array of material choices and combinations that can be utilized to construct building envelopes, this study will adapt assemblies proposed by Mucciarone (2011). The author acknowledges that the envelope retrofits that will be developed do not represent the only solution for achieving the retrofit goals. Additionally, building envelope retrofits for walls will only comprise interior retrofits as retrofitting on the exterior is typically less common in the Toronto context (Blaszak, 2010) and can jeopardize legal constraints such as setbacks. 
The hygrothermal analysis is not meant to be exhaustive and will not take into consideration all possible scenarios. The hygrothermal analysis is limited to a one dimensional analysis, the default Toronto climate file, the default modelling period, and typical moisture loads.

Cost considerations will focus exclusively on capital costs for the purpose of retrofit decision making. Cost estimations are limited to labour and material costs and will not include design, or consulting costs. The long term cost analysis is not intended to justify the deep energy retrofits from an investment perspective, but is meant to act as a theoretical comparison of future economic conditions. 


\section{Results and Discussion}

\subsection{Determine Archetypes Distribution}

The Toronto Neighbourhood Profile reports were analyzed considering the neighbourhoods falling within the project scope (see Appendix A). The Toronto Neighbourhood Profiles are adapted from Statistics Canada census data by the City of Toronto (City of Toronto, 2013) and at the time of writing only partial data was available from the 2011 census, therefore the complete 2006 data was utilized. In total 23 neighbourhoods were considered utilizing "Social Profile \#3 Neighbourhoods Families \& Dwellings" of the Toronto Neighbourhood Profiles which outlines the number of homes by structure type and the year in which they were built. The "Private Dwellings by Structure Type" data was tabulated to observe the proportion of each type of building in the neighbourhood including single-detached, semi-detached, row, apartment building, and other, as well as the total number of homes reported. This information provided insight as to whether the majority of homes in the neighbourhoods were representable by the archetypes developed by Blaszak and Richman (2013), which focused exclusively on single-detached homes, or whether semi-detached or row houses made up a majority of the homes.

The "Buildings by Period of Construction" data was then tabulated to determine the proportion of each archetype, as defined by Blaszak and Richman (2013), that was present in the neighbourhood (see Table 3). For this purpose, it was assumed that the percentage of buildings built in each construction period represented the percentage of single family homes built in the same period. The "Buildings by Period of Construction" 
data separated the periods of construction as follows: Before 1946, 1946-1960, 19611970, 1971-1980, 1981-1990, 1991-2000, 2001-2006, whereas Blaszak (2010) listed the vintages of the developed archetypes as: Century, Before 1940; War Time, 19401960; 70s OBC, 1970s; and Modern, after 2000. Correlating the vintage of the archetypes developed by Blaszak (2010) to the "Buildings by Period of Construction" delineations, Century Homes were taken to be the "Before 1946" separation; War Time Homes, 1946-1960; 70s OBC, 1971-1980; and Modern, 2001-2006, while other separations were not considered. Although the vintages listed by Blaszak (2010) correlated well to the "Buildings by Period of Construction" separations for the 70s OBC and Modern archetypes, the overlap in the Century and War Time archetype vintages should be noted. Although this inconsistency existed, the data presented in the Toronto Neighbourhood Profiles was insufficient to interpolate accurate separations between the Century and War Time archetypes. Therefore the separations as presented above were carried forward.

Utilizing the number of single family homes and the percentage of homes built in each period of construction, the proportion of single family homes represented by each archetype was determined. The results of this analysis are provided in full in Appendix B and summarized in Table 3 below: 
Table 3: Number of Buildings by Housing Type and Number of Homes by Archetype in Urban Toronto Neighbourhoods

\begin{tabular}{|c|c|c|c|c|c|c|c|c|c|c|c|}
\hline \multirow[b]{2}{*}{ \# } & \multirow[b]{2}{*}{ Name } & \multicolumn{6}{|c|}{ Number of Buildings by Housing Type } & \multicolumn{4}{|c|}{ \# of Single Family Homes by Archetype } \\
\hline & & Single & Semi & Row & Apartment & Other & Total & Century & War Time & $70 \mathrm{~s}$ OBC & Modern \\
\hline 62 & East End-Danforth & 1735 & 1880 & 350 & 4765 & 25 & 8755 & 854 & 254 & 184 & 90 \\
\hline 63 & The Beaches & 2580 & 1455 & 260 & 4810 & 5 & 9110 & 1631 & 307 & 109 & 178 \\
\hline 64 & Woodbine Corridor & 850 & 1500 & 215 & 2670 & 5 & 5240 & 500 & 129 & 33 & 22 \\
\hline 65 & Greenwood-Coxwell & 925 & 1415 & 295 & 3390 & 5 & 6030 & 478 & 161 & 80 & 9 \\
\hline 66 & Danforth Village-Toronto & 665 & 1220 & 25 & 2000 & 0 & 3910 & 445 & 86 & 48 & 7 \\
\hline 68 & North Riverdale & 785 & 1205 & 135 & 2810 & 5 & 4940 & 573 & 80 & 30 & 5 \\
\hline 70 & South Riverdale & 835 & 2205 & 1180 & 5505 & 25 & 9750 & 515 & 80 & 52 & 22 \\
\hline 81 & Trinity-Bellwoods & 320 & 720 & 1000 & 4370 & 25 & 6435 & 220 & 42 & 13 & 8 \\
\hline 86 & Roncesvalles & 630 & 995 & 360 & 4410 & 75 & 6470 & 419 & 78 & 36 & 8 \\
\hline 87 & High Park-Swansea & 2620 & 495 & 165 & 5725 & 30 & 9035 & 55 & 219 & 745 & 79 \\
\hline 88 & High Park North & 1375 & 580 & 110 & 8235 & 5 & 10305 & 49 & 358 & 301 & 6 \\
\hline 89 & Runnymede-Bloor West Village & 1980 & 765 & 50 & 965 & 5 & 3765 & 91 & 728 & 200 & 95 \\
\hline 90. & Junction Area & 750 & 965 & 540 & 2995 & 5 & 5255 & 27 & 66 & 282 & 0 \\
\hline 91 & Weston-Pellam Park & 535 & 1305 & 325 & 2120 & 20 & 4305 & 213 & 101 & 50 & 48 \\
\hline 92 & Corso Italia-Davenport & 1280 & 1225 & 110 & 2550 & 30 & 5195 & 693 & 272 & 99 & 5 \\
\hline 93 & Dovercourt-Wallace Emerson-Junction & 1590 & 2145 & 745 & 8815 & 30 & 13325 & 780 & 236 & 112 & 106 \\
\hline 94 & Wychwood & 945 & 920 & 255 & 3770 & 5 & 5895 & 516 & 166 & 97 & 19 \\
\hline 95 & Annex & 630 & 1120 & 620 & 12330 & 15 & 14715 & 248 & 82 & 57 & 40 \\
\hline 98 & Rosedale-Moore Park & 2450 & 445 & 245 & 6805 & 5 & 9950 & 883 & 363 & 257 & 215 \\
\hline 99 & Mount Pleasant East & 2155 & 1570 & 150 & 3115 & 190 & 7180 & 1010 & 325 & 224 & 45 \\
\hline 100 & Yonge-Eglinton & 1410 & 460 & 25 & 3330 & 10 & 5235 & 690 & 181 & 210 & 38 \\
\hline 103 & Lawrence Park South & 3415 & 110 & 25 & 2020 & 10 & 5580 & 2238 & 543 & 77 & 242 \\
\hline 105 & Lawrence Park North & 3110 & 865 & 20 & 1450 & 0 & 5445 & 2050 & 432 & 54 & 123 \\
\hline
\end{tabular}

Table 3 demonstrates that in 19 out of 23 neighbourhoods Century Homes were the most prevalent followed by War Time Homes. In three neighbourhoods the War Time Home was the most prevalent followed by the 70s OBC Home and in one neighbourhood the 70s OBC Home was the most prevalent followed by the War Time Home.

It should be noted that the total number of homes reported in the "Private Dwellings by Structure Type" data was not always consistent with the number of homes reported in the "Buildings by Period of Construction" data. Therefore the percentage of total homes was calculated separately for each data set. Also, as the archetypes developed by Blaszak and Richman (2013) were single-detached homes, the number of single-detached homes reported in the "Private Dwellings by Structure Type" data was utilized. Finally, in some of the Neighbourhood Profiles exact data for the number of 
"Buildings by Period of Construction" was not summarized. Although interpolation was possible visually, accuracy could not be ensured.

\subsection{Estimate Neighbourhood Energy Intensities}

To estimate the energy intensity of the 23 neighbourhoods analyzed above, the distribution of the archetypes in each neighbourhood was correlated to the total average energy intensity of the archetypes as calculated by Blaszak and Richman (2013). The total average energy intensity $\left(\mathrm{kWh} / \mathrm{m}^{2}\right)$ of each archetype (see Table 2) was multiplied by the number of single-detached homes represented by that archetype to determine the overall neighbourhood energy intensities. As this calculation did not take into consideration the total number of homes in the neighbourhoods, the average energy intensity per home was calculated by dividing the neighbourhood energy intensity by the number of single-detached homes in the neighbourhood. This calculation is described in equation [1] below:

Average Energy Intensity $=\frac{[(\text { Century } * 408)+(\text { War Time } * 263)+(70 \mathrm{~s} O B C * 251)+(\text { Modern } * 231)]}{[\text { Century }+ \text { WarTime }+70 \mathrm{~s} O B C+\text { Modern }]}$

Semi-detached homes and row houses were excluded from this calculation as no baseline energy intensity values were available. This is because Blaszak and Richman (2013) did not include semi-detached and row houses in the initial archetype development. For semi-detached homes and row houses it was not realistic to assume energy intensities similar to single-detached homes due to geometrical differences and energy implications of the shared walls in semi-detached homes and row houses. While 
this calculation omitted some housing types, it does give a representation of which neighbourhoods have the least efficient archetypes.

From the calculated results, the 23 neighbourhoods were ranked to determine which neighbourhoods had the highest average energy intensity. The ranking results are shown in Table 4 below:

Table 4: Average Yearly Energy Intensity of Urban Toronto Neighbourhoods

\begin{tabular}{|r|l|r|}
\hline$\#$ & Name & Average Energy Intensity $\left(\mathrm{kWh} / \mathrm{m}^{2}\right)$ \\
\hline 68 & lorth Riverdale & 383 \\
\hline 81 & lrinity-Bellwoods & 375 \\
\hline 86 & Roncesvalles & 374 \\
\hline 103 & Lawrence Park South & 373 \\
\hline 66 & Danforth Village-Toronto & 372 \\
\hline 70 & South Riverdale & 371 \\
\hline 64 & Woodbine Corridor & 367 \\
\hline 63 & The Beaches & 366 \\
\hline 105 & Lawrence Park North & 365 \\
\hline 65 & Greenwood-Coxwell & 356 \\
\hline 92 & Corso Italia-Davenport & 356 \\
\hline 94 & Wychwood & 354 \\
\hline 99 & Mount Pleasant East & 352 \\
\hline 93 & Dovercourt-Wallace Emerson-Junction & 351 \\
\hline 100 & Yonge-Eglinton & 349 \\
\hline 62 & East End-Danforth & 349 \\
\hline 95 & Annex & 343 \\
\hline 91 & Weston-Pellam Park & 333 \\
\hline 98 & Rosedale-Moore Park & 332 \\
\hline 89 & Runnymede-Bloor West Village & 270 \\
\hline 88 & High Park North & 268 \\
\hline 90 & Junction Area & 264 \\
\hline 87 & High Park-Swansea & 260 \\
\hline
\end{tabular}

The differences in total average energy intensity of the neighbourhoods are directly related to the archetypes located in the neighbourhoods. For example, North Riverdale has a high proportion of Century Homes, which have the highest total energy intensity, whereas High Park-Swansea has a larger proportion of 70s OBC Homes 
which are more energy efficient. Due to the varied distribution of archetypes, the energy intensity of the neighbourhoods decreases in minimal increments in the ranking, with few large gaps in energy intensity from one neighbourhood to the next. The five most energy intensive neighbourhoods were selected to be the target neighbourhoods as these neighbourhoods provided representation from the three areas of urban Toronto with the greatest concentration of single family homes; the East, West, and North, as outlined by Blaszak (2010). Additionally, these neighbourhoods cover approximately the same area as can be seen in Figure 7 below:

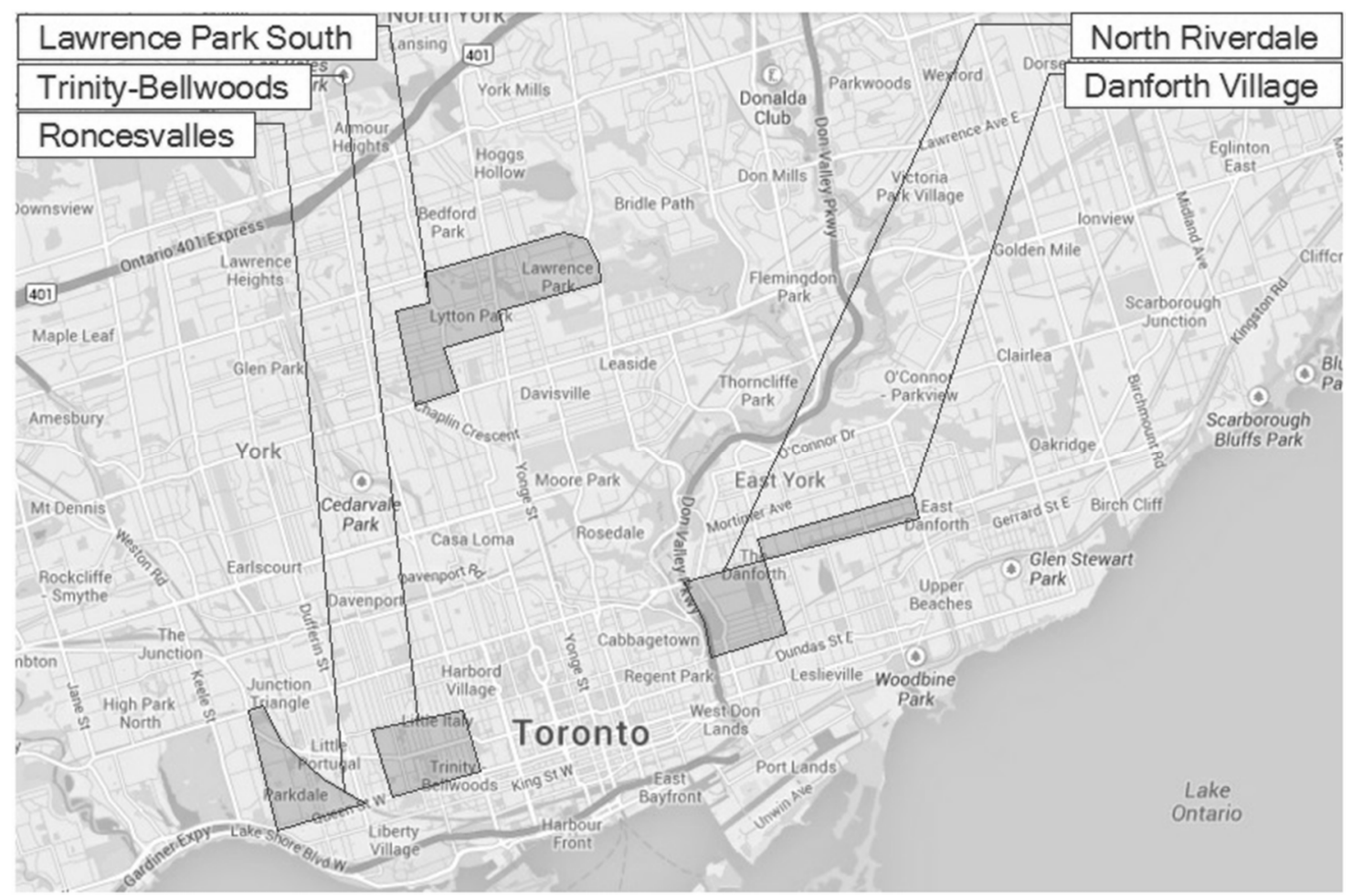

Figure 7: Map of Toronto Highlighting Target Neighbourhoods

Therefore the target neighbourhoods were North Riverdale, Trinity-Bellwoods, Roncesvalles, Lawrence Park South, and Danforth Village with average energy intensities of $383,375,374,373$, and $372 \mathrm{kWh} / \mathrm{m}^{2}$ respectively. The housing archetype 
distribution of these neighbourhoods was inspected further to determine which archetypes predominantly contributed to the high energy intensity.

Table 5 summarizes the archetype distribution and the percent contribution of each archetype to the energy intensity of the target neighbourhoods.

Table 5: Distribution and Energy Intensity Contribution of Archetypes in the Target Neighbourhoods

\begin{tabular}{|l|r|r|r|r|r|r|r|r|}
\hline & \multicolumn{2}{|l|}{ \# of Single-Detached Dwellings by Archetype } & \multicolumn{2}{c|}{ Overall Energy Intensity by Archetype (\%) } \\
\hline Name & Century & War Time & 70s OBC & Modern & Century & War Time & 70 s OBC & Modern \\
\hline North Riverdale & 573 & 80 & 30 & 5 & $88.8 \%$ & $7.9 \%$ & $2.9 \%$ & $0.4 \%$ \\
\hline Danforth Village & 445 & 86 & 48 & 7 & $83.4 \%$ & $10.4 \%$ & $5.5 \%$ & $0.7 \%$ \\
\hline Trinity-Bellwoods & 220 & 42 & 13 & 8 & $84.9 \%$ & $10.4 \%$ & $3.0 \%$ & $1.7 \%$ \\
\hline Roncesvalles & 419 & 78 & 36 & 8 & $84.5 \%$ & $10.1 \%$ & $4.5 \%$ & $0.9 \%$ \\
\hline Lawrence Park South & 2238 & 543 & 77 & 242 & $80.7 \%$ & $12.6 \%$ & $1.7 \%$ & $4.9 \%$ \\
\hline
\end{tabular}

Without exception, in each of these neighbourhoods the Century Home archetype was most common followed by the War Time archetype. For each neighbourhood with the exception of Lawrence Park South, the number of homes per archetype increased with age with the most homes being Century Homes and the least number of homes being Modern. Lawrence Park by comparison followed the same trend except there were a larger number of Modern homes then there were 70 s OBC homes. It was clear from the results of Table 5 that the Century and War Time archetypes represented the greatest contribution to the high energy intensities in these neighbourhoods contributing $80.7 \%$ to $88.8 \%$ and $7.9 \%$ to $12.6 \%$ respectively of the overall energy intensity. As the predominant homes in the target neighbourhoods were Century and War Time Homes and these two archetypes represented the largest total energy intensity of the four archetypes, 408 and $263 \mathrm{kWh} / \mathrm{m}^{2}$ respectively, as calculated by Blaszak and Richman (2013), this result was expected. Therefore, the Century and 
War Time archetypes were selected as the archetypes to be utilized to outline the process for developing deep energy retrofits for specific housing typologies.

\subsection{Considering Semi-Detached and Row Houses}

The archetypes developed by Blaszak and Richman (2013) only considered single-detached homes. Therefore, the number of semi-detached and row houses in the target neighbourhoods were considered to determine whether there was a majority of semi-detached or row houses in the neighbourhoods which could be developed as separate archetypes. Table 6 summarizes the number of each type of single family home contained within the target neighbourhoods

Table 6: Number of Buildings by Housing Type in the Target Neighbourhoods

\begin{tabular}{|l|r|r|r|}
\hline & \multicolumn{3}{|c|}{ \# of Building by Single Family Housing Type } \\
\hline Name & Single-Detached & Semi-Detached & Row \\
\hline North Riverdale & 785 & 1205 & 135 \\
\hline Danforth Village & 665 & 1220 & 25 \\
\hline Trinity-Bellwoods & 320 & 720 & 1000 \\
\hline Roncesvalles & 630 & 995 & 360 \\
\hline Lawrence Park South & 3415 & 110 & 25 \\
\hline
\end{tabular}

With the exception of Lawrence Park South, there were more semi-detached homes than single-detached homes in each target neighbourhood and with the exception of Trinity-Bellwoods; no neighbourhoods had a majority of row housing. Overall $50 \%$ of the homes in the target neighbourhoods were single-detached, 37\% were semi-detached, and $13 \%$ were row houses. This indicates that the archetypes developed by Blaszak and Richman (2013), which represent single-detached homes, only represent half of the homes in the target neighbourhoods. In order to represent a greater number of Toronto homes, semi-detached homes were also considered for retrofitting. Although row 
housing was the predominant housing type in one of the target neighbourhoods, it represented a small proportion overall at only $13 \%$ and therefore was not considered further.

Upon physical observation of the archetypes in the target neighbourhoods as well as a review of the CMHC pattern book (CMHC, 1947) for War Time Homes; it was determined that semi-detached War Time homes are not prevalent in Toronto, whereas semi-detached Century Homes are common. For this reason the semi-detached War Time archetype was not included in the study. The archetypes considered for retrofitting were therefore single-detached and semi-detached Century Homes, further denoted as Century Homes and Century-Semi Homes, as well as single-detached War Time Homes, further denoted as War Time Homes.

For the additional archetype representing the Century-Semi Home to be developed, the following characteristics (developed by Blaszak and Richman, 2013) needed to be determined through field study:

- Construction

- Structural design - load bearing masonry or light wood-frame, foundation, etc.

- Levels of insulation - separately in the walls, ceiling, foundation, etc.

- Materials - cladding, types of insulation, etc.

- glazing - amount, type, and orientation

- Geometry

- Size - volume, heated floor area, etc.

- Shape - rectangular or non-rectangular, number of storeys, etc.

- Vintage

- Year, decade, or period of construction

(Adapted from Blaszak and Richman, 2013) 
To match the data collection methodology of Blaszak and Richman (2013), the construction, geometry, and features data were collected by visual observation and direct measurement of sample archetypal homes. Average glazing areas and housing dimensions were obtained by direct measurements.

\subsection{Phase 1 Summary}

Determining the most inefficient neighbourhoods in urban Toronto yielded an interesting result. Many of the urban Toronto neighbourhoods considered in the analysis were constructed in the same vintage and largely utilized similar building techniques and typologies. The neighbourhoods that were constructed more recently tended to have lower energy intensities overall; a predictable result as homes that were more recently constructed tend to be more energy efficient. While it was possible to prepare a ranking and determine, based on the framework of the analysis, which neighbourhoods were the most energy intensive, the results only confirmed assumptions that the oldest neighbourhoods and buildings were the most inefficient. As such, it would be best to focus retrofitting on specific building vintages and not necessarily specific neighbourhoods in a Toronto context.

The archetype distribution was observed to be fairly consistent across all of the 23 urban neighbourhoods that had a high proportion of single family homes (greater than 2000 units/neighbourhood). With few exceptions, the Century archetype was the most prevalent followed by the War Time archetype. Generally, the number of homes represented by each archetype decreased with more recent vintages. The exceptions to this trend were the High Park neighbourhoods north and south of Bloor Street where the 
War Time and 70s OBC archetypes were predominant. The archetype distribution is clearly linked to the general age of the neighbourhoods as much of urban Toronto was developed around the turn of the century corresponding to the Century Home archetype (Blaszak, 2010).

With the knowledge that Century and War Time Homes represent the greatest proportion of Toronto's urban housing stock and also knowing that these two archetypes represent the greatest total energy intensity of the four developed archetypes, it appears as if there is a significant opportunity to retrofit these housing types to reduce energy intensity in the City of Toronto. This study was therefore justified in selecting these archetypes for retrofitting.

While Blaszak and Richman's (2013) study focused exclusively on singledetached dwellings during archetype development, the above analysis determined that single-detached dwellings make up only $50 \%$ of the single family homes in the target neighbourhoods and that semi-detached dwellings represent the majority of homes in three out of the five neighbourhoods. This led the research to consider retrofitting semidetached dwellings separately from single-detached dwellings. Creating a unique archetype for semi-detached dwellings was not feasible however, due to the fact that semi-detached dwellings have been constructed during many of the historical building periods. Therefore it would be best to create additional archetypes to represent semidetached homes from each of the construction periods. Being that this research targeted the Century and War Time archetypes for retrofitting, semi-detached Century and War Time Homes were initially considered in order to increase the inclusivity of the study. Throughout the research however, it became clear that semi-detached War Time 
Homes are not prevalent in Toronto and that all of the War Time Homes observed or investigated by the researcher were single-detached dwellings. Therefore the semidetached War Time archetype was removed which allowed the study to focus on singledetached and semi-detached Century Homes and single-detached War Time Homes.

\subsection{Data Collection for Baseline Energy Models}

With the archetypes identified, baseline energy models for the Century Home, Century-Semi Home, and War Time Home were developed. In order to ensure that the baseline models were created utilizing appropriate energy modelling techniques and parameters, the model development procedure established by Zirnhelt (2013) was utilized. The data required for Zirnhelt's model development procedure is summarized below:

- Geometry

- Building footprint

- Storey height

- Dimensions

- Glazing and doors

- Floor plan

- Shading devices and overhangs

- Envelope

- Materials and material properties

- Window constructions including frame, divider, reveal, and sill

- Door constructions

- Air tightness

- Basement

- Basement materials and material properties

- Wall and floor thicknesses

- Depth of wall below grade

- Internal Gains

- Types of major appliances

- Occupancy schedules 
- HVAC

- Thermostat location

- Type of heating and cooling

- Total ventilation flow rate

While some of the data outlined above was provided by Blaszak and Richman (2013) for the Century and War Time Homes, additional data was required for calibrated model preparation in EnergyPlus. Additionally, as Blaszak and Richman (2013) did not consider semi-detached homes in the archetype development, data collection was required in order to construct the Century-Semi Home archetype.

To collect representative housing data for the archetypes, homeowners were recruited from each of the five target neighbourhoods to participate in the study. Participants living in the three archetypal homes were asked whether any previous renovations, retrofits, or additions had been completed at their homes in order to understand whether the homes were typical of the archetypes, meaning as originally constructed, or whether modifications to the homes had been undertaken. Participants were requested to fill out a questionnaire survey to determine the HVAC system type and location in their home, the types of major appliances utilized, and their occupancy schedule so that internal gains could be determined. Additionally, participants were asked to provide access to the interior and exterior of their homes so that direct measurements of the building geometry and floor plan could be taken.

Participants were recruited exclusively through colleague referral which did not constitute a truly random sample. Participants were often neighbours of one another and tended to be grouped closely together within the target neighbourhoods which may have led to some bias in the data collection. Also, the boundaries of the target 
neighbourhoods appeared somewhat subjective and therefore for consistency, the boundaries outlined by the Toronto Neighbourhood Profiles were utilized. It should be acknowledged however that homeowners who lived within close proximity of the boundaries and were willing to participate were not excluded from the data collection. In total 29 homes were inspected and efforts were made to recruit the same number of participants from each neighbourhood. Additionally, efforts were made to collect data from an equal number of homes from each archetype, although there were significantly fewer War Time Homes present in all of the target neighbourhoods.

While the limitations of the data collection as outlined above existed, the purpose of this field study was to establish the data required to build and calibrate the baseline energy models for the purpose of the retrofit development process. In the data collection process convergences in the geometry, construction, and features were observed which allowed typical archetypical features to be discerned. Therefore, while some biases in the data existed, a general representation of archetypal homes was observed. The researcher was able to collect the sample data required to generate building energy models utilizing EnergyPlus from each neighbourhood and archetype.

In total 29 homes across the five target neighbourhoods and three archetypes were inspected. The distribution of the data collection is shown in Table 7 below:

Table 7: Number of Homes Inspected by Neighbourhood and Archetype

\begin{tabular}{|l|r|r|r|r|}
\hline Neighbourhood & Number of Houses & Century & Century-Semi & War Time \\
\hline North Riverdale & 6 & 3 & 2 & 1 \\
\hline Danforth Village & 5 & 2 & 2 & 1 \\
\hline Trinity-Bellwoods & 7 & 2 & 5 & 0 \\
\hline Lawrence Park South & 7 & 1 & 1 & 5 \\
\hline Roncesvalles & 4 & 3 & 1 & 0 \\
\hline Total & 29 & 11 & 11 & 7 \\
\hline
\end{tabular}


Efforts were made to conduct an equal number of inspections in each of the neighbourhoods and for each of the archetypes; however this was not achieved. While fairly even across the neighbourhoods, due to the distribution of willing participants, some neighbourhoods had larger numbers of inspections than others. Also, due to the fact that War Time Homes made up a small overall proportion of homes in each of the neighbourhoods, a predominance of Century and Century-Semi Homes were inspected. For each of the three housing types however, a repetition of building shapes and sizes was apparent. Therefore even though less War Time Homes were inspected overall, clear patterns of repetition emerged in the data sets which allowed typical housing sizes and shapes to be discerned

From the data that was collected, shown in full in Appendices C1 through C4, there was not always a majority of homes that fit the archetypal description outlined by Blaszak and Richman (2013). Of the 11 Century Homes that were inspected, seven homes resembled the archetype description outlined by Blaszak and Richman (2013) whereas only two War Time Homes resembled the archetypal description. Of the 11 Semi-Detached Century Homes four closely resembled the Century Home archetype. It is clear that there are many housing types in the neighbourhoods that do not closely resemble the archetypes as developed by Blaszak and Richman (2013), therefore it was decided that a visual inspection of the neighbourhoods would be performed to confirm the prevalence of the archetypal homes and to determine whether the homes that do not match the archetype description were common or represented outliers.

All of the neighbourhoods are roughly rectangular in shape except for Lawrence Park South. To perform the visual observation, five streets were selected from each 
neighbourhood in a grid formation with three streets being selected on the long axis of the neighbourhood and two being selected on the short axis. For Lawrence Park South, streets were selected to provide a sampling of each section of the neighbourhood (north, east, south, west, and central). The houses on the streets were assessed visually for their resemblance to the defined archetypes and a tally of the various housing types was prepared. The housing types for each period of construction are outlined and described below:

Century Home

1. Archetypal - Resembled the archetype defined by Blaszak and Richman (2013)

2. 2 Storey - Similar to the archetypal shape, however only two storeys in height

3. Wide Lot - Large home with significant space between neighbouring houses

4. Other - Other geometry or size than what is listed above

Century-Semi Home

1. Archetypal - Resembled the Century Home archetype defined by Blaszak and Richman (2013)

2. 2 Storey - Similar to the archetypal shape, however only two storeys in height

3. Other - Other geometry or size than what is listed above

War Time Home

1. Archetypal - Resembled the archetype defined by Blaszak and Richman (2013)

2. 1.5 Storey - Similar to the archetypal shape, however 1.5 storeys in height

3. 2 Storey - Similar to the archetypal shape, however two storeys in height 
4. Other - Other geometry or size than what is listed above

The results of the tally are shown in Appendix D and summarized in Table 8 and Table 9 below:

Table 8: Percentage of Total Single Family Homes Tallied by Neighbourhood

\begin{tabular}{|l|r|r|r|}
\hline Neighbourhood & Total Homes Tallied & Total Single-Family Homes & $\%$ of Total \\
\hline Riverdale & 651 & 2125 & $31 \%$ \\
\hline Danforth Village & 563 & 1910 & $29 \%$ \\
\hline Trinity Bellwoods & 424 & 1740 & $24 \%$ \\
\hline Lawrence Park South & 367 & 3550 & $10 \%$ \\
\hline Roncesvalles & 552 & 1985 & $28 \%$ \\
\hline All Neighbourhoods & 2557 & 11310 & $23 \%$ \\
\hline
\end{tabular}

Table 9: Tally and Percentages of Various Housing Types Observed in the Neighbourhoods

\begin{tabular}{|c|c|c|c|c|c|c|c|c|c|c|c|}
\hline & \multicolumn{3}{|c|}{ Semi } & \multicolumn{4}{|c|}{ Century } & \multicolumn{4}{|c|}{ War Time } \\
\hline Neighbourhood & Archetypal & 2 Storey & Other & Archetypal & Wide Lot & 2 Storey & Other & Archetypal & 2 Storey & 1.5 Storey & Other \\
\hline Riverdale & 210 & 108 & 8 & 222 & 2 & \begin{tabular}{|r|}
71 \\
\end{tabular} & 21 & 9 & 0 & 0 & 0 \\
\hline Danforth Village & 45 & 292 & 2 & 54 & 0 & 118 & 4 & 48 & 0 & 0 & 0 \\
\hline Trinity Bellwoods & 191 & 68 & 10 & 100 & 6 & 25 & 6 & 13 & 0 & 1 & 4 \\
\hline Lawrence Park South & 0 & 3 & 2 & 19 & 191 & 78 & 1 & 15 & 57 & 1 & 0 \\
\hline Roncesvalles & 162 & 76 & 6 & 218 & 2 & 62 & 7 & 5 & 7 & 7 & 0 \\
\hline All Neighbourhoods & 608 & 547 & 28 & 613 & 201 & 354 & 39 & 90 & 64 & 9 & 4 \\
\hline Percent Total & $51 \%$ & $46 \%$ & $2 \%$ & $51 \%$ & $17 \%$ & $29 \%$ & $3 \%$ & $54 \%$ & $38 \%$ & $5 \%$ & $2 \%$ \\
\hline
\end{tabular}

Of the combined 11310 homes, 2557 homes were tallied, making up $23 \%$ of all single family homes in the neighbourhoods. Across the neighbourhoods there was a small majority of archetypal homes. The Century and Century-Semi archetypal homes represented $51 \%$ of homes in the neighbourhoods, whereas the War Time Home archetypal home represented 54\%. Given the majority, although slight, only the archetypal homes that were inspected were considered for the development of the baseline energy models. The remaining homes were treated as outliers and removed from further consideration. Data collected for the archetypal homes, excluding the outliers, can be found in Appendices E1 through E3 


\subsection{Preparing Baseline Energy Models}

The three baseline energy models (i.e. Century Home, Century-Semi Home, and War Time Home) were constructed in a similar manner utilizing the same simulation parameters, run times, calculations methods, and weather file. Only building specific factors were different between the three energy models which included geometry, envelope constructions, air tightness, internal gains, and HVAC systems. This ensured that only building specific factors influenced the modelled energy consumption of the archetypes and removed variations arising from the modelling methodology. The models were constructed utilizing the calibrated model procedure developed by Zirnhelt (2013) where possible with any variations being outlined below.

As the archetypes were meant to represent typical Toronto buildings, there were no specific site related factors for the archetypes. For this reason several parameters were fixed in the models including building orientation and shading. The buildings were assumed to be north facing. As many of the Century and Century-Semi Homes in urban Toronto are situated on narrow lots with minimal spacing between buildings, the east and west face of the buildings were assumed to be $100 \%$ shaded whereas the north and south faces were assumed to be $0 \%$ shaded. For the War Time Homes, which are typically separated by driveways, all building faces were assumed to have $0 \%$ shading. Shading devices for the Century and Century-Semi Homes were constructed in EnergyPlus at a distance of $0.6 \mathrm{~m}$ from the building face, corresponding to the methodology of Markiel (2011). 


\subsubsection{Infiltration Model}

Zirnhelt (2013) utilized the ASHRAE (2009b) enhanced method for modelling air infiltration in EnergyPlus using the "Zonelnfiltration:FlowCoefficient" object. This was possible as detailed blower door testing results were available for the building that was modelled (Zirnhelt, 2013). As the archetypal buildings considered in this study were meant to represent typical homes, no detailed infiltration data was available, only general indications of the air changes per hour at $50 \mathrm{~Pa}(\mathrm{ACH})$ obtained from the EcoENERGY database. For this reason a different method of modelling air infiltration was required.

Zirnhelt (2013) had originally modelled air infiltration utilizing the Design Flow Rate method in EnergyPlus, "Zonelnfiltration:DesignFlowRate", which utilizes Equation [2] (EnergyPlus, 2013) as follows:

$$
\text { Infiltration }=\left(I_{\text {design }}\right)\left(F_{\text {schedule }}\right)\left[A+B\left|\left(T_{\text {zone }}-T_{\text {odb }}\right)\right|+C(\text { WindSpeed })+D\left(\text { WindSpeed }^{2}\right)\right]
$$

Several default coefficients for A, B, C, and D were provided by EnergyPlus (2013) which come from the EnergyPlus predecessor programs BLAST and DOE-2. Zirnhelt (2013) however indicated that little guidance is provided by EnergyPlus developers or the building simulation community as to which coefficients to select or how to calculate the coefficients. Zirnhelt (2013) also determined that utilizing the BLAST coefficients increased heating energy use by $28 \%$ compared to the DOE- 2 coefficients and therefore the Design Flow Rate calculation was deemed too uncertain for use. Gowri, Winiarski, and Jarnagin (2009) however conducted a sensitivity analysis of the DOE-2 and BLAST coefficients and found that the BLAST coefficients were highly sensitive to 
temperature variations and tended to over-predict energy loss; often by a factor of three or more compared to the DOE-2 coefficients. It was also found that the DOE-2 coefficients account for wind differences based on the floor height of buildings whereas the BLAST coefficients vary minimally between multiple floors. Gowri et al. (2009) concluded their report recommending the utilization of the DOE-2 coefficients for infiltration modelling in EnergyPlus. This study therefore utilized the DOE-2 coefficients in conjunction with the $\mathrm{ACH}$ at $50 \mathrm{~Pa}$ values obtained from the EcoENERGY database to model air infiltration in the building energy models.

\subsubsection{Internal Gains}

Internal heat gains generated in the homes from occupants, lighting, and appliances were modelled in accordance with the calibrated methodology of Zirnhelt (2013) utilizing data collected during the housing surveys conducted in this study. Occupant and lighting gains were associated with living spaces and sleeping spaces, but were not associated with basement areas as these were predominantly used for storage, not occupancy. For the Century Home archetype, the main floor level was considered to be living space, the second to be sleeping space, and the third level to be a home office. For the Century-Semi Home archetype, the main floor was considered to be living space and the second and third floors were considered sleeping spaces. For the War Time Home archetype the bedrooms were considered to be sleeping spaces and the remainder of the single storey was considered to be living space. These arrangements corresponded to actual housing uses as observed in Toronto homes. Zirnhelt (2013) modelled living and family rooms as separate zones and therefore modelled the internal gains separately, with the same level of occupancy but different 
schedules. This research modelled each floor as a distinct thermal zone and therefore there was no zonal difference between the living and family rooms. The internal gains from the living and family rooms were modelled together with a schedule that was the combination of the living and family room schedules modelled by Zirnhelt (2013).

Gains from home lighting were modelled for the typically occupied first floor, as well as second and third floor bedroom and office areas of the archetypal homes. The model utilized watts per zone floor area $\left(\mathrm{W} / \mathrm{m}^{2}\right)$ to calculate internal gains from lighting. The first floor areas were modelled utilizing $1.9 \mathrm{~W} / \mathrm{m}^{2}$ and the bedroom and office areas utilizing 3.07 W/m² utilizing the schedules of Zirnhelt (2013).

Internal gains from typical home appliances were also included in the models. The types of appliances, power usage, and schedules were based on the calibrated model by Zirnhelt (2013); however this data was supplemented with the results of the questionnaire surveys which requested what types of appliances were used in the sampled homes and the typical schedule of appliance use.

\subsubsection{Interzone Openings}

EnergyPlus does not inherently account for the transfer of energy between thermal zones due to doorways and stairwells. Omitting a portion of a wall or floor surface in the building geometry also omits the heat transfer associated with that surface (Zirnhelt, 2013). Therefore omitting a doorway or stairwell between zones also omits the heat transfer between the zones. To account for this, doorways and stairwells were modelled as glass surfaces with a high transmittance, high emissivity, high long wave transmittance, and very low thermal resistance as modelled by Zirnhelt (2013). 
Heat transfer through the openings was then modelled utilizing the simplified methodology of Meldem and Winklemann (1995) who provided heat transfer coefficients for various types of openings. Meldem and Winklemann (1995) provided a coefficient of $11 \mathrm{~W} / \mathrm{m}^{2} \mathrm{k}$ for door openings and Zirnhelt, (2013) assumed a coefficient of $20 \mathrm{~W} / \mathrm{m}^{2} \mathrm{k}$ for stairwells. These coefficients were utilized in the baseline model preparation for all archetypes.

\subsubsection{Envelope Framing Factors}

As the building envelopes of the archetypal homes do not incorporate any exterior insulation, all wooden framing members present thermal bridges. Framing members include studs, sill and top plates, and window and door framing. To account for thermal bridging in building envelope assemblies, a framing factor (FF) is often used which is the average percentage of envelope area that is bridged by wooden framing elements. It was not possible to collect FF data from the housing inspections associated with this research as architectural drawings were not available for the inspected homes and destructively opening a wall section to observe framing members was outside the scope of the research due to cost and inconvenience to the study participants. Several publications offered different recommended FF values. ASHRAE (1997) suggested a wall FF of $25 \%$ whereas the National Energy Code of Canada (NRC IRC, 2011) suggested $19 \%, 10 \%$, and $10 \%$ for walls, roofs, and floors respectively. A recent study conducted by Qasass, Gorgolewski, and Ge (2014) investigating the average FF in newer Toronto homes found that framing factors varied between $30-40 \%$ for walls, 8$10 \%$ for roofs, and $11-14 \%$ for floors depending on whether the homes were detached, semi-detached, or townhomes. Taking only the data for detached and semi-detached 
homes, average framing factors were calculated at $31.4 \%, 8.6 \%$, and $11.7 \%$ for walls, roofs, and floors respectively (Qasass et al., 2014).

To utilize the FF in determining envelope RSI values, a weighted average of the RSI value of the insulation and the RSI value of the wood framing members was calculated using Equation [3] below (Zirnhelt, 2013):

$$
R S I_{\text {effective }}=R S I_{\text {insulation }} *(1-F F)+R S I_{\text {wood }} *(F F)
$$

From this formula, the results of Qasass et al. (2014), which presented the highest framing factor, resulted in the lowest effective RSI value. Therefore to be conservative, these framing factors were utilized to construct the baseline energy models. It should be noted that the FF of newer Toronto homes does not necessarily reflect the FF of older Toronto homes due to possible changes in construction practice and methods. However due to the absence of architectural drawings and the unfeasibility of destructive investigations in the homes of participants, the FFs given by Qasass et al. (2014) were utilized.

Qasass et al. (2014) did not provide FF data for interior partition framing, however Zirnhelt (2013) utilized a FF of $15 \%$ calculated based on as-built drawings of a newer single-detached home in Ottawa. While the same limitations, as discussed above, apply to assuming a FF for the interior partition walls of older Toronto homes, the FF outlined by Zirnhelt (2013) was utilized to construct the baseline energy models. 


\subsubsection{Building Specific Parameters}

\section{The baseline energy models for the three archetypes were developed utilizing}

\section{the building specific parameters shown in Table 10 below:}

Table 10: Building Specific Parameters for Baseline Energy Models

\begin{tabular}{|c|c|c|c|c|}
\hline Archetypes & Century & Century-Semi & War Time & Reference \\
\hline Heated Floor Area & $250.9 m^{2}$ & $165.9 \mathrm{~m}^{2}$ & $131.7 \mathrm{~m}^{2}$ & Field Study \\
\hline Footprint & $5.8 \mathrm{~m} \times 13.4 \mathrm{~m}$ & $5.1 \mathrm{~m} \times 13.7 \mathrm{~m}$ & $6.5 \mathrm{~m} \times 12.8 \mathrm{~m}$ & Field Study \\
\hline \multicolumn{5}{|l|}{ Building } \\
\hline \# Storeys & 3 & 2.5 & 1 & Field Study \\
\hline Plan Shape & Rectangular & L-shape & Rectangular & Field Study \\
\hline Vintage & $<1940$ & $<1940$ & 1940-60 & Blaszak and Richman (2013) \\
\hline Lot Placement & Adjacent to Neighbours & Adjacent to Neighbours & Driveway on one side & Field Study \\
\hline Features & $\begin{array}{c}\text { Finished attic, full-width } \\
\text { porch }\end{array}$ & $\begin{array}{c}\text { Finished attic, full-width } \\
\text { porch }\end{array}$ & Half-width porch & Field Study \\
\hline Roof & $\begin{array}{c}\text { Gable } \\
\end{array}$ & Gable front, flat rear & Gable & Field Study \\
\hline Structure & Double-wythe brick & Double-wythe brick & Light-wood frame & Blaszak and Richman (2013) \\
\hline Cladding & Brick & Brick & Brick & Field Study \\
\hline \multicolumn{5}{|l|}{ Insulation RSI } \\
\hline Ceiling & 2.64 & 2.64 & 3.58 & Blaszak and Richman (2013) \\
\hline Walls & 1.01 & 1.01 & 1.65 & Blaszak and Richman (2013) \\
\hline Foundation & 0.55 & 0.55 & 0.83 & Blaszak and Richman (2013) \\
\hline \multicolumn{5}{|l|}{ Ceiling Assembly } \\
\hline & Shingle & Shingle & Shingle & Blaszak and Richman (2013) \\
\hline & OSB & OSB & 150mm Fibreglass & Blaszak and Richman (2013) \\
\hline & 100mm Fibreglass & 100mm Fibreglass & Gypsum & Blaszak and Richman (2013) \\
\hline & Lath and Plaster & Lath and Plaster & & Blaszak and Richman (2013) \\
\hline \multicolumn{5}{|l|}{ Wall Assembly } \\
\hline & Double Wythe Brick & Double Wyth Brick & Brick & Blaszak and Richman (2013) \\
\hline & 20mm Air Space & 20mm Air Space & 20mm Air Space & Blaszak and Richman (2013) \\
\hline & $25 \mathrm{~mm}$ Fibreglass & $25 \mathrm{~mm}$ Fibreglass & OSB & Blaszak and Richman (2013) \\
\hline & Lath and Plaster & Lath and Plaster & $50 \mathrm{~mm}$ Fibreglass & Blaszak and Richman (2013) \\
\hline & & & Gypsum & Blaszak and Richman (2013) \\
\hline \multicolumn{5}{|l|}{ Foundation Assembly } \\
\hline & Quadruple Wythe Brick & Quadruple Wythe Brick & $300 \mathrm{~mm}$ Concrete & Blaszak and Richman (2013) \\
\hline & & & $25 \mathrm{~mm}$ Fibreglass & Blaszak and Richman (2013) \\
\hline & & & Gypsum & Blaszak and Richman (2013) \\
\hline Air Leakage (ACH 50Pa) & 10.54 & 11.7 & 8.17 & EcoENERGY Database \\
\hline \multicolumn{5}{|l|}{ Glazing (\%) } \\
\hline Front & 19 & 15.6 & 15.8 & Field Study \\
\hline Side & 5.7 & 3.6 & 5.4 & Field Study \\
\hline Side & 3.2 & $\mathrm{~N} / \mathrm{A}$ & 3.6 & Field Study \\
\hline Rear & 15.6 & 10.8 & 20.1 & Field Study \\
\hline Window Type & Double Glazed Air Filled & Double Glazed Air Filled & Double Glazed Air Filled & Field Study \\
\hline Door Type & \begin{tabular}{|c|} 
Insulated \\
\end{tabular} & Insulated & \begin{tabular}{|c|} 
Insulated \\
\end{tabular} & Field Study \\
\hline \multicolumn{5}{|l|}{ HVAC System } \\
\hline Type & Forced Air Gas & Forced Air Gas & Forced Air Gas & Field Study \\
\hline Controls Location & Dining Room & Main Floor & Living Room & Field Study \\
\hline Vent Flow Rate & $1.3 \mathrm{~m}^{3} / \mathrm{s}$ & $1.3 \mathrm{~m}^{3} / \mathrm{s}$ & $1.0 \mathrm{~m}^{3} / \mathrm{s}$ & Field Study \\
\hline \multicolumn{5}{|l|}{ Internal Gains } \\
\hline \begin{tabular}{|l|l|} 
Lighting \\
\end{tabular} & 1.9 and $3.07 \mathrm{~W} / \mathrm{m}^{2}$ & 1.9 and $3.07 \mathrm{~W} / \mathrm{m}^{2}$ & 1.9 and $3.07 \mathrm{~W} / \mathrm{m}^{2}$ & Zirnhelt (2013) \\
\hline Appliances & Kitchen/Hot Water & Kitchen/Hot Water & Kitchen/Hot Water & Field Study \\
\hline Occupancy & 4 People & 4 People & 4 People & Field Study \\
\hline \multicolumn{5}{|l|}{ Framing Factor } \\
\hline Exterior Wall & $31.4 \%$ & $31.4 \%$ & $31.4 \%$ & Qasass et al. (2014) \\
\hline Interior Wall & $15.0 \%$ & $15.0 \%$ & $15.0 \%$ & Zirnhelt (2013) \\
\hline Floor & $11.7 \%$ & $11.7 \%$ & $11.7 \%$ & Qasass et al. (2014) \\
\hline Roof & $8.6 \%$ & $8.6 \%$ & $8.6 \%$ & Qasass et al. (2014) \\
\hline
\end{tabular}


The heated floor area, building footprint, glazing percentage, window and door type, and HVAC system were updated from the original data presented by Blaszak (2010) utilizing the data collected during the building survey and inspection field study. In all field study cases, the original single glazed windows had been updated to double glazed windows at some point during the life of the homes. Airtightness data was updated utilizing specific data from the EcoENERGY Database for the target neighbourhoods and archetypes. Insulation levels and building features were adapted from Blaszak and Richman (2013). Envelope assemblies were developed according to the insulation levels reported by Blaszak and Richman (2013), as well as through conversations with homeowners during the housing inspections.

\subsection{Validating the Baseline Energy Models}

To ensure the accuracy of the baseline energy models prepared utilizing the calibration method by Zirnhelt (2013), the energy consumption data of the baseline models was compared to the baseline energy consumption determined by Blaszak and Richman (2013), as well as the Natural Resources Canada Urban Archetypes Project (NRCan - CanmetENERGY, 2009). Calibration of the models was also performed.

Three separate calibration standards and guidelines are often cited in literature: ASHRAE Guideline 14 (ASHRAE, 2007), the International Performance Measurement and Valuation Protocol (Efficiency Valuation Organisation, 2007), and the U.S. Department of Energy M\&V Guidelines: Measurement and Verification for Federal Energy Projects (2008). Each of these documents provided standards for how to determine when a model is calibrated (Raftery, Keane, \& O'Donnell, 2011). All three 
guidelines however utilized the ASHRAE Guideline 14 statistical method for determining when a model is calibrated when considering monthly energy data. The ASHRAE Guideline (ASHRAE, 2007) stipulated that monthly energy consumption data for the modelled building and corresponding weather data should be collected for a period of at least one year. This data should be compared to the modelled data on a monthly basis. The model is considered calibrated when the statistical Normalized Mean Bias Error (NMBE) is within $+/-5 \%$ and the Coefficient of Variation of the Root Mean Squared Error (CVRSME) is less than or equal to $15 \%$. MBE and CVRSME are calculated using Equation [4] and Equation [5] (ASHRAE, 2007) as follows:

$$
\begin{aligned}
& N M B E=100 * \frac{\sum\left(Y_{i}-\hat{Y}_{i}\right)}{(n-1) * \bar{Y}} \\
& C V R S M E=100 * \frac{\sqrt{\frac{\sum\left(Y_{i}-\hat{Y}_{i}\right)^{2}}{n-1}}}{\bar{Y}}
\end{aligned}
$$

Where:

$$
\begin{gathered}
Y=\text { model predicted value } \\
\hat{Y}=\text { actual value } \\
\bar{Y}=\text { mean value of the measured data } \\
n=\text { number of samples }
\end{gathered}
$$

To calibrate to ASHRAE Guideline 14, monthly energy bill data was requested from the homeowners who participated the study. As the focus of the study was on heating and cooling loads and it was not possible to determine cooling loads from monthly electricity bills, only natural gas consumption for heating was utilized for 
calibration. It was assumed that the natural gas consumption during the summer months (June, July, and August) was only used for water heating and cooking and represents the typical monthly non-heating baseline (Hubler, Tupper, \& Greensfelder, 2010). The average summer natural gas usage was therefore removed from the gas consumption of each month to isolate natural gas consumption for space heating. The monthly natural gas consumption of the energy bills was compared to the heating load of the baseline energy models for each archetype considering NMBE and CVRSME. The baseline models were fine-tuned by testing the sensitivity of various input parameters, such as building envelope parameters, air infiltration, HVAC systems, and scheduling and comparing the value of the parameters to the collected housing data. This calibration methodology corresponds to several examples cited in the literature (Hubler et al. 2010, Raftery et al. 2011, Yoon, Lee, \& Claridge 2003). The models were fine-tuned until the statistical calibration targets were met.

\subsection{Century Home Baseline Energy Model}

Figure 8 shows the geometry of the Century Home utilized in the building energy model. 


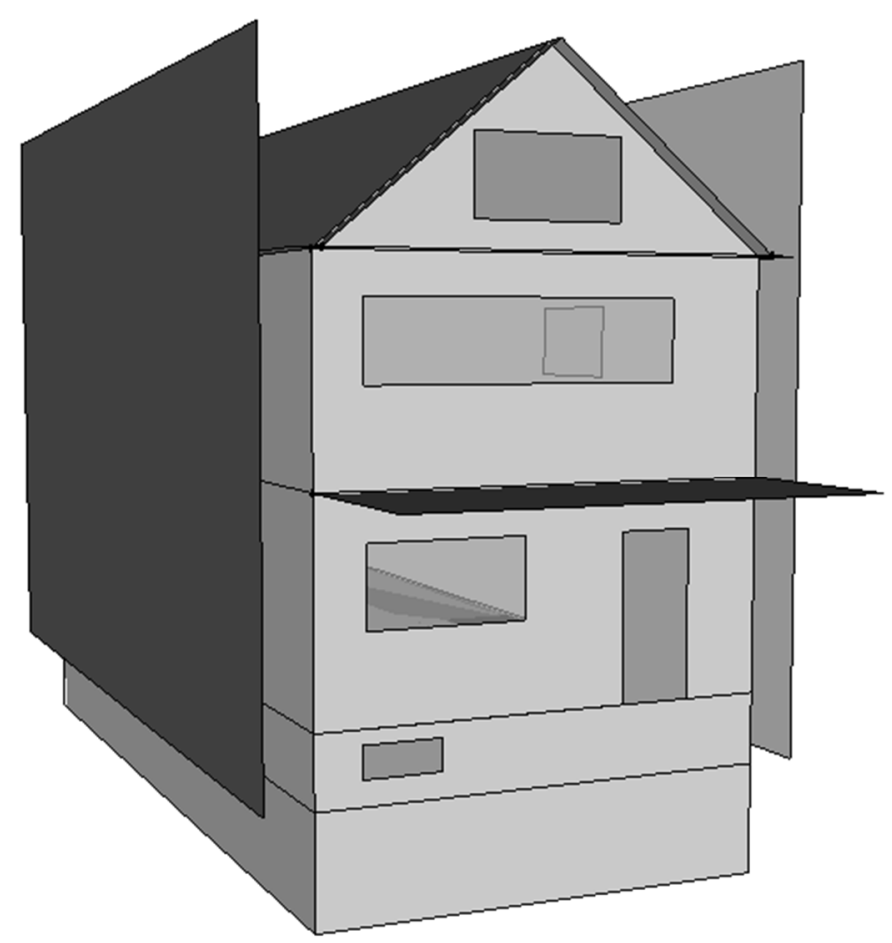

Figure 8: Geometry of Century Home Archetype Baseline Energy Model

The baseline energy model of the Century Home achieved a total overall energy use of $59,300 \mathrm{kWh} /$ year or an energy intensity of $236 \mathrm{kWh} / \mathrm{m}^{2}$ over the simulated year. This constituted a significant $53 \%$ difference from the total energy intensity of $408 \mathrm{kWh} / \mathrm{m}^{2}$ calculated by Blaszak and Richman (2013). This is likely due to differences in energy modelling software and methodology. From the CanmetENERGY Urban Archetypes Project, the energy intensities for Ottawa homes similar to the Century Home archetype ranged from 313 to $439 \mathrm{kWh} / \mathrm{m}^{2}$, with an average of $367 \mathrm{kWh} / \mathrm{m}^{2}$ (NRC CanmetENERGY, 2009). Considering only heating and cooling load, the Century Home achieved an energy use of $52,916 \mathrm{kWh} /$ year or an energy intensity of $211 \mathrm{kWh} / \mathrm{m}^{2}$ over the simulated year. 


\subsection{Century-Semi Home Baseline Energy Model}

Figure 9 shows the geometry of the Century-Semi Home utilized in the building energy model.

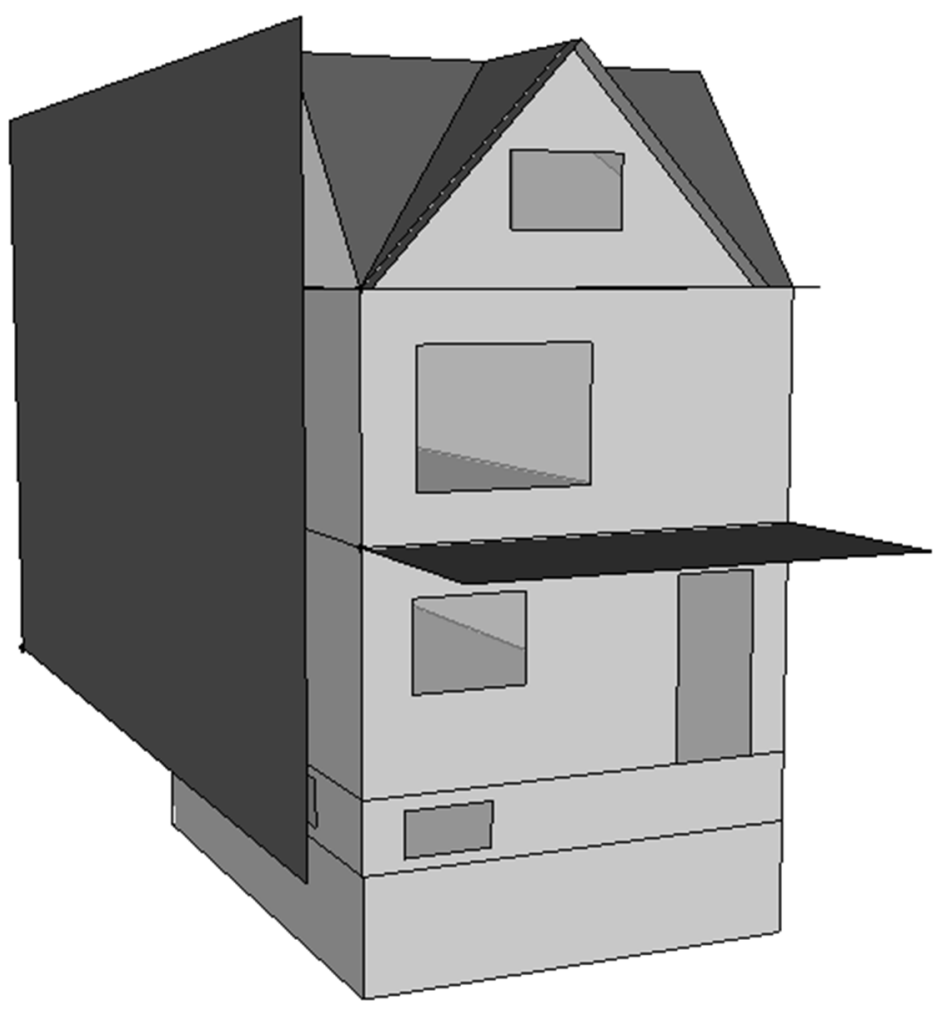

Figure 9: Geometry of Century-Semi Home Archetype Baseline Energy Model

The baseline energy model of the Century-Semi Home achieved a total overall energy use of $43,405 \mathrm{kWh}$ or an energy intensity of $262 \mathrm{kWh} / \mathrm{m}^{2}$ over the simulated year. Blaszak and Richman (2013) did not develop a Century-Semi archetype and therefore no energy intensity values existed for the Century-Semi for comparison. The CanmetENERGY Urban Archetypes Project included one semi-detached building in Ottawa built in the same period as the Century-Semi Home which had an energy intensity of $348 \mathrm{kWh} / \mathrm{m}^{2}$, corresponding to a $28 \%$ difference (NRC - CanmetENERGY, 2009). Considering only heating and cooling load, the Century-Semi Home achieved an 
energy use of $37,803 \mathrm{kWh} /$ year or an energy intensity of $228 \mathrm{kWh} / \mathrm{m}^{2}$ over the simulated year.

While it was expected that the Century-Semi would have slightly different overall energy intensity than the Century Home, it was expected that the Century-Semi would have smaller energy intensity due to the presence of the party wall which minimizes heat loss compared to an exterior wall. Considering the overall energy use of the baseline models, the Century-Semi used less energy overall, but had a larger energy intensity due to a smaller floor area. While the presence of the party wall was expected to lessen the overall energy use and intensity, other building factors appear to have offset the efficiency gains of the party wall, namely air tightness and geometry. The Century-Semi had an $\mathrm{ACH}$ of 11.7 at $50 \mathrm{~Pa}$ whereas the Century Home had an $\mathrm{ACH}$ of 10.54. The L-shaped geometry appears to have contributed to efficiency losses, due to the increase in surface area to volume ratio which typically results in lower energy efficiency (Markiel, 2011).

\subsection{War Time Home Baseline Energy Model}

Figure 10 shows the geometry of the War Time Home utilized in the building energy model. 


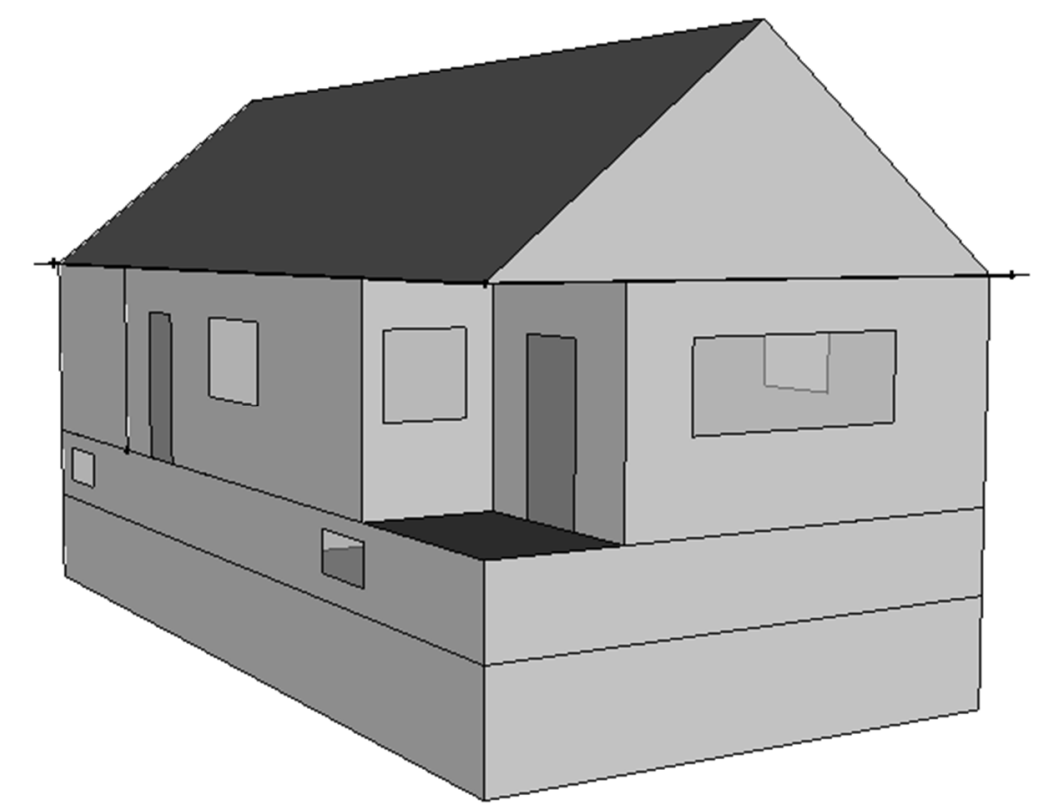

Figure 10: Geometry of War Time Home Archetype Baseline Energy Model

The baseline energy model of the War Time Home achieved an overall energy use of $33,600 \mathrm{kWh}$ or an energy intensity of $255 \mathrm{kWh} / \mathrm{m}^{2}$ over the simulated year. This constituted a difference of $3 \%$ from the energy intensity of $263 \mathrm{kWh} / \mathrm{m}^{2}$ calculated by Blaszak and Richman (2013). By comparison, the CanmetENERGY Urban Archetypes Project reported energy intensities of $279 \mathrm{kWh} / \mathrm{m}^{2}$ for similar homes in Ottawa (NRC CanmetENERGY, 2009) corresponding to a $7 \%$ difference from the baseline model. Considering only heating and cooling load, the War Time Home achieved an energy use of $27,506 \mathrm{kWh} /$ year or an energy intensity of $209 \mathrm{kWh} / \mathrm{m}^{2}$ over the simulated year.

In all three of the baseline determinations above, the energy intensities calculated in this study were smaller than the energy intensities determined by Blaszak and Richman (2013). Several trends were observed in the baseline determinations which could be used to test for errors in the energy models. The Century Home consumed the most energy overall followed by the Century-Semi and the War Time Homes. This was an expected result as the Century Home had the largest livable floor 
area and the War Time the smallest. Additionally the War Time Home had greater levels of insulation and air tightness than the other two archetypes. The energy intensities followed a different trend with the Century Home having the lowest energy intensity followed by the War Time Home and the Century-Semi Home. While there are many factors that are different between the three buildings that affect energy use, geometry, meaning the overall shape and size of the buildings, is the largest difference. To test whether the trends in energy use and energy intensity were due to geometry or due to errors or other factors, a simulation was run for each archetype keeping all factors the same except geometry. The Century-Semi and War Time models were altered to be identical to the Century Home model and internal gains, which varied between the models, were removed. The results of this simulation are found in Table 11 below:

Table 11: Comparison of Initial Baseline and Geometry Testing Results

\begin{tabular}{|l|r|r|r|r|}
\hline & \multicolumn{2}{|c|}{ Baseline } & \multicolumn{2}{c|}{ Geometry Test } \\
\hline Archetype & Energy Use $(\mathrm{kWh})$ & Energy Intensity $\left(\mathrm{kWh} / \mathrm{m}^{2}\right)$ & Energy Use $(\mathrm{kWh})$ & Energy Intensity $\left(\mathrm{kWh} / \mathrm{m}^{2}\right)$ \\
\hline Century Home & 59,300 & 236 & 57,914 & 230 \\
\hline Century-Semi & 43,405 & 262 & 41,577 & 251 \\
\hline War Time Home & 33,600 & 255 & 37,636 & 286 \\
\hline
\end{tabular}

These simulations yielded similar trends as outlined above with the Century Home consuming the most energy followed by Century-Semi and War Time and the Century Home having the lowest energy intensity. In these simulations however the War Time had the greatest energy intensity with the Century-Semi in the middle. This indicated that geometry is largely the most significant factor affecting energy use and intensity. In the case of the War Time Home, the more advanced building envelope and air tightness limited energy use and intensity, the results of which could be seen in the difference between the baseline results and the geometry testing. 


\subsection{Final Calibration of the Baseline Energy Models}

Energy bills were collected from a sample of archetypal homes. The homes were selected to ensure that they closely resembled the archetypes in geometry, size, and HVAC system and had not been altered by previous renovations or additions. This ensured that the homes resembled the geometry of the energy models. The heating set point was also determined for each home to ensure that the heating set point was identical to that of the energy models. This information is crucial as variations in heating set points can have significant effects on overall home energy usage and having different set points would lead to inaccuracies or difficulties in the calibration. In total, energy bills were collected from two Century Homes, and two Century-Semi Homes, for the years 2012 and 2013. Energy bill data was not available for any of the archetypal War Time Homes. EnergyPlus typically utilizes an average weather file whereas ASHRAE Guideline 14 requires actual yearly weather data; therefore downtown Toronto weather files for the years 2012 and 2013 were acquired for the purpose of calibration.

Energy bill data and calibration notes can be found in Appendix $G$ and Appendix $\mathrm{H}$ respectively. Generally the energy models over-predicted energy use compared to the energy bill data and many trials were undertaken in attempting to calibrate the energy models. First, calibration was attempted by fine tuning the energy models and comparing them to the energy bill data from both corresponding homes at once. Next, calibration was attempted by fine tuning the models and comparing them to each home energy bill data set separately. Envelope and air tightness parameters were altered to attempt to align instances where some months of the energy models over-predicted and others under-predicted, however calibration could not be achieved. Internal gain 
schedules and loads were also varied, but appeared to have little effect on overall energy usage.

Consulting the Enbridge Gas website, it was noted that natural gas billing does not necessarily truly reflect monthly energy use. Enbridge indicated that billing periods vary from 24 to 36 days (Enbridge Gas Distribution Inc., 2014). Also, natural gas meters are read every other month with the remaining months being estimated. This means that some months are used to compensate estimation errors in other months. This can explain why the baseline energy models significantly over-predicted energy use for some months and under-predicted others compared to the energy bills. To account for this discrepancy a normalization of the energy bill data to heating degree days was performed. Heating degree days (HDD) for central Toronto for both 2012 and 2013 (Government of Canada, 2014) were compared to both the energy usage of the energy models as well as the energy bills. Samples of this comparison are provided in Tables 12 and 13 below:

Table 12: Energy Bill Normalization Example - Century Home 2, 2012

\begin{tabular}{|l|r|r|r|r|r|r|}
\hline & EnergyPlus & Energy Bill & \multicolumn{1}{c|}{ Heating } & E+ Baseline & Energy Bill & \multicolumn{1}{c|}{ Normalized Energy Bill } \\
\hline & (GJ) & (GJ) & Degree Days & (GJ/HDD) & (GJ/HDD) & (Avg Energy Bill GJ/HDD * HDD) \\
\hline January & 25.98 & 27.78 & 578 & 0.0450 & 0.0481 & 19.62 \\
\hline February & 21.14 & 15.92 & 478 & 0.0442 & 0.0333 & 16.22 \\
\hline March & 16.06 & 14.08 & 344 & 0.0467 & 0.0409 & 11.68 \\
\hline April & 12.87 & 7.77 & 315 & 0.0409 & 0.0247 & 10.69 \\
\hline May & 4.05 & 5.05 & 100 & 0.0405 & 0.0505 & 3.39 \\
\hline September & 1.44 & 1.80 & 73 & 0.0198 & 0.0246 & 2.48 \\
\hline October & 9.18 & 5.70 & 231 & 0.0397 & 0.0247 & 7.84 \\
\hline November & 15.58 & 12.78 & 396 & 0.0393 & 0.0323 & 13.44 \\
\hline December & 21.83 & 13.31 & 503 & 0.0434 & 0.0265 & 17.07 \\
\hline & Sum & 104.18 & Average & 0.0399 & 0.0339 & 102.43 \\
\hline
\end{tabular}


Table 13: Energy Bill Normalization Example - Century-Semi Home 2, 2012

\begin{tabular}{|l|r|r|r|r|r|r|}
\hline & EnergyPlus & Energy Bill & \multicolumn{1}{c|}{ Heating } & E+ Baseline & Energy Bill & \multicolumn{1}{c|}{ Normalized Energy Bill } \\
\hline & \multicolumn{1}{|c|}{$(\mathrm{GJ})$} & \multicolumn{1}{c|}{$(\mathrm{GJ})$} & Degree Days & (GJ/HDD) & (GJ/HDD) & (Avg Energy Bill GJ/HDD * HDD) \\
\hline January & 18.69 & 25.18 & 578 & 0.0323 & 0.0436 & 17.11 \\
\hline February & 15.47 & 11.52 & 478 & 0.0324 & 0.0241 & 14.15 \\
\hline March & 12.18 & 13.39 & 344 & 0.0354 & 0.0389 & 10.18 \\
\hline April & 10.01 & 8.07 & 315 & 0.0318 & 0.0256 & 9.32 \\
\hline May & 3.68 & 4.13 & 100 & 0.0368 & 0.0413 & 2.96 \\
\hline September & 1.23 & 1.34 & 73 & 0.0169 & 0.0183 & 2.16 \\
\hline October & 6.78 & 0.00 & 231 & 0.0294 & & 6.84 \\
\hline November & 11.30 & 9.45 & 396 & 0.0285 & 0.0239 & 11.72 \\
\hline December & 15.59 & 10.67 & 503 & 0.0310 & 0.0212 & 14.89 \\
\hline & Sum & 83.75 & Average & 0.0305 & 0.0296 & 89.33 \\
\hline
\end{tabular}

The monthly energy usage from the energy models was divided by the monthly heating degree days which yielded a relatively consistent value of gigajoules of energy usage per degree day (GJ/HDD). The monthly energy bill data was also divided by the monthly heating degree days which yielded widely varying values by comparison. It was assumed that the gigajoules of energy use per heating degree day value should remain relatively constant in the energy bills (as was the case with the energy models) and therefore an average value was calculated. This average energy bill GJ/HDD (0.0339 and 0.0296 from Tables 12 and 13 respectively) was then multiplied by the number of heating degree days for each month to determine the normalized energy bill data. The results of these calculations for all houses are shown in Appendix I. The purpose of the normalization was to remove the varying time component from the energy bills and to instead rely on the energy usage per heating degree day of the home. As the heating degree days represent the actual calendar month, the intent of the normalization was to bring the energy bill data in line with the calendar month. Additionally, the normalization as presented provided estimated values where previous gaps in the energy bill data existed (see the month of October in Table 13). It should be acknowledged that the 
month of September presents a discrepancy as September typically had a lower GJ/HDD value than the other months. This may be the result of HVAC systems starting up late in the month after the hot summer or it could be the result of the homes staying warm relative to outdoor temperatures due to heat stored in the thermal mass of the buildings.

After normalization, the energy bill data demonstrated significantly less drastic monthly fluctuations. When compared to the energy models, the energy models overpredicted energy use for many months by a consistent margin. This meant that calibration could be achieved by fine tuning variables such as envelope insulation or air infiltration. Additionally, this method proved more attractive than previous attempts as the models could be calibrated for both 2012 and 2013 keeping all housing characteristics constant. For example Century House 1 achieved calibration for both 2012 and 2013 with the same envelope and air tightness parameters. The resulting calibrated graphs are shown in Figures 11 through 18 below: 


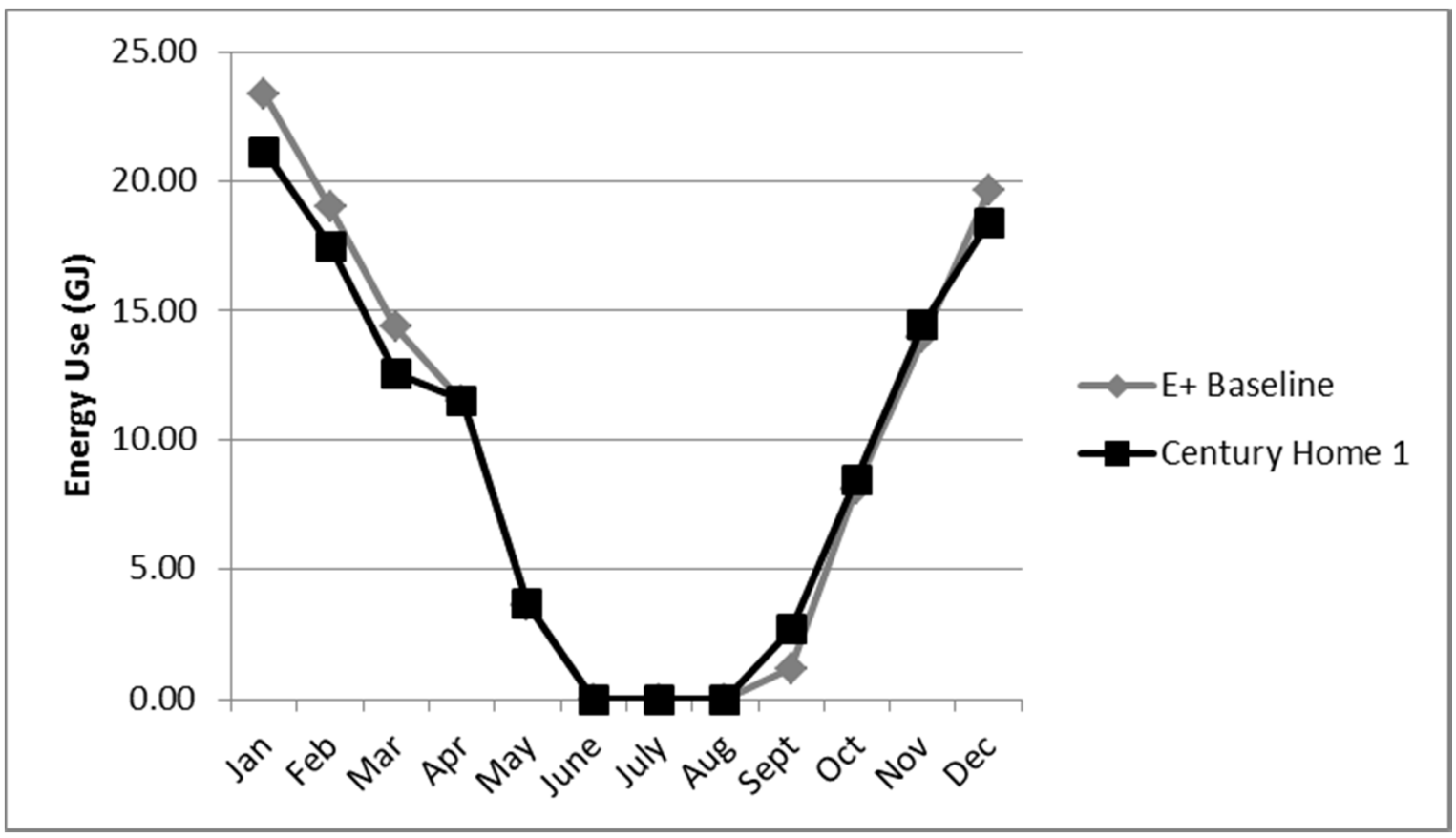

Figure 11: Century Home 1, 2012, monthly calibration results

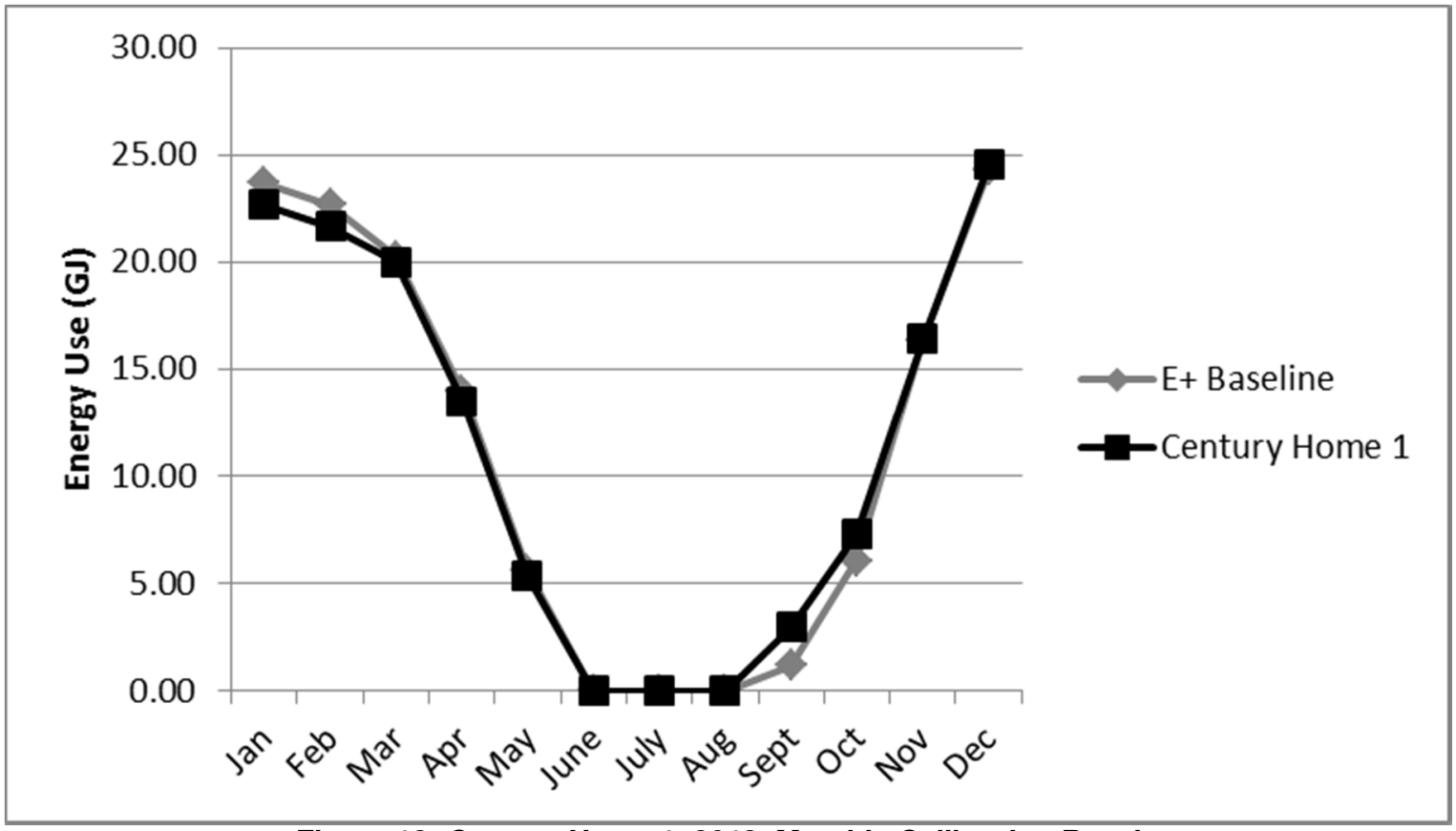

Figure 12: Century Home 1, 2013, Monthly Calibration Results 


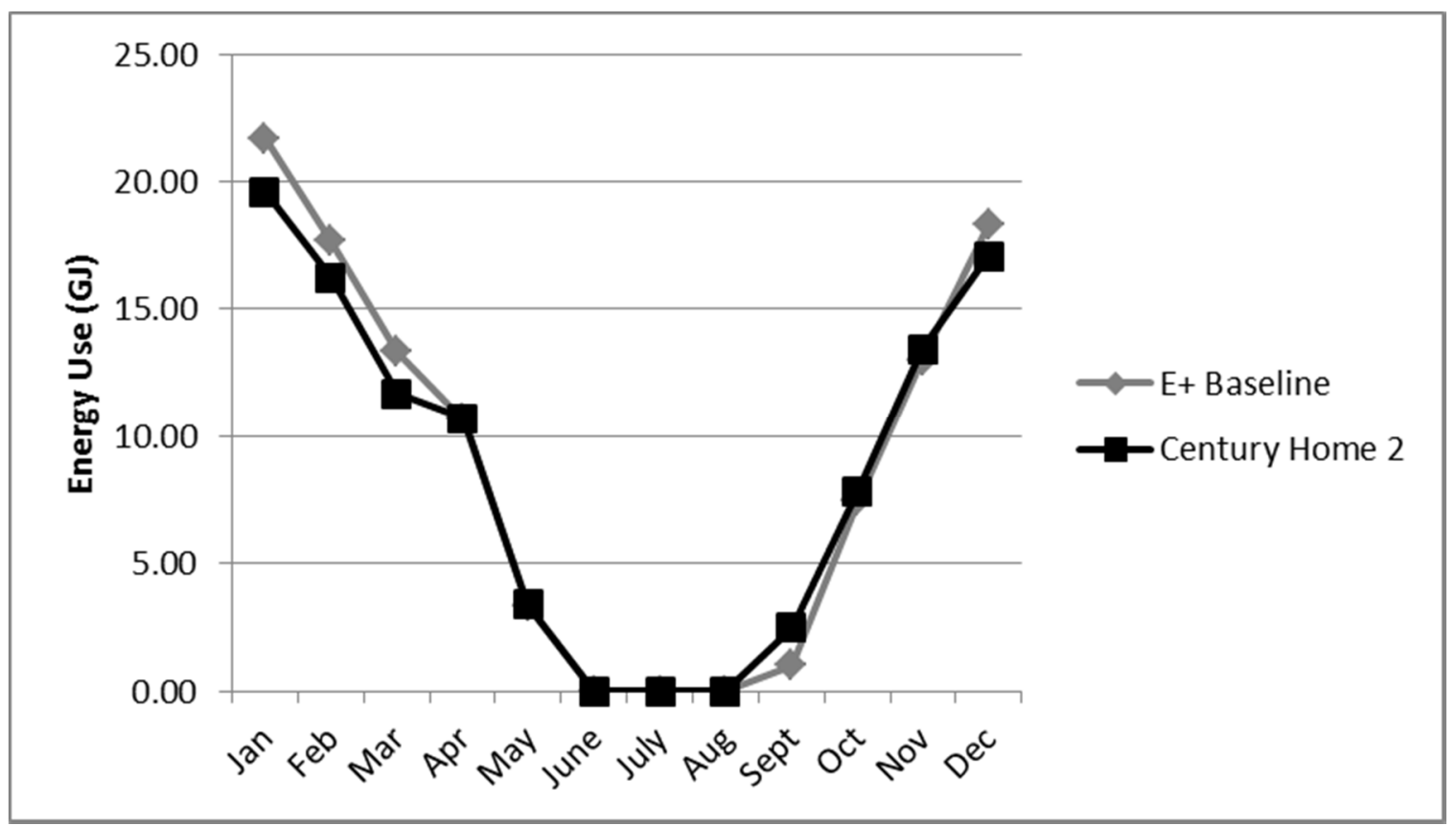

Figure 13: Century Home 2, 2012, Monthly Calibration Results

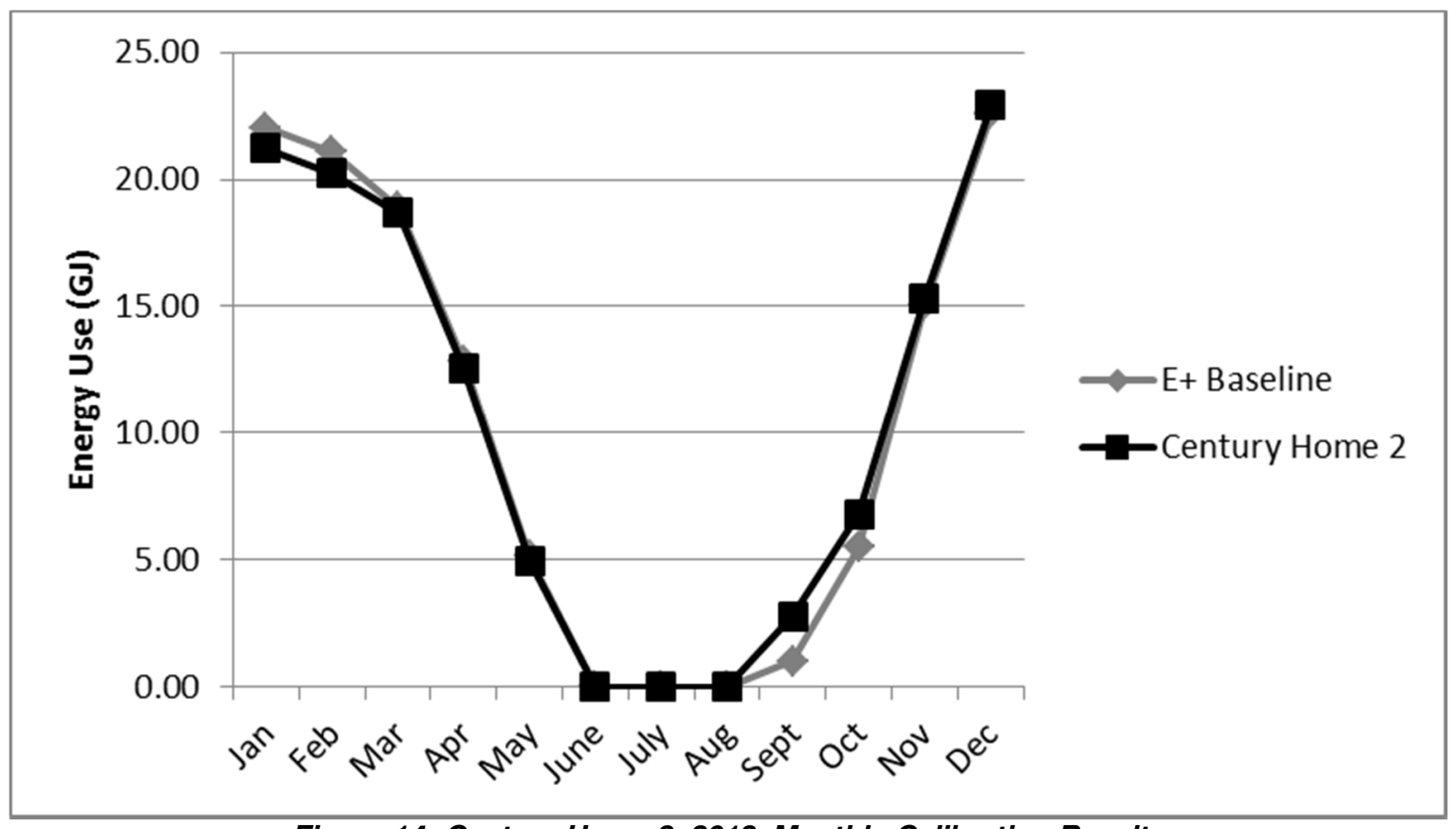

Figure 14: Century Home 2, 2013, Monthly Calibration Results 


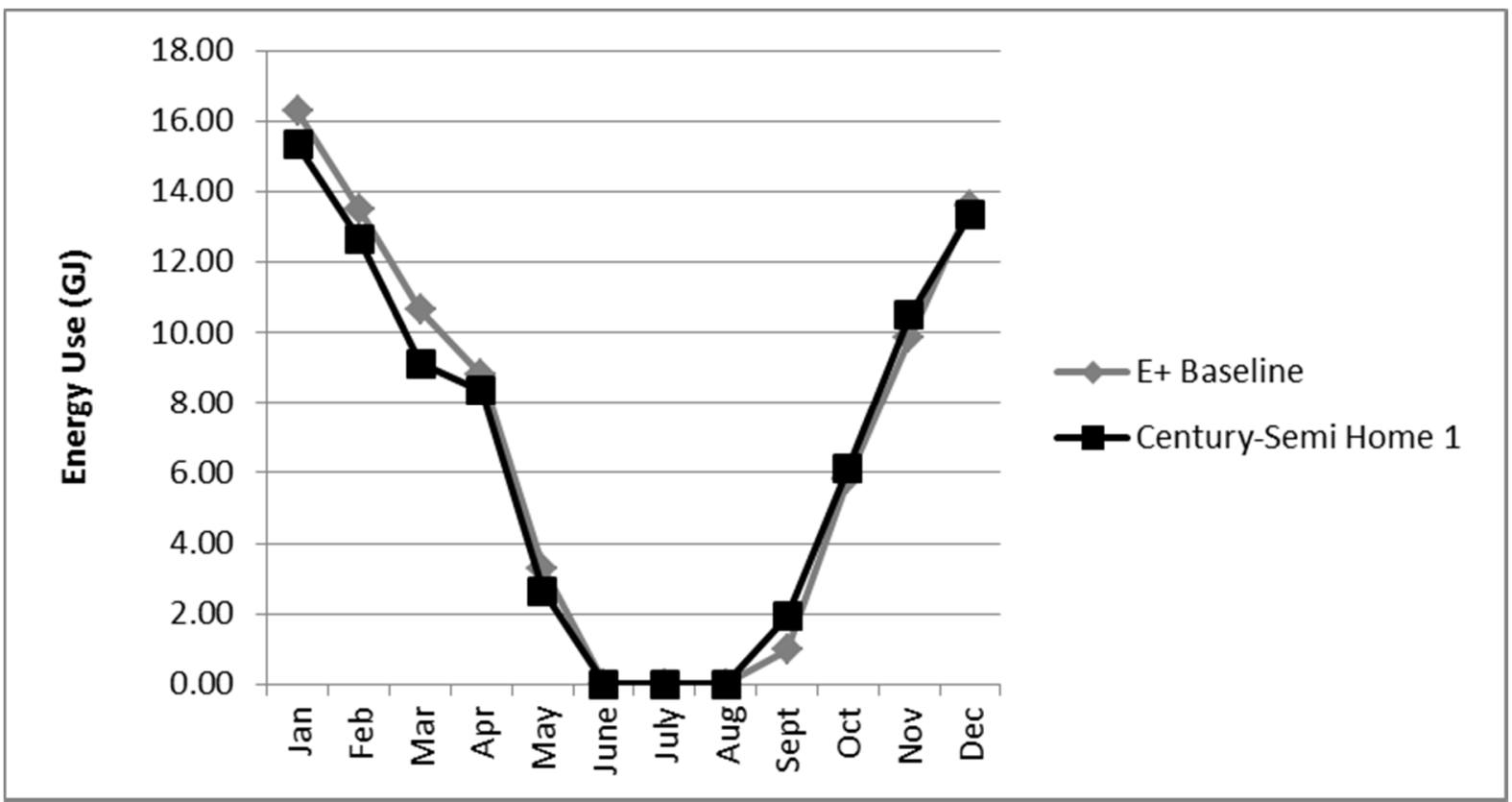

Figure 15: Century-Semi Home 1, 2012, Monthly Calibration Results

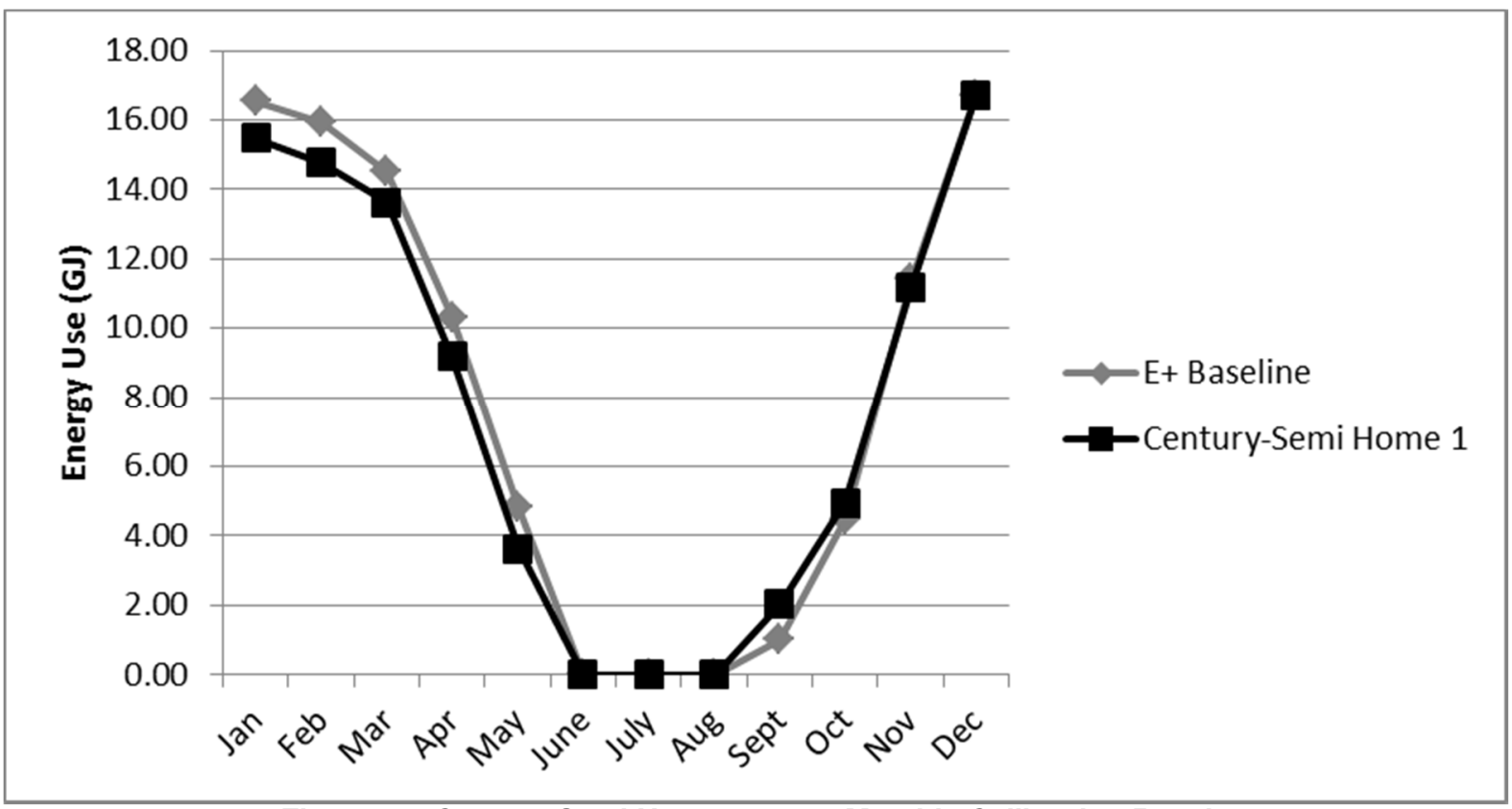

Figure 16: Century-Semi Home 1, 2013, Monthly Calibration Results 


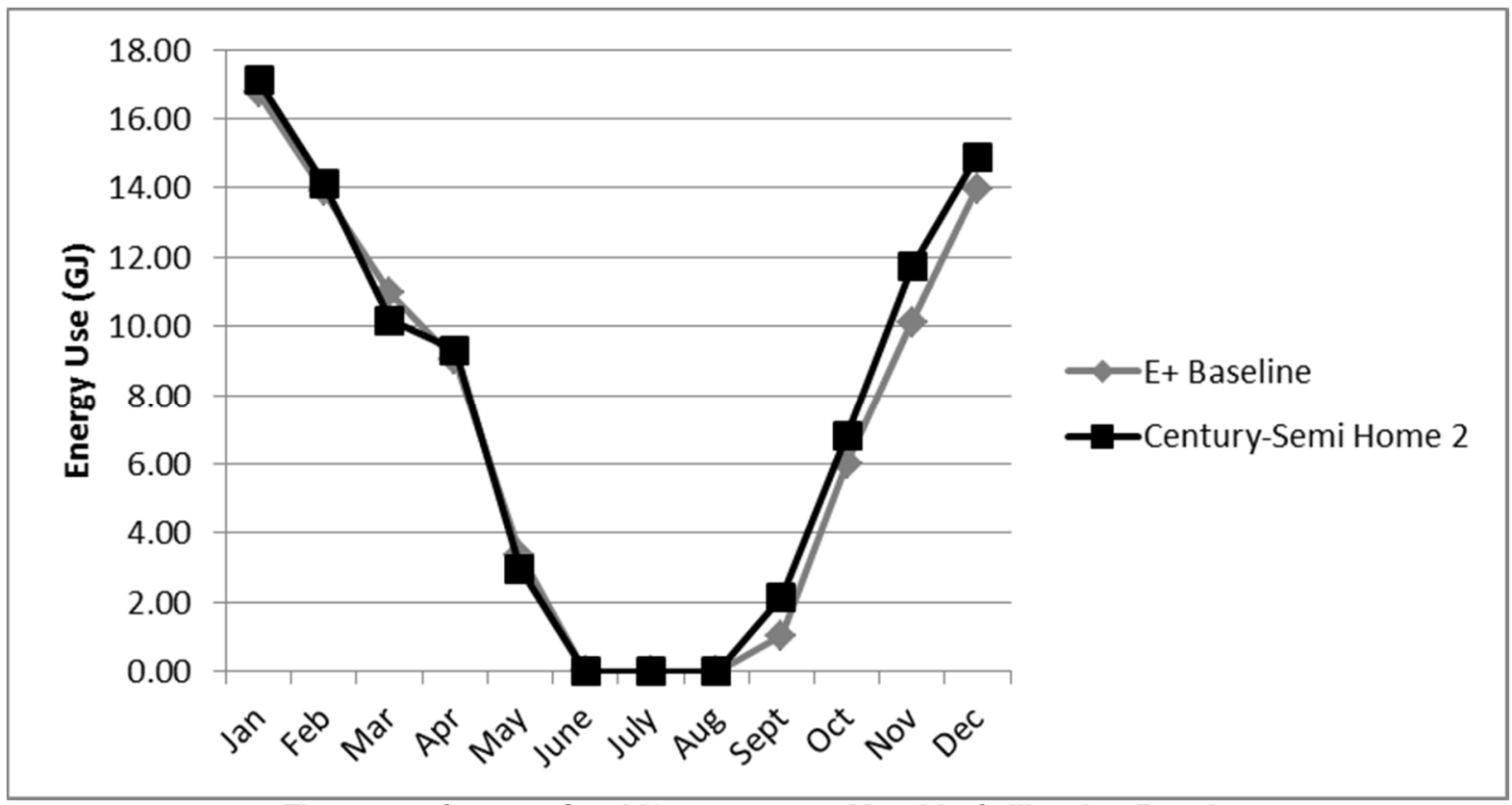

Figure 17: Century-Semi Home 2, 2012, Monthly Calibration Results

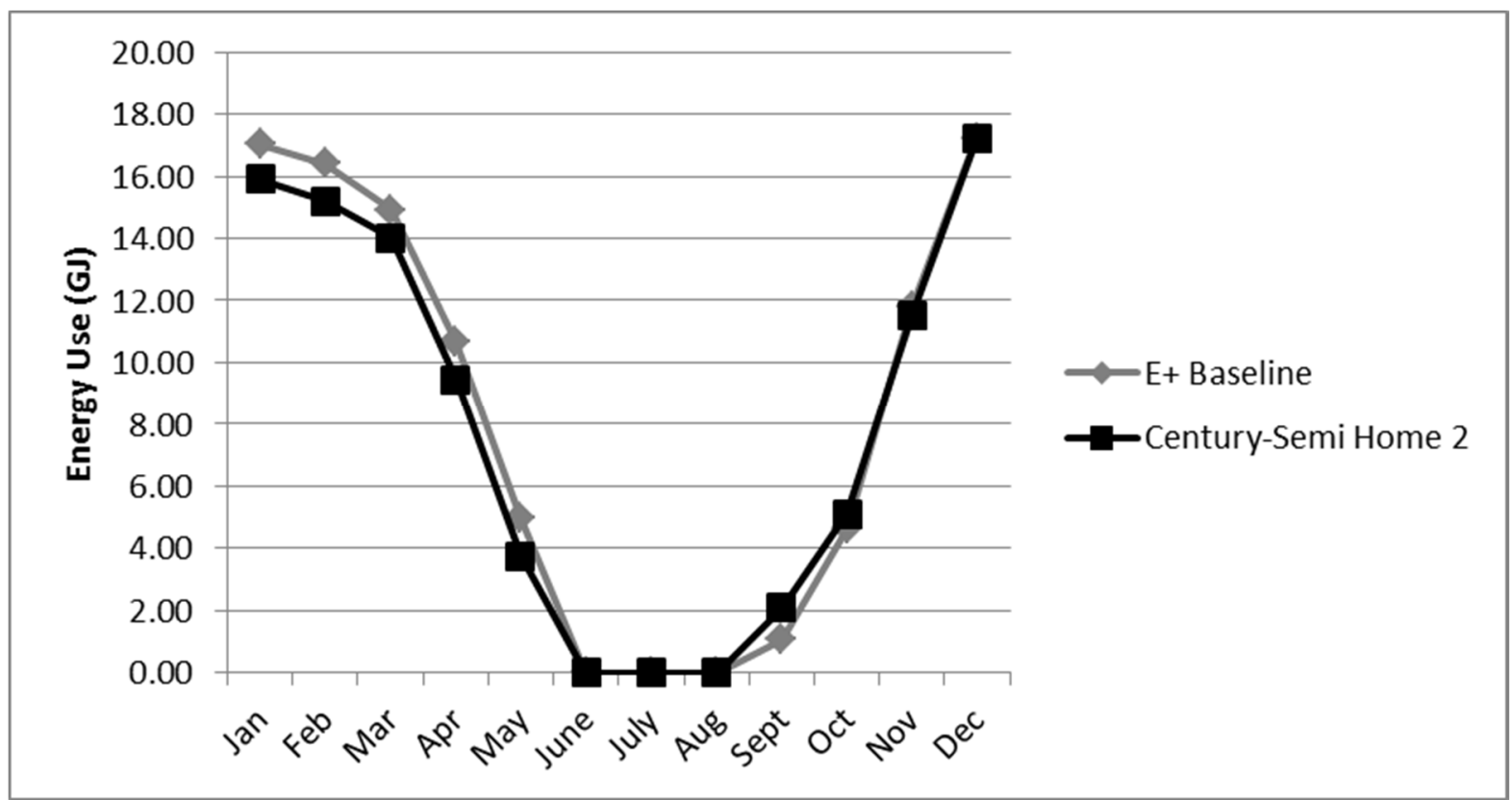

Figure 18: Century-Semi Home 2, 2013, Monthly Calibration Results

The statistical MBE and CVRSME values for each of the above calibrations are displayed in full in Appendix I and summarized in Table 14 below: 
Table 14: MBE and CVRSME Results for Energy Model Calibrations

\begin{tabular}{|l|l|r|r|}
\hline & Year & MBE & CVRSME \\
\hline \multirow{2}{*}{ Century Home 1 } & 2012 & $-4 \%$ & $12 \%$ \\
\cline { 2 - 4 } & 2013 & $0 \%$ & $7 \%$ \\
\hline \multirow{2}{*}{ Century Home 2 } & 2012 & $-4 \%$ & $13 \%$ \\
\cline { 2 - 4 } & 2013 & $1 \%$ & $7 \%$ \\
\hline \multirow{2}{*}{ Century-Semi Home 1 1} & 2012 & $-4 \%$ & $11 \%$ \\
\cline { 2 - 4 } & 2013 & $-5 \%$ & $11 \%$ \\
\hline \multirow{2}{*}{ Century-Semi Home 2 } & 2012 & $5 \%$ & $10 \%$ \\
\cline { 2 - 4 } & 2013 & $-5 \%$ & $11 \%$ \\
\hline
\end{tabular}

The calibration was successful as it allowed each home to be calibrated to its corresponding baseline energy model by only altering the global parameters of building envelope insulation and air tightness. The baseline energy models were meant to be an average representation of the archetypal homes and therefore the energy models utilized average or typical insulation and air tightness values. It is clear that these parameters vary from home to home and therefore it was reasonable to alter these parameters slightly to calibrate the energy model to actual home energy bill data.

Although it was proven that the baseline energy models could be calibrated to individual archetypal homes by making minor alterations to insulation and air tightness parameters, the objective of this study was to model an average or typical archetypal home. Therefore the baseline energy models with average insulation and air tightness parameters, as outlined in Table 10 above, were carried forward for the remainder of the research. As the baseline energy models were created identically except for variables that were different between the archetypes, it was reasonable to assume that the War Time Home energy model with average parameters was accurate although energy bill data was not available for calibration. Therefore all of the original baseline energy models, as developed in this study were carried forward. 
The final baseline energy use and intensities of the archetypes, for heating and cooling, utilizing the average EnergyPlus weather file, are summarized in Table 15 below:

Table 15: Final Baseline Energy Use and Energy Intensity by Archetype

\begin{tabular}{|l|r|r|}
\hline Archetype & Energy Use $(\mathrm{kWh})$ & Energy Intensity $\left(\mathrm{kWh} / \mathrm{m}^{2}\right)$ \\
\hline Century Home & 52,916 & 211 \\
\hline Century-Semi & 37,803 & 228 \\
\hline War Time Home & 27,506 & 209 \\
\hline
\end{tabular}

\subsection{Phase 2 Summary}

Evolving from the HOT2000 models of the housing archetypes constructed by Blaszak and Richman (2013) to EnergyPlus models of the archetypes in this study required significant additional data collection. The data required for HOT2000 modelling (Blaszak \& Richman, 2013) is a fraction of what is required to develop calibrated EnergyPlus models. The most significant data required related to the building geometry which must be drawn accurately in three dimensions to develop an EnergyPlus model. This means that careful attention must be paid to documenting building dimensions as well as the sizes, shapes, and slopes of building features. By surveying actual archetypal Toronto homes in the neighbourhoods targeted by the research two benefits could be identified: first, the data required for calibrated EnergyPlus models was collected from actual homes that could be retrofitted in the future utilizing the results of this study and second, the data collected by Blaszak and Richman (2013) could be verified utilizing data from the most energy intensive neighbourhoods in Toronto.

The housing inspections were successful in providing the data required to build baseline energy models in EnergyPlus, however several concerns arose from the 
process. First, the data collection did not represent a true random sampling of homes. This was because participants were recruited by referral and therefore many participants were recruited through their neighbours and friends. This led to many of the sampled homes being located geographically close together, sometimes on the same street, where housing types are typically very similar. Second, it was often not possible to conduct full data collection at each home. Some of the participants were uncomfortable with certain data collection methods and asked not to have the data included in the study, which led to incomplete data sets. Also some of the homes that were inspected had been separated into apartments and therefore the homeowners were not always able to allow the researcher into their tenants' unit. Similarly, it was rare to find a home that had not been substantially renovated by altering the floor plan or by the inclusion of additions. Homes that had been renovated or separated into apartments were not utilized for the calibration as the energy use profiles would likely be different than a typical archetypal home due to extra occupants or larger heated living areas. Although the primary structures of the homes were largely similar, the additions were rarely similar as they were often designed by different architects and added at various times over the life of the building. This provided challenges in describing the average geometry of each archetype. Further to this point, it became clear that the process of developing archetypes itself is a challenging process. While many of the homes built within the same period of construction exhibited similar features, such as structure type, cladding, and insulation levels, there was a wide variety of housing shapes and sizes. While some geometry patterns could be discerned, many homes were outside of the average and therefore it was difficult to describe one archetype that 
truly defined a period of construction. The development of archetypes however is still valuable as they provide general representations of typical housing types and provide indications of construction methods and materials. This not only provides information on the types of homes within the housing stock, but also on the typical energy use and efficiency. This knowledge allows retrofits to be developed on an archetypal basis, which is relevant for numerous homes, instead of on a case by case basis which is more time intensive. The housing archetypes utilized in this study were successful in establishing a representation of the urban Toronto housing stock, however it was determined that establishing a greater number of archetypes for each vintage is required in order to be representative of a greater proportion of the urban Toronto housing stock.

The data collected from Toronto homes proved useful in understanding the current state of Toronto housing. Collecting data and speaking with homeowners presented some general trends. The HVAC systems in many of the homes had been renovated with the original hot water radiator systems being replaced with forced air gas furnaces. Some homes had installed additional heating or cooling systems in additions or in the third floor of Century and Century-Semi Homes to deal with excessive heat in the summer and cold in the winter. These heating or cooling systems were typically either electric baseboards or heat pumps, however besides these isolated cases, heat pumps and electric baseboards were not prevalent.

The internal gain data provided predictable results with many homeowners being on a typical work schedule. Interestingly, many homeowners reported waiting until offpeak hours to utilize appliances such as dishwashers and clothes washers and dryers 
when electricity rates were lower. This indicated a level of energy literacy while also anecdotally indicating the success of the variable electricity rate structure.

The results of the baseline energy models followed a predictable trend with the Century Home consuming the most energy overall followed by the Century-Semi Home and the War Time Home. The larger size of the Century Home compared to the Century-Semi and War Time archetypes likely contributed the most to its energy use as did the lower insulation levels and air tightness compared to the War Time Home. Also, the Century Home had a greater window-to-wall ratio than the other two archetypes which likely contributed to greater heat loss. It was interesting to note however that the Century-Semi, which had a smaller floor area than the Century Home and had the advantage of minimal heat transfer through one wall (the party wall), had greater energy intensity than the Century Home. This appeared to be related in large part to geometrical differences between the Century-Semi which had an L-shaped footprint and the Century Home which had a rectangular footprint. While the Century-Semi had a much smaller floor area, the surface area to volume ratio of the home was larger resulting in greater heat loss. As predicted, the War Time Home had the lowest energy use overall and lowest energy intensity due to its small size and greater insulation and air tightness.

A building archetype is a theoretical construct meant to describe similar buildings and provide basic information on their typical features. Every building is different, however and an archetype will not fully grasp the reality of any one building. The implications of this were clear in developing energy models to approximate the energy usage of the archetypes. This study and the study by Blaszak and Richman (2013) 
collected data from buildings of the same archetype which ended up with different average data sets, which once modelled resulted in different energy usage and intensity values. The baseline energy models of this study did not achieve results similar to those of Blaszak and Richman (2013) or the Natural Resources Canada Urban Archetypes Project (NRCan - CanmetENERGY, 2009) except in the case of the War Time Home. This demonstrated not only the difference in data sets collected from archetypal homes, but also indicated differences in energy modelling methodologies and software programs. This study utilized many of the same parameters as Blaszak and Richman (2013), but reached significantly different results indicating that the results of modelling with HOT2000 differ from those of EnergyPlus. It is noteworthy that the EnergyPlus results of this study were much closer to the Toronto average housing energy intensity, as reported by the EcoENERGY database, than the results of Blaszak and Richman (2013).

The calibration exercise reinforced the need for accurate building specific data when developing calibrated energy models. This study found that it is of great importance to ensure that calibration data is accurate and that identical variables are being compared. It was found that the length of the months reported on the energy bills did not necessarily correlate to the calendar months utilized by the energy model. While the baseline energy models developed in this study reasonably approximated actual archetypal homes, several global parameters needed to be altered in order to match the actual homes, thereby highlighting the need for accurate home data on a case by case basis. It is important to note however that archetypes are meant to be typical representations of specific housing types. This study pursued calibration to test how 
accurately the baseline energy models approximated actual archetypal home energy use; however the purpose of the study was not to prepare case studies of actual homes. This study did not carry the calibrated models forward, but instead utilized the average and typical parameters of the archetypes for the final baseline energy models.

\subsection{Selecting Deep Energy Retrofit Strategies}

This study focused on building envelope and HVAC retrofits and exclusively on strategies to reduce energy use. Building envelope retrofit strategies discussed in the literature included increasing roof, wall, foundation wall, and slab insulation, as well as air sealing and replacing windows and doors. HVAC retrofits included installing high efficiency furnaces or alternative high efficiency heating and ventilation systems. Eight separate strategies were identified for deep energy retrofitting: wall insulation, roof insulation, foundation wall insulation, slab insulation, windows, air sealing, heating and cooling, and ventilation. For this study, wall, roof, foundation wall, and slab retrofits refer to increasing insulation levels. Window retrofits refer to decreasing window u-values through adding glass layers, surface coatings, or altering the gas mixture in the glazing units. Air sealing retrofits refer to increasing the air tightness of the building by sealing penetrations and air leakage paths. Heating and cooling retrofits refer to increasing furnace efficiency. Finally, ventilation retrofits refer to installing heat recovery or energy recovery ventilators of various efficiencies. Door replacement was not considered for retrofitting as many of the surveyed homes had previously replaced original uninsulated wood doors with newer insulated doors. 
For the eight retrofit strategies outlined above, three levels of implementation for each strategy were developed. For wall, roof, foundation wall, and slab insulation, the first level was modelled after RSI values specified by the 2012 Ontario Building Code (OBC, 2012) and the second and third levels were modelled after the high performance assemblies developed by Mucciarone (2011), as well as high RSI enclosure recommendations for Toronto's climate zone published by the Building Science Corporation (Straube 2011, Straube \& Grin 2010).

Window retrofit levels were developed utilizing standard glazing system constructions contained in the WINDOW 7 software program database (LBNL, 2014), as well as through contact with a large North American manufacturer of high efficiency windows (Alison Ray, Personal Communication, March 21, 2014). The overall U-factor of the retrofit windows was taken into consideration utilizing center of glass, edge of glass, frame, and divider U-values. The overall U-factors were calculated using an average window size of $1.4 \mathrm{~m}^{2}$ from the field study for the archetypal homes, as well as typical frame and divider materials and sizes observed during the field study.

The EcoENERGY database displays both pre-retrofit and post-retrofit $\mathrm{ACH}$ values. This data was analyzed for archetypal Toronto homes to determine what types of air sealing results were achievable and what types of retrofits were employed to achieve them. This was conducted to provide guidance in selecting the air sealing retrofit strategies in this research. Post-retrofit reductions in $\mathrm{ACH}$ values averaged $16 \%$, $14 \%$, and $13 \%$ for Century Homes, Century-Semi Homes, and War Time Homes respectively; however the range of $\mathrm{ACH}$ reductions varied considerably; -1 to $84 \%,-15$ to $69 \%$, and 3 to $40 \%$ respectively. The negative numbers represent an increase in 
$\mathrm{ACH}$ which could be the result of errors in the $\mathrm{ACH}$ testing or could be the result of a poorly performed retrofit which increased penetrations in the envelope. Also, no indication was given in the database as to what retrofits were implemented to achieve these results and therefore it was not possible to determine what strategies were employed to achieve the $\mathrm{ACH}$ reductions. Therefore, air sealing retrofits were modelled after Blaszak and Richman (2013) who developed expected ACH reductions and final retrofit air sealing expectations through interviews with industry experts. Air sealing expectations included a $10 \%$ reduction in $\mathrm{ACH}$ when new windows were installed and a requirement for both wall and roof retrofits to be undertaken in order to reach the lowest stated $\mathrm{ACH}$ values.

Finally, heating, cooling, and ventilation retrofit levels were modelled after manufacturer specifications and Energy Star certified products (Environmental Protection Agency, 2014) representing conventional, medium, and high efficiency levels. The retrofit strategies and levels of implementation are summarized in Tables 16 and 17 below:

Table 16: Century and Century-Semi Retrofit Strategies and Implementation Levels

\begin{tabular}{|l|c|c|c|c|}
\hline Strategy & Baseline & Level 1 & Level 2 & Level 3 \\
\hline Walls (RSI) & 1.01 & 4 & 6 & 10 \\
\hline Roof (RSI) & 2.64 & 9 & 10.5 & 13 \\
\hline Basement Walls (RSI) & 0.55 & 2 & 3 & 3.5 \\
\hline Slab (RSI) & 0.058 & 0.75 & 1 & 1.75 \\
\hline Windows (U-factor) & 2.7 & 1.9 & 1.2 & 1 \\
\hline Air Sealing (ACH at 50 Pa) & 10.54 Century / 11.7 Century-Semi & $20 \%$ Reduction & 3 & 1 \\
\hline Heating and Cooling & $80 \%$ Efficient & $90 \%$ Efficient & $94 \%$ Efficient & $97 \%$ Efficient \\
\hline Ventilation & N/A & $60 \%$ Efficient HRV & $85 \%$ Efficient HRV & $80 \%$ Efficient ERV \\
\hline
\end{tabular}


Table 17: War Time Retrofit Strategies and Implementation Levels

\begin{tabular}{|l|c|c|c|c|}
\hline Strategy & Baseline & Level 1 & Level 2 & Level 3 \\
\hline Walls (RSI) & 1.65 & 4 & 6 & 10 \\
\hline Roof (RSI) & 3.58 & 9 & 10.5 & 13 \\
\hline Basement Walls (RSI) & 0.83 & 2 & 3 & 3.5 \\
\hline Slab (RSI) & 0.058 & 0.75 & 1 & 1.75 \\
\hline Windows (U-factor) & 2.7 & 1.9 & 1.2 & 1 \\
\hline Air Sealing (ACH at 50 Pa) & 8.17 & $15 \%$ Reduction & 2 & 1 \\
\hline Heating and Cooling & $80 \%$ Efficient & $90 \%$ Efficient & $94 \%$ Efficient & $97 \%$ Efficient \\
\hline Ventilation & N/A & $60 \%$ Efficient HRV & $85 \%$ Efficient HRV & $80 \%$ Efficient ERV \\
\hline
\end{tabular}

While the strategies and levels of implementation were mostly consistent for the archetypes, some differences existed between Century and Century-Semi and War Time Homes. This is due to the different existing envelopes and structures of the archetypes leading to different assemblies being required to reach the same RSI value. Additionally, air sealing expectations varied for Century and War Time Homes (Blaszak \& Richman, 2013). Schematic drawings of the developed envelope retrofit assemblies are displayed in Figures 19 to 36 below:

Section

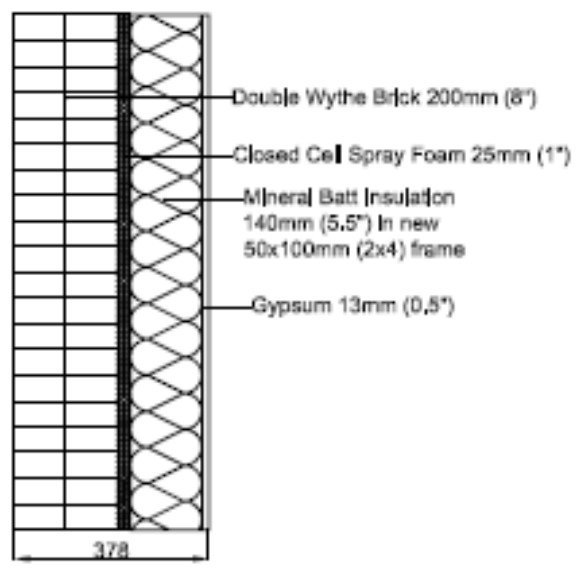

Figure 19: Masonry Walls (Century, Century-Semi) Level 1 - RSI 4 (R 22) 
Section

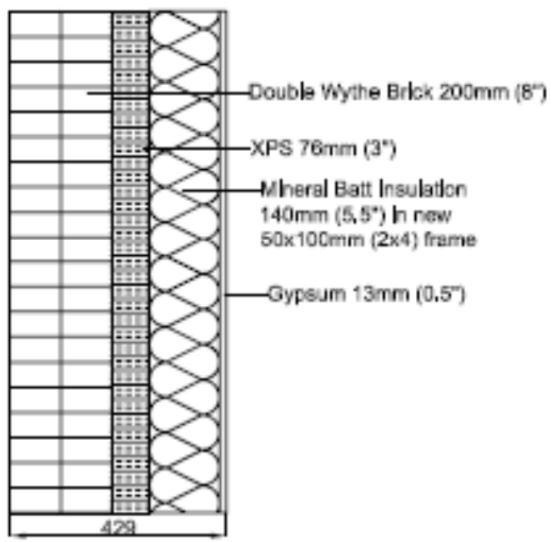

Plan

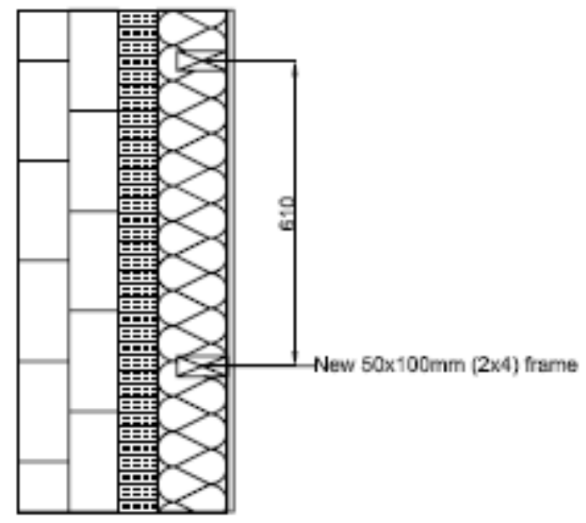

Figure 20: Masonry Walls Level 2 - RSI 6 (R 35)

Sectler

Flan

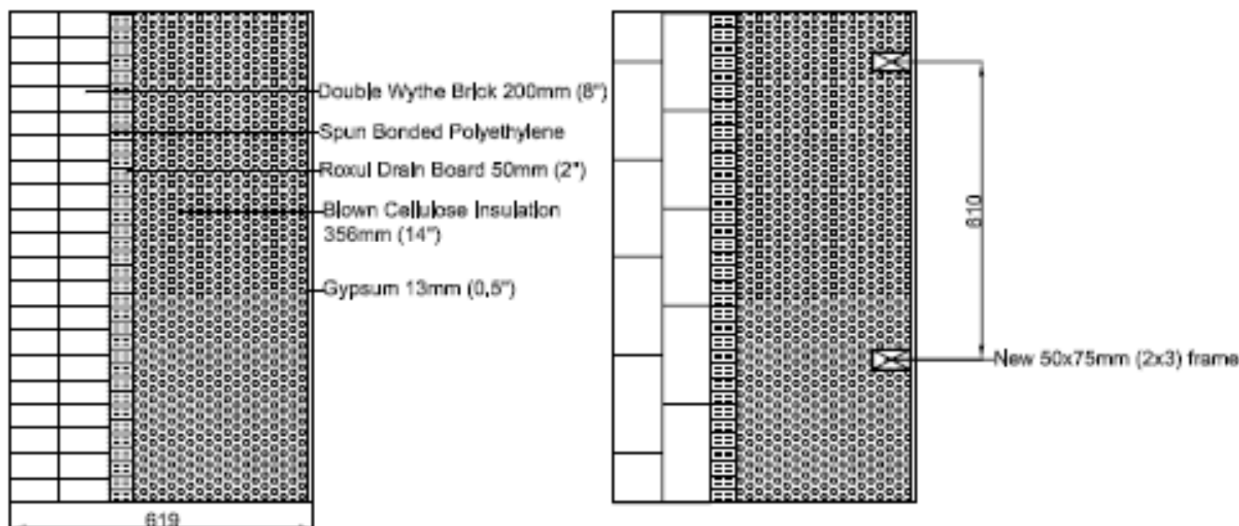

Figure 21: Masonry Walls Level 3 - RSI 10 (R 57)

Section

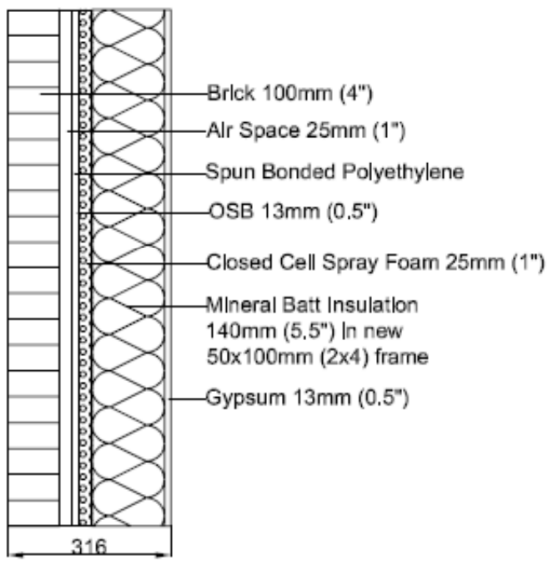

Plan

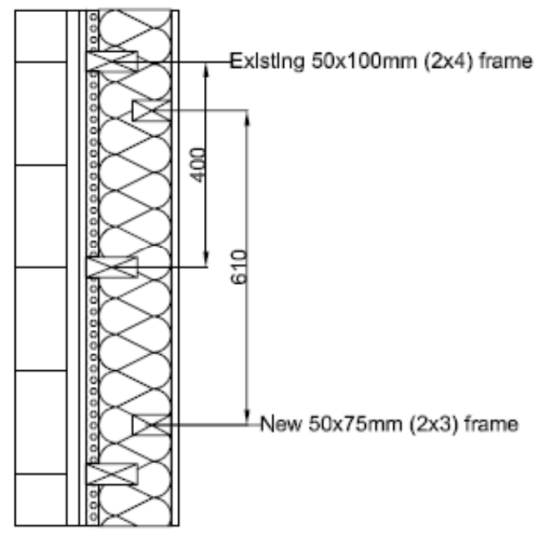

Figure 22: Wood Frame Walls (War Time) Level 1 - RSI 4 (R 22) 
Section

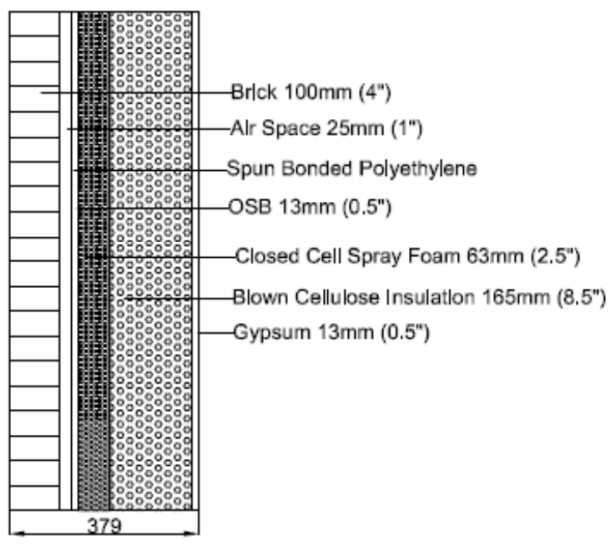

Figure 23: Wood Frame Walls Level 2 - RSI 6 (R 35)

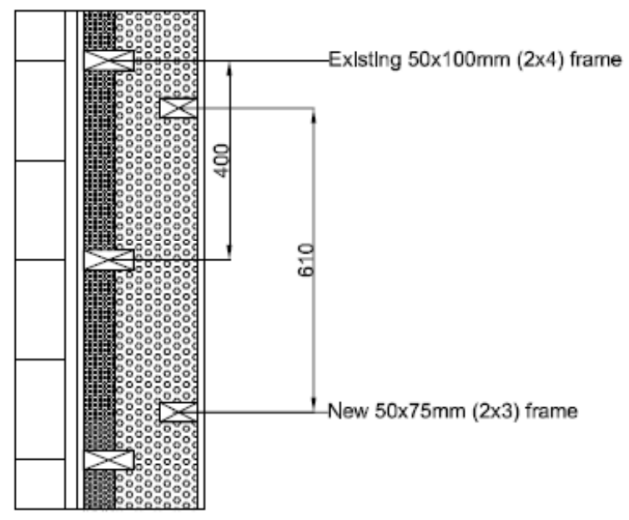

Sectlon

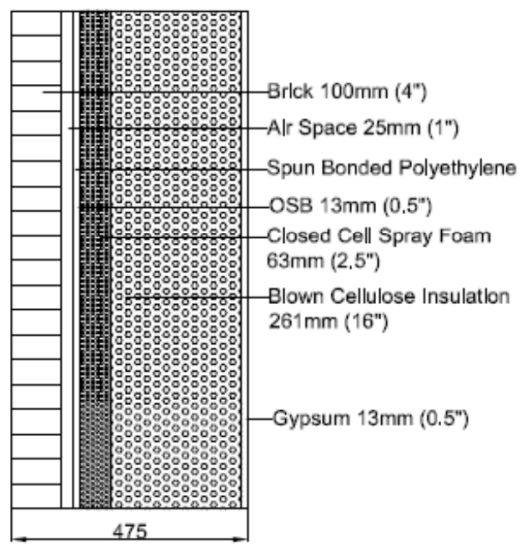

Plan

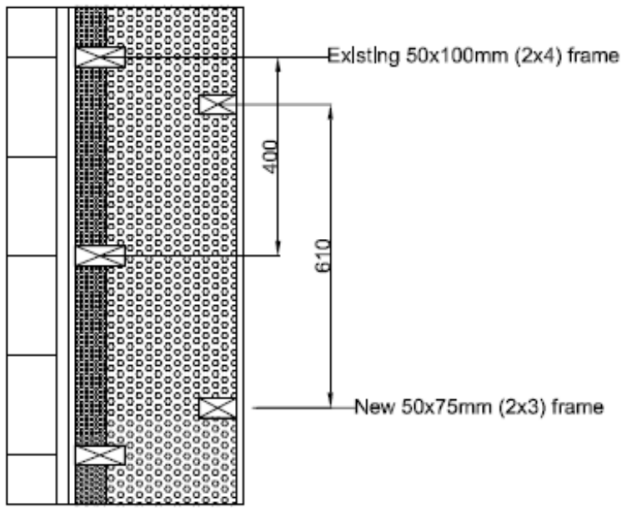

Figure 24: Wood Frame Walls Level 3 - RSI 10 (R 57)

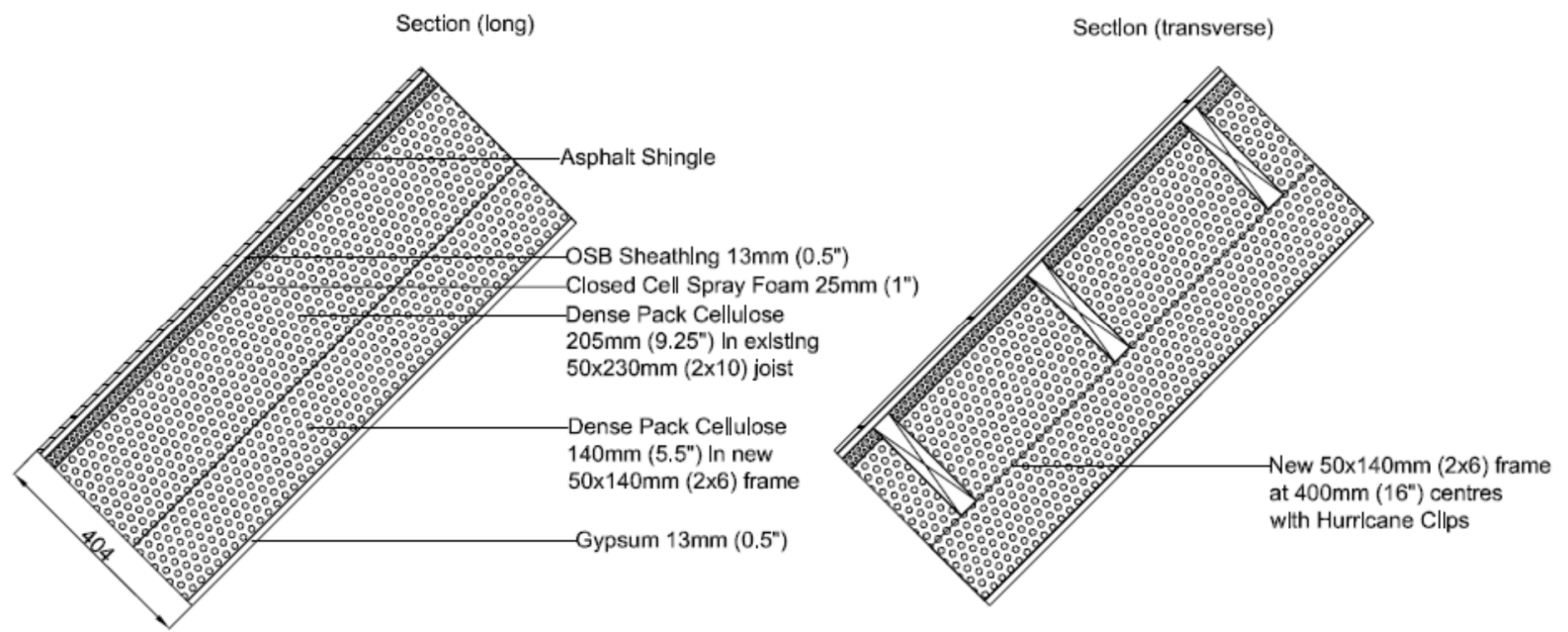

Figure 25: Cathedral Roof (Century, Century-Semi) Level 1 - RSI 9 (R 50) 

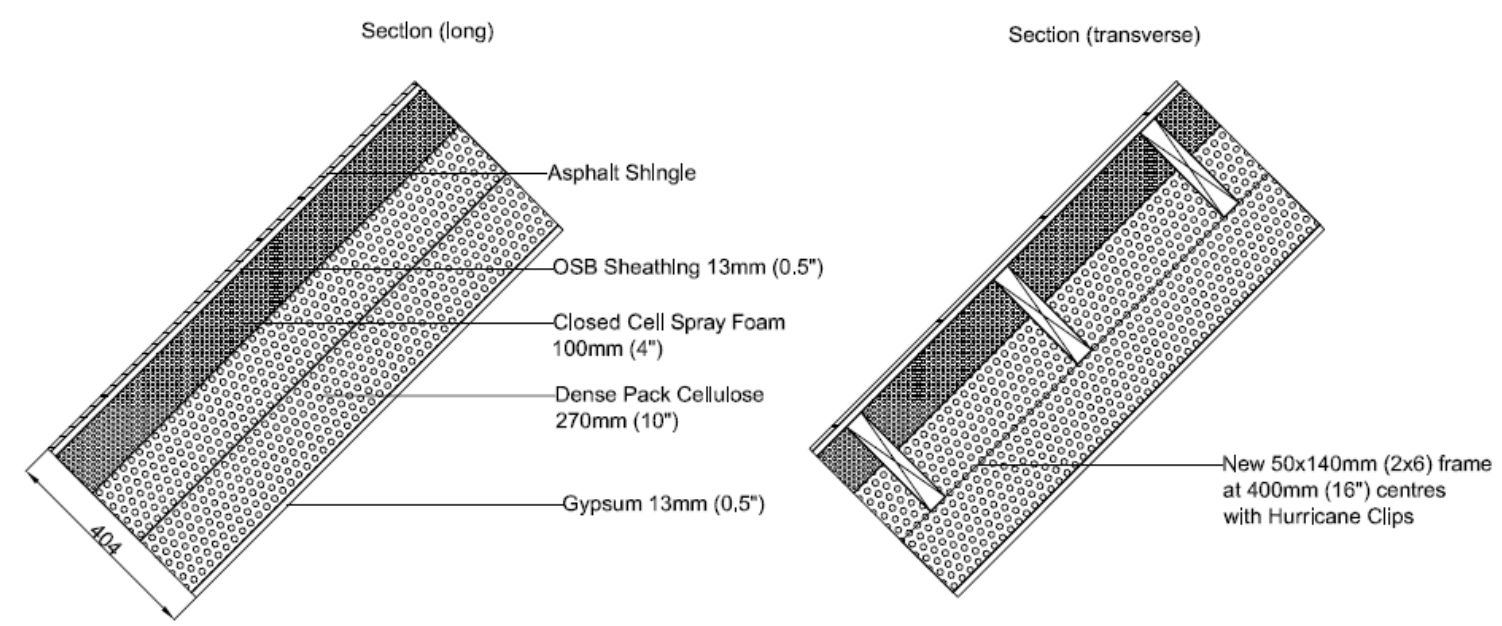

Figure 26: Cathedral Roof Level 2 - RSI 10.5 (R 60)

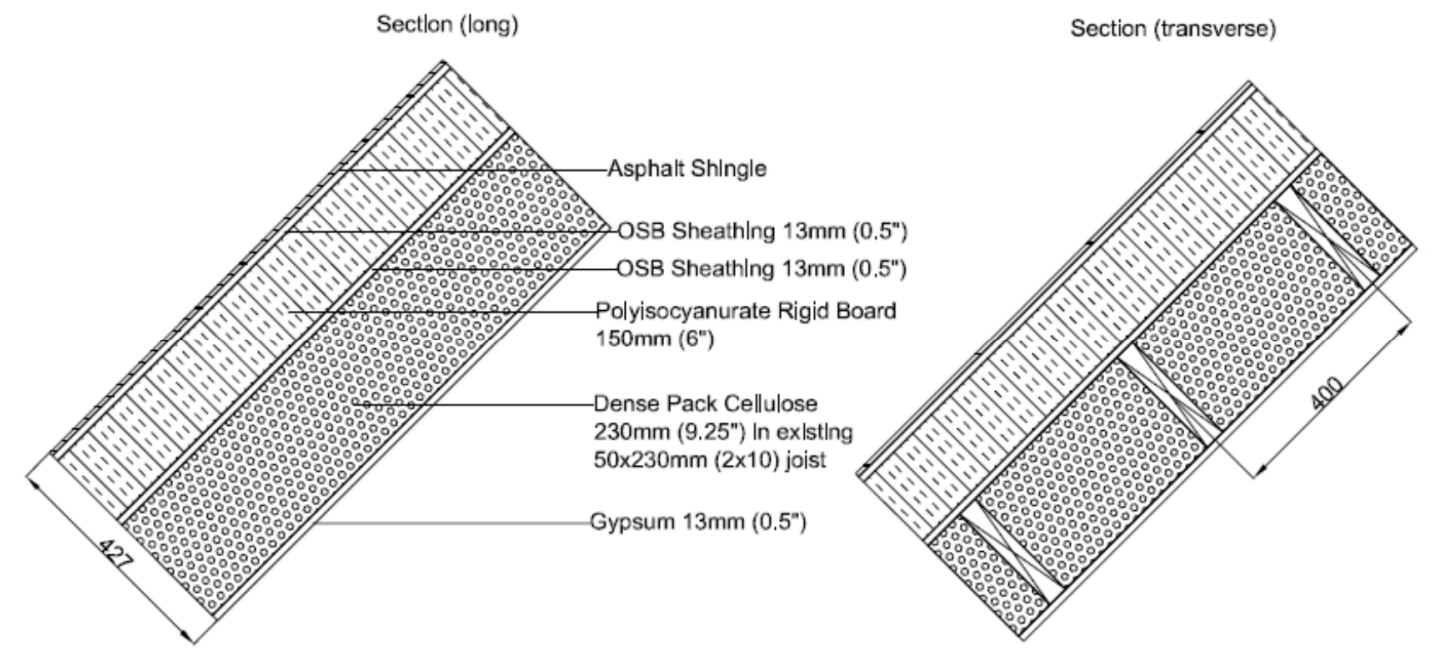

Figure 27: Cathedral Roof Level 3 - RSI 13 (R 75)

Sectlon (long)

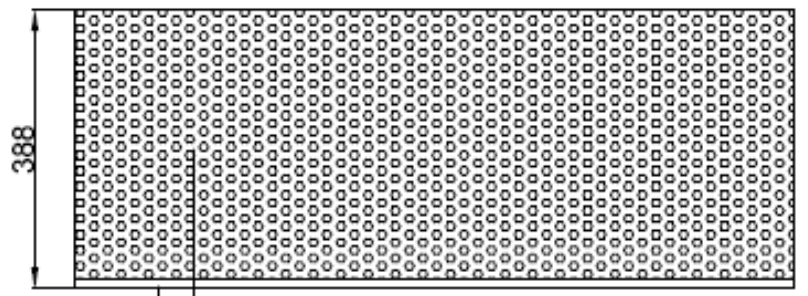

Blown Cellulose

$375 \mathrm{~mm}\left(15^{\prime \prime}\right)$ In exlstlng

attic space
Section (transverse)

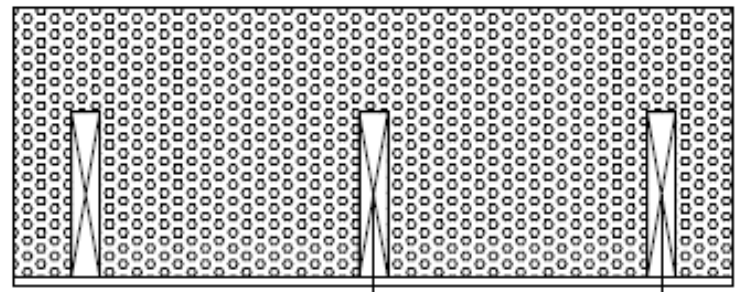

400

Figure 28: Attic Roof (War Time) Level 1 - RSI 9 (R 50) 
Sectlon (long)

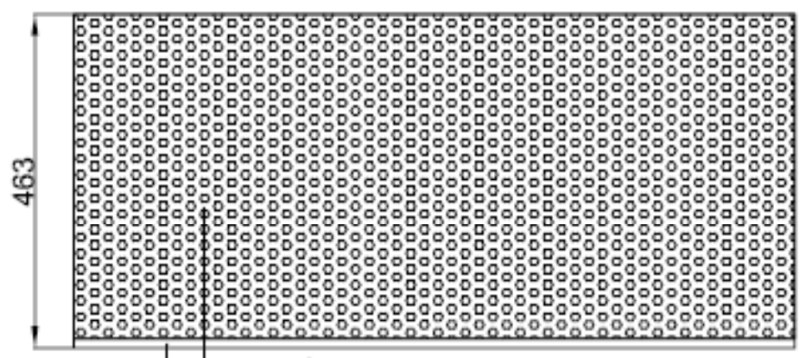

Blown Cellulose

$450 \mathrm{~mm}$ (18") In existing

attlc space

Lypsum 13mm (0.5")
Section (transverse)

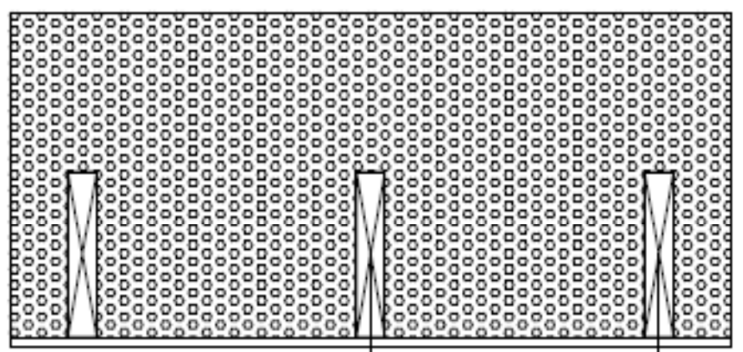

400

Figure 29: Attic Roof Level 2 - RSI 10.5 (R 60)

Sectlon (long)

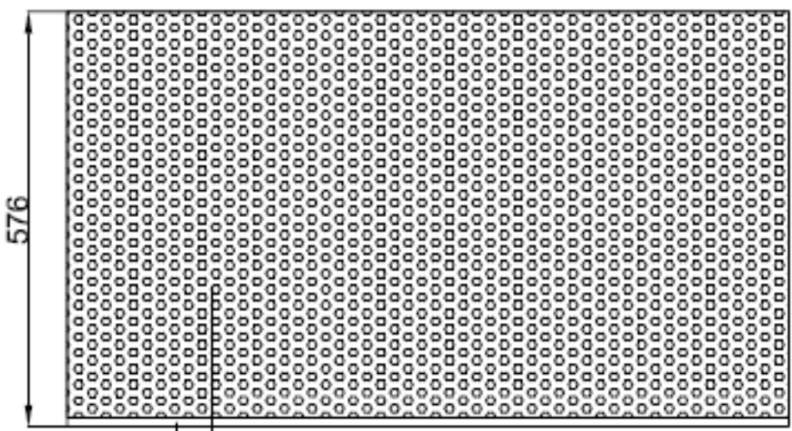

Blown Cellulose

$563 \mathrm{~mm}\left(22.5^{\prime \prime}\right)$ In existing

attic space

Gypsum 13mm (0.5")

Figure 30: Attic Roof Level 3 - RSI 13 (R 75)

Section

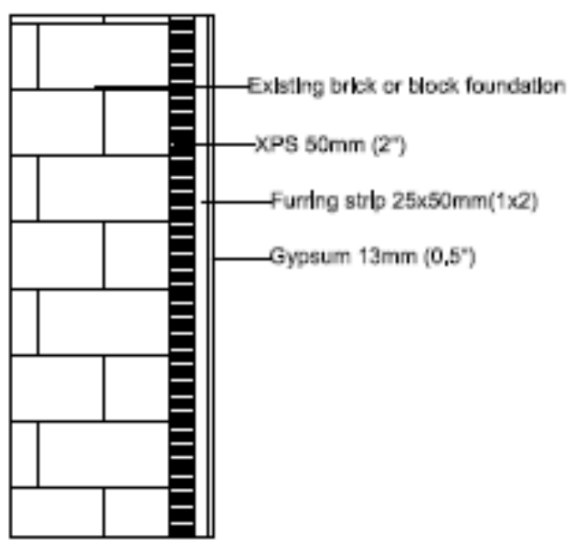

Sectlon (transverse)

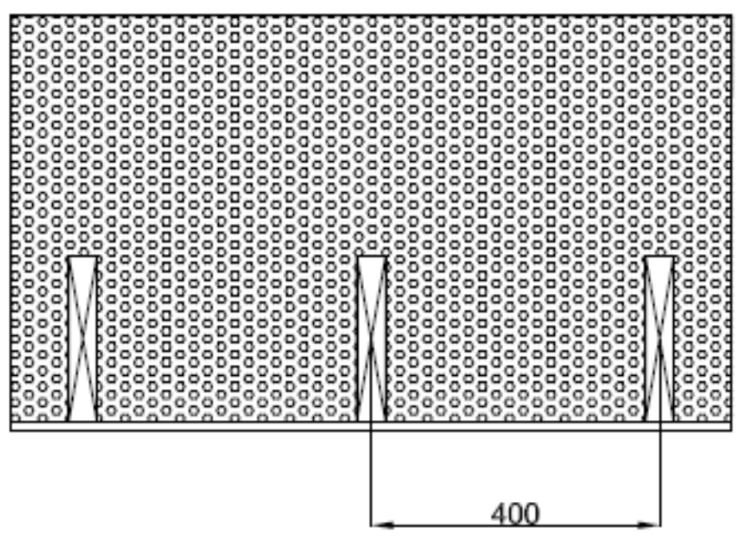

Figure 31: Basement Wall Level 1 - RSI 2 (R 12) 
Sectlon

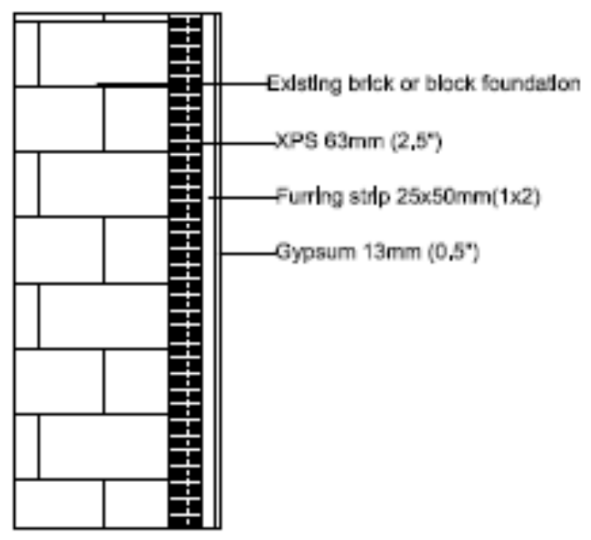

Figure 32: Basement Wall Level 2 - RSI 3 (R 15)

\section{Figure 32: Basement Wall Level $2-R S 13$ (R 15)}

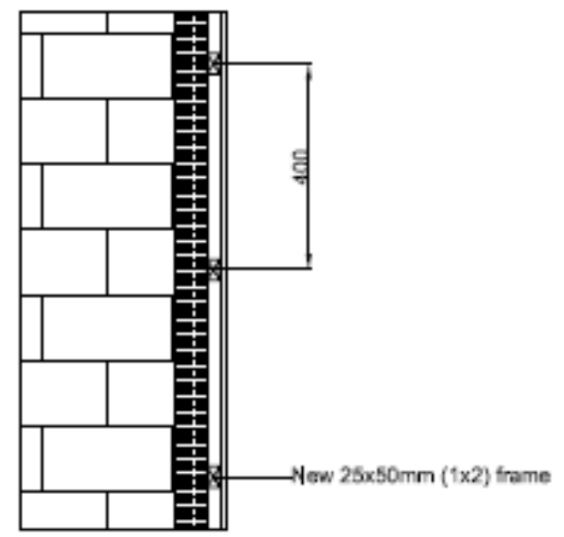

Sectlon

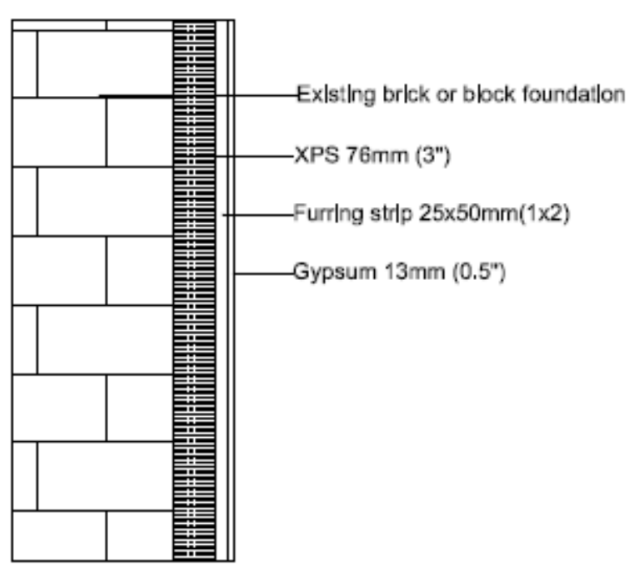

Plan

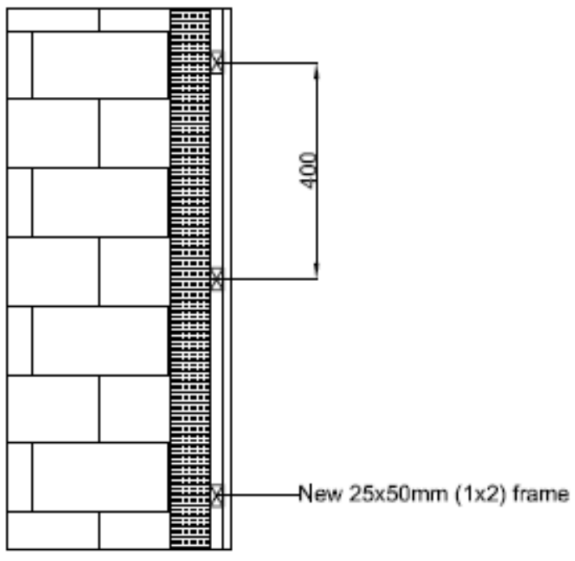

Figure 33: Basement Wall Level 3 - RSI 3.5 (R 20)

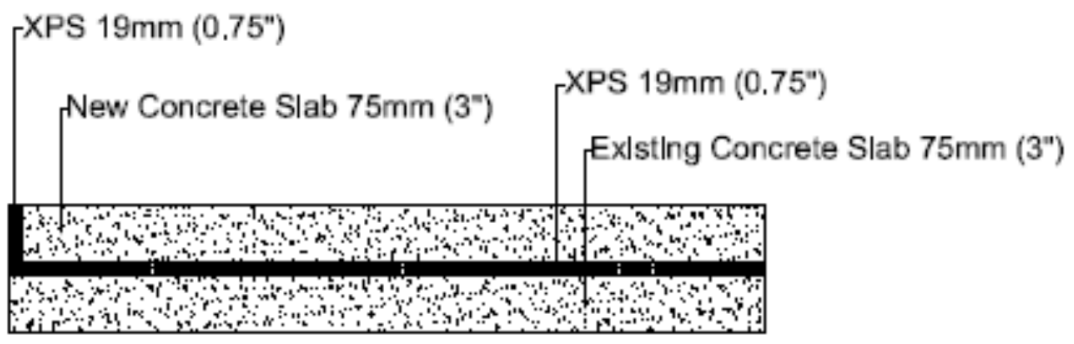

Figure 34: Slab Level 1 - RSI 0.75 (R 5) 


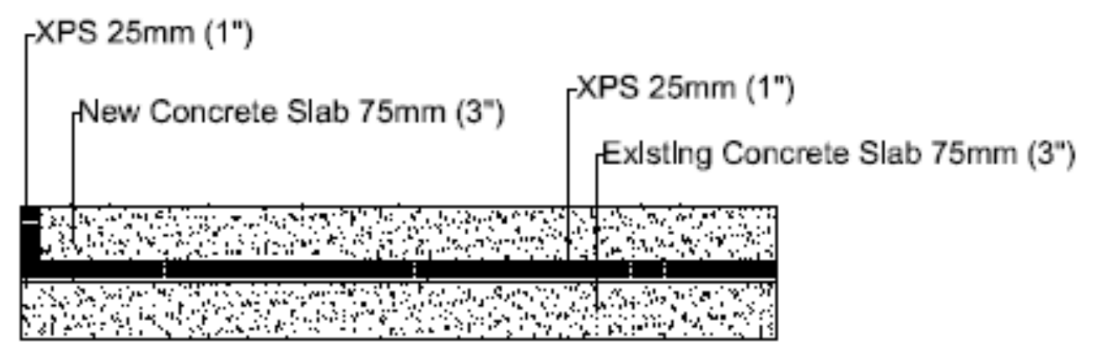

Figure 35: Slab Level 2 - RSI 1 (R 6)

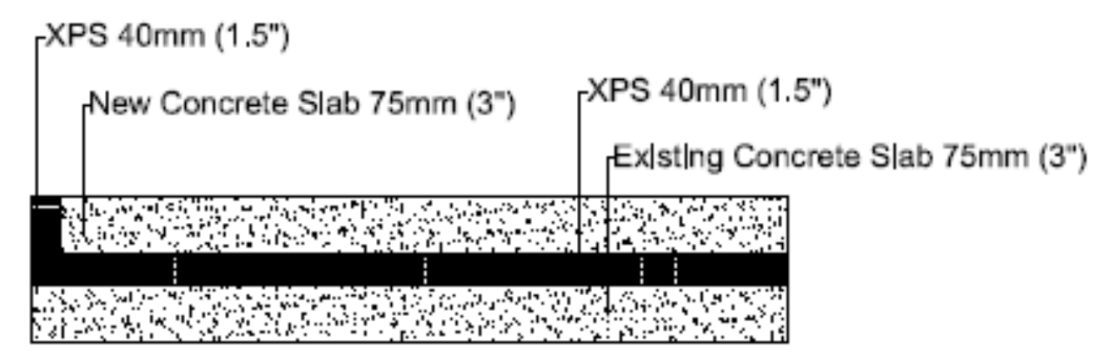

Figure 36: Slab Level 3 - RSI 1.75 (R 10)

\subsection{Hygrothermal Analysis of Retrofit Strategies}

Although the wall retrofit assemblies were chosen taking into consideration the hygrothermal performance results from Mucciarone (2011), further hygrothermal analysis was performed as Mucciarone's analysis was qualitative in nature and did not include roof, foundation wall, and slab assemblies. The hygrothermal analysis was performed prior to modelling the retrofits for the archetypes to ensure that the envelope retrofit assemblies would perform adequately in the retrofitted homes with minimal risk of moisture associated damage and deterioration. The baseline building envelope assemblies were analyzed followed by the three levels of retrofit assemblies to provide a basis for comparison. For the purpose of the hygrothermal analysis it was assumed that the baseline building envelope assemblies did not present a risk of moisture associated damage or deterioration.

The hygrothermal analysis considered wooden materials and quantified the number of condensation hours and decay hours over a three year modelling period. The 
numbers of condensation and decay hours were compared for the baseline and retrofit assemblies. Condensation hours are defined as the number of hours that the $\mathrm{RH}$ of the wooden components of the assemblies exceeds $80 \%$. Decay hours are defined as the number of hours that the moisture content of the wooden components of the assemblies, if present, exceeds $16 \%$. For the wood frame walls and cathedral roofs the inside surface of the sheathing was monitored for condensation and decay hours. For the masonry walls and attic roofs, the position that was monitored was the location of the wooden studs within the assembly. For the basement walls, the interior surface of the XPS insulation was monitored for condensation and decay hours as this surface was in direct contact with wooden furring strips. For the basement slab where no wooden materials were present, condensation hours were monitored for the interior surface of the XPS insulation and no decay hours were quantified as concrete and XPS are not subject to decay.

To perform the hygrothermal analysis, WUFI Pro 5.2 software was utilized. The simulations utilized the modelling parameters of Mucciarone (2011) unless otherwise noted. The modelling parameters were as follows:

- The Toronto cold year climate data file included with WUFI Pro 5.2 was utilized for the exterior weather conditions

- A user defined sine curve defined the interior conditions utilizing a mean temperature of 22 degrees Celsius with an amplitude of 2 degrees Celsius and a mean $\mathrm{RH}$ of $35 \%$ with an amplitude of $5 \%$

- All assemblies were simulated utilizing a south-east orientation to take into account high levels of sun exposure and driving rain 
- The simulations were carried out over the default three year period

- The initial RH of all materials was set to the default $80 \%$

- Exterior short wave absorptivity and emissivity were selected to be "brick, red" for exterior walls and "roofing bituminous felt" for roofs. The rain absorption factor was selected to be "according to inclination and construction type" for both the roofs and the walls

- It was assumed that there are no moisture sources within the assembly and no air exchange in the masonry walls of the Century and Century-Semi Homes. For the War Time Home which employs a ventilated brick façade, an air exchange source of $50 \mathrm{ACH}$ was modelled within the ventilated air space behind the brick, corresponding to the findings of Straube and Finch (2009).

- The attic roofs were modelled with a $150 \mathrm{~mm}$ air space beneath the shingles and OSB with an air exchange of $4 \mathrm{ACH}$ as per the modelling methodology of Lstiburek and Schumacher (2011).

The materials utilized for the WUFI analysis are outlined in Table 18 below: 
Table 18: Materials Utilized for WUFI Analysis

\begin{tabular}{|l|l|l|}
\hline Material & WUFI Database & WUFI Material Name \\
\hline Brick & North American Database & Brick (old) \\
\hline $25 \mathrm{~mm}$ air space & Generic Materials & Air Layer 25mm \\
\hline $150 \mathrm{~mm}$ air space & Generic Materials & Air Layer 150mm \\
\hline OSB & North American Database & Oriented Strand Board \\
\hline Shingle & North American Database & Asphalt Impregnated Paper (30 min Paper) \\
\hline Spun bonded polyethylene & North American Database & Spun Bonded Polyolefin \\
\hline Closed cell spray foam & North American Database & Sprayed Polyurethane Foam; Closed Cell \\
\hline Fibreglass insulation & North American Database & Fibreglass \\
\hline Mineral wool insulation & Fraunhofer-IBP-Germany & Mineral Wool \\
\hline Polyisocyanurate rigid board & North American Database & Polyisocyanurate Insulation \\
\hline XPS & North American Database & Extruded Polystyrene Insulation \\
\hline Roxul drain board & Fraunhofer-IBP-Germany & Mineral Insulation Board \\
\hline Cellulose insulation & North American Database & Cellulose Fibre Insulation \\
\hline Gypsum wall board & North American Database & Gypsum Board (USA) \\
\hline Lath & Fraunhofer-IBP-Germany & Hardwood \\
\hline Plaster & Fraunhofer-IBP-Germany & Interior Plaster (Gypsum Plaster) \\
\hline Concrete & Fraunhofer-IBP-Germany & Concrete, C35/45 \\
\hline
\end{tabular}

The envelope retrofit assemblies performed better than the baseline assemblies in all cases except the wood frame walls and the Level 1 cathedral roof which performed poorer than the baseline and demonstrated risk of moisture damage and deterioration.

The initial wood frame wall assemblies (see Appendix $\mathrm{J}$ ) showed high numbers of condensation and decay hours compared to the baseline assembly. It was determined that the polyethylene vapour retarders in the Level 1 and Level 2 assemblies were contributing to moisture accumulation and once the vapour retarders were removed the number of decay hours reduced to zero. For the Level 3 assembly, closed cell spray foam was added to the exterior of the cellulose insulation to form a moisture barrier layer. With this addition the decay hours reduced to zero. A comparison of the initial and final condensation and decay hours is shown in Figure 37 below: 


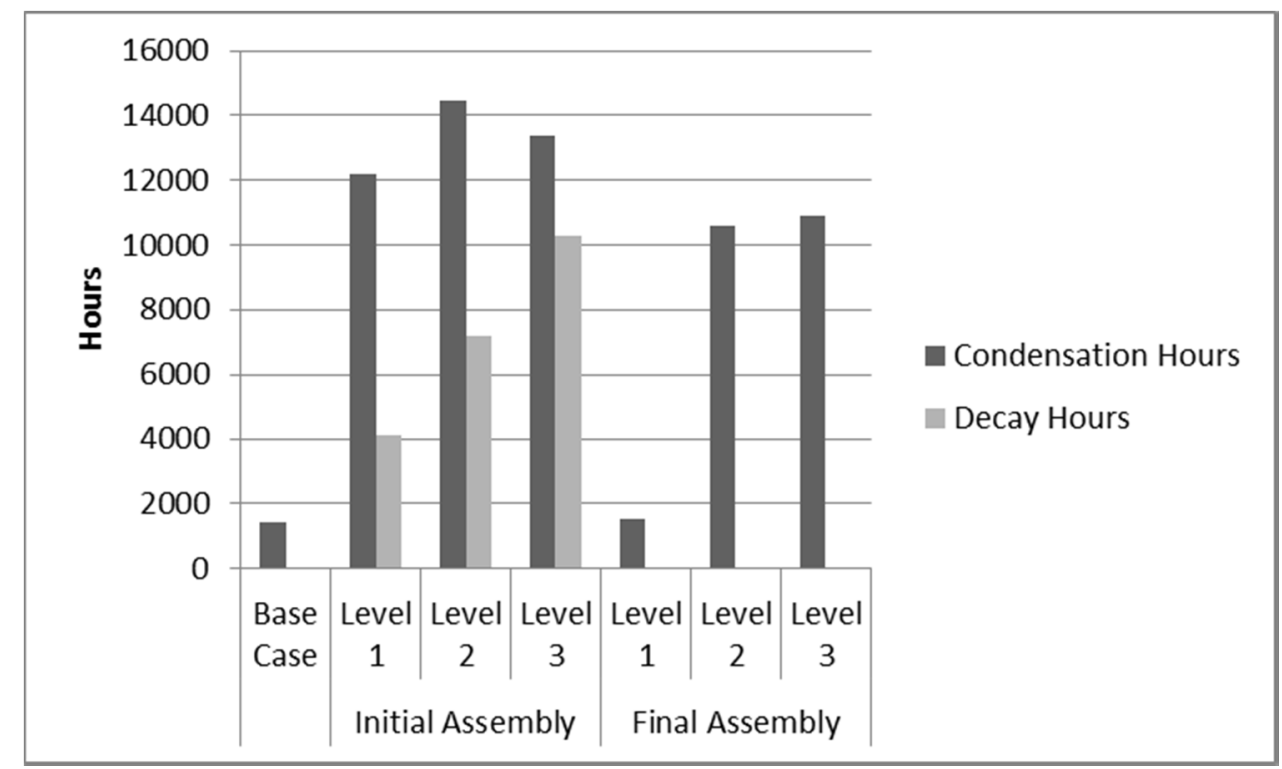

Figure 37: Condensation and Decay Hours in Initial and Final Wood Frame Wall Assemblies

The number of condensation hours in the retrofitted assemblies still exceeded that of the baseline; however the hygrothermal performance was deemed to be acceptable as the number of decay hours was zero. This means that while some condensation was present at the wood elements of the assemblies, there was no risk of decay in the wooden materials.

The initial Level 1 Cathedral Roof assembly (see Appendix J) originally showed a higher number of condensation hours than the baseline. As the Level 2 and Level 3 assemblies were performing better than the baseline, the Level 1 assembly was altered by adding a spray foam layer to the exterior of the assembly similar to the Level 2 and Level 3 assemblies. With this addition the number of condensation hours was reduced to below that of the baseline as can be seen in Figure 38 below: 


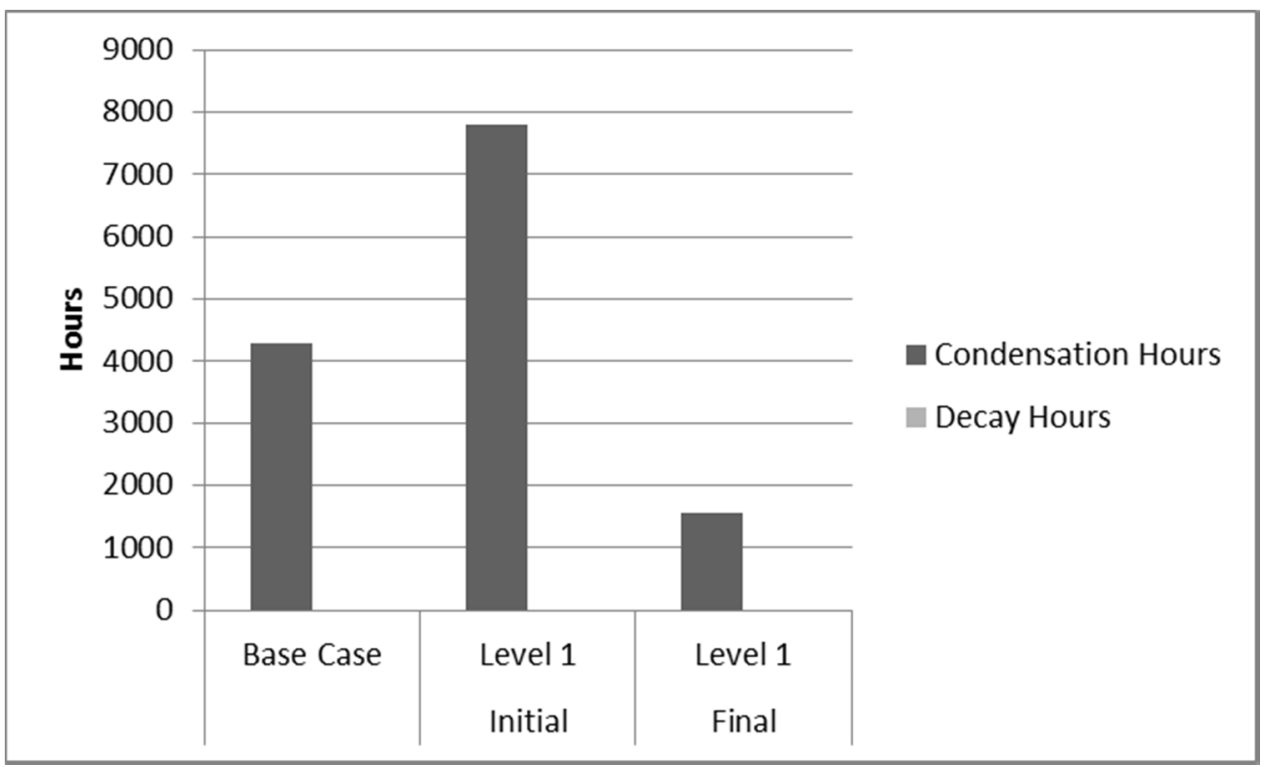

Figure 38: Condensation and Decay Hours in Initial and Final Level 1 Cathedral Roof Assembly

The final quantities of condensation and decay hours are summarized in Figures 39 and 40 as follows:

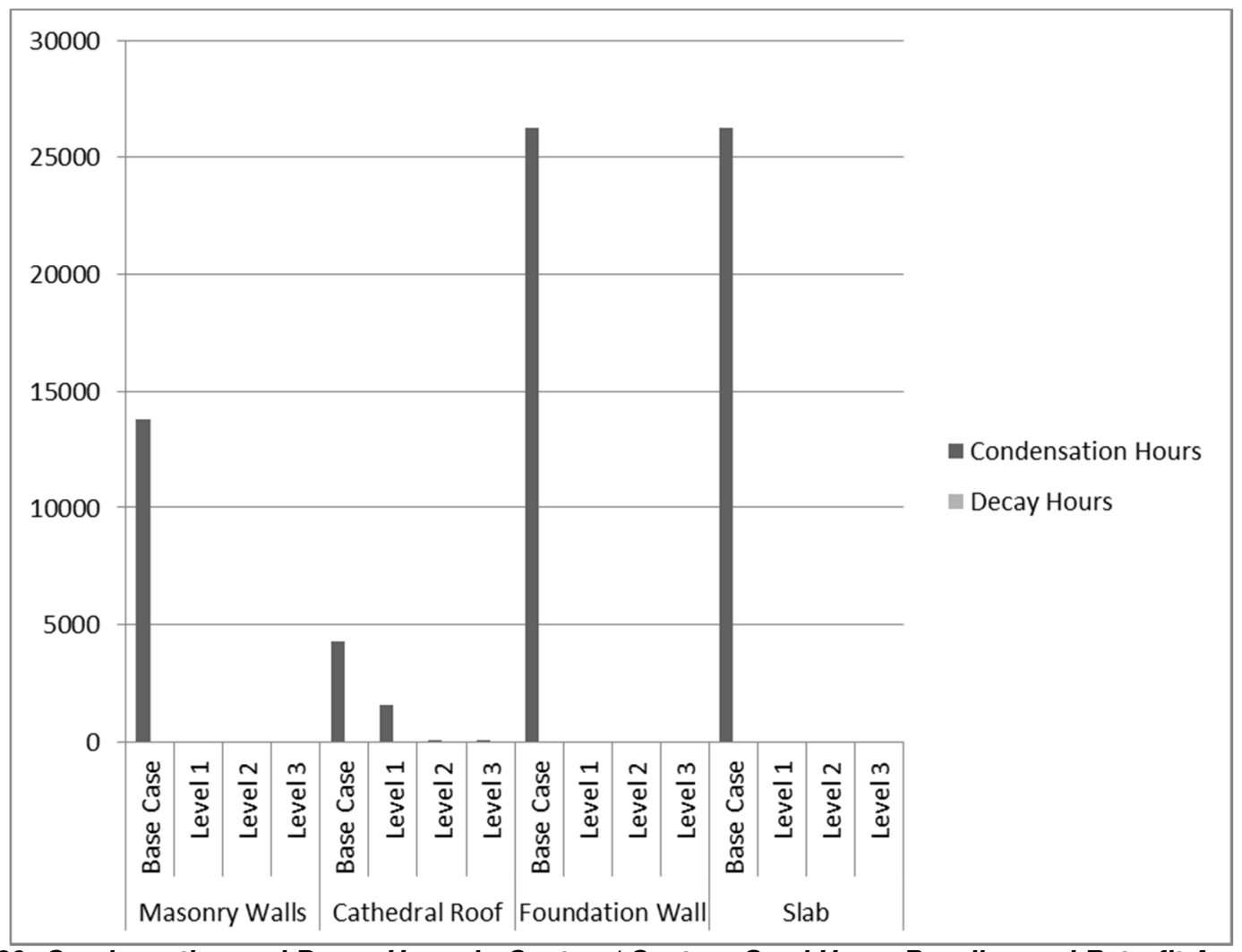

Figure 39: Condensation and Decay Hours in Century/ Century-Semi Home Baseline and Retrofit Assemblies 


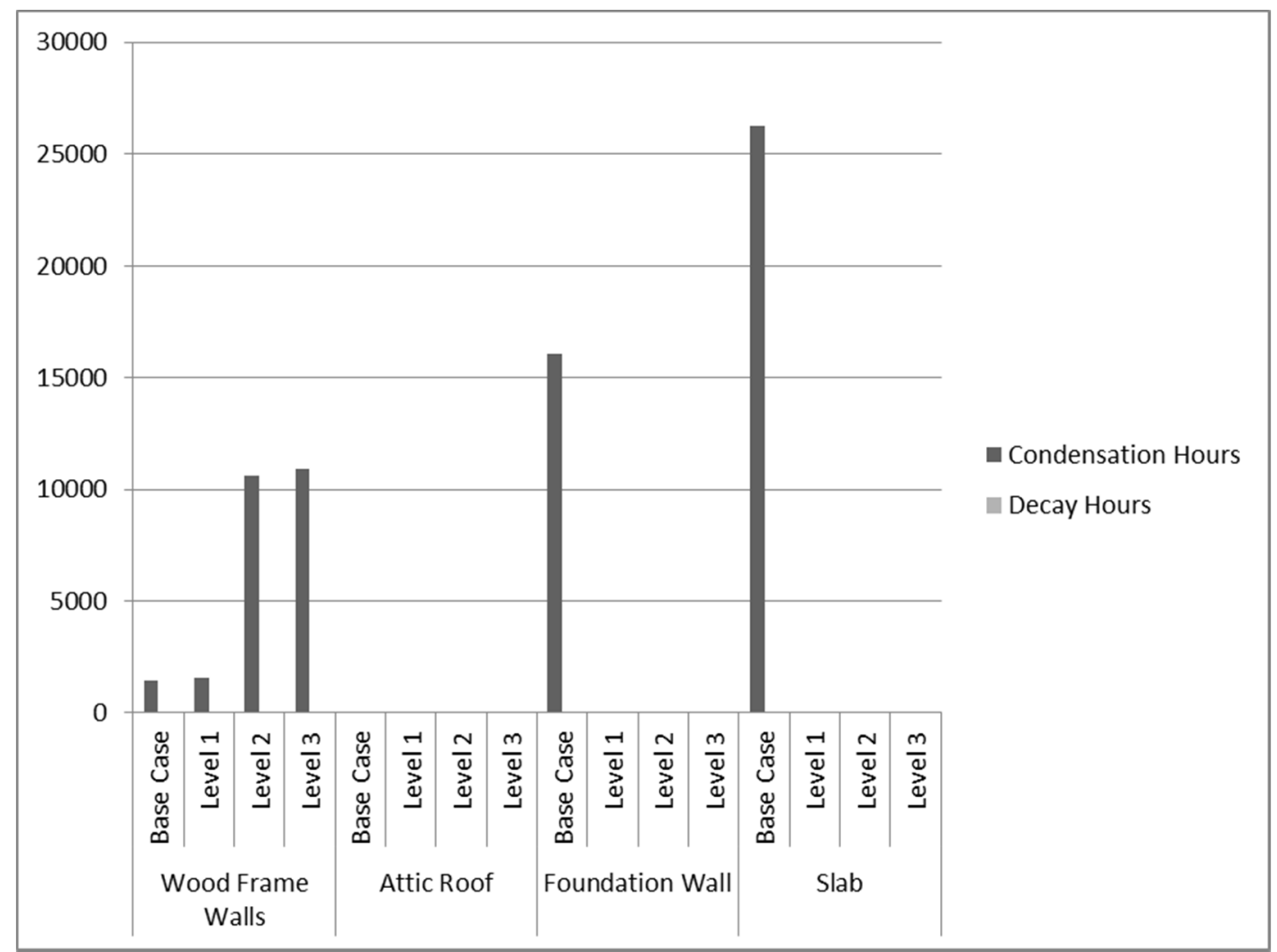

Figure 40: Condensation and Decay Hours in War Time Home Baseline and Retrofit Assemblies

In addition to the condensation and decay hours outlined above, the overall moisture content trends were observed to determine whether the assemblies were accumulating moisture over time (wetting) or dissipating moisture over time (drying). Moisture accumulation is an indication of potential for moisture damage and deterioration whereas static or decreasing moisture contents indicate limited risk for moisture damage. Examples of moisture content trends are shown in Figures 41 to 43 below: 


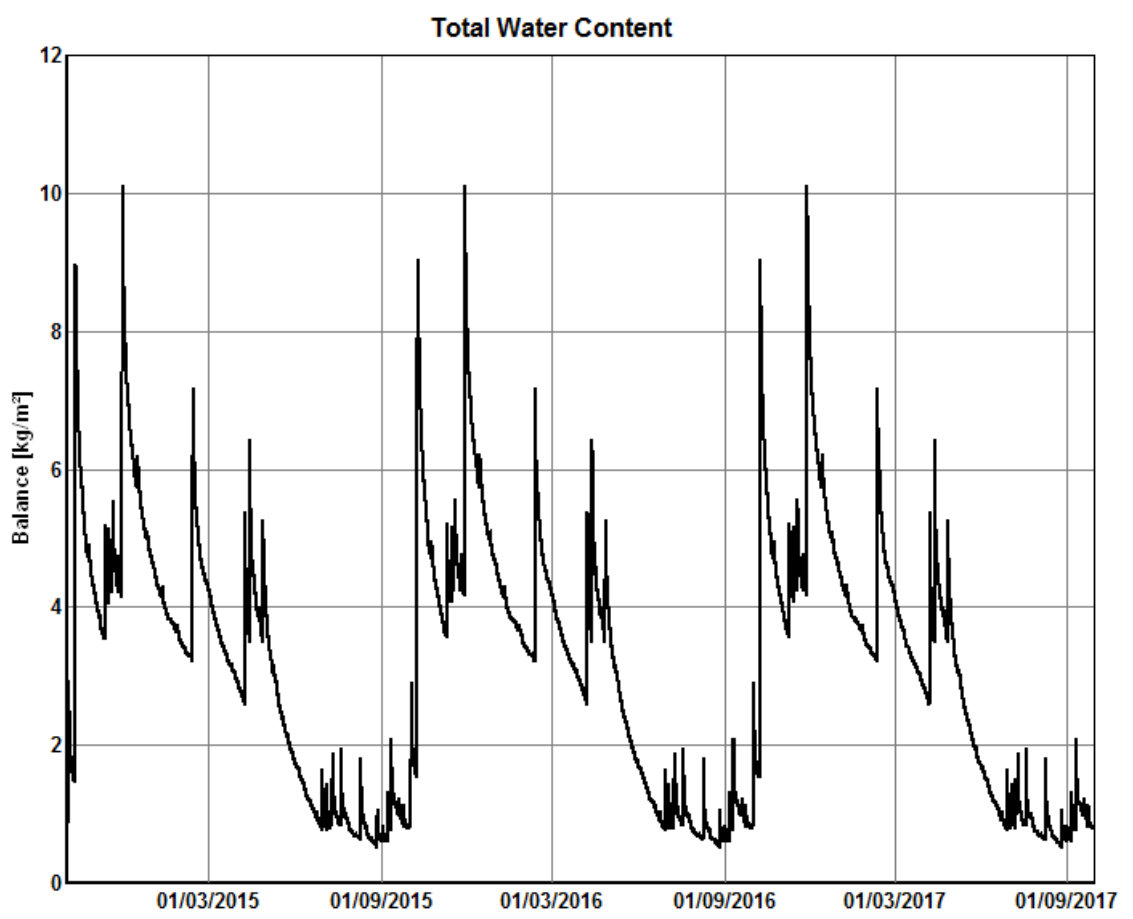

Figure 41: Example of Static Moisture Content Trend - Level 2 Masonry Wall Retrofit

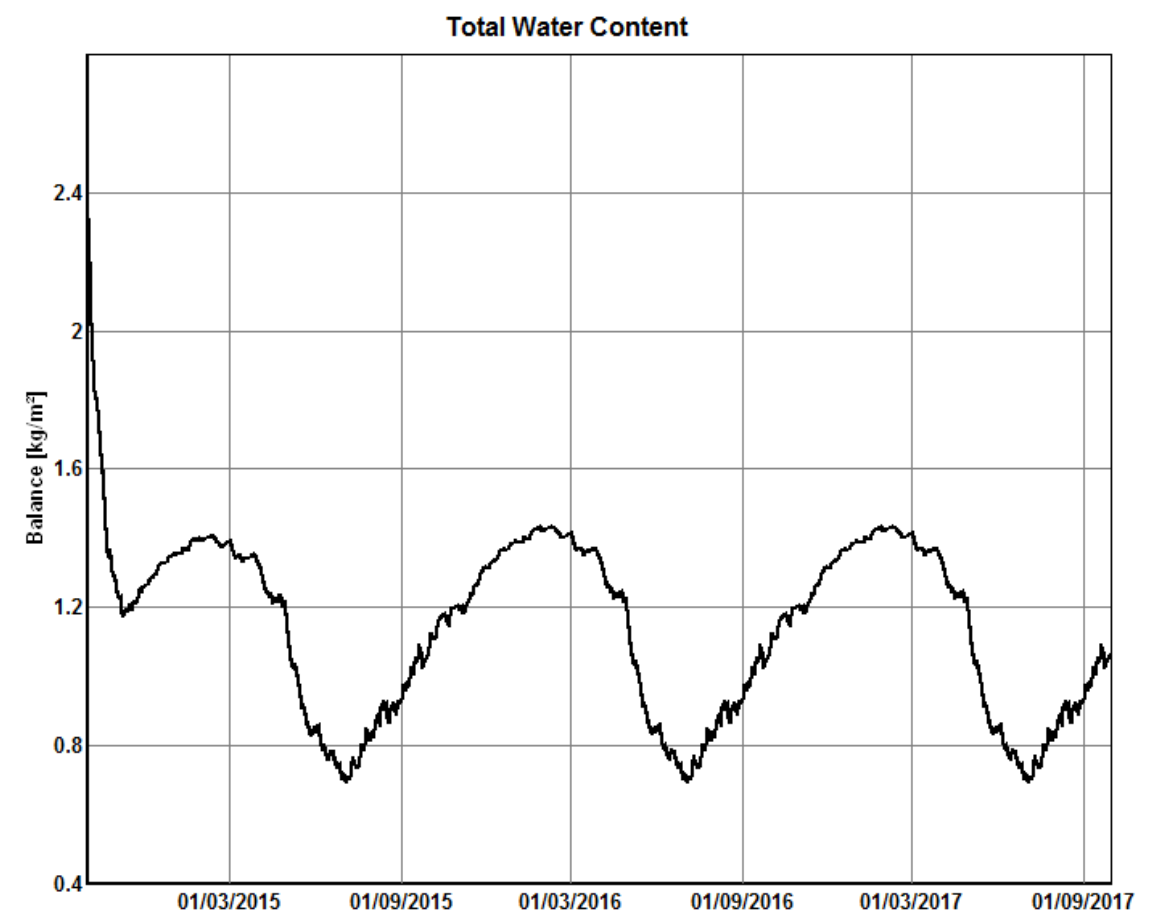

Figure 42: Example of Static Moisture Content Trend - Level 3 Cathedral Roof Retrofit 


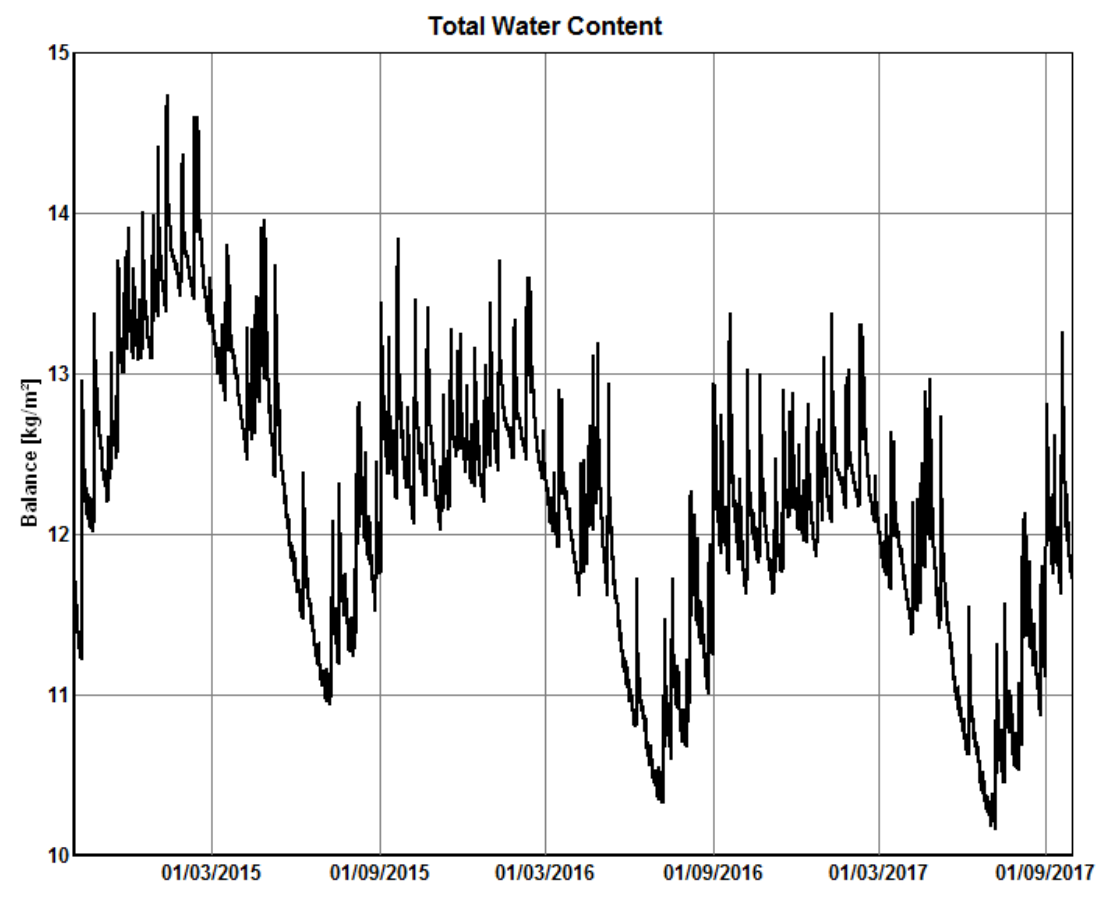

Figure 43: Example of Drying Moisture Content Trend - Level 2 Slab Retrofit

The moisture accumulation or drying trends of the simulations are summarized in Table 19 below:

Table 19: Hygrothermal Analysis Moisture Trend Summary for Retrofit Envelope Assemblies

\begin{tabular}{|c|l|l|l|l|l|l|l|l|}
\hline $\begin{array}{c}\text { Century Home and } \\
\text { Century-Semi }\end{array}$ & \multicolumn{4}{|c|}{ Masonry Walls } & \multicolumn{3}{c|}{ Cathedral Roof } \\
\cline { 2 - 8 } & Base Case & Level 1 & Level 2 & Level 3 & Base Case & Level 1 & Level 2 & Level 3 \\
\hline Moisture Trend & Static & Static & Static & Drying & Static & Static & Static & Static \\
\hline
\end{tabular}

\begin{tabular}{|c|l|l|l|l|l|l|l|l|}
\hline \multirow{2}{*}{$\begin{array}{c}\text { Century Home and } \\
\text { Century-Semi }\end{array}$} & \multicolumn{4}{|c|}{ Foundation Wall } & \multicolumn{3}{c|}{ Slab } \\
\cline { 2 - 9 } & Base Case & Level 1 & Level 2 & Level 3 & Base Case & Level 1 & Level 2 & Level 3 \\
\hline Moisture Trend & Static & Static & Static & Static & Static & Drying & Drying & Drying \\
\hline
\end{tabular}

\begin{tabular}{|l|l|l|l|l|l|l|l|l|}
\hline \multirow{2}{*}{ War Time Home } & \multicolumn{3}{|c|}{ Wood Frame Walls } & \multicolumn{3}{c|}{ Attic Roof } \\
\cline { 2 - 9 } & Base Case & Level 1 & Level 2 & Level 3 & Base Case & Level 1 & Level 2 & Level 3 \\
\hline Moisture Trend & Static & Static & Static & Static & Static & Static & Static & Static \\
\hline
\end{tabular}

\begin{tabular}{|l|l|l|l|l|l|l|l|l|}
\hline \multirow{2}{*}{ War Time Home } & \multicolumn{3}{|c|}{ Foundation Wall } & \multicolumn{3}{c|}{ Slab } \\
\cline { 2 - 9 } & Base Case & Level 1 & Level 2 & Level 3 & Base Case & Level 1 & Level 2 & Level 3 \\
\hline Moisture Trend & Wetting & Static & Static & Static & Static & Drying & Drying & Drying \\
\hline
\end{tabular}


As the retrofit assemblies showed lower numbers of condensation and decay hours than the baselines (except where otherwise noted) and also generally displayed static or decreasing moisture contents, the retrofit assemblies were expected to present low risks of moisture damage and deterioration.

\subsection{Retrofit Capital Costs Estimations}

The capital costs of the retrofit strategies were estimated both through R.S. Means construction cost data (Waier, Babbitt, Balboni, \& Charest, 2012) and through discussions with local contractors in the City of Toronto. Contractors were recruited to ascertain local market costs that reflect the reality of the Toronto retrofit industry. Three contractors, specializing in energy efficient or "green" renovations, were recruited in order to focus on contractors most familiar with the types of retrofits identified in this research. Contractors were provided with schematic drawings of the building envelope assemblies and were instructed to provide installed costs on a per square metre (square foot) basis wherever possible, inclusive of profit and overhead but exclusive of taxes. The retrofit costs were provided for a single home retrofit and did not include economies of scale which could result from retrofitting many houses in a similar manner. The guidelines provided indicated that the contractors were to assume:

- A full retrofit of the building (i.e. a single mobilization for all retrofits)

- No repairs were required to the existing structure

- No relocation of mechanical, electrical, and lighting components

- No interior finishing (i.e. painting)

- All retrofits were to include demolition of the existing structures to be replaced 
- Labour and material costs were to be provided

The total capital cost of each retrofit was calculated utilizing the sum of the component costs including demolition of the existing components and installation. The square metre cost of each retrofit was then applied to takeoff quantities from the Century, CenturySemi, and War Time Homes to ascertain the total cost of applying each retrofit to the homes. Finally the total capital costs were averaged to determine the average cost of applying each retrofit strategy to each of the archetypes.

The cost estimations from R.S. Means and the three Toronto contractors were compiled into tables for each of the retrofit strategies and levels of implementation. The cost estimate compilations are included in full in Appendix K. A sample can be found in Tables 20 and 21 below:

Table 20: Cost Summary for Wood Frame Wall Retrofit Level 1 Provided by Contractor 1

\begin{tabular}{|l|l|lr|}
\hline \multicolumn{3}{|c|}{ Masonry Wall Level 1} \\
\hline Component & Unit & Unit Cost \\
\hline Demolish Lath and Plaster & Floor & \$ $2,640.00$ \\
\hline Framing 50x100mm 610mm O.C. & L.m. & $\$$ & 19.69 \\
\hline Closed Cell Spray Foam 25mm & S.m. & $\$$ & 26.91 \\
\hline Mineral Batt Insulation 140mm & S.m. & $\$$ & 15.39 \\
\hline Gypsum Board 13mm & S.m. & $\$$ & 18.30 \\
\hline
\end{tabular}

Table 21: Cost Summary for Cathedral Roof Retrofit Level 1 Provided by Contractor 1

\begin{tabular}{|l|l|lr|}
\hline \multicolumn{3}{|c|}{ Cathedral Roof Level 1} \\
\hline Component & Unit & Unit Cost \\
\hline Demolish Lath and Plaster & Floor & $\$$ & 660.00 \\
\hline Framing 50x140mm 610mm O.C. & L.m. & $\$$ & 22.97 \\
\hline Closed Cell Spray Foam 25mm & S.m. & $\$$ & 26.91 \\
\hline Dense Pack Cellulose 345mm & S.m. & $\$$ & 41.44 \\
\hline Gypsum Board 13mm & S.m. & $\$$ & 18.30 \\
\hline
\end{tabular}

While consistency in the unit costs was requested, some contractors preferred to price items utilizing different units. Therefore a complete summary cost for each retrofit could 
not always be ascertained on a $\$ / \mathrm{m}^{2}\left(\$ / \mathrm{ft}^{2}\right)$ basis. All list items were applied to take-off quantities from the archetypal homes. The take-off quantities were calculated from the geometry of the homes utilized to prepare the building energy models. The take-off quantities are outlined in Tables 22 and 23 below:

Table 22: Take-off Quantities from the Three Archetypes - Area

\begin{tabular}{|c|c|c|c|c|c|}
\hline Area $\left(m^{2}\right)$ & Windows & Basement & Slab & Walls & Roofs \\
\hline Century & 22.6 & 86.7 & 77.7 & 208.2 & 100.9 \\
\hline Century-Semi & 13.5 & 48.1 & 63.2 & 148.5 & 68.7 \\
\hline War Time & 15.6 & 86.3 & 83.2 & 87.3 & 110.6 \\
\hline Area $\left(\mathrm{ft}^{2}\right)$ & Windows & Basement & Slab & Walls & Roofs \\
\hline Century & 243.3 & 933.2 & 836.4 & 2241.0 & 1086.1 \\
\hline Century-Semi & 145.3 & 517.7 & 680.3 & 1598.4 & 739.5 \\
\hline War Time & 167.9 & 928.9 & 895.6 & 939.7 & 1190.5 \\
\hline
\end{tabular}

Table 23: Take-off Quantities from the Three Archetypes - Linear Metres, Linear Feet

\begin{tabular}{|l|r|r|r|}
\hline Linear $(\mathrm{m})$ & Basement & \multicolumn{1}{l|}{ Walls } & \multicolumn{1}{l|}{ Roofs } \\
\hline Century & 37.7 & 77.1 & 13.4 \\
\hline Century-Semi & 22.9 & 57.1 & 13.7 \\
\hline War Time & 37.5 & 33.6 & 12.8 \\
\hline
\end{tabular}

\begin{tabular}{|l|r|r|r|}
\hline Linear (ft) & Basement & Walls & \multicolumn{1}{l|}{ Roofs } \\
\hline Century & 123.7 & 252.9 & 44.0 \\
\hline Century-Semi & 75.1 & 187.3 & 44.9 \\
\hline War Time & 123.0 & 110.2 & 42.0 \\
\hline
\end{tabular}

A sample calculation is provided in Table 24 below for calculating the cost of the Level 1 wall retrofit for the War Time Home utilizing the costs provided by Contractor 1 :

Table 24: Total Retrofit Cost Calculation Example - Level 1 Wall Retrofit - War Time Home

\begin{tabular}{|l|l|l|r|r|r|}
\hline Component & Unit & Unit Cost & Quantities & Total \\
\hline Demolish Gypsum and Fibreglass Insulation & Floor & $\$ 2,640.00$ & & $\$$ & $2,640.00$ \\
\hline Framing 50x75mm 610mm O.C. & L.m. & $\$ 19.69$ & 33.6 & $\$$ & 661.42 \\
\hline Closed Cell Spray Foam 25mm & S.m. & $\$ 26.91$ & 87.3 & $\$ 2,349.22$ \\
\hline Mineral Batt Insulation 140mm & S.m. & $\$ 15.39$ & 87.3 & $\$ 1,343.76$ \\
\hline Gypsum Board 13mm & S.m. & $\$ 18.30$ & 87.3 & $\$ 1,597.47$ \\
\hline
\end{tabular}


The unit costs were taken from Table 20 and the quantities from Tables 22 and 23 above and multiplied across to get the total cost of the retrofit for the War Time Home. This calculation was repeated for each retrofit and archetype which resulted in four total retrofit costs for each strategy; one from R.S. Means and one from each of the three contractors, which were then averaged. All retrofit costs are displayed in Appendix L and the average retrofit cost for each archetype and level of implementation is summarized in Table 25 below:

Table 25: Average Capital Cost for each Retrofit and Level of Implementation Organized by Archetype

\begin{tabular}{|c|c|c|c|c|c|}
\hline & & \multicolumn{4}{|c|}{ Average } \\
\hline Retrofit & Implementation & Century & $\mathrm{Ce}$ & iry-Semi & War Time \\
\hline \multirow{3}{*}{ Walls } & Level 1 & $\$ 21,079$ & $\$$ & 15,414 & $\$ 8,488$ \\
\hline & Level 2 & $\$ 21,585$ & $\$$ & 15,838 & $\$ 10,470$ \\
\hline & Level 3 & $\$ 23,226$ & $\$$ & 16,993 & $\$ 11,199$ \\
\hline \multirow{3}{*}{ Ceiling } & Level 1 & $\$ 9,878$ & $\$$ & 6,975 & $\$ 1,890$ \\
\hline & Level 2 & $\$ 11,398$ & $\$$ & 8,010 & $\$ 2,155$ \\
\hline & Level 3 & $\$ 16,563$ & $\$$ & 11,680 & $\$ 2,610$ \\
\hline \multirow{3}{*}{$\begin{array}{c}\text { Basement } \\
\text { Walls }\end{array}$} & Level 1 & $\$ 4,340$ & $\$$ & 2,749 & $\$ 6,467$ \\
\hline & Level 2 & $\$ 4,576$ & $\$$ & 2,879 & $\$ 6,699$ \\
\hline & Level 3 & $\$ \quad 4,755$ & $\$$ & 2,979 & $\$ 6,878$ \\
\hline \multirow{3}{*}{ Slab } & Level 1 & $\$ 5,065$ & $\$$ & 4,176 & $\$ 5,402$ \\
\hline & Level 2 & $\$ 5,362$ & $\$$ & 4,418 & $\$ 5,720$ \\
\hline & Level 3 & $\$ 5,565$ & $\$$ & 4,582 & $\$ 5,937$ \\
\hline \multirow{3}{*}{ Windows } & Level 1 & $\$ 18,509$ & $\$$ & 11,586 & $\$ 13,029$ \\
\hline & Level 2 & $\$ 20,597$ & $\$$ & 12,833 & $\$ 14,471$ \\
\hline & Level 3 & $\$ 24,359$ & $\$$ & 15,080 & $\$ 17,067$ \\
\hline \multirow{3}{*}{ Air Sealing } & Level 1 & $\$ 1,335$ & $\$$ & 1,205 & $\$ 1,182$ \\
\hline & Level 2 & $\$ 1,500$ & $\$$ & 1,500 & $\$ 1,500$ \\
\hline & Level 3 & $\$ 1,500$ & $\$$ & 1,500 & $\$ 1,500$ \\
\hline \multirow{3}{*}{ Furnace } & Level 1 & $\$ 3,150$ & $\$$ & 3,150 & $\$ 3,150$ \\
\hline & Level 2 & $\$ 3,665$ & $\$$ & 3,665 & $\$ 3,665$ \\
\hline & Level 3 & $\$ 4,333$ & $\$$ & 4,333 & $\$ 4,333$ \\
\hline \multirow{3}{*}{ HRV/ERV } & Level 1 & $\$ 2,125$ & $\$$ & 2,125 & $\$ 2,125$ \\
\hline & Level 2 & $\$ 3,256$ & $\$$ & 3,256 & $\$ 3,256$ \\
\hline & Level 3 & 3,726 & $\$$ & 3,726 & $\$ 3,726$ \\
\hline
\end{tabular}


Capital costs were not initially provided for air sealing levels 2 and 3 as these levels were achieved through the combination of exterior wall and roof retrofits. An additional cost of $\$ 1500$ was assumed however, based conservatively on the average cost of air sealing level 1, to account for labour and materials (tapes, sealant, etc.) required for contractors to seal penetrations and leakage paths during wall and roof retrofits. Some contractors were not able to provide cost estimations for all retrofits and therefore some gaps existed in the data sets. These gaps were typically related to material costs and were filled with manufacturer cost data where possible. In one case, Contractor 2 was not able to provide any cost data for furnace retrofits.

Generally the cost estimation data sets provided by R.S. Means and the three contractors were similar. In a few instances the cost estimation in one data set was significantly higher or lower than the others, however in these instances the remaining data sets tended to be similar. A graphical comparison of the cost estimates is provided in Figures 44 to 49 below: 


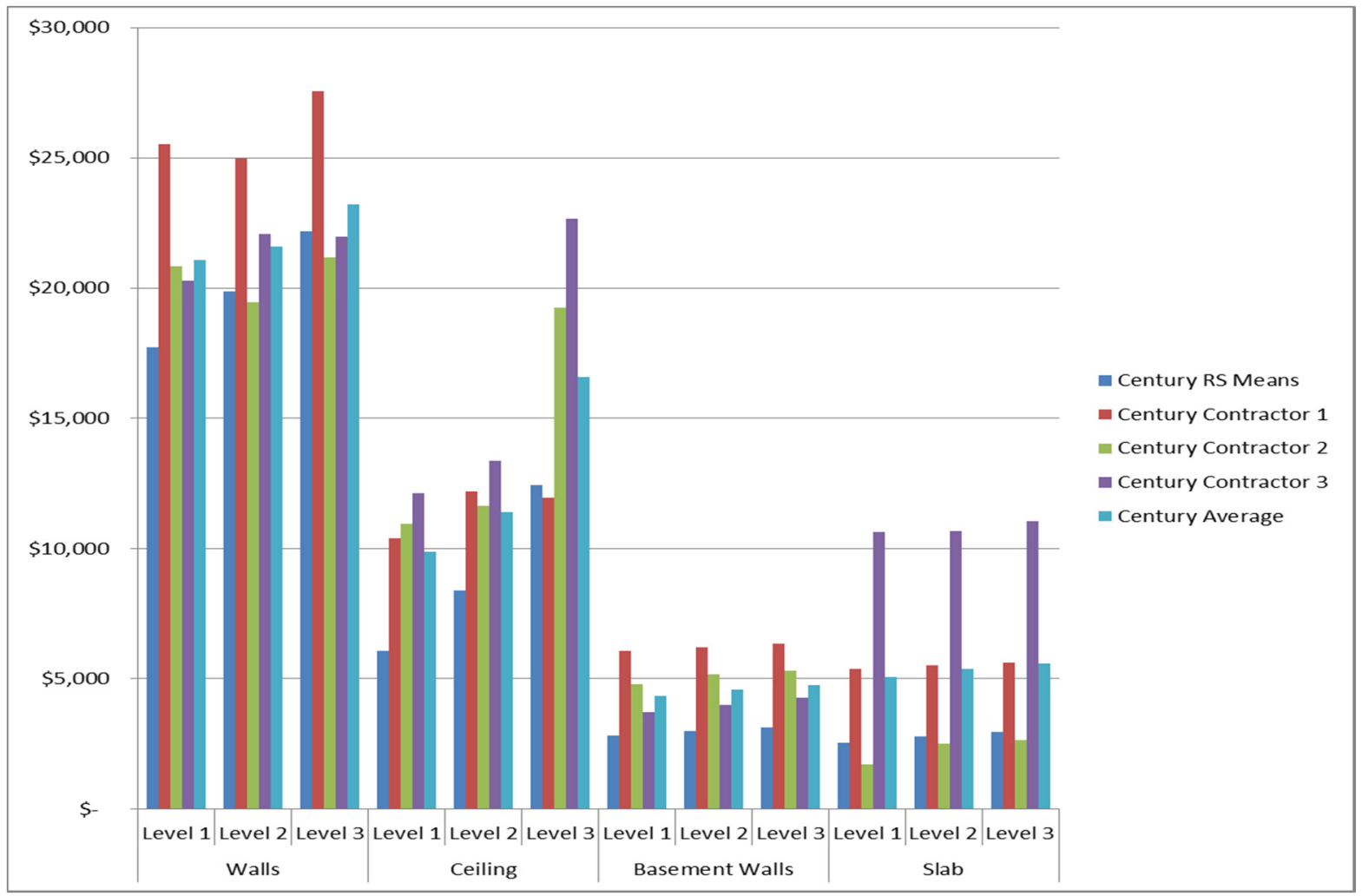

Figure 44: Century Home Cost Estimate Comparison - Walls, Roof, Basement Walls, and Slab

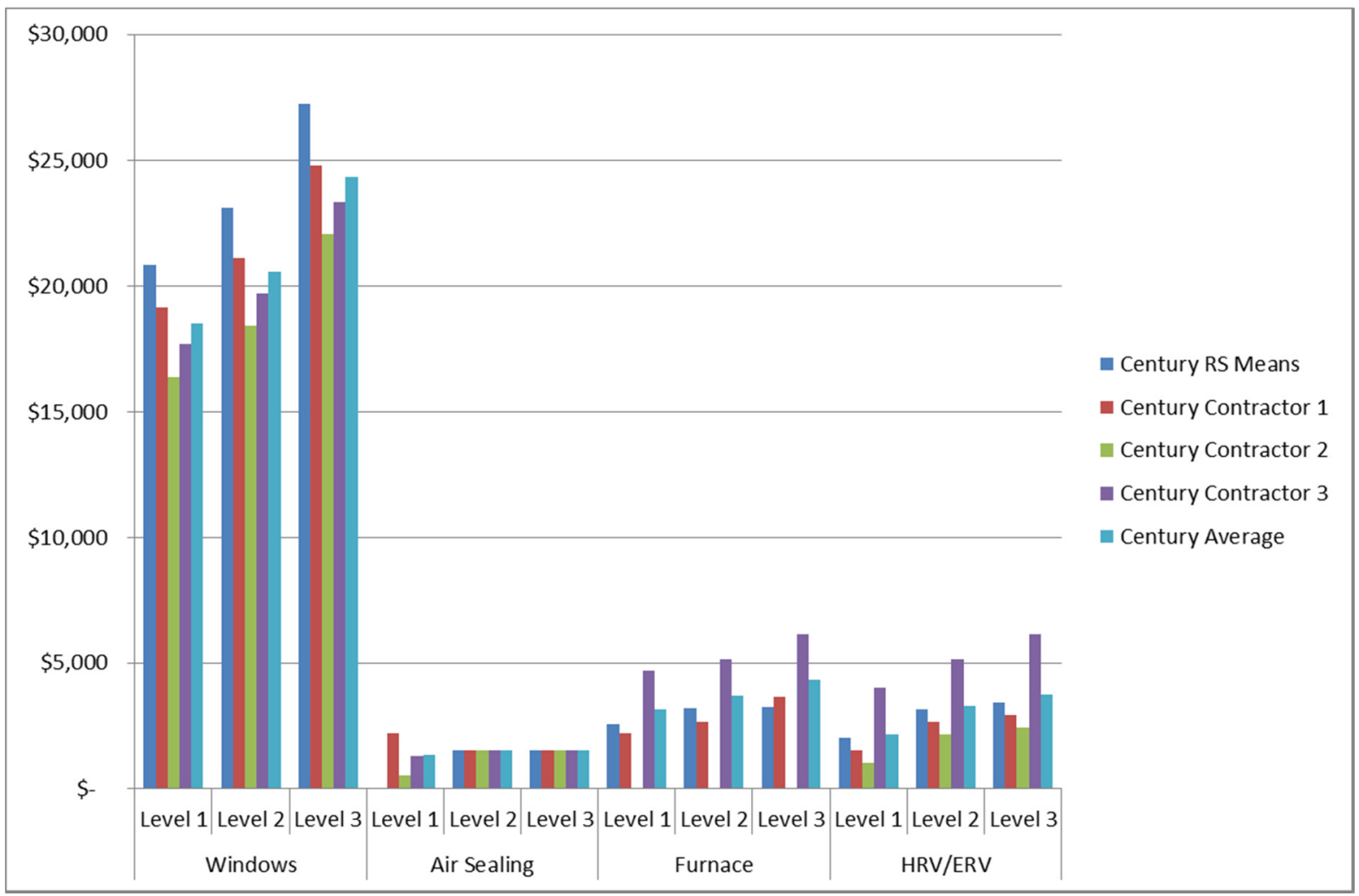

Figure 45: Century Home Cost Estimate Comparison - Windows, Air Sealing, Furnace, HRV/ERV 


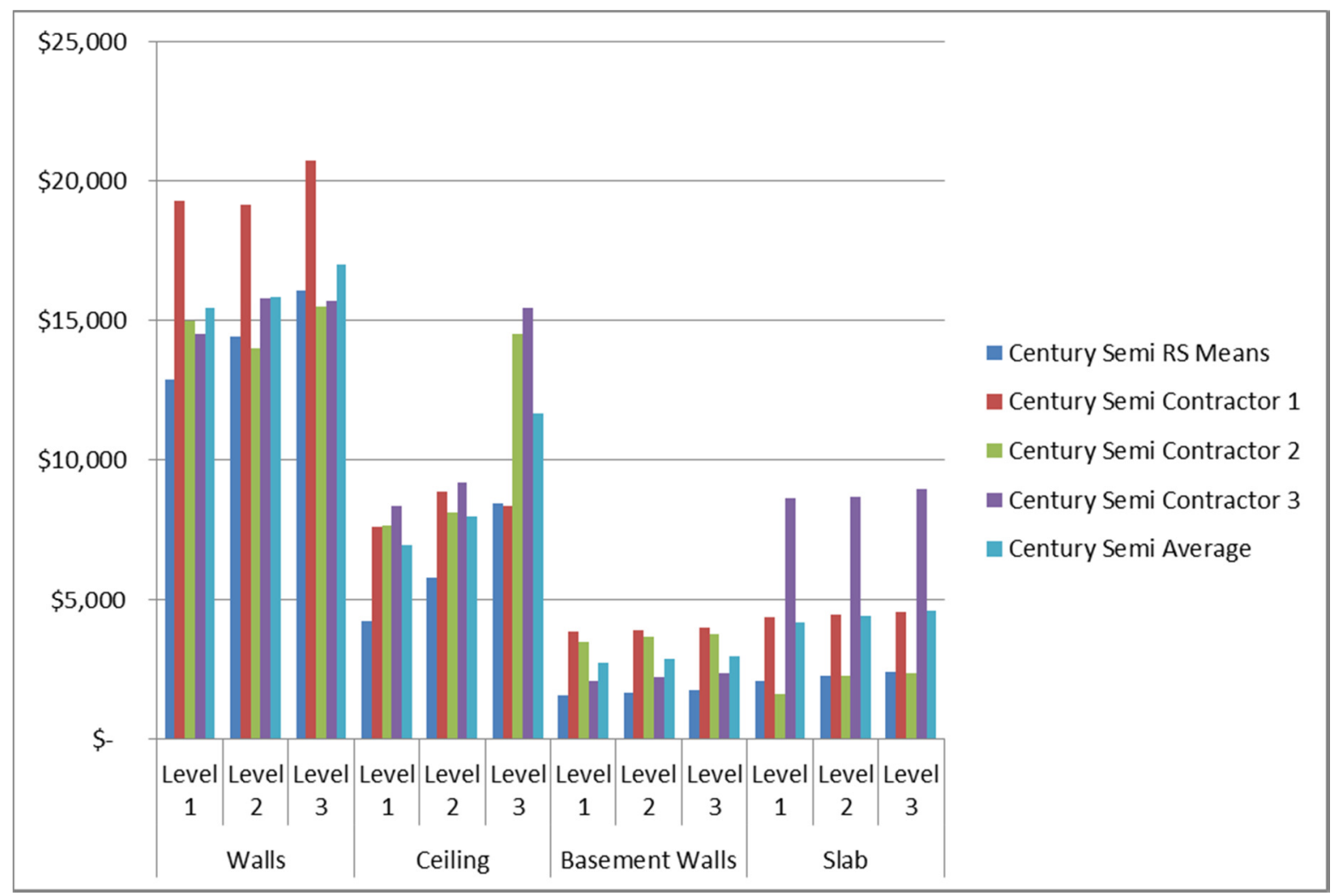

Figure 46: Century-Semi Home Cost Estimate Comparison - Walls, Roof, Basement Walls, and Slab

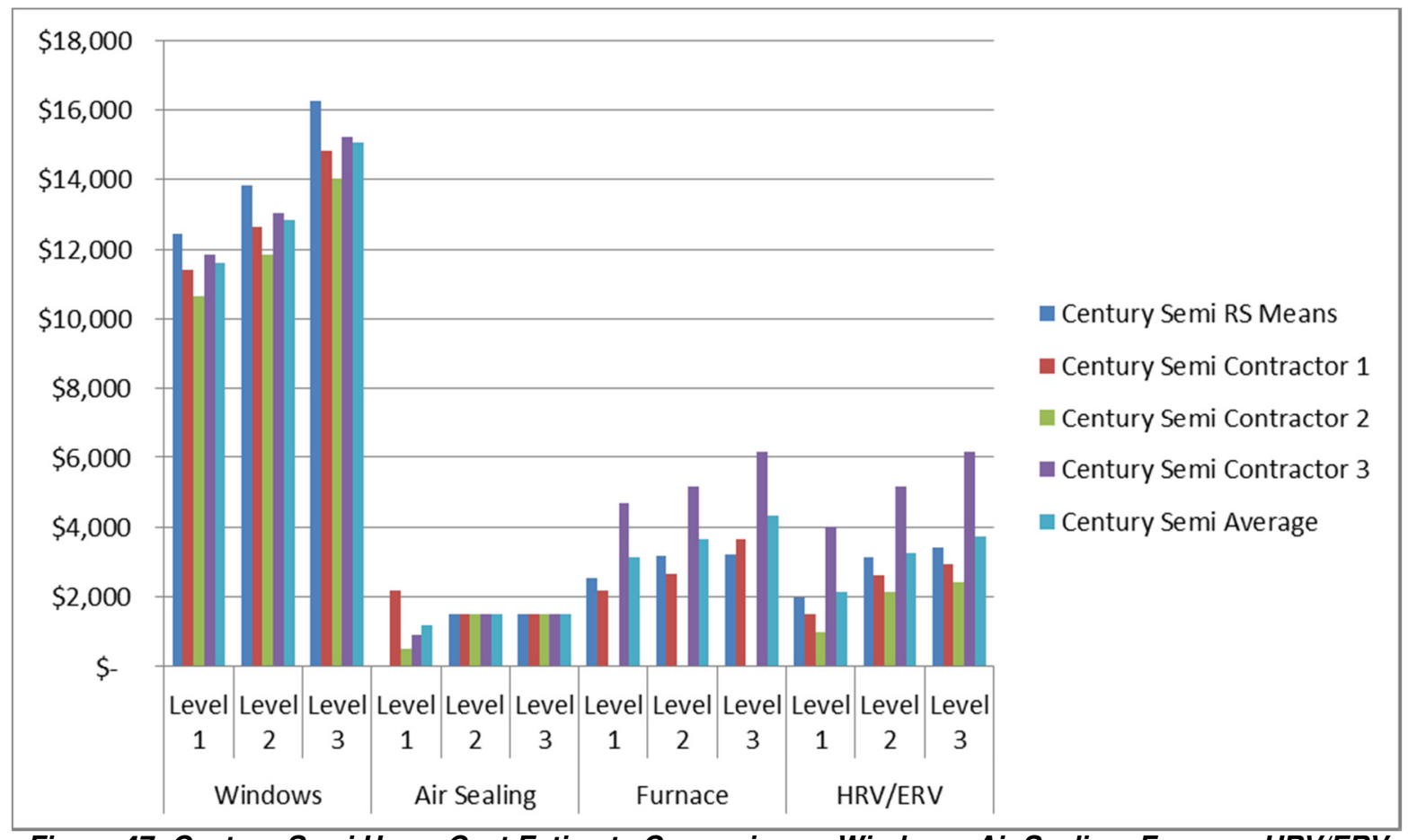

Figure 47: Century-Semi Home Cost Estimate Comparison - Windows, Air Sealing, Furnace, HRV/ERV 


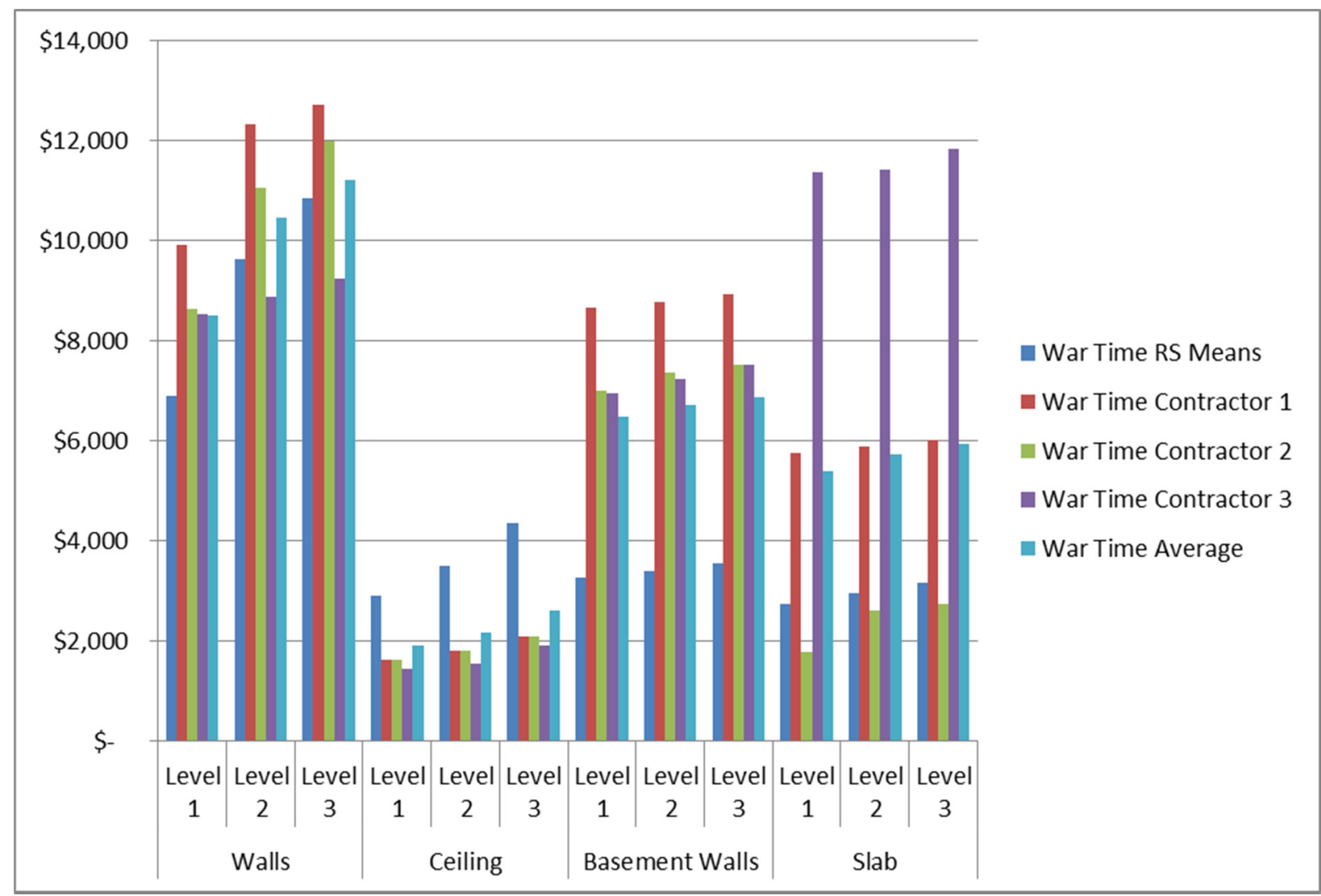

Figure 48: War Time Home Cost Estimate Comparison - Walls, Roof, Basement Walls, and Slab

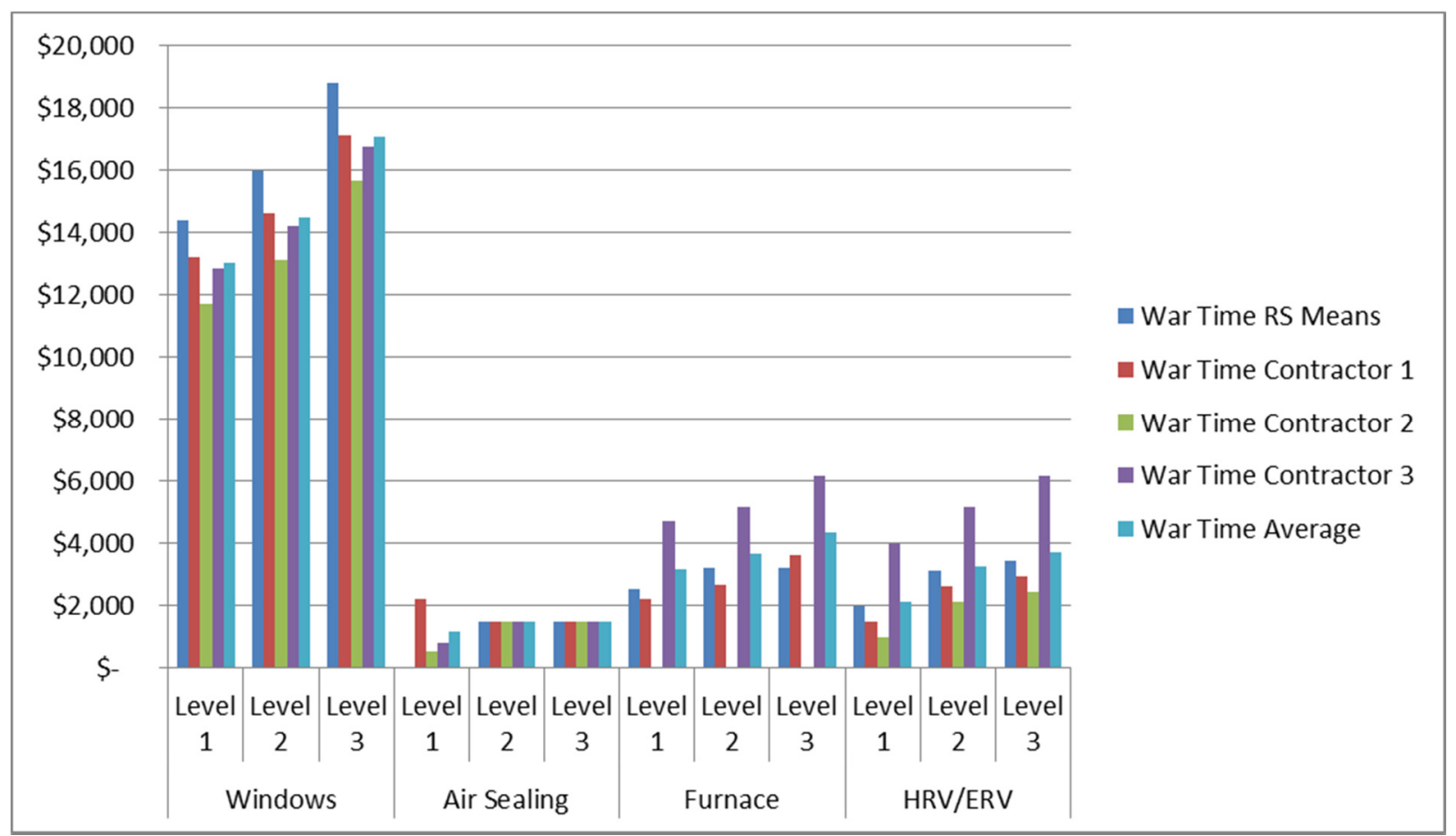

Figure 49: War Time Home Cost Estimate Comparison - Windows, Air Sealing, Furnace, HRV/ERV 
While some outliers appeared, overall the average values appeared to reflect a general consensus. It should be noted however that the differences between the cost estimations from the various contractors often had a scale of several thousands of dollars, which can be a significant difference for a homeowner who is looking to finance retrofits for their home.

\subsection{Modelling Retrofit Strategies}

The methodology for modelling the retrofit strategies and selecting the most successful combination of strategies followed a Brute Force Sequential Search method as described in the literature review. Level 1 of each retrofit strategy was applied to the baseline energy models and the resulting energy use reduction was quantified. The "rule" that was utilized to select the most appropriate retrofit was the lowest capital cost

per unit of energy saved $\left(\$ / \mathrm{kWh} / \mathrm{m}^{2}\right.$ saved $)$ over the one year modelling period. This ensured that the strategy that was selected not only provided a reduction in energy use, but also demonstrated the most attractive cost/benefit. For example if two retrofit strategies resulted in similar energy savings, but one was twice as expensive, the option with the lower cost was selected even if it resulted in lower energy savings, as it provided a more attractive cost/benefit. From the application of the Level 1 retrofit strategies, the most attractive option based on the "rule" was selected and formed the new baseline. The Level 1 retrofits were then applied to the new baseline, as well as Level 2 of the initially selected strategy. This process was repeated in an iterative manner until the retrofit targets were met. A schematic example of the iterative process is shown in Figure 50 below: 


\begin{tabular}{|l|l|l|l|l|l|l|l|l|}
\hline Retrofit & Walls & Roof & Basement & Slab & Windows & Air Sealing & Furnace & HRV/ERV \\
\hline Round 1 & & & & & & & & \\
\hline Round 2 & & & & & & & & \\
\hline Round 3 & & & & & & & & \\
\hline Round 4 & & & & & & & & \\
\hline Round 5 & & & & & & & & \\
\hline Round 6 & & & & & & & & \\
\hline Round 7 & & & & & & & & \\
\hline
\end{tabular}

Figure 50: Brute Force Sequential Search Method for Retrofit Determination

Once the retrofit target was met, the retrofit package that met the target and the process for meeting the target was determined and the capital cost was calculated.

During the energy modelling process it was assumed that air tightness levels 2 and 3 were achieved only when both level 2 wall and roof and level 3 wall and roof retrofits were applied respectively. It was also assumed that air sealing at envelope penetrations and leakage paths was conducted during wall and roof retrofits. While there would likely be an $\mathrm{ACH}$ reduction from implementing a wall retrofit without also implementing a roof retrofit, and vice versa, this potential reduction was not considered in the modelling. As the wall retrofit assemblies were of various thicknesses, a new floor area for the archetypal homes was calculated when each new wall assembly was applied. To calculate area, the exterior building dimensions were drawn to scale and the floor area was drawn by offsetting the exterior dimensions by the thickness of the retrofit wall assembly. An example drawing is shown in Figure 51 below: 


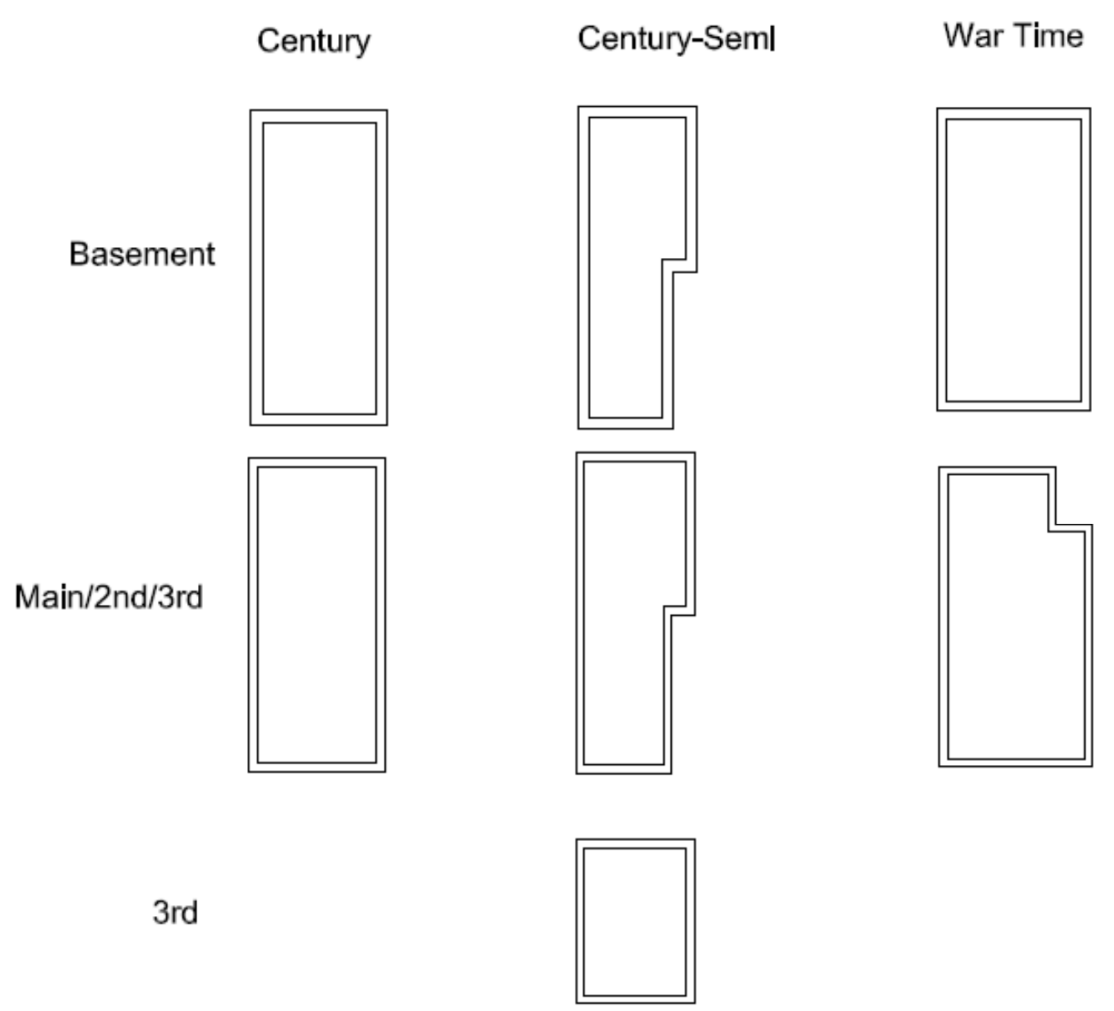

Figure 51: Building Floor Area Drawing Example

The resulting floor area was then calculated utilizing the interior dimensions. Additionally, to reach the EnerPHit $t_{\text {EQUIV }}$ requirement treated floor area (TFA) was utilized in the energy intensity calculation. Treated floor area was calculated utilizing the Level 3 wall assembly and subtracting the interior wall and stair areas, followed by applying a multiplier (Passive House Institute, 2012). This calculation is shown in Table 26 below:

Table 26: Treated Floor Area Calculations for EnerPHit ${ }_{E Q U I V}$

\begin{tabular}{|l|r|r|r|r|r|r|}
\hline Century & Floor Area $\left(\mathrm{m}^{2}\right)$ & Interior Walls $\left(\mathrm{m}^{2}\right)$ & Stairs $\left(\mathrm{m}^{2}\right)$ & Net $\left(\mathrm{m}^{2}\right)$ & TFA Multiplier & TFA $\left(\mathrm{m}^{2}\right)$ \\
\hline Basement & 59.1 & 0 & 0.8 & 58.3 & 0.6 & 34.9 \\
\hline Main Floor & 55.5 & 4.2 & 2 & 49.3 & 1 & 49.3 \\
\hline Second Floor & 55.5 & 8.4 & 2 & 45.1 & 1 & 45.1 \\
\hline Third Floor & 55.5 & 2.9 & 2 & 50.6 & 1 & 50.6 \\
\hline
\end{tabular}




\begin{tabular}{|l|r|r|r|r|r|r|}
\hline Century-Semi & Floor Area $\left(\mathrm{m}^{2}\right)$ & Interior Walls $\left(\mathrm{m}^{2}\right)$ & Stairs $\left(\mathrm{m}^{2}\right)$ & Net $\left(\mathrm{m}^{2}\right)$ & TFA Multiplier & TFA $\left(\mathrm{m}^{2}\right)$ \\
\hline Basement & 44.9 & 5 & 0.8 & 39.1 & 0.6 & 23.5 \\
\hline Main Floor & 42.1 & 2.4 & 2 & 37.7 & 1 & 37.7 \\
\hline Second Floor & 42.1 & 8.9 & 2 & 31.2 & 1 & 31.2 \\
\hline Third Floor & 22.3 & 3.1 & 2 & 17.2 & 1 & 17.2 \\
\hline \multicolumn{1}{r}{} & & & & Total TFA & 109.6 \\
\hline
\end{tabular}

\begin{tabular}{|l|r|r|r|r|r|r|}
\hline War Time & Floor Area $\left(\mathrm{m}^{2}\right)$ & Interior Walls $\left(\mathrm{m}^{2}\right)$ & Stairs $\left(\mathrm{m}^{2}\right)$ & Net $\left(\mathrm{m}^{2}\right)$ & TFA Multiplier & TFA $\left(\mathrm{m}^{2}\right)$ \\
\hline Basement & 67.9 & 4.9 & 0.8 & 62.2 & 1 & 62.2 \\
\hline Main Floor & 61.8 & 4.9 & 2 & 54.9 & 1 & 54.9 \\
\hline & & & & & Total TFA & 117.1 \\
\hline
\end{tabular}

The floor areas utilized for each of the wall retrofit assemblies and the TFA are outlined in Table 27 below:

Table 27: Floor Areas for Wall Retrofits and Treated Floor Area for EnerPHit ${ }_{E Q U I V}$

\begin{tabular}{|l|r|r|r|r|r|}
\hline Archetype & Baseline $\left(\mathrm{m}^{2}\right)$ & Level 1 $\left(\mathrm{m}^{2}\right)$ & Level $2\left(\mathrm{~m}^{2}\right)$ & Level 3 $\left(\mathrm{m}^{2}\right)$ & Level 3 TFA $\left(\mathrm{m}^{2}\right)$ \\
\hline Century & 250.9 & 235.5 & 229.8 & 210.1 & 179.9 \\
\hline Century-Semi & 165.9 & 152.4 & 147.5 & 130.6 & 109.6 \\
\hline War Time & 131.7 & 126.4 & 123.9 & 119.9 & 117.1 \\
\hline
\end{tabular}

For each of the three archetypes both the $75 \mathrm{kWh} / \mathrm{m}^{2}$ and EnerPHit EQUIV $_{\text {. }}$ objectives were achieved. An example of the modelling results is shown in Figure 52 below:

\begin{tabular}{|c|c|c|c|c|c|c|c|c|c|c|c|c|}
\hline Baseline: $\mathbf{2 0 9}$ & \multicolumn{4}{|c|}{ Round 1} & \multicolumn{4}{|c|}{ Round 2} & \multicolumn{4}{|c|}{ Round 3} \\
\hline Retrofit & Intensity & Saved & Cost & \$/Saved & Intensity & Saved & Cost & \$/Saved & Intensity & Saved & Cost & \$/Saved \\
\hline Walls & 192 & 17 & $\$ 8,488$ & 499 & 174 & 19 & $\$ 8,488$ & 447 & 155 & 16 & $\$ 8,488$ & 530 \\
\hline Roof & 193 & 16 & $\$ 1,890$ & 118 & 191 & 2 & $\$ 2,155$ & 1078 & 170 & 1 & $\$ 2,155$ & 2155 \\
\hline Basement Walls & 187 & 22 & $\$ 6,467$ & 294 & 171 & 22 & $\$ 6,467$ & 294 & 153 & 18 & $\$ 6,467$ & 359 \\
\hline Slab & 181 & 28 & $\$ 5,402$ & 193 & 166 & 27 & $\$ 5,402$ & 200 & 148 & 23 & $\$ 5,402$ & 235 \\
\hline Windows & 200 & 9 & $\$ 13,029$ & 1448 & 184 & 9 & $\$ 13,029$ & 1448 & 163 & 8 & $\$ 13,029$ & 1629 \\
\hline Air Sealing & 206 & 3 & $\$ 1,182$ & 394 & 190 & 3 & $\$ 1,182$ & 394 & 169 & 2 & $\$ 1,182$ & 591 \\
\hline Heating/Cooling & 186 & 23 & $\$ 3,150$ & 137 & 171 & 22 & $\$ 3,150$ & 143 & 164 & 7 & $\$ 3,665$ & 524 \\
\hline Ventilation & 201 & 8 & $\$ 2,125$ & 266 & 186 & 7 & $\$ 2,125$ & 304 & 166 & 5 & $\$ 2,125$ & 425 \\
\hline
\end{tabular}

Figure 52: Energy Modelling Results Example

This example demonstrates how the energy intensity results from the energy model were documented with the "Saved" column being the difference between the baseline 
and the baseline upgraded with the retrofit strategy. The cost of the retrofit strategy was displayed and the resulting cost per unit of energy saved was quantified.

The Century Home, with a baseline energy intensity of $211 \mathrm{kWh} / \mathrm{m}^{2}$, achieved the $75 \mathrm{kWh} / \mathrm{m}^{2}$ target at Round 7 of the energy modelling and achieved the EnerPHit $t_{\text {EQUIV }}$ target at Round 14. The Century-Semi Home, with a baseline energy intensity of 228 $\mathrm{kWh} / \mathrm{m}^{2}$, achieved the $75 \mathrm{kWh} / \mathrm{m}^{2}$ target at Round 8 and the EnerPHit EQuiv $_{\text {target }}$ at Round 17. The War Time Home, with a baseline energy intensity of $209 \mathrm{kWh} / \mathrm{m}^{2}$, achieved the $75 \mathrm{kWh} / \mathrm{m}^{2}$ target at Round 7 of the energy modelling and achieved the

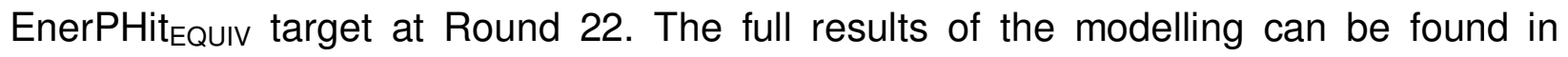
Appendix $M$ with the results summarized in Tables 28 to 30 below:

Table 28: Century Home Energy Modelling Results by Round

\begin{tabular}{|l|c|c|c|c|c|c|c|c|c|}
\hline Retrofit & Walls & Roof & Basement & Slab & Windows & Air Sealing & Furnace & HRV/ERV & $\mathrm{kWh} / \mathrm{m}^{2}$ \\
\hline Round 1 & Baseline & Baseline & Baseline & Baseline & Baseline & Baseline & Level 1 & Baseline & 188 \\
\hline Round 2 & Baseline & Baseline & Baseline & Baseline & Baseline & Level 1 & Level 1 & Baseline & 181 \\
\hline Round 3 & Baseline & Baseline & Level 1 & Baseline & Baseline & Level 1 & Level 1 & Baseline & 169 \\
\hline Round 4 & Baseline & Baseline & Level 1 & Level 1 & Baseline & Level 1 & Level 1 & Baseline & 144 \\
\hline Round 5 & Level 1 & Baseline & Level 1 & Level 1 & Baseline & Level 1 & Level 1 & Baseline & 108 \\
\hline Round 6 & Level 2 & Baseline & Level 1 & Level 1 & Baseline & Level 1 & Level 1 & Baseline & 83 \\
\hline Round 7 & Level 2 & Level 1 & Level 1 & Level 1 & Baseline & Level 1 & Level 1 & Baseline & $\mathbf{7 4}$ \\
\hline Round 8 & Level 2 & Level 2 & Level 1 & Level 1 & Baseline & Level 2 & Level 1 & Baseline & 57 \\
\hline Round 9 & Level 2 & Level 2 & Level 1 & Level 1 & Baseline & Level 2 & Level 2 & Baseline & 55 \\
\hline Round 10 & Level 2 & Level 2 & Level 1 & Level 1 & Baseline & Level 2 & Level 2 & Level 1 & 54 \\
\hline Round 11 & Level 3 & Level 2 & Level 1 & Level 1 & Baseline & Level 2 & Level 2 & Level 1 & 46 \\
\hline Round 12 & Level 3 & Level 3 & Level 1 & Level 1 & Baseline & Level 3 & Level 2 & Level 1 & 38 \\
\hline Round 13 & Level 3 & Level 3 & Level 1 & Level 1 & Level 1 & Level 3 & Level 2 & Level 1 & 31 \\
\hline Round 14 & Level 3 & Level 3 & Level 1 & Level 1 & Level 2 & Level 3 & Level 2 & Level 1 & $\mathbf{2 2}$ \\
\hline
\end{tabular}


Table 29: Century-Semi Home Energy Modelling Results by Round

\begin{tabular}{|c|c|c|c|c|c|c|c|c|c|}
\hline Retrofit & Walls & Roof & Basement & Slab & Windows & Air Sealing & Furnace & $\mathrm{HRV} / \mathrm{ERV}$ & $\mathrm{kWh} / \mathrm{m}^{2}$ \\
\hline Round 1 & Baseline & Baseline & Baseline & Baseline & Baseline & Baseline & Level 1 & Baseline & 203 \\
\hline Round 2 & Baseline & Baseline & Baseline & Baseline & Baseline & Level 1 & Level 1 & Baseline & 194 \\
\hline Round 3 & Baseline & Baseline & Baseline & Level 1 & Baseline & Level 1 & Level 1 & Baseline & 172 \\
\hline Round 4 & Baseline & Baseline & Level 1 & Level 1 & Baseline & Level 1 & Level 1 & Baseline & 150 \\
\hline Round 5 & Level 1 & Baseline & Level 1 & Level 1 & Baseline & Level 1 & Level 1 & Baseline & 119 \\
\hline Round 6 & Level 2 & Baseline & Level 1 & Level 1 & Baseline & Level 1 & Level 1 & Baseline & 97 \\
\hline Round 7 & Level 2 & Level 1 & Level 1 & Level 1 & Baseline & Level 1 & Level 1 & Baseline & 86 \\
\hline Round 8 & Level 2 & Level 2 & Level 1 & Level 1 & Baseline & Level 2 & Level 1 & Baseline & 63 \\
\hline Round 9 & Level 2 & Level 2 & Level 1 & Level 1 & Baseline & Level 2 & Level 2 & Baseline & 60 \\
\hline Round 10 & Level 2 & Level 2 & Level 1 & Level 2 & Baseline & Level 2 & Level 2 & Baseline & 58 \\
\hline Round 11 & Level 2 & Level 2 & Level 1 & Level 3 & Baseline & Level 2 & Level 2 & Baseline & 55 \\
\hline Round 12 & Level 2 & Level 2 & Level 2 & Level 3 & Baseline & Level 2 & Level 2 & Baseline & 53 \\
\hline Round 13 & Level 2 & Level 2 & Level 2 & Level 3 & Baseline & Level 2 & Level 2 & Level 1 & 52 \\
\hline Round 14 & Level 2 & Level 2 & Level 2 & Level 3 & Level 1 & Level 2 & Level 2 & Level 1 & 47 \\
\hline Round 15 & Level 2 & Level 2 & Level 2 & Level 3 & Level 2 & Level 2 & Level 2 & Level 1 & 39 \\
\hline Round 16 & Level 3 & Level 2 & Level 2 & Level 3 & Level 2 & Level 2 & Level 2 & Level 1 & 30 \\
\hline Round 17 & Level 3 & Level 3 & Level 2 & Level 3 & Level 2 & Level 3 & Level 2 & Level 1 & 22 \\
\hline
\end{tabular}

Table 30: War Time Home Energy Modelling Results by Round

\begin{tabular}{|c|c|c|c|c|c|c|c|c|c|}
\hline Retrofit & Walls & Roof & Basement & Slab & Windows & Air Sealing & Furnace & $\mathrm{HRV} / \mathrm{ERV}$ & $\mathrm{kWh} / \mathrm{m}^{2}$ \\
\hline Round 1 & Baseline & Level 1 & Baseline & Baseline & Baseline & Baseline & Baseline & Baseline & 193 \\
\hline Round 2 & Baseline & Level 1 & Baseline & Baseline & Baseline & Baseline & Level 1 & Baseline & 171 \\
\hline Round 3 & Baseline & Level 1 & Baseline & Level 1 & Baseline & Baseline & Level 1 & Baseline & 148 \\
\hline Round 4 & Baseline & Level 1 & Level 1 & Level 1 & Baseline & Baseline & Level 1 & Baseline & 112 \\
\hline Round 5 & Baseline & Level 1 & Level 1 & Level 1 & Baseline & Baseline & Level 1 & Level 1 & 106 \\
\hline Round 6 & Level 1 & Level 1 & Level 1 & Level 1 & Baseline & Baseline & Level 1 & Level 1 & 91 \\
\hline Round 7 & Level 2 & Level 1 & Level 1 & Level 1 & Baseline & Baseline & Level 1 & Level 1 & 69 \\
\hline Round 8 & Level 2 & Level 1 & Level 1 & Level 1 & Baseline & Level 1 & Level 1 & Level 1 & 67 \\
\hline Round 9 & Level 2 & Level 1 & Level 1 & Level 1 & Baseline & Level 1 & Level 2 & Level 1 & 64 \\
\hline Round 10 & Level 2 & Level 1 & Level 1 & Level 1 & Level 1 & Level 1 & Level 2 & Level 1 & 56 \\
\hline Round 11 & Level 2 & Level 1 & Level 1 & Level 1 & Level 2 & Level 1 & Level 2 & Level 1 & 47 \\
\hline Round 12 & Level 2 & Level 2 & Level 1 & Level 1 & Level 2 & Level 2 & Level 2 & Level 1 & 42 \\
\hline Round 13 & Level 2 & Level 3 & Level 1 & Level 1 & Level 2 & Level 2 & Level 2 & Level 1 & 40 \\
\hline Round 14 & Level 2 & Level 3 & Level 1 & Level 2 & Level 2 & Level 2 & Level 2 & Level 1 & 37 \\
\hline Round 15 & Level 2 & Level 3 & Level 1 & Level 3 & Level 2 & Level 2 & Level 2 & Level 1 & 34 \\
\hline Round 16 & Level 2 & Level 3 & Level 2 & Level 3 & Level 2 & Level 2 & Level 2 & Level 1 & 31 \\
\hline Round 17 & Level 2 & Level 3 & Level 2 & Level 3 & Level 2 & Level 2 & Level 2 & Level 2 & 30 \\
\hline Round 18 & Level 2 & Level 3 & Level 2 & Level 3 & Level 2 & Level 2 & Level 2 & Level 3 & 29 \\
\hline Round 19 & Level 2 & Level 3 & Level 2 & Level 3 & Level 2 & Level 2 & Level 3 & Level 3 & 28 \\
\hline Round 20 & Level 2 & Level 3 & Level 3 & Level 3 & Level 2 & Level 2 & Level 3 & Level 3 & 27 \\
\hline Round 21 & Level 2 & Level 3 & Level 3 & Level 3 & Level 3 & Level 2 & Level 3 & Level 3 & 25 \\
\hline Round 22 & Level 3 & Level 3 & Level 3 & Level 3 & Level 3 & Level 3 & Level 3 & Level 3 & 23 \\
\hline
\end{tabular}


From the tables above it is possible to observe where in the iterative modelling process each retrofit strategy and level of implementation was selected. For the Century Home and Century-Semi Home, initially upgrading the furnace and increasing air tightness provided significant energy savings with the least amount of cost. Basement envelope parameters were then upgraded followed by above grade walls and the roof. It is interesting to note that window upgrades were not required to meet the first energy targets and were only upgraded during the final rounds to meet the EnerPHit EQUIV targets.

The War Time Home followed a different path than the Century Home and Century-Semi Home with roof and ventilation upgrades being made early in the process and air sealing upgrades being made later in the process. This was due to the low cost of increasing the attic insulation and the greater initial air tightness. Also, as the walls of the War Time Home had greater insulation than the other archetypes, the energy savings from wall retrofits were less pronounced, therefore lower cost upgrades such as ventilation were initially more attractive from a cost/benefit standpoint. The War Time Home was similar to the other archetypes in that envelope and furnace upgrades contributed the most to energy intensity reductions and that window upgrades were not a priority. This is because of the high cost of the windows relative to the energy savings.

It can also be seen from Tables 28 to 30 that not all upgrades were required for the Century Home and the Century-Semi home to meet the targets, whereas all upgrades were required for the War Time Home to meet the targets. The Century Home only required Level 3 upgrades for the walls, roof, and air sealing. The Century-Semi was similar although it required greater basement and slab upgrades to meet the 
EnerPHit ${ }_{E Q U I V}$ target. The reason the War Time Home required a greater number of upgrades was likely the small size and compactness of the home. Smaller homes, like the War Time Home, have a large surface area to volume ratio, meaning that the conditioned volume of air within the building is small relative to the exterior wall/roof areas through which energy is transferred. While smaller homes will tend to use less energy overall, they tend to be less efficient from an energy intensity standpoint.

Additionally of interest is the "diminishing return point" (DRP) for each retrofit strategy which is defined here as the point after which increasing the level of implementation, and therefore cost, begins to yield minimal benefits from an energy perspective. The levels of implementation required to meet the performance targets for each retrofit strategy are summarized in Table 31 below:

Table 31: Retrofit Level Required to Meet Performance Targets with Diminishing Return Point Highlighted

\begin{tabular}{|l|c|c|c|c|c|c|c|c|}
\hline & \multicolumn{7}{|c|}{ Level Required to Meet Targets } \\
\hline Retrofit & Walls & Roof & Basement & Slab & Windows & Air Sealing & Furnace & HRV/ERV \\
\hline Century Home & Level 3 & Level 3 & Level 1 & Level 1 & Level 2 & Level 3 & Level 2 & Level 1 \\
\hline Century-Semi Home & Level 3 & Level 3 & Level 2 & Level 3 & Level 2 & Level 3 & Level 2 & Level 1 \\
\hline War Time Home & Level 3 & Level 3 & Level 3 & Level 3 & Level 3 & Level 3 & Level 3 & Level 3 \\
\hline
\end{tabular}

The implementation levels highlighted in green did not exceed the DRP indicating that greater levels of implementation were possible while still exhibiting a favourable cost/benefit. The implementation levels highlighted in red exceeded the DRP indicating that cost/benefit of these strategies was not optimized. The strategies that exceeded the DRP often did so due to their low cost relative to other strategies. Table 32 below, showing Round 13 of the Century-Semi Home modelling, provides an example: 
Table 32: Example of Exceeding DRP

\begin{tabular}{|l|r|r|c|r|}
\cline { 2 - 5 } \multicolumn{1}{c|}{} & \multicolumn{4}{c|}{ Round 13 } \\
\hline Retrofit & Intensity & \multicolumn{1}{c|}{ Saved } & Cost & $\$ /$ Saved \\
\hline Walls & 46 & 7 & $\$ 16,993$ & 2428 \\
\hline Roof & 52 & 1 & $\$ 11,680$ & 11680 \\
\hline Basement Walls & 52 & 1 & $\$ 2,979$ & 2979 \\
\hline Slab & & & & \\
\hline Windows & 48 & 5 & $\$ 11,586$ & 2317 \\
\hline Air Sealing & & & & \\
\hline Heating/Cooling & 52 & 1 & $\$ 4,333$ & 4333 \\
\hline Ventilation & 52 & 1 & $\$ 2,125$ & 2125 \\
\hline
\end{tabular}

In this example, Ventilation was selected by the "rule" as it demonstrates the lowest cost per unit of energy saved, however only one unit of energy was saved. The reason Ventilation was selected was because it had a lower capital cost relative to other strategies. The "rule" forced Ventilation to be upgraded beyond its DRP, instead of selecting a strategy that saved significantly more energy such as the Wall upgrade. Considering the DRP highlighted a weakness in the retrofit decision making "rule" indicating that great care must be taken when selecting the "rule" in order to ensure that appropriate retrofit decisions are being made.

\subsection{Estimating Capital Costs to Reach Energy Intensity Targets}

Once the retrofits and levels of implementation that were required to meet the targets were identified, the capital costs of achieving the targets could be calculated utilizing the average capital costs of the retrofit strategies as ascertained from R.S. Means and the Toronto contractors. The capital cost related only to materials and labour and does not include design, consulting, or inspections. The sensitivity of each retrofit strategy was also determined on a per round basis. The sensitivity indicates the cost range within which the retrofit would still be most attractive option based on 
cost/benefit. The incremental cost and sensitivity for each round of retrofitting is shown

in Tables 33 to 35 below:

Table 33: Century Home Retrofit Cost Increments by Round

\begin{tabular}{|c|c|c|c|c|c|c|c|c|c|c|}
\hline Retrofit & Walls & Roof & Basement & Slab & Windows & Air Sealing & Furnace & HRV/ERV & Sensitivity & \$ Total Package \\
\hline Round 1 & 0 & 0 & 0 & 0 & 0 & 0 & $\$ 3,150$ & 0 & $\$ 3,150-\$ 3,841$ & $\$ \quad 3,150$ \\
\hline Round 2 & 0 & 0 & 0 & 0 & 0 & $\$ 1,335$ & $\$ 3,150$ & 0 & $\$ 1,335-\$ 2,534$ & 4,485 \\
\hline Round 3 & 0 & 0 & 4,340 & 0 & 0 & 1,335 & $\$ 3,150$ & 0 & $\$ 4,340-\$ 4,680$ & 8,825 \\
\hline Round 4 & 0 & 0 & $\$ 4,340$ & $\$ 5,065$ & 0 & 1,335 & $\$ 3,150$ & 0 & $\$ 5,065-\$ 13,100$ & 13,890 \\
\hline Round 5 & $\$ 21,079$ & 0 & $\$ 4,340$ & $\$ 5,065$ & 0 & $\$ 1,335$ & $\$ 3,150$ & 0 & $\$ 21,079-\$ 21,996$ & 34,969 \\
\hline Round 6 & $\$ 21,585$ & 0 & $\$ 4,340$ & $\$ 5,065$ & 0 & $\$ 1,335$ & $\$ 3,150$ & 0 & $\$ 21,585-\$ 22,900$ & 35,475 \\
\hline Round 7 & $\$ 21,585$ & $\$ 9,878$ & 4,340 & $\$ 5,065$ & 0 & $\$ 1,335$ & $\$ 3,150$ & 0 & $\$ 9,878-\$ 16,497$ & 45,353 \\
\hline Round 8 & $\$ 21,585$ & $\$ 11,398$ & 4,340 & $\$ 5,065$ & 0 & 1,500 & $\$ 3,150$ & 0 & $\$ 12,898-\$ 20,774$ & 47,039 \\
\hline Round 9 & $\$ 21,585$ & $\$ 11,398$ & 4,340 & $\$ 5,065$ & 0 & 1,500 & $\$ 3,665$ & 0 & $\$ 3,665-\$ 4,250$ & 47,554 \\
\hline Round 10 & $\$ 21,585$ & $\$ 11,398$ & 4,340 & $\$ 5,065$ & 0 & 1,500 & $\$ 3,665$ & $\$ 2,125$ & $\$ 2,125-\$ 2,167$ & 49,678 \\
\hline Round 11 & $\$ 23,226$ & $\$ 11,398$ & $\$ 4,340$ & 5,065 & 0 & 1,500 & $\$ 3,665$ & $\$ 2,125$ & $\$ 23,226-\$ 24,680$ & 51,319 \\
\hline Round 12 & $\$ 23,226$ & $\$ 16,563$ & 4,340 & $\$ 5,065$ & 0 & 1,500 & $\$ 3,665$ & $\$ 2,125$ & $\$ 18,063-\$ 18,510$ & 56,483 \\
\hline Round 13 & $\$ 23,226$ & $\$ 16,563$ & 4,340 & $\$ 5,065$ & $\$ 18,509$ & 1,500 & $\$ 3,665$ & $\$ 2,125$ & $\$ 18,509-\$ 22,792$ & 74,992 \\
\hline Round 14 & $\$ 23,226$ & $\$ 16,563$ & 4,340 & 5,065 & $\$ 20,597$ & 1,500 & $\$ 3,665$ & $\$ 2,125$ & $\$ 20,597-\$ 29,304$ & 77,080 \\
\hline
\end{tabular}

Table 34: Century-Semi Home Retrofit Cost Increments by Round

\begin{tabular}{|c|c|c|c|c|c|c|c|c|c|c|}
\hline Retrofit & Walls & Roof & Basement & Slab & Windows & Air Sealing & Furnace & HRV/ERV & Sensitivity & \$Total Package \\
\hline Round 1 & 0 & 0 & 0 & 0 & 0 & 0 & $\$ 3,150$ & 0 & $\$ 3,150-\$ 3,350$ & $\$ \quad 3,150$ \\
\hline Round 2 & 0 & 0 & 0 & 0 & 0 & $\$ 1,205$ & $\$ 3,150$ & 0 & $\$ 1,205-\$ 1,638$ & 4,355 \\
\hline Round 3 & 0 & 0 & 0 & $\$ 4,176$ & 0 & $\$ 1,205$ & $\$ 3,150$ & 0 & $\$ 4,176-\$ 6,050$ & 8,531 \\
\hline Round 4 & 0 & 0 & $\$ 2,749$ & $\$ 4,176$ & 0 & 1,205 & $\$ 3,150$ & 0 & $\$ 2,749-\$ 10,934$ & 11,279 \\
\hline Round 5 & $\$ 15,414$ & 0 & $\$ 2,749$ & $\$ 4,176$ & 0 & 1,205 & $\$ 3,150$ & 0 & $\$ 15,414-\$ 16,244$ & 26,693 \\
\hline Round 6 & $\$ 15,838$ & 0 & $\$ 2,749$ & $\$ 4,176$ & 0 & 1,205 & $\$ 3,150$ & 0 & $\$ 15,838-\$ 16,126$ & 27,117 \\
\hline Round 7 & $\$ 15,838$ & $\$ 6,975$ & $\$ 2,749$ & $\$ 4,176$ & 0 & $\$ 1,205$ & $\$ 3,150$ & 0 & $\$ 6,975-\$ 10,076$ & 34,092 \\
\hline Round 8 & $\$ 15,838$ & $\$ 8,010$ & $\$ 2,749$ & $\$ 4,176$ & 0 & 1,500 & $\$ 3,150$ & 0 & $\$ 9,510-\$ 28,106$ & 35,422 \\
\hline Round 9 & $\$ 15,838$ & $\$ 8,010$ & $\$ 2,749$ & $\$ 4,176$ & 0 & $\$ 1,500$ & $\$ 3,665$ & 0 & $\$ 3,665-\$ 5,793$ & 35,937 \\
\hline Round 10 & $\$ 15,838$ & $\$ 8,010$ & $\$ 2,749$ & $\$ 4,418$ & 0 & 1,500 & $\$ 3,665$ & 0 & $\$ 4,418-\$ 4,634$ & 36,179 \\
\hline Round 11 & $\$ 15,838$ & $\$ 8,010$ & $\$ 2,749$ & $\$ 4,582$ & 0 & 1,500 & $\$ 3,665$ & 0 & $\$ 4,582-\$ 5,793$ & 36,344 \\
\hline Round 12 & $\$ 15,838$ & $\$ 8,010$ & $\$ 2,879$ & $\$ 4,582$ & 0 & 1,500 & $\$ 3,665$ & 0 & $\$ 2,879-\$ 3,862$ & 36,474 \\
\hline Round 13 & $\$ 15,838$ & $\$ 8,010$ & $\$ 2,879$ & $\$ 4,582$ & 0 & 1,500 & $\$ 3,665$ & $\$ 2,125$ & $\$ 2,125-\$ 2,317$ & 38,599 \\
\hline Round 14 & $\$ 15,838$ & $\$ 8,010$ & $\$ 2,879$ & $\$ 4,582$ & $\$ 11,586$ & 1,500 & 3,665 & 2,125 & $\$ 11,586-\$ 12,140$ & 50,185 \\
\hline Round 15 & $\$ 15,838$ & $\$ 8,010$ & 2,879 & $\$ 4,582$ & $\$ 12,833$ & 1,500 & $\$ 3,665$ & 2,125 & $\$ 12,833-\$ 15,104$ & 51,432 \\
\hline Round 16 & $\$ 16,993$ & $\$ 8,010$ & 2,879 & 4,582 & $\$ 12,833$ & 1,500 & 3,665 & 2,125 & $\$ 16,993-\$ 26,811$ & 52,587 \\
\hline Round 17 & $\$ 16,993$ & $\$ 11,680$ & $\$ 2,879$ & 4,582 & $\$ 12,833$ & 1,500 & 3,665 & 2,125 & $\$ 13,180$ - \$23,832 & 56,257 \\
\hline
\end{tabular}


Table 35: War Time Home Retrofit Cost Increments by Round

\begin{tabular}{|c|c|c|c|c|c|c|c|c|c|c|}
\hline Retrofit & Walls & Roof & Basement & Slab & Windows & Air Sealing & Furnace & $\mathrm{HRV} / \mathrm{ERV}$ & Sensitivity & \$Total Package \\
\hline Round 1 & 0 & $\$ 1,890$ & 0 & 0 & 0 & \begin{tabular}{|l|}
0 \\
\end{tabular} & 0 & 0 & $\$ 1,890-\$ 2,192$ & $\$ \quad 1,890$ \\
\hline Round 2 & 0 & $\$ 1,890$ & 0 & 0 & 0 & 0 & $\$ 3,150$ & 0 & $\$ 3,150-\$ 4,400$ & 5,040 \\
\hline ound 3 & 0 & $\$ 1,890$ & 0 & $\$ 5,402$ & 0 & 0 & 3,150 & 0 & 57 &, 442 \\
\hline Round 4 & 0 & $\$ 1,890$ & $\$ 6,467$ & $\$ 5,402$ & & 0 & 3,150 & 0 & $\$ 6,467-\$ 10,944$ & 16,909 \\
\hline Roun & 0 & $\$ 1,890$ & $\$ 6,467$ & $\$ 5,402$ & 0 & 0 & 3,150 & $\$ 2,125$ & $\$ 2$ & 034 \\
\hline Round 6 & $\$ 8,488$ & $\$ 1,890$ & $\$ 6,467$ & $\$ 5,402$ & 0 & 0 & 3,150 & 2,125 & $\$ 8,488-\$ 8,865$ & 27,521 \\
\hline Round 7 & $\$ 10,470$ & $\$ 1,890$ & $\$ 6,467$ & $\$ 5,402$ & 0 & 0 & 3,150 & 2,125 & $\$ 10,470-\$ 13,002$ & 29,504 \\
\hline Round 8 & 10,470 & $\$ 1,890$ & $\$ 6,467$ & $\$ 5,402$ & 0 & 1,182 & 3,150 & 2,125 & $\$ 1,182-\$ 2,444$ & 30,686 \\
\hline Rour & $\$ 10,470$ & $\$ 1,890$ & $\$ 6,467$ & $\$ \quad 5,402$ & 0 & 1,1 & 3,665 & 2,125 & $\$ 3$, & 201 \\
\hline d 10 & $\$ 10,470$ & $\$ 1,890$ & $\$ 6,467$ & $\$ 5,402$ & $\$ 13,029$ & 1,182 & 3,665 & 2,125 & $\$ 13,0$ & 231 \\
\hline Round 11 & $\$ 10,470$ & $\$ 1,890$ & $\$ 6,467$ & $\$ 5,402$ & $\$ 14,471$ & 1,182 & 3,665 & 2,125 & $\$ 14$, & 672 \\
\hline Round 12 & $\$ 10,470$ & $\$ 2,155$ & $\$ 6,467$ & $\$ 5,402$ & $\$ 14,471$ & 1,500 & 3,665 & 2,125 & $\$ 3,6$ & 255 \\
\hline d 13 & $\$ 10,470$ & $\$ 2,610$ & $\$ 6,467$ & $\$ \quad 5,402$ & $\$ 14,471$ & 1,500 & 3,665 & 2,125 & $\$ 2$ & 5,710 \\
\hline Round 14 & $\$ 10,470$ & $\$ 2,610$ & $\$ 6,467$ & $\$ 5,720$ & $\$ 14,471$ & 1,500 & 3,665 & 2,125 & $-\$ 6$ & 47,028 \\
\hline Round 15 & $\$ 10,470$ & $\$ 2,610$ & $\$ 6,467$ & $\$ \quad 5,937$ & & 1,500 & 3,665 & & $-\$ 9$ & 245 \\
\hline Round 16 & $\$ 10,470$ & $\$ 2,610$ & $\$ 6,699$ & $\$ \quad 5,937$ & $\$ 14,471$ & 1,500 & 3,665 & 2,125 & $-\$ 9$ & 7,477 \\
\hline Round 17 & $\$ 10,470$ & $\$ 2,610$ & $\$ 6,699$ & $\$ \quad 5,937$ & $\$ 14,471$ & 1,500 & 3,665 & 3,256 & $5-\$ 4$ & 48,608 \\
\hline Round 18 & $\$ 10,470$ & $\$ 2,610$ & 6,699 & $\$ 5,937$ & $\$ 14,471$ & 1,500 & 3,665 & 3,726 & $\$ 3,7$ & 49,078 \\
\hline Round 19 & $\$ 10,470$ & $\$ 2,610$ & 6,699 & $\$ 5,937$ & $\$ 14,471$ & 1,500 & 4,333 & 3,726 & $3-\$ 6$ & 49,746 \\
\hline Round 20 & $\$ 10,470$ & $\$ 2,610$ & 6,878 & 5,937 & $\$ 14,471$ & 1,500 & 4,333 & 3,726 & $8-\$ 11,199$ & 49,925 \\
\hline Round 21 & $\$ 10,470$ & $\$ 2,610$ & 6,878 & 5,937 & $\$ 17,067$ & 1,500 & 4,333 & 3,726 & $\$ 17,067-\$ 22,398$ & 52,522 \\
\hline Round 22 & $\$ 11,199$ & $\$ 2,610$ & 6,878 & 5,937 & $\$ 17,067$ & 1,500 & 4,333 & 3,726 & $\$ 12,699-N / A$ & 53,250 \\
\hline
\end{tabular}

The sensitivity analysis highlights the importance of attaining accurate cost data. In some cases the difference between the selected retrofit strategy and the next most attractive strategy, based on the cost/benefit, was small. This means that a minor variation in cost would have resulted in a different strategy being selected. This is important for the Century Home and the Century-Semi Home as not all strategies were required to meet the targets, therefore a different set of strategies may have emerged if costs varied outside of the sensitivity range. This is less important for the War Time Home as all strategies were utilized to meet the targets; therefore the order of selection was not as important.

The cost for each archetype to meet the performance targets is summarized in Table 36 below: 
Table 36: Capital Cost to Reach Performance Targets for Each Archetype

\begin{tabular}{|l|ll|lr|}
\hline Archetype & \multicolumn{2}{|c|}{$75 \mathrm{kWh} / \mathrm{m}^{2}$} & \multicolumn{2}{|l|}{ EnerPHit $_{\text {EQUIV }}$} \\
\hline Century & $\$$ & 45,353 & $\$$ & 77,080 \\
\hline Century-Semi & $\$$ & 35,422 & $\$$ & 56,257 \\
\hline War Time & $\$$ & 29,504 & $\$$ & 53,250 \\
\hline
\end{tabular}

In all cases the cost of retrofitting increases with the size of the building and the cost to meet the EnerPHit target.

To compare the cost/benefits of the retrofits to the baselines, a long term cost estimation was conducted. While it was discussed above that there is inherent uncertainty regarding future cost estimations and that homeowners typically rely on capital costs for decision making instead of future cost, this estimation was prepared for the purpose of comparison. The following parameters were utilized in the calculation:

- Retrofits were financed over a 25 year mortgage period (Canadian Bankers Association, 2013)

- The natural gas price for heating was $\$ 0.185 / \mathrm{m}^{3}$ (Ontario Energy Board, 2014)

- The average electricity price (on-peak, mid-peak, off-peak) for cooling was \$0.107/kWh (Toronto Hydro, 2014)

- The mortgage interest rate was assumed to be $4 \%$

- The currency inflation rate was 2.4\% (Trading Economics, 2014)

- Energy cost escalation was a low of $8 \%$ and a high of $12 \%$ per year corresponding to estimates utilized in the literature (Sustainable Buildings Canada 2012, Sharp 2012).

- Repair and maintenance costs for the homes were not considered 
The yearly cost of the retrofits financed over the 25 year period was calculated using Equation [6] below:

$$
P=L \frac{\left[C(1+C)^{N}\right]}{\left[(1+C)^{N}-1\right]}
$$

Where:

$\mathrm{P}=$ yearly payment

$\mathrm{N}=$ \# of payments

$\mathrm{L}=$ Loan

$\mathrm{C}=$ period interest rate

The yearly payments were then summed to determine the total capital cost over the 25 year financing period.

The total utility costs for heating and cooling over the 25 year financing period were then calculated utilizing an aggregated inflation rate. The aggregated inflation rate is the fuel price escalation rate less the currency inflation rate. This takes into consideration the rising cost of energy in relation to the increased purchasing power due to currency inflation. Two fuel price escalation scenarios were considered, $8 \%$ and $12 \%$ and compared. A sample utility cost calculation is presented in Table 37 below: 
Table 37: Utility Cost Estimation for the Century Home over 25 Year Period at a Fuel Price Escalation of 12\%

\begin{tabular}{|c|c|c|c|c|c|c|}
\hline \multirow[b]{2}{*}{ Year 1} & \multicolumn{2}{|c|}{$75 \mathrm{kWh} / \mathrm{m}^{2}$ Target } & \multicolumn{2}{|c|}{ EnerPHit $_{\text {EQUIV }}$ Target } & \multicolumn{2}{|c|}{ Baseline } \\
\hline & $\$$ & 359 & $\$$ & 141 & $\$$ & 940 \\
\hline Year 2 & $\$$ & 393 & $\$$ & 155 & $\$$ & 1,030 \\
\hline Year 3 & $\$$ & 431 & $\$$ & 169 & $\$$ & 1,129 \\
\hline Year 4 & $\$$ & 473 & $\$$ & 186 & $\$$ & 1,238 \\
\hline Year 5 & $\$$ & 518 & $\$$ & 203 & $\$$ & 1,356 \\
\hline Year 6 & $\$$ & 568 & $\$$ & 223 & $\$$ & 1,487 \\
\hline Year 7 & $\$$ & 622 & $\$$ & 244 & $\$$ & 1,629 \\
\hline Year 8 & $\$$ & 682 & $\$$ & 268 & $\$$ & 1,786 \\
\hline Year 9 & $\$$ & 747 & $\$$ & 294 & $\$$ & 1,957 \\
\hline Year 10 & $\$$ & 819 & $\$$ & 322 & $\$$ & 2,145 \\
\hline Year 11 & $\$$ & 898 & $\$$ & 353 & $\$$ & 2,351 \\
\hline Year 12 & $\$$ & 984 & $\$$ & 386 & $\$$ & 2,577 \\
\hline Year 13 & $\$$ & 1,079 & $\$$ & 424 & $\$$ & 2,824 \\
\hline Year 14 & $\$$ & 1,182 & $\$$ & 464 & $\$$ & 3,095 \\
\hline Year 15 & $\$$ & 1,296 & $\$$ & 509 & $\$$ & 3,392 \\
\hline Year 16 & $\$$ & 1,420 & $\$$ & 558 & $\$$ & 3,718 \\
\hline Year 17 & $\$$ & 1,556 & $\$$ & 611 & $\$$ & 4,075 \\
\hline Year 18 & $\$$ & 1,706 & $\$$ & 670 & $\$$ & 4,466 \\
\hline Year 19 & $\$$ & 1,869 & $\$$ & 734 & $\$$ & 4,895 \\
\hline Year 20 & $\$$ & 2,049 & $\$$ & 805 & $\$$ & 5,364 \\
\hline Year 21 & $\$$ & 2,245 & $\$$ & 882 & $\$$ & 5,879 \\
\hline Year 22 & $\$$ & 2,461 & $\$$ & 967 & $\$$ & 6,444 \\
\hline Year 23 & $\$$ & 2,697 & $\$$ & 1,059 & $\$$ & 7,063 \\
\hline Year 24 & $\$$ & 2,956 & $\$$ & 1,161 & $\$$ & 7,741 \\
\hline Year 25 & $\$$ & 3,240 & $\$$ & 1,273 & $\$$ & 8,484 \\
\hline Sum & $\$$ & 33,251 & $\$$ & 13,059 & $\$$ & 87,063 \\
\hline
\end{tabular}

The results of the long term cost estimations for each archetype at a fuel price escalation of $8 \%$ are outlined in Table 38 below:

Table 38: 25 Year Cost Estimation with a Fuel Price Escalation of 8\%

\begin{tabular}{|l|lc|lr|lr|}
\hline Century Home & \multicolumn{2}{|c|}{ Finance Cost } & \multicolumn{2}{|c|}{ Energy Cost } & \multicolumn{2}{|l|}{ Total 25 Year Cost } \\
\hline Baseline & $\$$ & - & $\$$ & 48,759 & $\$$ & 48,759 \\
\hline $75 \mathrm{kWh} / \mathrm{m}^{2}$ Target & $\$$ & 47,167 & $\$$ & 18,622 & $\$$ & 65,789 \\
\hline EnerPHit $_{\text {EQUIV }}$ Target & $\$$ & 80,163 & $\$$ & 7,314 & $\$$ & 87,477 \\
\hline
\end{tabular}




\begin{tabular}{|l|cc|cr|rr|}
\hline Century-Semi Home & \multicolumn{2}{|c|}{ Finance Cost } & \multicolumn{2}{|c|}{ Energy Cost } & Total 25 Year Cost \\
\hline Baseline & $\$$ & - & $\$$ & 38,488 & $\$$ & 38,488 \\
\hline $75 \mathrm{kWh} / \mathrm{m}^{2}$ Target & $\$$ & 36,839 & $\$$ & 9,959 & $\$$ & 46,798 \\
\hline EnerPHit $_{\text {EQUIV }}$ Target & $\$$ & 58,507 & $\$$ & 4,772 & $\$$ & 63,279 \\
\hline
\end{tabular}

\begin{tabular}{|l|lc|lr|lr|}
\hline War Time Home & \multicolumn{2}{|c|}{ Finance Cost } & \multicolumn{2}{|l|}{ Energy Cost } & Total 25 Year Cost \\
\hline Baseline & $\$$ & - & $\$$ & 25,936 & $\$$ & 25,936 \\
\hline $75 \mathrm{kWh} / \mathrm{m}^{2}$ Target & $\$$ & 30,684 & $\$$ & 9,492 & $\$$ & 40,176 \\
\hline EnerPHit $_{\text {EQUIV }}$ Target & $\$$ & 55,380 & $\$$ & 4,202 & $\$$ & 59,582 \\
\hline
\end{tabular}

In each of the scenarios presented above, the baseline is the most attractive from a cost/benefit perspective utilizing the fuel price escalation rate of $8 \%$. The results of utilizing a fuel price escalation of $12 \%$ while keeping all other parameters constant are shown in Table 39 below:

Table 39: 25 Year Cost Estimation with a Fuel Price Escalation of 12\%

\begin{tabular}{|l|cc|cr|lr|}
\hline Century Home & \multicolumn{2}{|c|}{ Finance Cost } & \multicolumn{2}{|l|}{ Energy Cost } & Total 25 Year Cost \\
\hline Baseline & $\$$ & - & $\$$ & 87,063 & $\$$ & 87,063 \\
\hline $75 \mathrm{kWh} / \mathrm{m}^{2}$ Target & $\$$ & 47,167 & $\$$ & 33,251 & $\$$ & 80,418 \\
\hline EnerPHit $_{\text {EQUIV }}$ Target & $\$$ & 80,163 & $\$$ & 13,059 & $\$$ & 93,222 \\
\hline
\end{tabular}

\begin{tabular}{|l|cc|cr|lr|}
\hline Century-Semi Home & \multicolumn{2}{|c|}{ Finance Cost } & Energy Cost & Total 25 Year Cost \\
\hline Baseline & $\$$ & - & $\$$ & 68,724 & $\$$ & 68,724 \\
\hline $75 \mathrm{kWh} / \mathrm{m}^{2}$ Target & $\$$ & 36,839 & $\$$ & 17,783 & $\$$ & 54,622 \\
\hline EnerPHit $_{\text {EQuIV }}$ Target & $\$$ & 58,507 & $\$$ & 8,521 & $\$$ & 67,028 \\
\hline
\end{tabular}

\begin{tabular}{|l|lc|lr|lr|}
\hline War Time Home & \multicolumn{2}{|c|}{ Finance Cost } & \multicolumn{2}{|l|}{ Energy Cost } & Total 25 Year Cost \\
\hline Baseline & $\$$ & - & $\$$ & 46,310 & $\$$ & 46,310 \\
\hline $75 \mathrm{kWh} / \mathrm{m}^{2}$ Target & $\$$ & 30,684 & $\$$ & 16,949 & $\$$ & 47,633 \\
\hline EnerPHit $_{\text {EQUIV Target }}$ & $\$$ & 55,380 & $\$$ & 7,502 & $\$$ & 62,882 \\
\hline
\end{tabular}

In this scenario some of the retrofit options became more attractive from a cost/benefit perspective compared to the baseline case. The $75 \mathrm{kWh} / \mathrm{m}^{2}$ target became more attractive for both the Century and the Century-Semi and the EnerPHit $t_{\text {EQUIV }}$ target became more attractive for the Century-Semi. The baseline case was still the most attractive for the War Time Home. 
The researcher acknowledges that many assumptions were made in this analysis and that significant uncertainty exists in attempting to quantify the future economic conditions of buildings. What this analysis underlines however is that despite the high capital costs of implementing the retrofits, under certain economic conditions the retrofits can become more cost effective than the baseline. While past research has indicated that homeowners tend to make retrofit decisions based on initial capital costs (Aydinalp et al., 2001), the results of this research indicate that homeowners should take into consideration long term capital costs.

\subsection{Phase 3 Summary}

The retrofit strategy determination sought to develop a sampling of the possible retrofits that could be applied to the archetypes. While the study was limited to building envelope and HVAC retrofits, there are many other strategies that could be employed to reduce building energy use, for example site shading and passive solar strategies, or to produce energy such as renewable energy systems. Additionally, the retrofits focused on specific assemblies, insulation types, and insulation thicknesses selected from among the wide array of possibilities. The selected retrofit strategies, levels of implementation, and assemblies represent a single example of how to apply deep energy retrofits to the archetypal homes with many other potentially successful options being possible.

The hygrothermal analysis outlined some of the challenges that can be faced when developing retrofit assemblies. As many older homes rely on natural air infiltration and exfiltration to avoid moisture damage and deterioration, adding insulation and air 
sealing the envelope can have a detrimental effect on moisture performance. The assemblies in this research largely appeared to experience moisture drive from the exterior of the assembly (inwards from the cladding). Therefore hygroscopic insulation materials such as cellulose could not be placed next to the brick cladding. In most cases a spray foam, XPS, or mineral wool layer was needed to separate the cellulose from the brick cladding in order to block moisture or allow it to drain. The wood frame wall retrofit assemblies initially had a polyethylene vapour retarder on the interior side of the insulation which caused significant moisture issues as the inward driving moisture was maintained in the wall assembly by the vapour retarder. The results of the hygrothermal analysis highlighted the need for careful retrofit assembly planning to ensure that moisture does not infiltrate the assembly and that any moisture that does enter is allowed to dry either to the interior, exterior, or both. Throughout the analysis alterations were made to the assemblies which ensured that they performed better than the baseline assemblies from a hygrothermal perspective.

The retrofit cost analysis provided a first step in quantifying the cost of retrofits for single family homes in urban Toronto. In general there appeared to be a convergence of estimates for the retrofit strategies between the three contractors and R.S. Means, however some outliers representing high and low estimates were present. As outlined above, while the cost estimations were relatively similar, they were often separated by thousands of dollars and while this may appear similar when considering retrofits costing tens of thousands of dollars, for a homeowner looking to finance a retrofit these differences could be considerable. The cost estimations that were collected proved useful in the retrofit decision making process, however the sample size was small. In 
order to truly reflect an average cost for the retrofit strategies many more sources should be sought.

Blaszak and Richman (2010) had found that walls were the greatest source of heat loss in the Century Home followed by ventilation, foundation walls, and windows. This study confirmed that the walls were the greatest source of heat loss; however it differed in that it found ventilation and windows to be less of a priority for retrofitting. For the War Time Home, Blaszak and Richman (2013) found that heat loss was shared relatively equally between the walls, foundation, ventilation, and windows. The results of this study confirmed the results that the War Time Home shares heat loss more evenly than the Century Home, however again this study did not find ventilation and windows to be priority retrofits. Additionally Blaszak and Richman (2013) indicated that roofs were not a priority retrofit in either of the two housing types, whereas this study found roofs to be a higher priority. These differences can be attributed somewhat to the differences in the geometry and features of the archetypal homes considered in the research, but mostly to differences in modelling methodology as this study utilized EnergyPlus software whereas Blaszak and Richman (2013) utilized HOT2000.

The research was successful in achieving the energy intensity targets for deep energy retrofitting. While each building followed a slightly different approach to meet the targets, the retrofits that contributed to the greatest reduction in energy intensity were similar. In all cases furnace efficiency and the building envelope components were responsible for the majority of the energy consumption. It was particularly interesting to find that windows did not provide an attractive cost/benefit in the research. While the RSI value of windows is significantly less than a wall assembly, windows were not found 
to be a large source of heat loss in the archetypal homes and were one of the more cost intensive retrofits. As similar retrofits were applied to all three of the archetypes, the differences in the retrofit strategies and levels of implementation required to meet the targets can be attributed to the geometry of the archetypes. The War Time Home has a larger surface area to volume ratio than the other two archetypes and is therefore likely to be less energy efficient which was shown by the level of retrofits required to reach the targets. There were also differences in geometry between the Century Home and the Century-Semi that can explain the differences in the retrofits required to meet the targets. The Century-Semi had an L-shaped geometry whereas the Century Home was rectangular. This geometrical difference proved to be a larger factor in increasing energy use in the Century-Semi than the party wall was in decreasing energy use compared to the Century Home.

While the retrofits were successful in achieving the target energy intensities there were significant drawbacks. First, the capital cost of the retrofits would likely be prohibitive for the average homeowner with a range of $\$ 30,000$ to $\$ 80,000$ depending on the housing type and target achieved. Additionally, as the retrofits were applied to the interior of the homes, significant floor space loss was experienced. The floor space lost due to the application of the retrofits was 15 to $40 \mathrm{~m}^{2}$ for the Century Home, 14 to $35 \mathrm{~m}^{2}$ for the Century-Semi Home, and 5 to $12 \mathrm{~m}^{2}$ for the War Time Home. This loss of floor space would likely be a significant drawback for a homeowner. 


\subsection{Summary of Process for Retrofit Development and Analysis}

The following is a summary of the process for developing and analyzing deep energy retrofits for specific housing archetypes that was developed in this study.

\subsubsection{Select Archetype for Study and Performance Target}

Any housing archetype and location can be selected for study utilizing the process. The process can be applied to single-detached, semi-detached, and row houses. Any energy use target can be selected for the archetype.

\subsubsection{Collect Representative Data for the Archetype}

Data must be collected for the archetype in order to develop the baseline energy model. The required data is shown in Appendix $\mathrm{C}$ and is summarized below:

- Geometry

- Building footprint

- Storey height

- Dimensions

- Glazing and doors

- Floor plan

- Shading devices and overhangs

- Envelope

- Materials and material properties

- Window constructions including frame, divider, reveal, and sill

- Door constructions

- Air tightness

- Basement

- Basement materials and material properties

- Wall and floor thicknesses

- Depth of wall below grade

- Internal Gains

- Types of major appliances

- Occupancy schedules 
- HVAC

- Thermostat location

- Type of heating and cooling

- Total ventilation flow rate

\subsubsection{Prepare Baseline Energy Model}

The baseline energy model preparation methodology outlined in this study followed the calibrated model development procedure by Zirnhelt (2013) and refers specifically to EnergyPlus software.

\subsubsection{Select Retrofit Strategies}

This process has been developed to allow any retrofit strategy to be incorporated. This includes but is not limited to: building envelope components, air sealing, and HVAC systems.

\subsubsection{Perform Hygrothermal Analysis of Building Envelope Retrofits}

Perform hygrothermal analysis of the building envelope retrofit assemblies, if included, considering both condensation and decay hours. Compare the results to the base case assemblies of the archetype. If the retrofit assemblies result in greater condensation and decay hours than the baseline, modify the assemblies to ensure condensation and decay hours are below that of the baseline.

\subsubsection{Perform Cost Estimation of the Retrofits}

Estimate the cost of the retrofits through the use of R.S. Means Construction Cost Data or through local contractors. Costs should be estimated through the use of multiple sources in order to determine an average cost for each retrofit strategy. 


\subsubsection{Select "Rule" for Retrofit Decision Making}

The "rule" should be selected to take into consideration the retrofitting goals. For example if energy use reduction is the goal of the study, the "rule" could be to select the retrofits that result in the greatest energy use reduction. Careful attention should be paid when selecting the rule to ensure that all retrofit goals are taken into consideration.

\subsubsection{Perform Modelling: Brute Force Sequential Search Method}

Model each retrofit strategy utilizing the Brute Force Sequential Search Method outlined in this study. In each round, select the most appropriate retrofit strategy based on the "rule". Continue modelling in an iterative manner until the retrofit performance target is met.

\subsubsection{Quantify Overall Retrofit Costs to Reach Performance Target}

Quantify the total capital cost of the retrofit package that met the performance target.

The above steps outline the process, as developed in this study, to develop and analyze deep energy retrofits for specific housing archetypes. The process was meant to be applicable to any housing archetype in any geographical area. The process was also meant to be customizable to take into consideration a variety of retrofitting goals and performance targets. 


\section{Contributions and Further Research}

The significant contribution of this research was the establishment of a process through which to develop deep energy retrofits for specific housing archetypes or typologies. While this research focused on the downtown core of the City of Toronto and specifically Century, Century-Semi, and War Time Homes, the process could be applied to other municipalities and housing types. The research determined the type of building specific data that is required to develop accurate and calibrated baseline energy models for single family homes and provided a methodology for collecting the required data and carrying out the calibration based on ASHRAE Guideline 14. The research also provided a sample methodology for developing building envelope and HVAC retrofit strategies and for carrying out quantitative hygrothermal analyses on the envelope assemblies. A retrofit modelling and decision making process was proposed and initial work was conducted to estimate the cost of building retrofits and to take this into consideration when determining the most attractive retrofits.

While this work provided a framework for developing deep energy retrofits for specific housing types, many instances where the research could be further developed, expanded, or carried forward were identified. As mentioned above, the research methodology could be applied to other areas of Toronto as well as other municipalities and could focus on any single family housing archetype or typology. The research could be expanded by considering 70s OBC and Modern homes; the other housing archetypes developed by Blaszak and Richman (2013). Additionally the research could be applied to row houses in addition to single-detached and semi-detached housing types. 
The observation study of the research demonstrated that the Toronto archetypes developed by Blaszak and Richman (2013) made up a slight majority of the homes in the target neighbourhoods. This means that within the designation of "Century Home" or "War Time Home" other additional building types and shapes are prevalent and could be developed as separate archetypes.

For this study many of the parameters of the individual archetypal homes were averaged together to determine typical values. While similarities were observed in the archetypal building parameters there was some variation. Additionally many homes had been renovated with additions or alterations, meaning that despite their similarities, each building was different. Therefore there is broad opportunity for deep energy retrofits to be explored through individual case studies instead of on a typical or archetypal basis. Furthermore this study assumed many building and site specific parameters to be constant for the archetypal homes. Site specific parameters such as shading and building orientation and building specific parameters such as geometry and window-to-wall ratio were kept constant. There is an opportunity to expand on the results by conducting a sensitivity analysis on these parameters to determine what affects they may have on the overall energy usage of the retrofitted homes.

The retrofit strategies and levels of implementation presented in this study provided a sampling of possible strategies and the researcher acknowledges that there are many additional methods for meeting the retrofit goals. As such, future research could explore additional retrofit strategies and levels of implementation, different material choices and constructions, and alternative HVAC equipment such as heat pumps or radiant floor heating. While this research did not find windows to be a priority 
upgrade for any of the archetypes, future research could attempt to quantify at what window-to-wall ratio windows would become a priority. Future research could also explore exterior retrofits which would not compromise the floor space of the homes and would lead to less disruption to the lives of building occupants. Additionally, this study found that the diminishing return points of the developed retrofits were sometimes exceeded. As such, future research could attempt to accurately define the diminishing return point for each retrofit strategy when applied to the housing archetypes and thereby determine what the optimal implementation level is for each retrofit and the resulting energy intensity.

The retrofit decision making process could be further explored by utilizing a different decision making process than the Brute Force Sequential Search Method or by conducting a full optimization. Finally, the retrofit cost analysis could be further developed by consulting with a greater number of contractors and by attempting to incorporate a more detailed analysis of future energy costs and savings. 


\section{Conclusions}

\subsection{Neighbourhoods and Archetypes}

Of the 23 urban Toronto neighbourhoods considered in the research scope, North Riverdale, Trinity-Bellwoods, Roncesvalles, Lawrence Park South, and Danforth Village were calculated to have the highest average energy intensity and were selected as the target neighbourhoods. It was determined that Century Homes and War Time Homes made up the majority of homes in most of the 23 neighbourhoods and therefore it would be prudent to focus deep energy retrofits on specific housing typologies as opposed to specific neighbourhoods. In this case the oldest of the archetypal homes developed by Blaszak and Richman (2013) were the most prevalent and the most energy intensive. Therefore retrofitting efforts should be directed towards the Century Home and War Time Home archetypes.

In three out of the five target neighbourhoods, semi-detached homes outnumbered single-detached homes and in one neighbourhood, row houses also outnumbered single-detached homes. Therefore greater effort should be focused towards deep energy retrofits for semi-detached and row housing typologies to reduce the energy use of single family homes in urban Toronto.

\subsection{Baseline Energy Model Data Collection and Preparation}

The majority of the homes inspected for data collection did not match the archetypal description of Blaszak and Richman (2013) despite being developed during the same period of construction. This means that within the designation of "Century Home" or "War Time Home" many different housing typologies exist and could be developed as separate archetypes. For the buildings that did match the archetypal 
descriptions of Blaszak and Richman (2013), the geometry and features were largely very similar. The exception to this being that many homes had been renovated with altered floor plans and HVAC systems or additions. This study determined that the archetypes as described by Blaszak and Richman (2013) were still relevant despite the number of additional typologies observed, as the archetypes were the majority housing types in the target neighbourhoods. The majority was slight, however and therefore additional archetypes should be developed in the future to represent a greater number of Toronto's urban single family homes.

The archetypal home data collected by Blaszak and Richman (2013) was not sufficient to create calibrated energy models utilizing EnergyPlus software. Additional data collection was required and was successfully collected through housing inspections and questionnaire surveys. The most significant data required in the inspections related to the building geometry, which had to be drawn accurately in three dimensions to develop the EnergyPlus models. This means that careful attention must be paid to documenting building dimensions as well as the sizes, shapes, and slopes of building features when conducting inspections. The baseline energy models prepared in this study utilizing EnergyPlus, appeared to be more accurate than the models prepared in HOT2000 by Blaszak and Richman (2013) as the EnergyPlus modelling results were significantly closer to the energy bill data than the HOT2000 modelling results for similar homes. This can be attributed to differences in the modelling software and methodology as this study utilized the calibration method developed by Zirnhelt (2013).

Calibrating the average archetypal energy models to actual building data provided some interesting insights. In order to calibrate an energy model utilizing 
ASHRAE Guideline 14 or other similar guidelines the energy model must be a representation of an actual building. In this study where the model was a theoretical building, calibrating to the statistical requirements of the guideline was possible, however the guideline specifically stated that the energy model should be a representation of an actual building not a theoretical one. Also, energy bills do not provide the level of data required for a detailed calibration. Electricity bills are not sufficient to separate cooling loads from home electricity usage and energy bills do not necessarily reflect actual monthly energy usage. Therefore more extensive real building monitoring should be utilized in order to collect the data required to calibrate an energy model.

\subsection{Deep Energy Retrofits}

The deep energy retrofit targets were achievable by each of the archetypes. The retrofit pathway followed by each of the archetypes showed some similarities and some differences. The Century Home and Century-Semi Home did not require all of the developed retrofits and levels of implementation to reach the targets whereas the War Time Home required Level 3 retrofits for all of the retrofit strategies. This was likely due to the greater surface area to volume ratio of the War Time Home compared to the other archetypes. Additionally, it was more difficult for the Century-Semi archetype to reach the targets compared to the Century Home which had largely similar initial features. This is likely attributable to geometrical differences between the rectangular Century Home and the L-shaped Century-Semi.

In all three instances the building envelope system and the furnace tended to have the greatest impact on energy intensity. Specifically upgrading the exterior walls 
and slab of the homes yielded the greatest energy use reduction for heating and cooling, however upgrading the roof yielded less of an impact on energy efficiency. Upgrading the efficiency of the furnace had the most attractive cost/benefit due to the relatively low cost of upgrading the furnace compared to that of the building envelope components. The windows presented the least attractive cost/benefit as they did not tend to be an area of high heat loss and had some of the highest capital costs. It is important to note however that none of the homes surveyed in the field study had the original single glazed windows, but had at some point upgraded to double glazed units.

The retrofit packages to meet the targets were associated with large capital costs and significant reductions in interior floor space. This may present barriers for the implementation of the retrofits by homeowners. However, it was also found that the diminishing return point was exceeded for many of the retrofits developed in the research; therefore a more economical retrofitting solution may be possible. The exceeded diminishing return point presented a limitation in the "rule" that was selected for retrofit decision making and indicated that care should be taken when selecting the "rule" to ensure that it does not illogically provide preference for certain retrofits over others.

Overall the results of this study indicated that significant energy efficiency gains are possible by retrofitting Century Homes, Century-Semi Homes, and War Time Homes in urban Toronto. The research outlined a process for developing and analyzing deep energy retrofits for specific housing typologies or archetypes and has shown that is it possible to retrofit the archetypal homes to achieve high levels of energy efficiency including a theoretical equivalency to the Passive House EnerPHit certification. While 
the capital costs of the retrofit packages to meet the targets were high, the costs are likely significantly less than the cost of demolishing and rebuilding the home to a similar level of energy efficiency. 


\section{Appendix A: Toronto Neighbourhood Profile Sample}

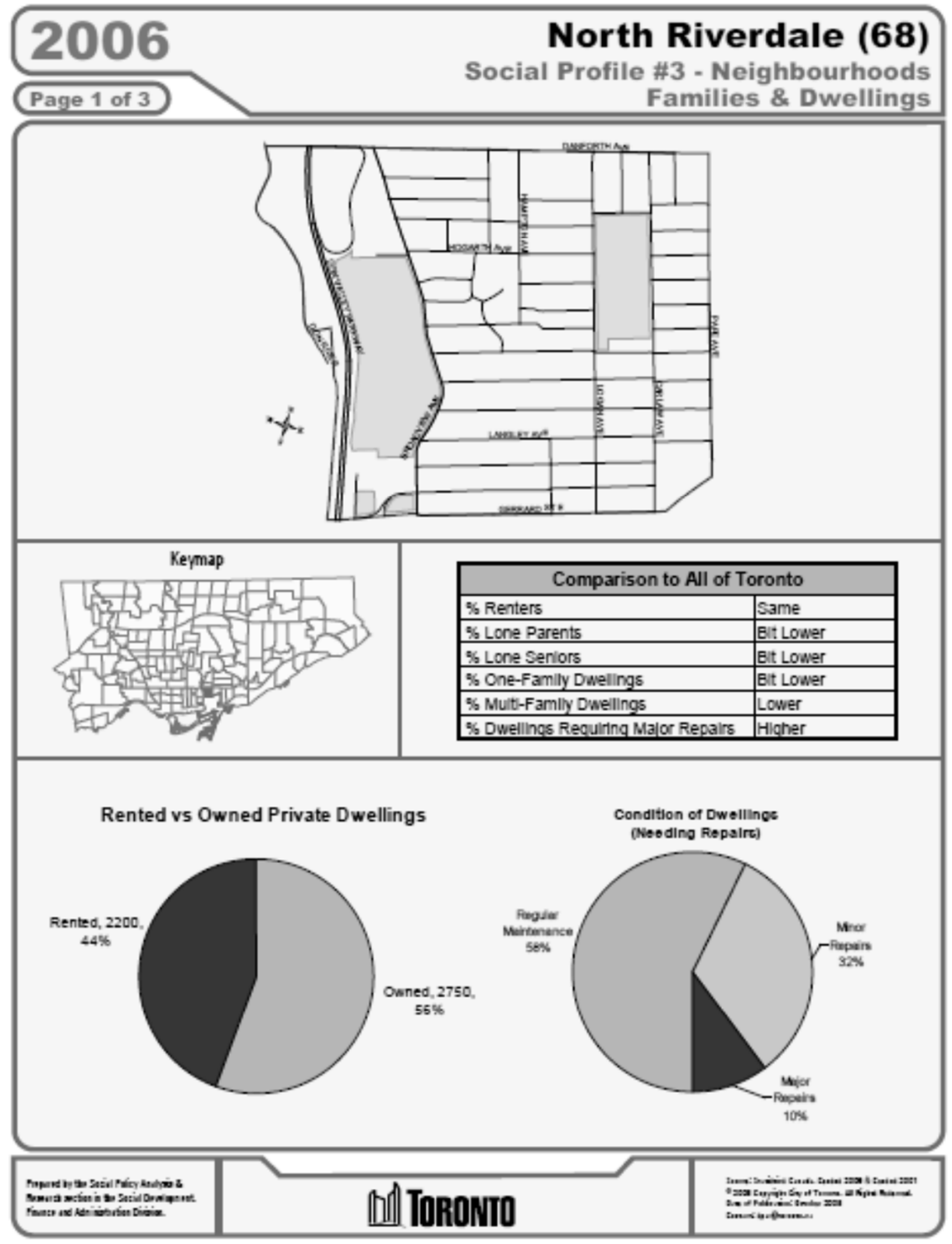




\section{North Riverdale (68) \\ Social Profile \#3 - Neighbourhoods Families \& Dwellings}
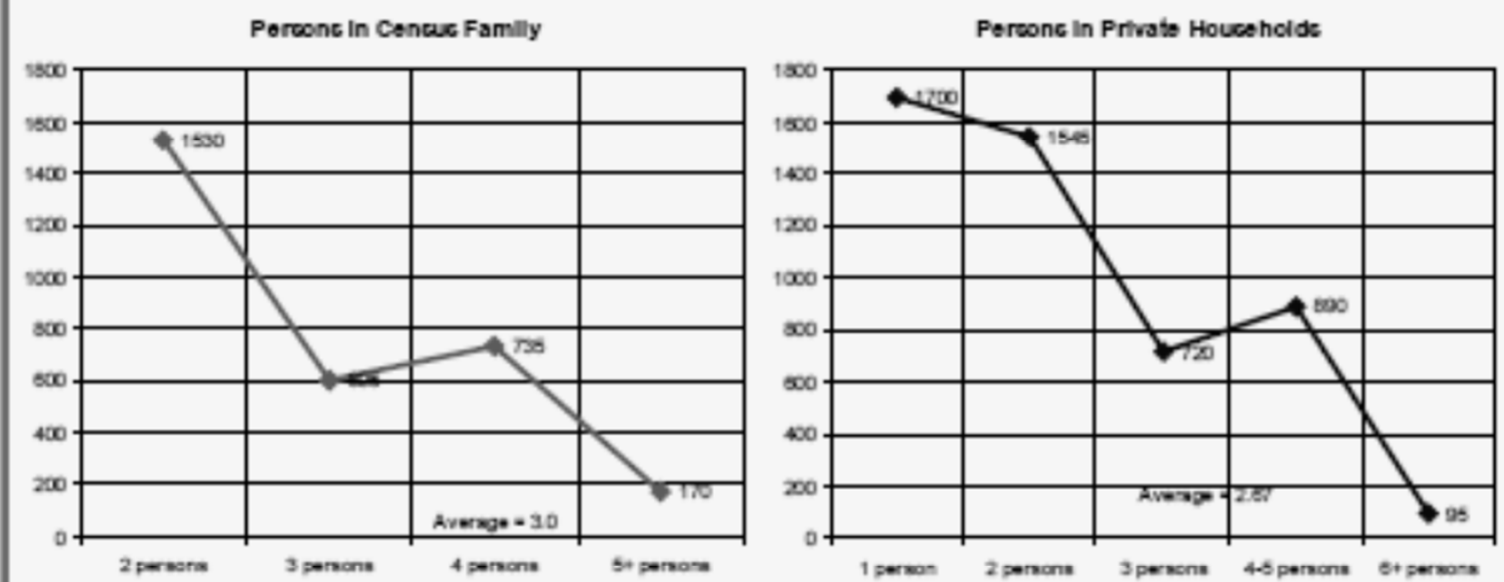

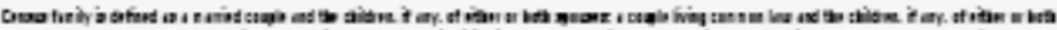

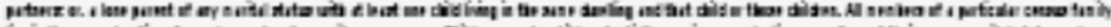

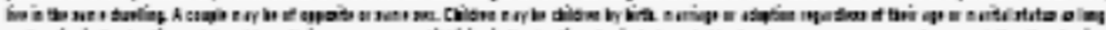

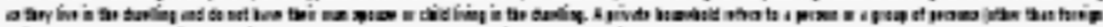

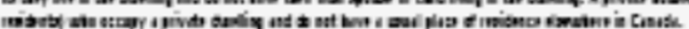

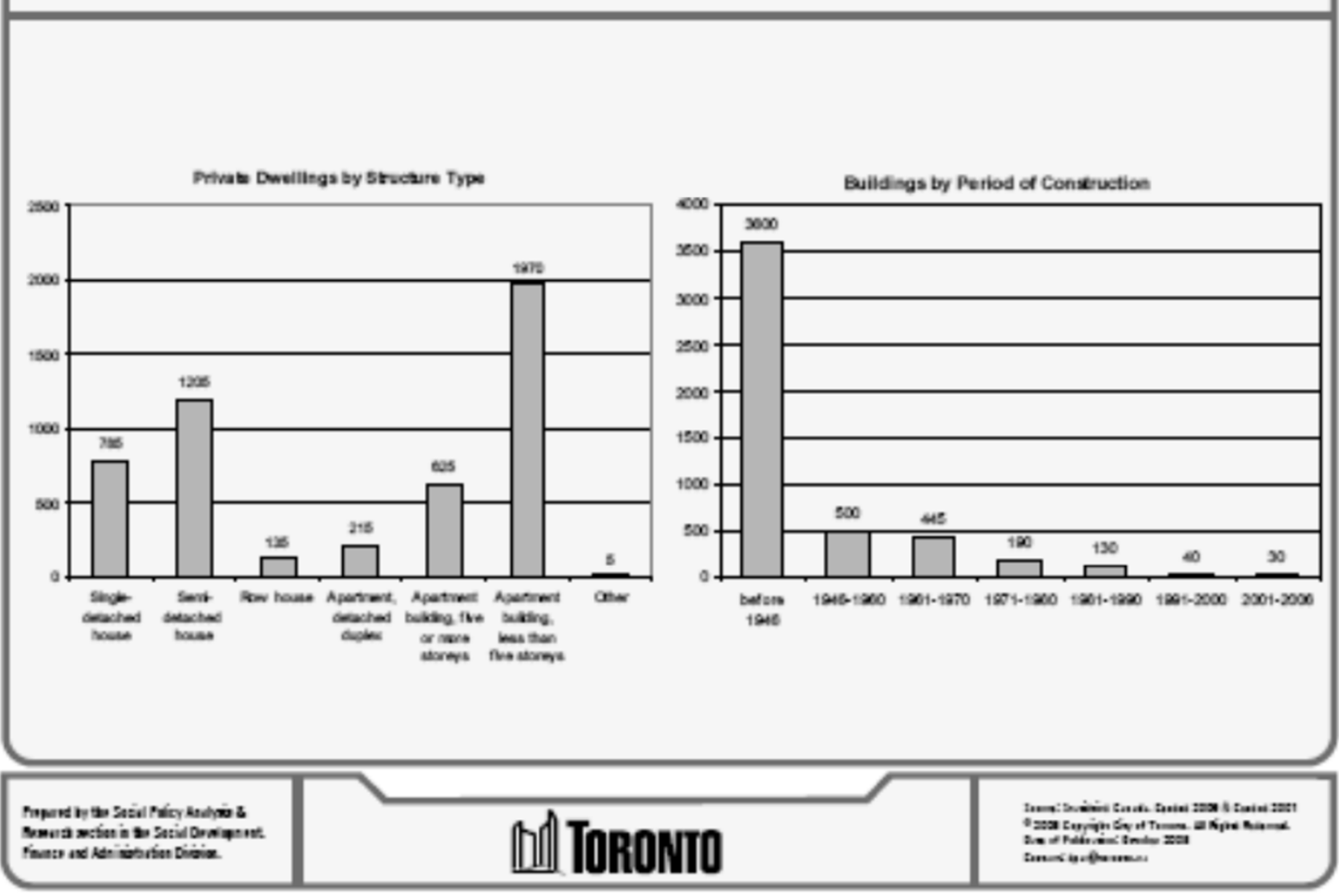




\section{6}

Page 3 of 3

North Riverdale (68)

Social Profile \#3 - Neighbourhoods Families \& Dwellings

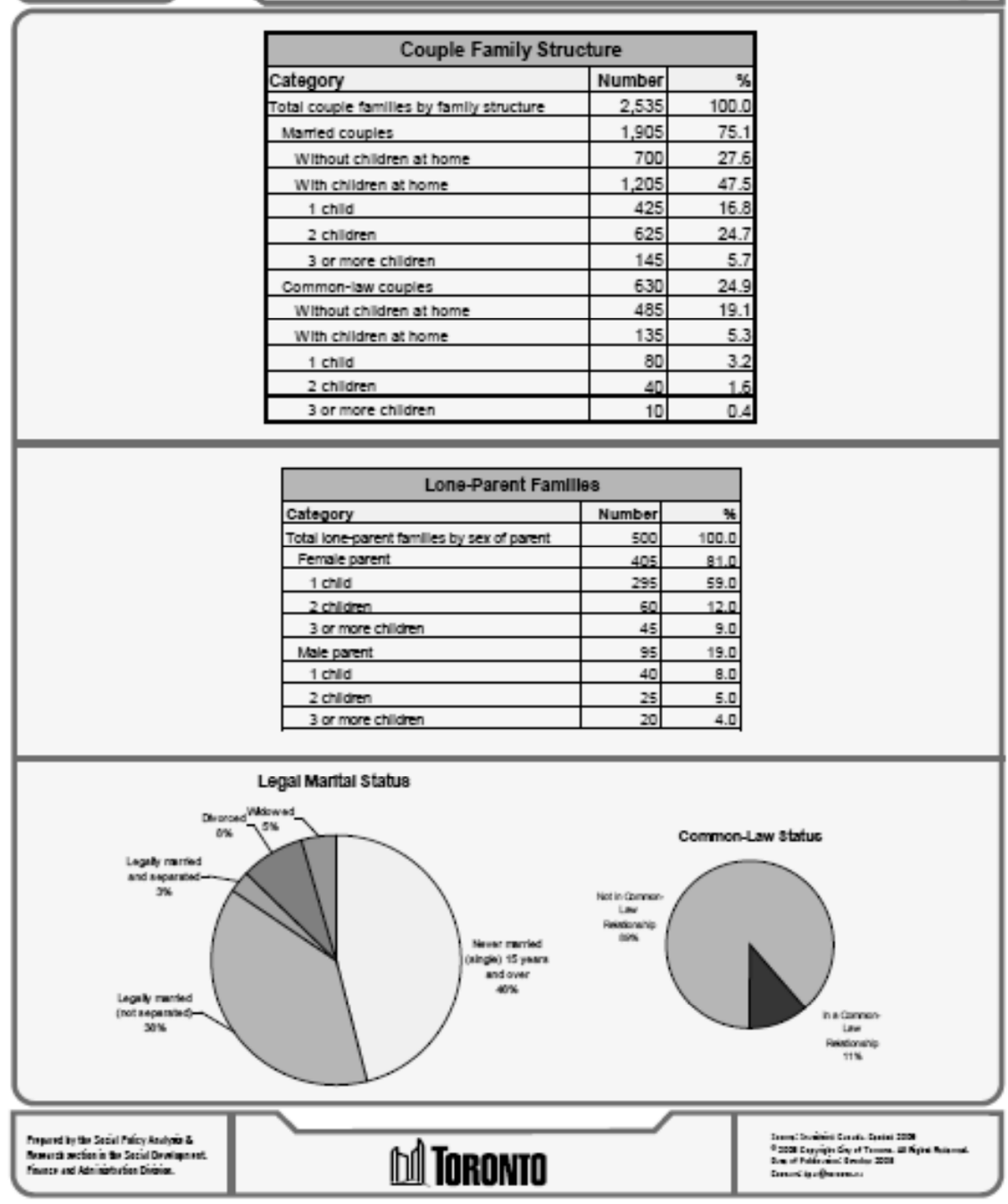




\section{Appendix B: Neighbourhood Data Compiled From Toronto Neighbourhood Profiles}

\begin{tabular}{|c|c|c|c|c|c|c|c|c|c|c|c|c|c|c|c|c|c|c|}
\hline & & & Number & of Builc & dings by Hous & $\operatorname{sing}$ Typ & & & umber of $B$ & uildings By & Archetype & & \# of Singl & e Family Dw & vellings by $A$ & Archetype & Overall Energy Intensity & Average Energy Intensity \\
\hline \# & Name & Single & Semi & Row & Apartment & Other & Total & Century & War Time & $70 \mathrm{~s} O B C$ & Modern & Total & Century & War Time & $70 \mathrm{SOBC}$ & Modern & $\mathrm{kWh} / \mathrm{m} 2$ & $\mathrm{kWh} / \mathrm{m} 2$ \\
\hline 62 & East End-Danforth & 1735 & 1880 & 350 & 4765 & 25 & 8755 & 4305 & 1280 & 930 & 455 & 8750 & 854 & 254 & 184 & 90 & 482,155 & 349 \\
\hline & The Beaches & 2580 & 1455 & 260 & 4810 & 5 & 9110 & 5760 & 1085 & 385 & 630 & 9110 & 1631 & 307 & 109 & 178 & 814,951 & 366 \\
\hline 64 & Woodbine Corridor & 850 & 1500 & 215 & 2670 & 5 & 5240 & 3080 & 795 & 205 & 135 & 5240 & 500 & 129 & 33 & 22 & 251,166 & 367 \\
\hline & Greenwood-Coxwell & 925 & 1415 & 295 & 3390 & 5 & 6030 & 3125 & 1055 & 525 & 60 & 6050 & 478 & 161 & 80 & 9 & 259,627 & 356 \\
\hline & Danforth Village-Toronto & 665 & 1220 & 25 & 2000 & 0 & 3910 & 2620 & 505 & 280 & 40 & 3915 & 445 & 86 & 48 & 7 & 217,640 & 372 \\
\hline & North Riverdale & 785 & 1205 & 135 & 2810 & 5 & 4940 & 3600 & 500 & 190 & 30 & 4935 & 573 & 80 & 30 & 5 & 263,245 & 383 \\
\hline 70 & South Riverdale & 835 & 2205 & \begin{tabular}{|c|}
1180 \\
\end{tabular} & 5505 & 25 & 9750 & 5995 & 935 & 605 & 255 & 9725 & 515 & 80 & 52 & 22 & 249,223 & 371 \\
\hline 81 & Trinity-Bellwoods & 320 & 720 & \begin{tabular}{|c|}
1000 \\
\end{tabular} & 4370 & 25 & 6435 & 4405 & 840 & 250 & 160 & 6395 & 220 & 42 & 13 & 8 & 105,976 & 375 \\
\hline & Roncesvalles & 630 & 995 & 360 & 4410 & 75 & 6470 & 4285 & 795 & 370 & 85 & 6450 & 419 & 78 & 36 & 8 & 202,173 & 374 \\
\hline 87 & High Park-Swansea & 2620 & 495 & 165 & 5725 & 30 & 9035 & 80 & 320 & 1090 & 115 & 3835 & 55 & 219 & 745 & 79 & 284,856 & 260 \\
\hline & High Park North & 1375 & 580 & 110 & 8235 & 5 & 10305 & 165 & 1195 & 1005 & 20 & 4585 & 49 & 358 & 301 & 6 & 191,474 & 268 \\
\hline & Runnymede-Bloor West Village & 1980 & 765 & 50 & 965 & 5 & 3765 & 135 & 1075 & 295 & 140 & 2925 & 91 & 728 & 200 & 95 & 300,682 & 270 \\
\hline 90 & Junction Area & 750 & 965 & 540 & 2995 & 5 & 5255 & 255 & 620 & 2660 & 0 & 7080 & 27 & 66 & 282 & 0 & 99,021 & 264 \\
\hline & Weston-Pellam Park & 535 & 1305 & 325 & 2120 & 20 & 4305 & 1700 & 810 & 400 & 380 & 4270 & 213 & 101 & 50 & 48 & 137,172 & 333 \\
\hline 92 & Corso Italia-Davenport & 1280 & 1225 & 110 & 2550 & 30 & 5195 & 2800 & 1100 & 400 & 20 & 5170 & 693 & 272 & 99 & 5 & 380,465 & 356 \\
\hline & Dovercourt-Wallace Emerson-Junction & 1590 & 2145 & 745 & 8815 & 30 & 13325 & 6600 & 2000 & 950 & 900 & 13450 & 780 & 236 & 112 & 106 & 433,278 & 351 \\
\hline & Wychwood & 945 & 920 & 255 & 3770 & 5 & 5895 & 2650 & 850 & 500 & 100 & 4850 & 516 & 166 & 97 & 19 & 283,179 & 354 \\
\hline 95 & Annex & 630 & 1120 & 620 & 12330 & 15 & 14715 & 5785 & 1905 & 1330 & 930 & 14725 & 248 & 82 & 57 & 40 & 145,893 & 343 \\
\hline & Rosedale-Moore Park & 2450 & 445 & 245 & 6805 & 5 & 9950 & 3570 & 1465 & 1040 & 870 & 9900 & 883 & 363 & 257 & 215 & 570,148 & 332 \\
\hline & Mount Pleasant East & 2155 & 1570 & 150 & 3115 & 190 & 7180 & 3355 & 1080 & 745 & 150 & 7160 & 1010 & 325 & 224 & 45 & 564,190 & 352 \\
\hline 100 & Yonge-Eglinton & 1410 & 460 & 25 & 3330 & 10 & 5235 & 2550 & $\frac{600}{670}$ & 775 & 140 & 5210 & 690 & 181 & 210 & 38 & 390,653 & 349 \\
\hline 103 & Lawrence Park South & 3415 & 110 & 25 & 2020 & 10 & 5580 & 3650 & 885 & 125 & 395 & 5570 & 2238 & 543 & 77 & 242 & $1,130,920$ & 373 \\
\hline 105 & Lawrence Park North & 3110 & 865 & 20 & 1450 & 0 & 5445 & 3580 & 755 & 95 & 215 & 5430 & 2050 & 432 & 54 & 123 & 992,402 & 365 \\
\hline
\end{tabular}




\section{Appendix C1: Housing Inspection Data: Century Home}

\begin{tabular}{|c|c|c|c|c|c|c|c|c|c|c|c|c|c|c|}
\hline & & & & \multicolumn{2}{|c|}{ Footprint } & & & & Wall Thickness & \multicolumn{5}{|c|}{ Height $(m)$} \\
\hline \# & House Type & Neighbourhood & Shape & Width $(\mathrm{m})$ & Length $(\mathrm{m})$ & Structure & Cladding & Roof & Basement (m) & Basement & Above Grade & Storey 1 & Storey 2 & Storey 3 \\
\hline 3 & Century & Riverdale & $L$ & 6.7 & 13.1 & Brick & Brick & Shingle & 0.3 & 1.5 & 0.85 & 2.6 & 2.6 & 2.5 \\
\hline 5 & Century & Riverdale & Rectangle & 6.5 & 10.2 & Brick & Brick & Shingle & 0.4 & 1.2 & 0.8 & 2.6 & 2.6 & 2.5 \\
\hline 6 & Century & Riverdale & L & 5.3 & 15.7 & Brick & Brick & Shingle & 0.45 & 1.7 & 1.2 & 2.7 & 2.6 & 2.5 \\
\hline 12 & Century & Danforth Village & Rectangle & 5 & 13 & Brick & Brick/Stucco & Shingle & 0.5 & 1.3 & 0.6 & 2.75 & 3 & 2.5 \\
\hline 15 & Century & Trinity-Bellwoods & Rectangle & 5.7 & 16.9 & Brick & Brick & Shingle & 0.3 & & 0.7 & 2.8 & 2.7 & 2.3 \\
\hline 16 & Century & Trinity-Bellwoods & Rectangle & 6.2 & 13 & Brick & Brick & Shingle & & & 0.9 & 2.5 & 2.5 & 2.3 \\
\hline 18 & Century & Roncesvalles & $L$ & 10.4 & 15.8 & Brick & Brick & Shingle & & & 0.9 & 2.8 & 2.8 & 2.6 \\
\hline 20 & Century & Roncesvalles & Rectangle & 5 & 16.6 & Brick & Brick & Shingle & & & 1.1 & 2.5 & 2.5 & \\
\hline 21 & Century & Roncesvalles & Rectangle & 7.3 & 11 & Brick & Brick/Wood & Shingle & 0.4 & 1.4 & 1 & 2.6 & 2.6 & \\
\hline 24 & Century & Danforth Village & Rectangle & 5.2 & 12.1 & Brick & Brick & Shingle & & & 1.5 & 2.7 & 2.6 & \\
\hline 29 & Century & Lawrence Park South & Rectangle & 5.8 & 9.4 & Brick & Brick/Wood & Shingle & 0.4 & 1.6 & 0.75 & 2.6 & 2.6 & \\
\hline Ave & rages or Typi & cal Characteristics & & 6.3 & 13.3 & & & & 0.4 & 1.5 & 0.9 & 2.7 & 2.6 & 2.5 \\
\hline
\end{tabular}

\begin{tabular}{|c|c|c|c|c|c|c|c|c|c|c|c|c|c|c|c|c|c|c|c|c|c|c|c|c|c|c|c|c|c|}
\hline \multicolumn{6}{|c|}{ North Glazing (m2) } & \multicolumn{6}{|c|}{ East Glazing (m2) } & \multicolumn{5}{|c|}{ West Glazing (m2) } & \multicolumn{9}{|c|}{ South Glazing (m2) } & \multicolumn{4}{|c|}{ Window to Wall Ratio } \\
\hline 1 & 2 & 3 & 4 & 5 & 6 & 1 & 2 & 3 & 4 & 5 & 6 & 1 & 2 & 3 & 4 & 5 & 1 & 2 & 3 & 4 & 5 & 6 & 7 & 8 & 9 & North & East & West & South \\
\hline 0.68 & 2.3 & 0.45 & 2.55 & 1.28 & 1.35 & 0.68 & 1.2 & & & & & 0.54 & & & & & 0.68 & 2.3 & 0.85 & 1.2 & 0.78 & 1.2 & & & & 19.9 & 2.6 & 0.75 & 16.2 \\
\hline 0.49 & 0.3 & 2.27 & 1.8 & 2.88 & 1.28 & 0.63 & 1 & 1 & & & & 0.4 & 1.2 & & & & 0.63 & 2.88 & 2.13 & 0.69 & 1.36 & 1.8 & & & & 19.1 & 4.3 & 2.6 & 20.1 \\
\hline 1.01 & 0.94 & 0.96 & 1.81 & 0.96 & 2.67 & 0.81 & 0.7 & & & & & 1.05 & 0.4 & 0.71 & & & 1.3 & 2.63 & 1.72 & 1.29 & 2.63 & 1.72 & 1.29 & 0.44 & 3.6 & 22.8 & 1.4 & 2 & 34.9 \\
\hline 1.68 & 2.08 & 1.62 & & & & 0.94 & 3.24 & 1.38 & & & & 0.24 & 0.33 & 1.91 & & & 1.08 & 1.28 & 0.55 & 1.08 & & & & & & 15.4 & 6.7 & 2.8 & 11.4 \\
\hline 1.1 & 3.42 & 1.87 & 2.38 & 0.26 & 0.88 & 1.28 & 2.81 & 1.32 & 1.45 & 0.53 & & & & & & & 1.36 & 3.59 & 0.56 & 0.76 & & & & & & 25.6 & 7.1 & & 12.9 \\
\hline 2.52 & 3.26 & 0.82 & 1.2 & & & 1.12 & 0.45 & 1.28 & 2.88 & 2.34 & 2.17 & 0.56 & 0.35 & 0.84 & \begin{tabular}{|l|}
0.48 \\
\end{tabular} & 1.13 & 1.36 & 0.77 & & & & & & & & 17.8 & 11.8 & 3.9 & 4.9 \\
\hline 1.53 & 3.2 & 3.2 & & & & 1.08 & 2.09 & 1.5 & 1.5 & 1.44 & 2.25 & 1.08 & 2.44 & 1.5 & 4.3 & 1.4 & 0.85 & 1.44 & 0.35 & 1.68 & 1.68 & 0.75 & & & & 10.5 & 10.6 & 11.6 & 8.9 \\
\hline 1.68 & 1.56 & & & & & 3.96 & 0.54 & 5.04 & 1.12 & 0.5 & & 0.675 & 1.12 & 0.93 & & & 1.32 & 1.32 & 0.56 & & & & & & & 10.6 & 11 & 2.7 & 10.5 \\
\hline 0.6 & 2.3 & 3.3 & & & & 1.3 & 0.85 & & & & & 0.88 & 0.33 & 0.42 & 0.6 & 2.28 & 1.43 & 1.12 & 0.77 & & & & & & & 13.7 & 3.2 & 6.6 & 7.3 \\
\hline 1.92 & 2.56 & & & & & & & & & & & 0.4 & 2.4 & 2.88 & 1.28 & & 1.2 & 1.28 & 0.66 & & & & & & & 12.7 & & 6.9 & 8.9 \\
\hline 0.28 & 2.8 & 0.9 & 2.66 & & & & & & & & & 0.9 & 0.6 & 0.3 & 0.51 & & 0.45 & 0.25 & 1.26 & 1.26 & & & & & & 19.2 & & 3.3 & 9.3 \\
\hline & & & & & & & & & & & & & & & & & & & & & & & & & & 17.0 & 6.5 & 4.3 & 13.2 \\
\hline
\end{tabular}


Window Frame Data (cm)

\begin{tabular}{|c|c|c|c|c|c|c|c|c|c|c|c|}
\hline \multicolumn{12}{|c|}{ Window Frame Data $(\mathrm{cm})$} \\
\hline Frame Width & Out Projection & In Projection & Divider Type & Divider Width & \# Horiz & \# Vert & Projection & Sill Depth & Sill Material & Reveal Depth & Reveal Material \\
\hline 4 & & 2.5 & Lite & 2.5 & 1 & & 2.5 & 10 & wood & 10 & wood \\
\hline 3 & & 1 & Lite & 7 & 1 & & 3 & 13 & wood & 13 & wood \\
\hline 4 & 1 & 3 & & & & & & 20 & wood & 20 & wood \\
\hline 8 & 1 & 1 & & & & & & 8 & wood & 4 & wood \\
\hline 6 & 1 & 1 & Lite & 4 & 1 & & 1 & 12 & wood & 7 & wood \\
\hline 4 & 1 & 1 & Lite & 4 & 1 & & 1 & 10 & wood & 5 & wood \\
\hline 4 & 1 & 2 & Lite & 2.5 & 1 & & 2 & 10 & wood & 12 & wood \\
\hline 7 & 4 & 2 & Lite & 8 & 1 & 1 & 3 & 14 & wood & 9 & wood \\
\hline 5 & 1 & 1 & Lite & 4 & 1 & & 1 & 27 & wood & 12 & wood \\
\hline 8 & 1 & 1 & Lite & 9 & 0 & 1 & 1 & 15 & wood & 15 & wood \\
\hline 7 & 1 & 2 & Lite & 4 & 1 & 0 & 2 & 9 & wood & 9 & wood \\
\hline 5.5 & 1.3 & 1.6 & & 5.0 & 0.9 & 0.7 & 1.8 & 13.5 & & 10.5 & \\
\hline
\end{tabular}

\begin{tabular}{|r|r|r|r|r|r|r|r|r|l|l|}
\hline \multicolumn{1}{|r|}{ Front Doors (m2) } & \multicolumn{6}{|l|}{ Rear Doors (m2) } & \multicolumn{2}{l|}{ Side Doors (m2) } & \\
\hline 1 & & 2 & 1 & \multicolumn{1}{l|}{2} & & 3 & 1 (East) & \multicolumn{1}{l|}{2} & HVAC & Thermostat Location \\
\hline 1.9 & & & 1.6 & 1.6 & & & & & Forced Air Gas & Dining Room \\
\hline 1.9 & & & 1.6 & & & & & & Forced Air Gas & Main Entrance \\
\hline 1.8 & & & 1.8 & 1.8 & 1.8 & & & & Forced Air Gas & Dining Room \\
\hline 1.78 & & & 1.78 & & & & & & Hot Water Rad & Dining Room \\
\hline 1.99 & 1.6 & & 1.79 & 1.71 & & & & & Gas and Rad & Main Entrance \\
\hline 1.89 & 1.6 & & 1.89 & 0.6 & & & 1.62 & & Hot Water Rad & Main Hallway \\
\hline 1.4 & 1.4 & 1.8 & 1.8 & 1.8 & 1.8 & 1.4 & 1.8 & & Hot Water Rad & Main Floor \\
\hline 1.68 & 1.68 & 1.5 & & & & & 1.68 & 1.68 & Forced Air Gas & Main Hallway \\
\hline 1.7 & & & 1.6 & 1.7 & 1.7 & & 1.6 & & Hot Water Rad & Living Room \\
\hline 1.89 & & & 1.78 & 1.8 & 1.8 & & & & Forced Air Gas & Living Room \\
\hline 1.79 & & & 1.4 & 1.4 & 1.4 & 1.4 & 1.6 & & Forced Air Gas & Basement Stair \\
\hline 1.8 & 1.6 & 1.7 & 1.7 & 1.6 & 1.7 & 1.4 & 1.7 & 1.7 & & \\
\hline
\end{tabular}




\section{Appendix C2: Housing Inspection Data: Century-Semi}

\begin{tabular}{|c|c|c|c|c|c|c|c|c|c|c|c|c|c|c|}
\hline & & & & \multicolumn{2}{|c|}{ Footprint } & & & & Wall Thickness & \multicolumn{5}{|c|}{ Height (m) } \\
\hline \# & House Type & Neighbourhood & Shape & Width $(\mathrm{m})$ & Length $(\mathrm{m})$ & Structure & Cladding & Roof & Basement $(\mathrm{m})$ & Basement & Above Grade & Storey 1 & Storey 2 & Storey 3 \\
\hline 1 & Cent-Semi & Riverdale & $\mathrm{L}$ & 5 & 13.1 & Wood Frame & Brick & Shingle & & & 1.25 & \begin{tabular}{|r|}
2.6 \\
\end{tabular} & \begin{tabular}{r|}
2.5 \\
\end{tabular} & 2.5 \\
\hline 4 & Cent-Semi & Riverdale & Rectangle & 5 & 13 & Brick & Brick & Shingle & 0.4 & 1.25 & 0.85 & 2.6 & 2.6 & 2.5 \\
\hline 7 & Cent-Semi & Danforth Village & $\mathrm{L}$ & 5 & 14 & Brick & Brick/wood & Shingle & 0.4 & 1.4 & 0.6 & 2.6 & 2.6 & 2.5 \\
\hline 8 & Cent-Semi & Trinity-Bellwoods & $\mathrm{L}$ & 5.4 & 14.6 & Brick & Brick & Shingle & & & 0.65 & 2.6 & 2.7 & 3.7 \\
\hline 9 & Cent-Semi & Danforth Village & $\mathrm{L}$ & 4.6 & 14.2 & Brick & Brick/Stucco & Shingle & 0.3 & 1.4 & 0.95 & 2.6 & 2.5 & \\
\hline 10 & Cent-Semi & Lawrence Park & & & & & & & & & & & & \\
\hline 11 & Cent-Semi & Trinity-Bellwoods & L & 5.6 & 10 & & Siding & Shingle & & & 0.75 & 2.6 & 2.5 & \\
\hline 13 & Cent-Semi & Trinity-Bellwoods & $\mathrm{L}$ & 4.9 & 16 & Brick & Brick/Siding & Shingle & 0.4 & 1.8 & 0.35 & 3 & 3 & \\
\hline 14 & Cent-Semi & Trinity-Bellwoods & Rectangle & 7 & 13.6 & Brick & Brick/Siding & Shingle & & & 0.95 & 2.75 & 2.6 & 2.5 \\
\hline 17 & Cent-Semi & Trinity-Bellwoods & $\mathrm{L}$ & 6.5 & 15 & Brick & Brick & Shingle & 0.3 & 1.5 & 0.7 & 2.6 & 2.6 & \\
\hline 19 & Cent-Semi & Roncesvalles & Rectangle & 5.9 & 9.3 & Brick/Wood & Brick & Tile & 0.4 & 1.5 & 0.75 & 1.9 & 2.5 & \\
\hline Ave & rages or Typi & cal Characteristics & & 5.5 & 13.3 & & & & 0.4 & 1.5 & 0.8 & 2.6 & 2.6 & 2.7 \\
\hline
\end{tabular}

\begin{tabular}{|c|c|c|c|c|c|c|c|c|c|c|c|c|c|c|c|c|c|c|c|c|c|c|c|c|c|c|}
\hline \multicolumn{5}{|c|}{ North Glazing (m2) } & \multicolumn{6}{|c|}{ East Glazing (m2) } & \multicolumn{4}{|c|}{ West Glazing (m2) } & \multicolumn{8}{|c|}{ South Glazing (m2) } & \multicolumn{4}{|c|}{ Window to Wall Ratio } \\
\hline 1 & 2 & 3 & 4 & 5 & 1 & 2 & 3 & 4 & 5 & 6 & 1 & 2 & 3 & 4 & 1 & 2 & 3 & 4 & 5 & 6 & 7 & 8 & North & East & West & South \\
\hline 1.3 & 0.35 & 0.75 & 3 & & 0.7 & 0.6 & 0.7 & & & & & & & & 0.7 & 0.7 & 0.8 & & & & & & 16.8 & 2.2 & & 6.8 \\
\hline 1.98 & 0.56 & 0.56 & 0.98 & 0.72 & 0.54 & 0.54 & 1.15 & 1.15 & 1.08 & 1.08 & & & & & 0.9 & 0.6 & 1.2 & 0.6 & & & & & 14.3 & 7 & & 9.8 \\
\hline 1.61 & 2.1 & 0.8 & 0.5 & 0.35 & 0.35 & 0.54 & 2.18 & 0.63 & 0.98 & & & & & & 0.42 & 2 & 0.71 & 0.25 & 1.73 & 0.14 & 0.43 & 0.66 & 15.5 & 4.7 & & 15.3 \\
\hline 2.43 & 2.43 & 0.47 & 0.47 & & 0.42 & & & & & & & & & & 1.05 & 1.48 & 0.6 & 1.05 & & & & & 15.6 & 0.3 & & 11.3 \\
\hline 1.62 & 162 & & & & 1.28 & 0.49 & 2.4 & 1.2 & 1.62 & 0.49 & & & & & 0.43 & 1.3 & 1.17 & 1.56 & & & & & 11.7 & 9.3 & & 15.8 \\
\hline & & & & & & & & & & & & & & & & & & & & & & & & & & \\
\hline 2.7 & 1.35 & 1.35 & & & 0.7 & 0.33 & 0.72 & & & & 0.45 & 0.4 & 0.3 & 0.56 & 1.35 & 1.35 & & & & & & & 19.4 & 13.1 & 3.1 & 9.7 \\
\hline 2.34 & 0.53 & 2.7 & 1.05 & & 1.04 & & & & & & 0.49 & 0.48 & & & 1.11 & 0.88 & 1.36 & 1.14 & & & & & 17.4 & 0.9 & 2.8 & 13.6 \\
\hline 7.68 & 1.28 & 1.56 & & & 1.89 & 2.6 & 1.36 & & & & & & & & 0.44 & 1.75 & 1.4 & 1.65 & 1.75 & 1.75 & 1.4 & & 20.1 & 6.8 & & 19.4 \\
\hline 2.72 & 2.04 & 2.28 & 1.71 & 0.9 & & & & & & & 0.16 & 1.71 & 0.95 & 1.8 & 1.7 & 1.9 & 0.9 & 0.4 & 0.65 & & & & 25.1 & & 5.2 & 14.5 \\
\hline 0.45 & 1.68 & 0.7 & 0.7 & & & & & & & & & & & & 0.45 & 0.66 & 1.68 & 1.26 & 0.4 & & & & 8.9 & & & 11.2 \\
\hline & & & & & & & & & & & & & & & & & & & & & & & 16.5 & 5.5 & 3.7 & 12.7 \\
\hline
\end{tabular}


Window Frame Data $(\mathrm{cm})$

\begin{tabular}{|c|c|c|c|c|c|c|c|c|c|c|c|}
\hline \multicolumn{12}{|c|}{ Window Frame Data $(\mathrm{cm})$} \\
\hline Frame Width & Out Projection & In Projection & Divider Type & Divider Width & \# Horiz & \#Vert & Projection & Sill Depth & Sill Material & Reveal Depth & Reveal Material \\
\hline 2 & 1 & 1 & Lite & 4 & 1 & 1 & 4 & & & & \\
\hline 5 & 2 & 3 & Lite & 8 & 1 & & 3 & 6 & wood & 6 & wood \\
\hline 6 & 7 & 9 & & & & & & $30 / 9$ & wood/marble & $30 / 9$ & wood \\
\hline 4 & 5 & 5 & Lite & 8 & 1 & & 5 & 12 & wood & 8 & wood \\
\hline 8 & 2 & 2 & Lite & 9 & 1 & 1 & 7 & 10 & wood & 10 & wood \\
\hline & & & & & & & & & & & \\
\hline 2 & 1 & & Lite & 8 & 1 & 1 & 5 & 10 & Aluminum & 8 & Aluminum \\
\hline 8 & 2 & & Lite & 9 & 1 & 1 & 2 & 10 & wood & 5 & wood \\
\hline 4 & 2 & 2 & Lite & 9 & 1 & 1 & 6 & 13 & Ceramic & 13 & Wood \\
\hline 4 & 1 & 1 & Lite & 6 & 1 & & 1 & 12 & wood & 12 & wood \\
\hline 10 & 2 & 2 & Lite & 15 & & 1 & 2 & 17 & wood & 17 & wood \\
\hline 5.3 & 2.5 & 3.1 & & 8.4 & 1.0 & 1.0 & 3.9 & 10.4 & & 6.0 & \\
\hline
\end{tabular}

\begin{tabular}{|c|c|c|c|c|c|c|c|c|}
\hline \multicolumn{2}{|c|}{ Front Doors (m2) } & \multicolumn{3}{|c|}{ Rear Doors (m2) } & \multicolumn{2}{|c|}{ Side Doors (m2) } & \multirow[b]{2}{*}{ HVAC } & \multirow[b]{2}{*}{ Thermostat Location } \\
\hline \begin{tabular}{|l|}
1 \\
\end{tabular} & 2 & 1 & 2 & 3 & 1 (East) & 2 & & \\
\hline 2.2 & & 2.2 & 2.2 & 2.2 & & & Hot Water Rad & Front Hallway \\
\hline 1.15 & & 3.2 & 1.7 & & & & Forced Air Gas & Top of Main Stairs \\
\hline 1.7 & & 1.4 & 1.4 & & 1.48 & 1.48 & Forced Air Gas & Main Floor \\
\hline 1.05 & 1.05 & 1.33 & 1.33 & & & & Forced Air Gas & Main Floor \\
\hline 1.81 & & 1.35 & & & 1.5 & & Forced Air Gas & Main Room First Floor \\
\hline & & & & & & & & \\
\hline 1.6 & & 1.52 & & & 1.6 & & Forced Air Gas & Main Floor \\
\hline 1.7 & & & & & 1.6 & & Forced Air Gas & Main Floor Hallway \\
\hline 1.68 & 1.68 & 2.2 & 2.2 & & & & Hot Water Rad & Basement \\
\hline 1.89 & & & & & 1.7 & & Forced Air Gas & Main Hall by Kitchen \\
\hline 1.8 & & 1.6 & 1.6 & & & & Forced Air Gas & Main Floor Hallway \\
\hline 1.7 & 1.4 & 1.9 & 1.7 & 2.2 & 1.6 & 1.5 & & \\
\hline
\end{tabular}




\section{Appendix C3: Housing Inspection Data: War Time Home}

\begin{tabular}{|c|c|c|c|c|c|c|c|c|c|c|c|c|c|}
\hline & & & & \multicolumn{2}{|c|}{ Footprint } & & & & Wall Thickness & \multicolumn{4}{|c|}{ Height $(m)$} \\
\hline \# & House Type & Neighbourhood & Shape & Width $(\mathrm{m})$ & Length $(\mathrm{m})$ & Structure & Cladding & Roof & Basement $(\mathrm{m})$ & Basement & Above Grade & Storey 1 & Storey 2 \\
\hline 2 & War Time & Danforth Village & Rectangle & $\begin{array}{r}6.3 \\
\end{array}$ & 13.9 & Wood Frame & Vinyl Siding & Shingle & $\begin{array}{r}0.35 \\
\end{array}$ & 1.1 & \begin{tabular}{r|}
0.85 \\
\end{tabular} & $\begin{array}{r}2.6 \\
\end{array}$ & \\
\hline 22 & War Time & Riverdale & Rectangle & 6.7 & 11.6 & Wood Frame & Brick & Shingle & 0.4 & 1.4 & 1.2 & 2.5 & \\
\hline 23 & War Time & Lawrence Park South & L-Shaped & 9.4 & 9.5 & Wood Frame & Brick & Shingle & 0.3 & 1.3 & 1.1 & 2.5 & 2.5 \\
\hline 25 & War Time & Lawrence Park South & Rectangle & 5.8 & 8.9 & Wood Frame & Brick & Shingle & 0.4 & 1.5 & 0.9 & 2.6 & 2.5 \\
\hline 26 & War Time & Lawrence Park South & L-Shaped & 9.1 & 15.5 & Wood Frame & Brick/Siding & Shingle & 0.4 & 1.4 & 0.8 & 2.6 & 2.5 \\
\hline 27 & War Time & Lawrence Park South & L-Shaped & 9.4 & 9.1 & Wood Frame & Brick & Shingle & & & 0.75 & 2.6 & 2.5 \\
\hline 28 & War Time & Lawrence Park South & L-Shaped & 11.5 & 8.8 & Wood/Block & Brick & Shingle & 0.3 & 1.5 & 0.9 & 2.6 & 2.5 \\
\hline \multicolumn{3}{|c|}{ Averages or Typical Characteristics } & & 8.3 & 11.0 & & & & 0.4 & 1.4 & 0.9 & 2.6 & 2.5 \\
\hline
\end{tabular}

\begin{tabular}{|c|c|c|c|c|c|c|c|c|c|c|c|c|c|c|c|c|c|c|c|c|c|c|c|c|c|}
\hline \multicolumn{5}{|c|}{ North Glazing (m2) } & \multicolumn{5}{|c|}{ East Glazing (m2) } & \multicolumn{4}{|c|}{ West Glazing (m2) } & \multicolumn{8}{|c|}{ South Glazing (m2) } & \multicolumn{4}{|c|}{ Window to Wall Ratio } \\
\hline 1 & 2 & 3 & 4 & 5 & 1 & 2 & 3 & 4 & 5 & 1 & 2 & 3 & 4 & 1 & 2 & 3 & 4 & 5 & 6 & 7 & 8 & North & East & West & South \\
\hline 1.05 & 1 & & & & 0.425 & 0.425 & & & & & & & & 1.5 & 1.5 & 0.425 & 0.425 & 0.55 & & & & 12.5 & 2.7 & & 26.9 \\
\hline 1.54 & 2.6 & 0.6 & & & 1.68 & 1 & 0.5 & 0.25 & & 0.35 & 1.2 & & & 1.3 & 1.3 & 0.35 & 0.35 & & & & & 19.1 & 8 & 3.6 & 13.3 \\
\hline 3.23 & 1.43 & 0.77 & 1 & & 0.33 & 0.54 & 0.77 & & & 0.47 & 0.38 & 0.3 & 0.25 & 2.85 & 1.08 & 1.08 & 1.44 & & & & & 11.2 & 2.1 & 1.8 & 11.2 \\
\hline 0.41 & 2.73 & 3 & 0.79 & & 0.41 & 0.41 & 0.7 & 0.77 & 0.79 & 0.41 & & & & 0.41 & 0.81 & 1.33 & 1.33 & & & & & 19.9 & 5.8 & 0.8 & 7.3 \\
\hline 2.16 & 2.28 & 0.22 & 2.16 & & 0.25 & 0.54 & 1.08 & & & 0.44 & 0.44 & 0.25 & & 0.45 & 1.82 & 1.82 & 0.8 & 0.96 & 1.8 & 1.68 & 1.68 & 12.7 & 2 & 1.2 & 20.5 \\
\hline 0.39 & 2.52 & 1.26 & 0.72 & 2.52 & 0.3 & 0.66 & & & & 0.8 & 1.05 & 0.66 & 0.3 & 0.8 & 1.5 & 2.88 & 5.4 & 0.96 & 0.96 & & & 15.4 & 1.4 & 4.2 & 26 \\
\hline 0.9 & 3.22 & 1.26 & 1.26 & 1.26 & 3.36 & & & & & 0.81 & 0.6 & 0.6 & 0.98 & 0.35 & 0.78 & 0.55 & 1.44 & 1 & 2.66 & 1.17 & 2.34 & 13.1 & 5.2 & 4.6 & 17.1 \\
\hline & & & & & & & & & & & & & & & & & & & & & & 14.8 & 3.9 & 2.7 & 17.5 \\
\hline
\end{tabular}


Window Frame Data $(\mathrm{cm})$

\begin{tabular}{|c|c|c|c|c|c|c|c|c|c|c|c|}
\hline Frame Width & Out Projection & In Projection & Divider Type & Divider Width & \# Horiz & \# Vert & Projection & Sill Depth & Sill Material & Reveal Depth & Reveal Material \\
\hline 8 & 10 & $\begin{array}{r}5 \\
\end{array}$ & & & & & & \begin{tabular}{|r|}
10 \\
\end{tabular} & \begin{tabular}{|l|} 
wood \\
\end{tabular} & $\begin{array}{r}10 \\
\end{array}$ & wood \\
\hline 4 & 3 & 3 & Lite & 4 & 1 & 1 & 1 & 12 & wood & 12 & wood \\
\hline 5 & 1 & 1 & Suspended & 2 & 4 & 2 & & 15 & wood & 10 & wood \\
\hline 7 & 3 & 3 & & & & & & 15 & wood & 11 & wood \\
\hline 4 & 1 & 2 & Lite & 3 & 1 & & 5 & 11 & wood & 11 & wood \\
\hline 4 & 1 & 2 & Lite & 3 & 3 & 2 & 2 & 11 & wood & 11 & wood \\
\hline 5 & 1 & 2 & Lite & 3 & 1 & 0 & 2 & 13 & wood & 13 & wood \\
\hline 5.3 & 2.9 & 2.6 & & 3.0 & 2.0 & 1.3 & 2.5 & 12.4 & & 11.1 & \\
\hline
\end{tabular}

\begin{tabular}{|c|c|c|c|c|c|c|c|}
\hline \multirow{2}{*}{$\begin{array}{c}\text { Front Doors (m2) } \\
1\end{array}$} & \multicolumn{3}{|c|}{ Rear Doors (m2) } & \multicolumn{2}{|c|}{ Side Doors (m2) } & \multirow[b]{2}{*}{ HVAC } & \multirow[b]{2}{*}{ Thermostat Location } \\
\hline & 1 & 2 & 3 & 1 (East) & 2 & & \\
\hline 1.8 & & & & 1.19 & & Forced Air Gas & Main Room \\
\hline & & & & 1.6 & 1.6 & Forced Air Gas & Main Room \\
\hline 1.78 & 1.7 & 1.7 & 1.7 & 1.5 & & Hot Water Rad & Living Room \\
\hline 1.78 & 1.6 & 1.6 & & 1.5 & & Forced Air Gas & Living Room \\
\hline 1.5 & 1.89 & 1.89 & & 1.39 & & Hot Water Rad & Dining Room \\
\hline 1.78 & 1.71 & 1.71 & & 1.33 & & Hot Water Rad & Dining Room \\
\hline 1.78 & & & & 1.8 & 1.43 & Hot Water Rad & Dining Room \\
\hline 1.7 & 1.7 & 1.7 & 1.7 & 1.5 & 1.5 & & \\
\hline
\end{tabular}




\section{Appendix C4: Housing Inspection Data: Survey Results}

\begin{tabular}{|c|c|c|c|c|c|c|c|c|c|c|c|c|c|c|c|c|c|}
\hline \multirow[b]{2}{*}{ \# } & \multirow[b]{2}{*}{ House Type } & \multirow{2}{*}{ Neighbourhood } & \multirow{2}{*}{$\begin{array}{l}\text { Renovations } \\
\text { By Owner? }\end{array}$} & \multirow{2}{*}{$\begin{array}{l}\text { Renovated } \\
\text { Previously? }\end{array}$} & \multicolumn{7}{|c|}{ Appliances (hours/use) } & \multicolumn{6}{|c|}{ Appliances (Time of Use - D, N, WD, WN, R) } \\
\hline & & & & & Kitchen Fan & Stove & Fridge & Dishwasher & Washer & Dryer & Other & Kitchen Fan & Stove & Dishwasher & Washer & Dryer & Other \\
\hline 1 & Cent-Semi & Riverdale & Yes & & \begin{tabular}{|r|}
0.5 \\
\end{tabular} & 0.5 & Always & & & & & \begin{tabular}{|l|l}
$\mathrm{R}$ & $\mathrm{a}$ \\
$\mathrm{N}$
\end{tabular} & $\mathrm{D}, \mathrm{N}, \mathrm{WD}, \mathrm{WN}$ & & & & \\
\hline 2 & War Time & Danforth Village & Yes & & $<1$ & 0.75 & Always & & 1.75 & & & $\mathrm{R}$ & $\mathrm{N}, \mathrm{WD}, \mathrm{WN}$ & & $\mathrm{N}, \mathrm{WD}$ & & \\
\hline 3 & Century & Riverdale & No & Yes & & 2 & Always & 6 & 3 & 4 & & $\mathrm{R}$ & $\mathrm{N}$ & $\mathrm{N}$ & $\mathrm{N}$ & $\mathrm{N}$ & \\
\hline 4 & Cent-Semi & Riverdale & Yes & No & 0.5 & 1 & Always & 1 & 4.5 & 1 & & $\mathrm{~N}, \mathrm{WD}, \mathrm{WN}$ & $D, N, W D, W N$ & $\mathrm{~N}, \mathrm{WD}, \mathrm{WN}$ & WD & WD & \\
\hline 5 & Century & Riverdale & & & & & & & & & & & & & & & \\
\hline 6 & Sentury & Riverdale & Yes & No & 0.5 & $1.5-2$ & Always & 1.5 & 4 & 5 & & $R$ & $\mathrm{~N}, \mathrm{WD}, \mathrm{WN}$ & $\mathrm{N}, \mathrm{WN}$ & WD,WN & WD,WN & \\
\hline 7 & Cent-Semi & Danforth Village & Yes & Yes & & $.5-1$ & Always & 1.3 & 3.5 & 3.5 & & & $D, N, W D, W N$ & $\mathrm{~N}, \mathrm{WN}$ & $\mathrm{N}, \mathrm{WN}$ & $\mathrm{N}, \mathrm{WN}$ & \\
\hline 8 & Cent-Semi & Trinity-Bellwoods & Yes & No & 0.5 & 1 & Always & & & & & $\mathrm{N}$ & $\mathrm{N}$ & & & & Heater - D,N \\
\hline 9 & Cent-Semi & Danforth Village & Yes & No & 2 & 2 & Always & 0.5 & & 0.005 & & $D, N, W D, W N$ & $D, N, W D, W N$ & $\mathrm{~N}, \mathrm{WD}, \mathrm{WN}$ & $D, N, W D, W N$ & $D, W, W D, W N$ & \\
\hline 10 & Cent-Semi & Lawrence Park South & & & & & & & & & & & & & & & \\
\hline 11 & Cent-Semi & Trinity-Bellwoods & No & No & & 0.3 & Always & & & & & & $D, N, W D$ & & & & \\
\hline 12 & Century & Danforth Village & No & Yes & 2 & 2 & Always & 1 & 1 & 1 & & $\mathrm{~N}, \mathrm{WD}, \mathrm{WN}$ & $\mathrm{N}, \mathrm{WD}, \mathrm{WN}$ & $\mathrm{N}, \mathrm{WN}$ & $\mathrm{N}, \mathrm{WD}$ & $\mathrm{N}, \mathrm{WD}$ & \\
\hline 13 & Cent-Semi & Trinity-Bellwoods & No & Yes & 0.5 & 1 & Always & 1 & 1 & 1 & & $\mathrm{~N}$ & $D, N, W D, W N$ & $\mathrm{~N}$ & $D, W D$ & D, WD & \\
\hline 14 & Cent-Semi & Trinity-Bellwoods & No & Yes & & 0.5 & Always & & 0.5 & 0.5 & & $\mathrm{R}$ & $\mathrm{N}, \mathrm{WD}, \mathrm{WN}$ & & $D, N, W D$ & $D, N, W D$ & \\
\hline 15 & Century & Trinity-Bellwoods & Yes & Yes & & 1 & Always & 4/week & 3/Week & $3 / w$ & & $\mathrm{~N}$ & $\mathrm{~N}$ & $\mathrm{~N}$ & $\mathrm{~N}, \mathrm{WD}$ & $N, W D$ & \\
\hline 16 & Century & Trinity-Bellwoods & No & Yes & & 1 & Always & 1 & $\begin{array}{lll}1 & 1 \\
\end{array}$ & 1 & & $R$ & $\mathrm{~N}, \mathrm{WD}, \mathrm{WN}$ & $\mathrm{N}$ & $\mathrm{N}$ & $\mathrm{N}$ & \\
\hline 17) & Cent-Semi & Trinity-Bellwoods & No & Yes & 0.50 & 0.5 & Always & 1.5 & 1.5 & 2 & & $\mathrm{~N}, \mathrm{WD}, \mathrm{WN}$ & $\mathrm{N}, \mathrm{WD}, \mathrm{WN}$ & $\mathrm{N}, \mathrm{WN}$ & WD & WD & \\
\hline 18 & Century & Roncesvalles & No & No & & 1 & Always & & 1 & 2 & & & $\mathrm{D}, \mathrm{N}$ & & WN, R & WN, R & \\
\hline 19 & Cent-Semi & Roncesvalles & Yes & No & 0.5 & 0.5 & Always & 1.5 & 1 & 1 & & $\mathrm{~N}, \mathrm{WN}$ & $\mathrm{N}, \mathrm{WN}$ & $D, N, W D$ & $N, W D$ & $\mathrm{~N}, \mathrm{WD}$ & \\
\hline 20 & Century & Roncesvalles & No & Yes & & 2 & Always & & & & & & $\mathrm{D}, \mathrm{N}, \mathrm{WD}, \mathrm{WN}$ & & & & \\
\hline 21 & Century & Roncesvalles & Yes & Yes & 1 & 2 & Always & 1 & 1 & 1 & & $\mathrm{D}, \mathrm{N}, \mathrm{WD}, \mathrm{WN}$ & $D, N, W D, W N$ & $\mathrm{~N}, \mathrm{WN}$ & D & D & \\
\hline 22 & War Time & Riverdale & Yes & No & & 0.5 & Always & 1 & 1 & 1 & & \begin{tabular}{|l|l}
$R$ \\
\end{tabular} & $\mathrm{~N}, \mathrm{WD}, \mathrm{WN}$ & $\mathrm{N}$ & $\mathrm{N}$ & $\mathrm{N}$ & $A / C-R$ \\
\hline 23 & War Time & Lawrence Park South & Yes & No & 0.25 & 1 & Always & 1 & 0.5 & 1 & & $N, R$ & $\mathrm{~N}, \mathrm{WN}$ & $\mathrm{N}, \mathrm{WN}$ & $\mathrm{N}$ & $\mathrm{N}$ & Microwave $\mathrm{D}, \mathrm{N}$ \\
\hline 24 & Century & Danforth Village & Yes & Yes & 2 & 2 & Always & 1 & 1 & 1 & & $\mathrm{~N}, \mathrm{WD}$ & N, WD & $\mathrm{N}, \mathrm{WD}$ & N, WD & $N, W D$ & \\
\hline 25 & War Time & Lawrence Park South & Yes & No & 0.25 & 1 & Always & 2 & 1 & I & & $R$ & $\mathrm{~N}, \mathrm{WD}, \mathrm{WN}$ & $\mathrm{N}, \mathrm{WD}, \mathrm{WN}$ & $\mathrm{N}, \mathrm{WD}, \mathrm{WN}$ & $\mathrm{N}$ & \\
\hline 26 & War Time & Lawrence Park South & Yes & No & & 1 & Always & 1.5 & 2 & 2 & & R & $\mathrm{N}$ & $\mathrm{N}$ & WD & WD & \\
\hline 27 & War Time & Lawrence Park South & Yes & No & & 2 & Always & 1 & 2 & 2. & Always & & $\mathrm{N}, \mathrm{WD}, \mathrm{WN}$ & $\mathrm{N}$ & $\mathrm{N}, \mathrm{WD}$ & $\mathrm{N}, \mathrm{WD}$ & Freezer A \\
\hline 28 & War Time & Lawrence Park South & No & Yes & & 2 & Always & 2 & 4 & 4 & & & $D, N$ & $\mathrm{~N}, \mathrm{WD}, \mathrm{WN}$ & $\mathrm{N}, \mathrm{WD}, \mathrm{WN}$ & $\mathrm{N}, \mathrm{WD}, \mathrm{WM}$ & \\
\hline 29 & Century & Lawrence Park South & Yes & Yes & & $0.5-1$ & Always & 1 & 1 & 0.75 & Always & $R$ & $\mathrm{~N}$ & $\mathrm{~N}$ & $\mathrm{~N}$ & $\mathrm{~N}$ & Freezer A \\
\hline
\end{tabular}




\section{Appendix D: Observation Study Results}

\begin{tabular}{|c|c|c|c|c|c|c|c|c|c|c|c|c|c|}
\hline \multirow[b]{2}{*}{ Neighbourhood/Street } & \multicolumn{3}{|c|}{ Semi } & \multicolumn{4}{|c|}{ Century } & \multicolumn{4}{|c|}{ War Time } & \multirow{2}{*}{$\begin{array}{l}\text { Total Single- } \\
\text { Family Homes }\end{array}$} & \multirow{2}{*}{$\%$ of Total } \\
\hline & Arch. & 2 Storey & Other & Arch. & Wide Lot & 2 Storey & Other & Arch. & 2 Storey & 1.5 Storey & Other & & \\
\hline Riverdale & & & & & & & & & & & & 2125 & \\
\hline Carlaw Ave. & 57 & 5 & 2 & 71 & 0 & 19 & 6 & 2 & 0 & 0 & 0 & & \\
\hline Pape Ave. & 65 & 33 & 2 & 34 & 1 & 20 & 4 & 1 & 0 & 0 & 0 & & \\
\hline Jones Ave. & 21 & 20 & 4 & 34 & 1 & 15 & 7 & 3 & 0 & 0 & 0 & & \\
\hline Wolfrey Ave. & 21 & 16 & 0 & 29 & 0 & 10 & 1 & 1 & 0 & 0 & 0 & & \\
\hline Withrow Ave. & 46 & 34 & 0 & 54 & 0 & 7 & 3 & 2 & 0 & 0 & 0 & & \\
\hline Total & 210 & 108 & 8 & 222 & 2 & 71 & 21 & 9 & 0 & 0 & 0 & 651 & $31 \%$ \\
\hline Danforth Village & & & & & & & & & & & & 1910 & \\
\hline Milverton Blvd. & 15 & 169 & 2 & 7 & 0 & 31 & 0 & 3 & 0 & 0 & 0 & & \\
\hline Glebeholm Blvd. & 7 & 75 & 0 & 3 & 0 & 24 & 1 & 6 & 0 & 0 & 0 & & \\
\hline Strathmore Blvd. & 16 & 41 & 0 & 36 & 0 & 27 & 0 & 27 & 0 & 0 & 0 & & \\
\hline Coxwell Ave. & 0 & 0 & 0 & 6 & 0 & 31 & 3 & 11 & 0 & 0 & 0 & & \\
\hline Donlands Ave. & 7 & 7 & 0 & 2 & 0 & 5 & 0 & 1 & 0 & 0 & 0 & & \\
\hline Total & 45 & 292 & 2 & 54 & 0 & 118 & 4 & 48 & 0 & 0 & 0 & 563 & $29 \%$ \\
\hline Trinity Bellwoods & & & & & & & & & & & & 1740 & \\
\hline Shaw St. & 45 & 16 & 1 & 20 & 0 & 3 & 0 & 1 & 0 & 0 & 0 & & \\
\hline Crawford St. & 49 & 4 & 1 & 41 & 3 & 3 & 2 & 0 & 0 & 0 & 0 & & \\
\hline Grace St. /Gore Vale Ave. & 59 & 12 & 3 & 17 & 2 & 2 & 1 & 0 & 0 & 0 & 0 & & \\
\hline Manning Ave. & 9 & 14 & 2 & 5 & 1 & 6 & 0 & 9 & 0 & 0 & 3 & & \\
\hline Palmerston Ave. & 29 & 22 & 3 & 17 & 0 & 11 & 3 & 3 & 0 & 1 & 1 & & \\
\hline Total & 191 & 68 & 10 & 100 & 6 & 25 & 6 & 13 & 0 & 1 & 4 & 424 & $24 \%$ \\
\hline Lawrence Park South & & & & & & & & & & & & 3550 & \\
\hline Mona Dr. / Shields Ave. & 0 & 0 & 2 & 10 & 16 & 22 & 1 & 4 & 20 & 0 & 0 & & \\
\hline Proudfoot Ave. / Castlewood Rd. & 0 & 0 & 0 & 3 & 0 & 36 & 0 & 10 & 21 & 0 & 0 & & \\
\hline Glencairn Ave. & 0 & 3 & 0 & 5 & 123 & 17 & 0 & 0 & 7 & 0 & 0 & & \\
\hline Duplex Ave. & 0 & 0 & 0 & 1 & 13 & 3 & 0 & 1 & 8 & 1 & 0 & & \\
\hline Dinnick Cres. / Dundurn Rd. & 0 & 0 & 0 & 0 & 39 & 0 & 0 & 0 & 1 & 0 & 0 & & \\
\hline Total & 0 & 3 & 2 & 19 & 191 & 78 & 1 & 15 & 57 & 1 & 0 & 367 & $10 \%$ \\
\hline Roncesvalles & & & & & & & & & & & & 1985 & \\
\hline Lansdowne Ave. & 26 & 12 & 1 & 36 & 0 & 7 & 1 & 1 & 1 & 0 & 0 & & \\
\hline Sorauren Ave. & 46 & 13 & 2 & 44 & 1 & 16 & 1 & 0 & 2 & 1 & 0 & & \\
\hline Macdonell Ave. & 37 & 12 & 2 & 73 & 1 & 17 & 2 & 2 & 2 & 0 & 0 & & \\
\hline Fern Ave. / Pearson Ave. & 45 & 35 & 0 & 58 & 0 & 18 & 3 & 1 & 1 & 6 & 0 & & \\
\hline Seaforth Ave. & 8 & 4 & 1 & 7 & 0 & 4 & 0 & 1 & 1 & 0 & 0 & & \\
\hline Total & 162 & 76 & 6 & 218 & 2 & 62 & 7 & 5 & 7 & 7 & 0 & 552 & $28 \%$ \\
\hline All Neighbourhoods & 608 & 547 & 28 & 613 & 201 & 354 & 39 & 90 & 64 & 9 & 4 & 2557 & $23 \%$ \\
\hline Percent Total & $51 \%$ & $46 \%$ & $2 \%$ & $51 \%$ & $17 \%$ & $29 \%$ & $3 \%$ & $54 \%$ & $38 \%$ & $5 \%$ & $2 \%$ & 11310 & Total homes \\
\hline
\end{tabular}




\section{Appendix E1: Archetype Data: Century Home}

\begin{tabular}{|c|c|c|c|c|c|c|c|c|c|c|c|c|c|c|}
\hline & & & & \multicolumn{2}{|c|}{ Footprint } & & & & Wall Thickness & \multicolumn{5}{|c|}{ Height $(\mathrm{m})$} \\
\hline \# & House Type & Neighbourhood & Shape & Width $(\mathrm{m})$ & Length $(\mathrm{m})$ & Structure & Cladding & Roof & Basement $(\mathrm{m})$ & Basement & Above Grade & Storey 1 & Storey 2 & Storey 3 \\
\hline 3 & Century & Riverdale & L & 6.7 & 13.1 & Brick & Brick & Shingle & 0.3 & 1.5 & 0.85 & 2.6 & 2.6 & 2.5 \\
\hline 5 & Century & Riverdale & Rectangle & 6.5 & 10.2 & Brick & Brick & Shingle & 0.4 & 1.2 & 0.8 & 2.6 & 2.6 & 2.5 \\
\hline 6 & Century & Riverdale & L & 5.3 & 15.7 & Brick & Brick & Shingle & 0.45 & 1.7 & 1.2 & 2.7 & 2.6 & 2.5 \\
\hline 12 & Century & Danforth Village & Rectangle & 5 & 13 & Brick & Brick/Stucco & Shingle & 0.5 & 1.3 & 0.6 & 2.75 & 3 & 2.5 \\
\hline 15 & Century & Trinity-Bellwoods & Rectangle & 5.7 & 16.9 & Brick & Brick & Shingle & 0.3 & & 0.7 & 2.8 & 2.7 & 2.3 \\
\hline 16 & Century & Trinity-Bellwoods & Rectangle & 6.2 & 13 & Brick & Brick & Shingle & & & 0.9 & 2.5 & 2.5 & 2.3 \\
\hline 24 & Century & Danforth Village & Rectangle & 5.2 & 12.1 & Brick & Brick & Shingle & & & 1.5 & 2.7 & 2.6 & \\
\hline Ave & rages or Typ & ical Characteristics & Rectangle & 5.8 & 13.4 & Brick & Brick & Shingle & 0.4 & 1.4 & 0.9 & 2.7 & 2.7 & 2.4 \\
\hline
\end{tabular}

\begin{tabular}{|c|c|c|c|c|c|c|c|c|c|c|c|c|c|c|c|c|c|c|c|c|c|c|c|c|c|c|c|c|c|}
\hline \multicolumn{6}{|c|}{ North Glazing (m2) } & \multicolumn{6}{|c|}{ East Glazing (m2) } & \multicolumn{5}{|c|}{ West Glazing (m2) } & \multicolumn{9}{|c|}{ South Glazing (m2) } & \multicolumn{4}{|c|}{ Window to Wall Ratio } \\
\hline 1 & 2 & 3 & 4 & 5 & 6 & 1 & 2 & 3 & 4 & 5 & 6 & 1 & 2 & 3 & 4 & 5 & 1 & 2 & 3 & 4 & 5 & 6 & 7 & 8 & 9 & North & East & West & South \\
\hline 0.68 & 2.3 & 0.45 & 2.55 & 1.28 & 1.35 & 0.68 & 1.2 & & & & & 0.54 & & & & & 0.68 & 2.3 & 0.85 & 1.2 & 0.78 & 1.2 & & & & 19.9 & 2.6 & 0.75 & 16.2 \\
\hline 0.49 & 0.3 & 2.27 & 1.8 & 2.88 & 1.28 & 0.63 & 1 & 1 & & & & 0.4 & 1.2 & & & & 0.63 & 2.88 & 2.13 & 0.69 & 1.36 & 1.8 & & & & 19.1 & 4.3 & 2.6 & 20.1 \\
\hline 1.01 & 0.94 & 0.96 & 1.81 & 0.96 & 2.67 & 0.81 & 0.7 & & & & & 1.05 & 0.4 & 0.71 & & & 1.3 & 2.63 & 1.72 & 1.29 & 2.63 & 1.72 & 1.29 & 0.44 & 3.6 & 22.8 & 1.4 & 2 & 34.9 \\
\hline 1.68 & 2.08 & 1.62 & & & & 0.94 & 3.24 & 1.38 & & & & 0.24 & 0.33 & 1.91 & & & 1.08 & 1.28 & 0.55 & 1.08 & & & & & & 15.4 & 6.7 & 2.8 & 11.4 \\
\hline 1.1 & 3.42 & 1.87 & 2.38 & 0.26 & 0.88 & 1.28 & 2.81 & 1.32 & 1.45 & 0.53 & & & & & & & 1.36 & 3.59 & 0.56 & 0.76 & & & & & & 25.6 & 7.1 & & 12.9 \\
\hline 2.52 & 3.26 & 0.82 & 1.2 & & & 1.12 & 0.45 & 1.28 & 2.88 & 2.34 & 2.17 & 0.56 & 0.35 & 0.84 & 0.48 & 1.13 & 1.36 & 0.77 & & & & & & & & 17.8 & 11.8 & 3.9 & 4.9 \\
\hline 1.92 & 2.56 & & & & & & & & & & & 0.4 & 2.4 & 2.88 & 1.28 & & 1.2 & 1.28 & 0.66 & & & & & & & 12.7 & & 6.9 & 8.9 \\
\hline & & & & & & & & & & & & & & & & & & & & & & & & & & 19.0 & 5.7 & 3.2 & 15.6 \\
\hline
\end{tabular}

Window Frame Data $(\mathrm{cm})$

\begin{tabular}{|c|c|c|c|c|c|c|c|c|c|c|c|}
\hline \multicolumn{12}{|c|}{ Window Frame Data $(\mathrm{cm})$} \\
\hline Frame Width & Out Projection & In Projection & Divider Type & Divider Width & \# Horiz & \# Vert & Projection & Sill Depth & Sill Material & Reveal Depth & Reveal Material \\
\hline 4 & & 2.5 & Lite & 2.5 & 1 & & 2.5 & 10 & wood & 10 & wood \\
\hline 3 & & 1 & Lite & 7 & 1 & & 3 & 13 & wood & 13 & wood \\
\hline 4 & 1 & 3 & & & & & & 20 & wood & 20 & wood \\
\hline 8 & 1 & 1 & & & & & & 8 & wood & 4 & wood \\
\hline 6 & 1 & 1 & Lite & 4 & 1 & & 1 & 12 & wood & 7 & wood \\
\hline 4 & 1 & 1 & Lite & 4 & 1 & & 1 & 10 & wood & 5 & wood \\
\hline 8 & 1 & 1 & Lite & 9 & 0 & 1 & 1 & 15 & wood & 15 & wood \\
\hline 5.3 & 1.0 & 1.5 & Lite & 5.3 & 0.8 & 1.0 & 1.7 & 12.6 & wood & 10.6 & wood \\
\hline
\end{tabular}




\begin{tabular}{|c|c|c|c|c|c|c|c|}
\hline \multicolumn{2}{|c|}{ Front Doors (m2) } & \multicolumn{3}{|c|}{ Rear Doors (m2) } & \multirow{2}{*}{$\frac{\text { Side Doors (m2) }}{1 \text { (East) }}$} & \multirow{2}{*}{ HVAC } & \multirow[b]{2}{*}{ Thermostat Location } \\
\hline 1 & 2 & 1 & 2 & 3 & & & \\
\hline 1.9 & & 1.6 & 1.6 & & & Forced Air Gas & Dining Room \\
\hline 1.9 & & 1.6 & & & & Forced Air Gas & Main Entrance \\
\hline 1.8 & & 1.8 & 1.8 & 1.8 & & Forced Air Gas & Dining Room \\
\hline 1.78 & & 1.78 & & & & Hot Water Rad & Dining Room \\
\hline 1.99 & 1.6 & 1.79 & 1.71 & & & Gas and Rad & Main Entrance \\
\hline 1.89 & 1.6 & 1.89 & 0.6 & & 1.62 & Hot Water Rad & Main Hallway \\
\hline 1.89 & & 1.78 & 1.8 & 1.8 & & Forced Air Gas & Living Room \\
\hline 1.9 & 1.6 & 1.7 & 1.5 & 1.8 & 1.6 & Forced Air Gas & Dining Room \\
\hline
\end{tabular}




\section{Appendix E2: Archetype Data: Century-Semi}

\begin{tabular}{|c|c|c|c|c|c|c|c|c|c|c|c|c|c|c|}
\hline & & & & \multicolumn{2}{|c|}{ Footprint } & & & & Wall Thickness & \multicolumn{5}{|c|}{ Height (m) } \\
\hline$\#$ & House Type & Neighbourhood & Shape & Width $(\mathrm{m})$ & Length $(\mathrm{m})$ & Structure & Cladding & Roof & Basement $(\mathrm{m})$ & Basement & Above Grade & Storey 1 & Storey 2 & Storey 3 \\
\hline 1 & Cent-Semi & Riverdale & $L$ & 5 & 13.1 & Wood Frame & Brick & Shingle & & & 1.25 & 2.6 & 2.5 & 2.5 \\
\hline 4 & Cent-Semi & Riverdale & Rectangle & 5 & 13 & Brick & Brick & Shingle & 0.4 & 1.25 & 0.85 & 2.6 & 2.6 & 2.5 \\
\hline & Cent-Semi & Danforth Village & $\mathrm{L}$ & 5 & 14 & Brick & Brick/wood & Shingle & 0.4 & 1.4 & 0.6 & 2.6 & 2.6 & 2.5 \\
\hline & Cent-Se mi & Trinity-Bellwoods & $\mathrm{L}$ & 5.4 & 14.6 & Brick & Brick & Shingle & & & 0.65 & 2.6 & 2.7 & 2.7 \\
\hline Ave & erages or Тyp & ical Characteristics & L & 5.1 & 13.7 & Brick & Brick & Shingle & 0.4 & 1.3 & 0.8 & 2.6 & 2.6 & 2.6 \\
\hline
\end{tabular}

\begin{tabular}{|c|c|c|c|c|c|c|c|c|c|c|c|c|c|c|c|c|c|c|c|c|c|}
\hline \multicolumn{5}{|c|}{ North Glazing (m2) } & \multicolumn{6}{|c|}{ East Glazing (m2) } & \multicolumn{8}{|c|}{ South Glazing (m2) } & \multicolumn{3}{|c|}{ Window to Wall } \\
\hline 1 & 2 & 3 & 4 & 5 & 1 & 2 & 3 & 4 & 5 & 6 & 1 & 2 & 3 & 4 & 5 & 6 & 7 & 8 & North & East & South \\
\hline 1.3 & 0.35 & 0.75 & 3 & & 0.7 & 0.6 & 0.7 & & & & 0.7 & 0.7 & 0.8 & & & & & & 16.8 & 2.2 & 6.8 \\
\hline 1.98 & 0.56 & 0.56 & 0.98 & 0.72 & 0.54 & 0.54 & 1.15 & 1.15 & 1.08 & 1.08 & 0.9 & 0.6 & 1.2 & 0.6 & & & & & 14.3 & 7 & 9.8 \\
\hline 1.61 & 2.1 & 0.8 & 0.5 & 0.35 & 0.35 & 0.54 & 2.18 & 0.63 & 0.98 & & 0.42 & 2 & 0.71 & 0.25 & 1.73 & 0.14 & 0.43 & 0.66 & 15.5 & 4.7 & 15.3 \\
\hline 2.43 & 2.43 & 0.47 & 0.47 & & 0.42 & & & & & & 1.05 & 1.48 & 0.6 & 1.05 & & & & & 15.6 & 0.3 & 11.3 \\
\hline & & & & & & & & & & & & & & & & & & & 15.6 & 3.6 & 10.8 \\
\hline
\end{tabular}

Window Frame Data $(\mathrm{cm})$

\begin{tabular}{|c|c|c|c|c|c|c|c|c|c|c|c|}
\hline Frame Width & Out Projection & In Projection & Divider Type & Divider Width & \# Horiz & \# Vert & Projection & Sill Depth & Sill Material & Reveal Depth & Reveal Material \\
\hline 2 & 1 & 1 & Lite & 4 & 1 & 1 & 4 & & & & \\
\hline 5 & 2 & 3 & Lite & 8 & 1 & & 3 & 6 & wood & 6 & wood \\
\hline 6 & 7 & 9 & & & & & & $30 / 9$ & wood/marble & $30 / 9$ & wood \\
\hline 4 & 5 & 5 & Lite & 8 & 1 & & 5 & 12 & wood & 8 & wood \\
\hline 4.3 & 3.8 & 4.5 & Lite & 6.7 & 1.0 & 1.0 & 4.0 & 9.0 & wood & 6.0 & wood \\
\hline
\end{tabular}

\begin{tabular}{|r|r|r|r|r|r|r|l|l|}
\hline \multicolumn{1}{|r|}{ Front Doors (m2) } & \multicolumn{2}{|c|}{ Rear Doors (m2) } & \multicolumn{2}{|c|}{ Side Doors (m2) } & & \\
\hline 1 & 2 & 1 & 2 & 3 & 1 (East) & 2 & HVAC & Thermostat Location \\
\hline 2.2 & & 2.2 & 2.2 & 2.2 & & & Hot Water Rad & Front Hallway \\
\hline 1.75 & & 3.2 & 1.7 & & & & Forced Air Gas & Top of Main Stairs \\
\hline 1.7 & & 1.4 & 1.4 & & 1.48 & 1.48 & Forced Air Gas & Main Floor \\
\hline 1.8 & 1.8 & 1.33 & 1.33 & & & & Forced Air Gas & Main Floor \\
\hline 1.9 & 1.8 & 2.0 & 1.7 & 2.2 & 1.5 & 1.5 & Forced Air Gas & Main Floor \\
\hline
\end{tabular}




\section{Appendix E3: Archetype Data: War Time Home}

\begin{tabular}{|c|c|c|c|c|c|c|c|c|c|c|c|c|}
\hline & & & & \multicolumn{2}{|c|}{ Footprint } & & & & Wall Thickness & \multicolumn{3}{|c|}{ Height (m) } \\
\hline \# & House Type & Neighbourhood & Shape & Width $(\mathrm{m})$ & Length $(\mathrm{m})$ & Structure & Cladding & Roof & Basement $(\mathrm{m})$ & Basement & Above Grade & Storey 1 \\
\hline & WarTime & Danforth Village & Rectangle & 6.3 & 13.5 & Wood Frame & Vinyl Siding & Shingle & 0.35 & 1.1 & 0.85 & 2.6 \\
\hline & War Time & Riverdale & Rectangle & 6.7 & 11.6 & Wood Frame & Brick & Shingle & 0.4 & 1.4 & 1.2 & 2.5 \\
\hline & rages or Typi & cal Characteristics & Rectangle & 6.5 & $12 . \varepsilon$ & Wood Frame & Brick & Shingle & 0.4 & 1.3 & 1.0 & 2.6 \\
\hline
\end{tabular}

\begin{tabular}{|c|c|c|c|c|c|c|c|c|c|c|c|c|c|c|c|c|c|}
\hline \multicolumn{3}{|c|}{ North Glazing (m2) } & \multicolumn{4}{|c|}{ East Glazing (m2) } & \multicolumn{2}{|c|}{ West Glazing (m2) } & \multicolumn{5}{|c|}{ South Glazing (m2) } & \multicolumn{4}{|c|}{ Window to Wall Ratio } \\
\hline 1 & 2 & 3 & 1 & 2 & 3 & 4 & \begin{tabular}{|l|}
1 \\
\end{tabular} & 2 & 1 & 2 & 3 & 4 & 5 & North & East & West & South \\
\hline 1.05 & 1 & & 0.425 & 0.425 & & & & & 1.5 & 1.5 & 0.425 & 0.425 & 0.55 & 12.5 & 2.7 & & 26.9 \\
\hline 1.54 & 2.6 & 0.6 & 1.68 & 1 & 0.5 & 0.25 & 0.35 & 1.2 & 1.3 & 1.3 & 0.35 & 0.35 & & 19.1 & 8 & 3.6 & 13.3 \\
\hline & & & & & & & & & & & & & & 15.8 & 5.4 & 3.6 & 20.1 \\
\hline
\end{tabular}

\section{Window Frame Data $(\mathrm{cm})$}

\begin{tabular}{|c|c|c|c|c|c|c|c|c|c|c|c|}
\hline Frame Width & Out Projection & In Projection & Divider Type & Divider Width & \# Horiz & \# Vert & Projection & Sill Depth & Sill Material & Reveal Depth & Reveal Material \\
\hline 8 & 10 & 5 & & & & & & 10 & wood & 10 & wood \\
\hline 4 & 3 & 3 & Lite & 4 & 1 & 1 & 1 & 12 & wood & 12 & wood \\
\hline 6.0 & 6.5 & 4.0 & Lite & 4.0 & 1.0 & 1.0 & 1.0 & 11.0 & wood & 11.0 & wood \\
\hline
\end{tabular}

\begin{tabular}{|r|r|r|l|l|}
\hline Front Doors (m2) & \multicolumn{2}{|c|}{ Side Doors (m2) } & & \\
\hline 1 & 1 (East) & \multicolumn{1}{|l|}{2} & HVAC & Thermostat Location \\
\hline 1.8 & 1.19 & & Forced Air Gas & Main Room \\
\hline & 1.6 & 1.6 & Forced Air Gas & Main Room \\
\hline 1.8 & 1.4 & 1.6 & Forced Air Gas & Main Room \\
\hline
\end{tabular}




\section{Appendix F: Baseline Energy Model Development}

- Initial baseline models were compared to the baselines of Blaszak (2010)

- Century Home used the most energy and was very close to Blaszak (2010)

- Century-Semi used less energy than Century overall, but $\mathrm{kWh} / \mathrm{m}^{2}$ was greater than Century Home

- War Time Home used the least energy but was not consistent with the results of Blaszak (2010)

- More information is needed to calibrate the models (energy bills)

- Retrofit assemblies were tested to ensure that Level 3 retrofits will meet the performance targets

- The $75 \mathrm{kWh} / \mathrm{m}^{2}$ target was easily achievable for all archetypes

- None of the archetypes achieved the $25 \mathrm{kWh} / \mathrm{m}^{2}$ target

- A sensitivity analysis was performed increasing the efficiency of each retrofit parameter separately

- The models were still very far from reaching the target

- The models were checked for significant errors in the coding

- An error was discovered for air tightness

- $\mathrm{ACH}$ at $50 \mathrm{~Pa}$ was entered whereas EnergyPlus requires $\mathrm{ACH}$ natural

- $\mathrm{ACH}$ at $50 \mathrm{~Pa}$ was converted to $\mathrm{ACH}$ natural

- Models were tested again and all targets were met

- The error was also present in the baseline models and was corrected

- Baseline models for Century and Century-Semi are now significantly different than Blaszak (2010)

- War Time is much closer to the results of Blaszak (2010)

- Century uses the most energy followed by Century-Semi and War Time

- Century-Semi is the most energy intensive, followed by War Time and Century

- Blaszak found Century to be more energy intensive than War Time

- Further calibration using energy bill data is to be undertaken to confirm model accuracy 


\section{Appendix G: Energy Bill Data}

\begin{tabular}{|c|c|c|c|c|c|c|}
\hline & \multicolumn{3}{|c|}{ House 1 Century } & \multicolumn{3}{|c|}{ House 2 Century } \\
\hline & Gas $\mathrm{m}^{3}$ & w/o Hot Water & GJ & Gas $\mathrm{m}^{3}$ & w/o Hot Water & GJ \\
\hline Jan-12 & 0 & 0 & 0.00 & 776 & 726 & 27.78 \\
\hline Feb-12 & 0 & 0 & 0.00 & 466 & 416 & 15.92 \\
\hline Mar-12 & 452 & 402 & 15.38 & 418 & 368 & 14.08 \\
\hline Apr-12 & 392 & 342 & 13.08 & 253 & 203 & 7.77 \\
\hline May-12 & 0 & 0 & 0.00 & 182 & 132 & 5.05 \\
\hline Jun-12 & 63 & 13 & 0.50 & 71 & 21 & 0.80 \\
\hline Jul-12 & 63 & 13 & 0.50 & 59 & 9 & 0.34 \\
\hline Aug-12 & 36 & 0 & 0.00 & 34 & 0 & 0.00 \\
\hline Sep-12 & 110 & 60 & 2.30 & 97 & 47 & 1.80 \\
\hline Oct-12 & 175 & 125 & 4.78 & 199 & 149 & 5.70 \\
\hline Nov-12 & 423 & 373 & 14.27 & 384 & 334 & 12.78 \\
\hline Dec-12 & 435 & 385 & 14.73 & 398 & 348 & 13.31 \\
\hline Year Total & & & 65.54 & & & 105.33 \\
\hline Jan-13 & 793 & 743 & 28.43 & 771 & 721 & 27.59 \\
\hline Feb-13 & 810 & 760 & 29.08 & 796 & 746 & 28.54 \\
\hline Mar-13 & 620 & 570 & 21.81 & 489 & 439 & 16.80 \\
\hline Apr-13 & 567 & 517 & 19.78 & 546 & 496 & 18.98 \\
\hline May-13 & 196 & 146 & 5.59 & 162 & 112 & 4.29 \\
\hline Jun-13 & 109 & 59 & 2.26 & 82 & 32 & 1.22 \\
\hline Jul-13 & 55 & 5 & 0.19 & 0 & 0 & 0.00 \\
\hline Aug-13 & 59 & 9 & 0.34 & 51 & 1 & 0.04 \\
\hline Sep-13 & 122 & 72 & 2.75 & 114 & 64 & 2.45 \\
\hline Oct-13 & 114 & 64 & 2.45 & 111 & 61 & 2.33 \\
\hline Nov-13 & 426 & 376 & 14.39 & 389 & 339 & 12.97 \\
\hline Dec-13 & 0 & 0 & 0.00 & 620 & 570 & 21.81 \\
\hline Year Total & & & 127.06 & & & 137.01 \\
\hline
\end{tabular}




\begin{tabular}{|c|c|c|c|c|c|c|}
\hline & \multicolumn{3}{|c|}{ House 1 Century-Semi } & \multicolumn{3}{|c|}{ House 2 Century-Semi } \\
\hline & Gas $\mathrm{m}^{3}$ & w/o Hot Water & GJ & Gas $\mathrm{m}^{3}$ & w/o Hot Water & GJ \\
\hline Jan-12 & 745 & 695 & 26.59 & 687 & 658 & 25.18 \\
\hline Feb-12 & 153 & 103 & 3.94 & 330 & 301 & 11.52 \\
\hline Mar-12 & 387 & 337 & 12.89 & 379 & 350 & 13.39 \\
\hline Apr-12 & 216 & 166 & 6.35 & 240 & 211 & 8.07 \\
\hline May-12 & 156 & 106 & 4.06 & 137 & 108 & 4.13 \\
\hline Jun-12 & 65 & 15 & 0.57 & 21 & 0 & 0.00 \\
\hline Jul-12 & 59 & 9 & 0.34 & 29 & 0 & 0.00 \\
\hline Aug-12 & 37 & 0 & 0.00 & 21 & 0 & 0.00 \\
\hline Sep-12 & 88 & 38 & 1.45 & 64 & 35 & 1.34 \\
\hline Oct-12 & 108 & 58 & 2.22 & 0 & 0 & 0.00 \\
\hline Nov-12 & 264 & 214 & 8.19 & 276 & 247 & 9.45 \\
\hline Dec-12 & 298 & 248 & 9.49 & 308 & 279 & 10.67 \\
\hline Year Total & & & 76.10 & & & 83.75 \\
\hline Jan-13 & 511 & 461 & 17.64 & 582 & 553 & 21.16 \\
\hline Feb-13 & 588 & 538 & 20.58 & 555 & 526 & 20.12 \\
\hline Mar-13 & 429 & 379 & 14.50 & 437 & 408 & 15.61 \\
\hline Apr-13 & 319 & 269 & 10.29 & 342 & 313 & 11.98 \\
\hline May-13 & 148 & 98 & 3.75 & 133 & 104 & 3.98 \\
\hline Jun-13 & 60 & 10 & 0.38 & 0 & 0 & 0.00 \\
\hline Jul-13 & 54 & 4 & 0.15 & 29 & 0 & 0.00 \\
\hline Aug-13 & 77 & 27 & 1.03 & 27 & 0 & 0.00 \\
\hline Sep-13 & 97 & 47 & 1.80 & 66 & 37 & 1.42 \\
\hline Oct-13 & 63 & 13 & 0.50 & 84 & 55 & 2.10 \\
\hline Nov-13 & 0 & 0 & 0.00 & 277 & 248 & 9.49 \\
\hline Dec-13 & 0 & 0 & 0.00 & 471 & 442 & 16.91 \\
\hline Year Total & & & 70.63 & & & 102.77 \\
\hline
\end{tabular}




\section{Appendix H: Model Calibration}

\section{Century:}

- 4 Separate simulations took place using two energy bill sets and years

○ House 1, 2012

- House 1, 2013

- House 2, 2012

- House 2, 2013

- Pre-calibration energy usage comparison is as follows (note: months were energy bill data was missing are omitted):

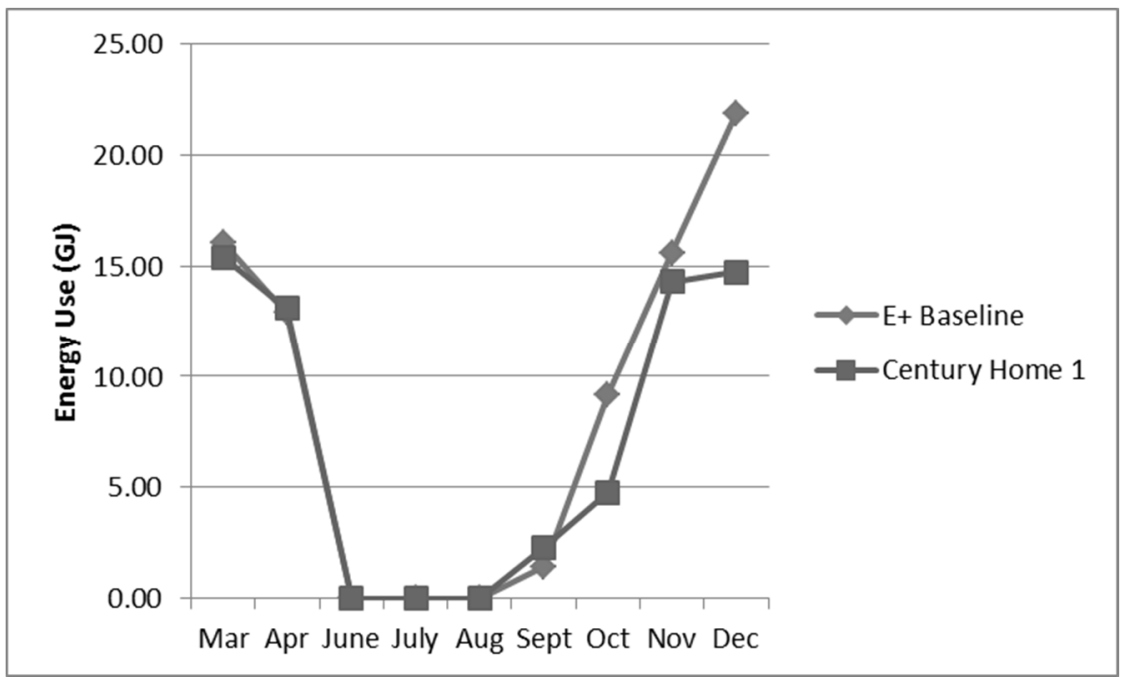

Century Home 1, 2012, monthly pre-calibration results

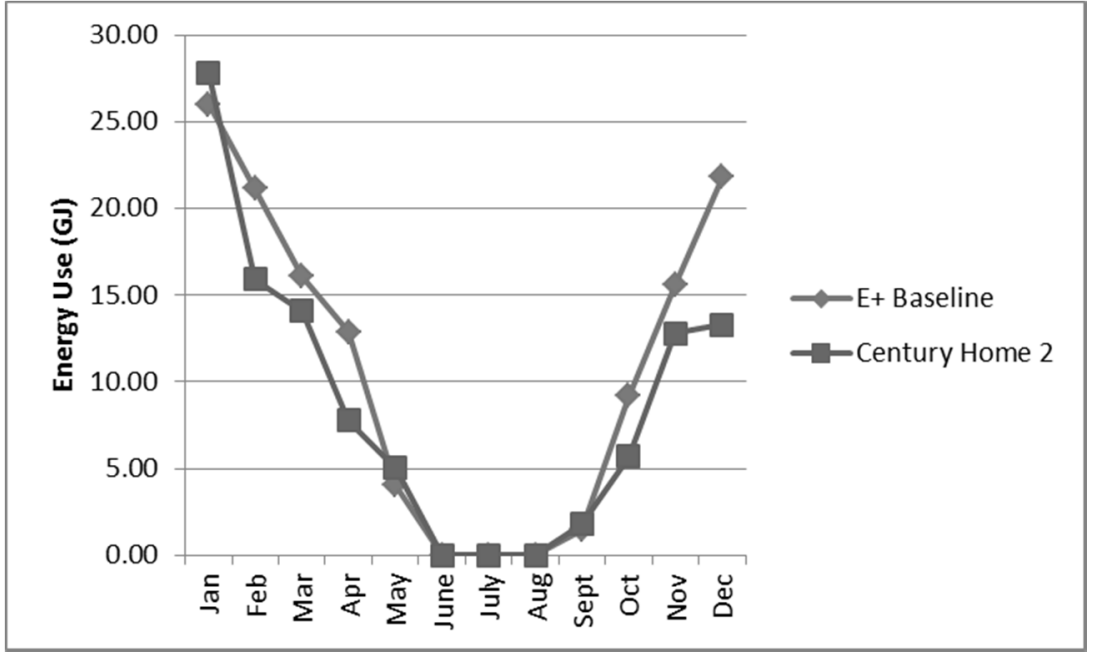

Century Home 2, 2012, monthly pre-calibration results 


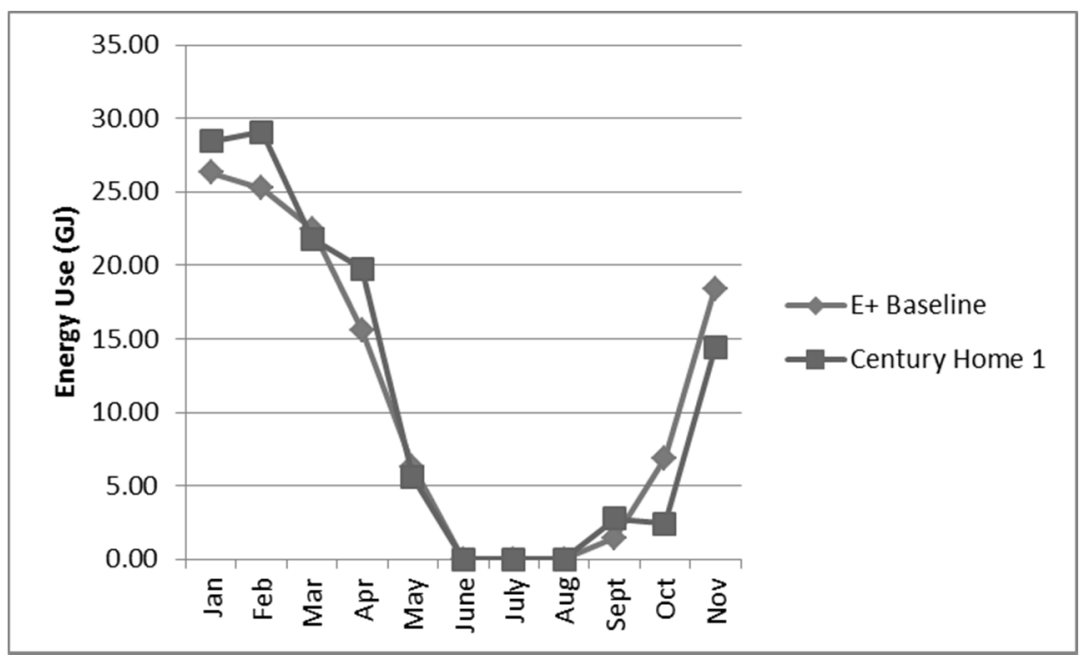

Century Home 1, 2013, monthly pre-calibration results

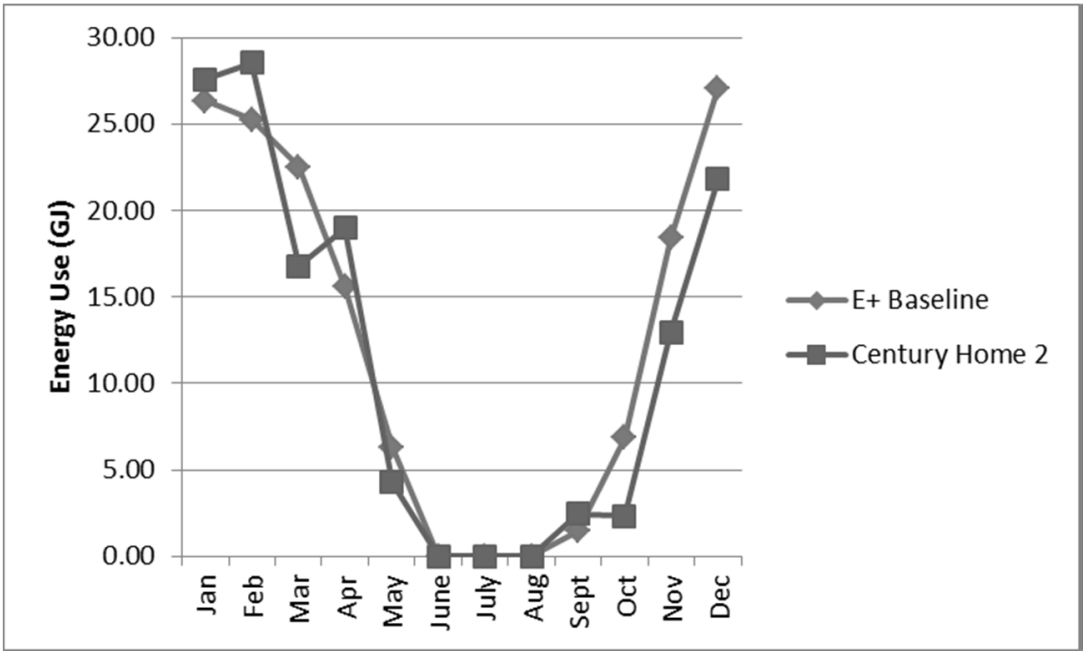

Century Home 2, 2013, monthly pre-calibration results

- In all cases, the energy model tended to over-predict energy use

- Insulation was increased in walls from $25 \mathrm{~mm}$ to $75 \mathrm{~mm}$ and in roof from $100 \mathrm{~mm}$ to $200 \mathrm{~mm}$. This is still within the average ranges given by Blaszak (2010)

- For 2012, models were much closer to measured data, except:

○ January under-predicts

- December over-predicts

- For 2013, models were much closer to measured data, except:

- January, February, and April under-predicts

- October, November, December over-predict

- Air Tightness was increased within the tolerances of the LBL N-Factor

- Calibration could not be achieved

\section{Internal Gain Calibration:}

- Number of occupants was increased by 1 to 5 people total 
- All appliance loads were doubled

- All lighting loads were doubled

- Heating load dropped slightly, uniformly across all months. The model does not appear to be very sensitive to internal gain adjustments

\section{Century-Semi:}

- 4 Separate simulations took place using two energy bill sets and years

○ House 1, 2012

○ House 1, 2013

○ House 2, 2012

- House 2, 2013

- Pre-calibration energy usage comparison is as follows (note months where energy bill data was missing are omitted):

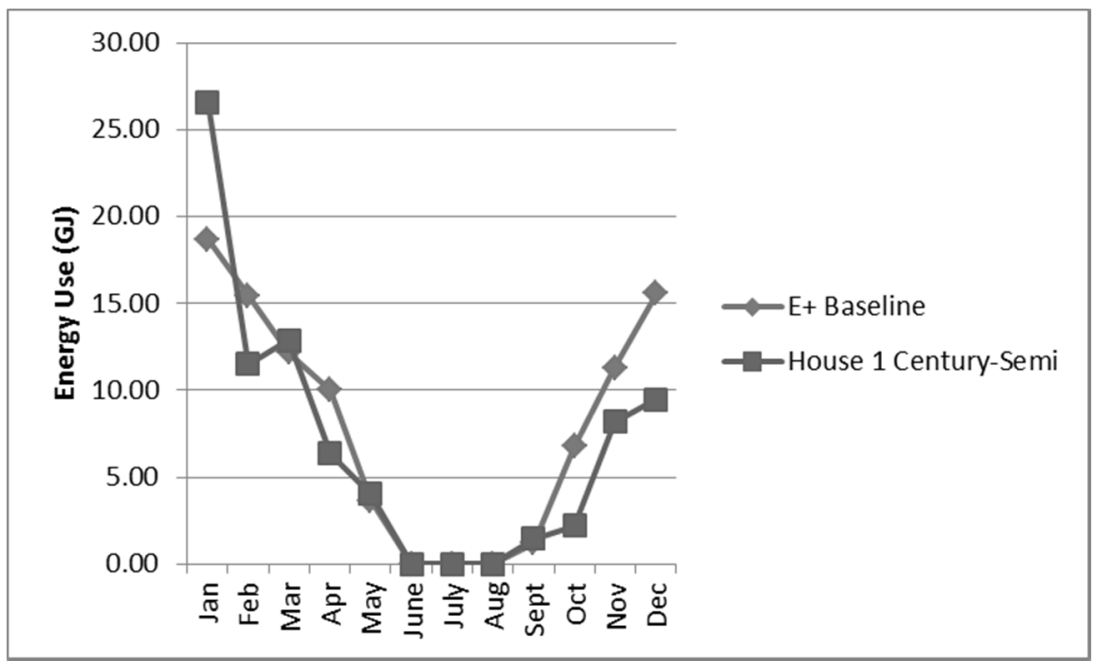

Century-Semi Home 1, 2012, monthly pre-calibration results

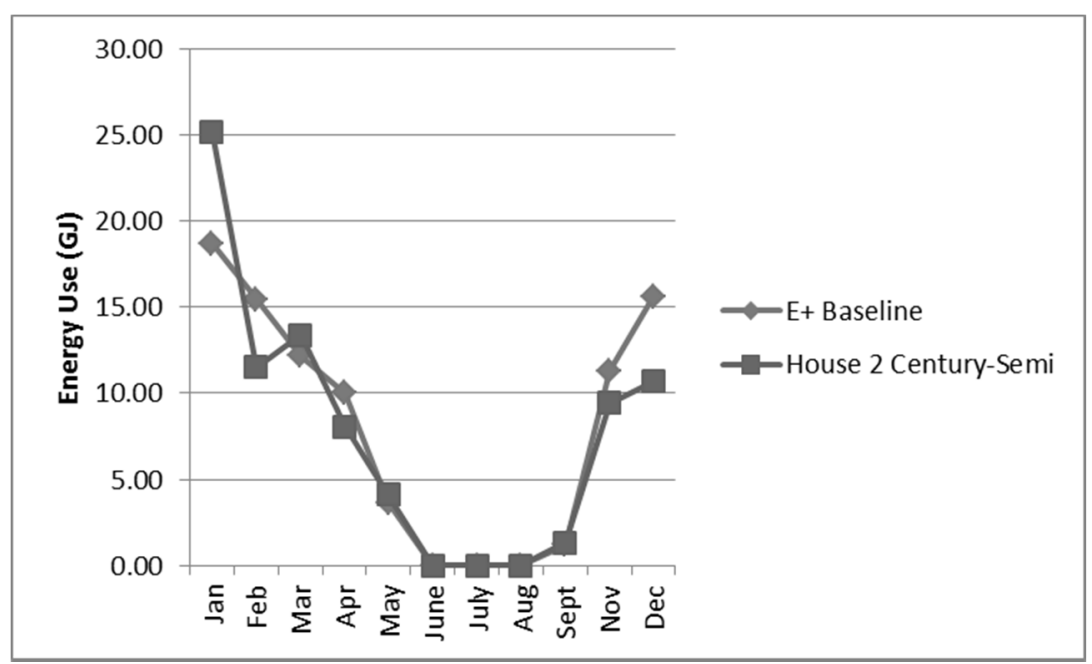

Century-Semi Home 2, 2012, monthly pre-calibration results 


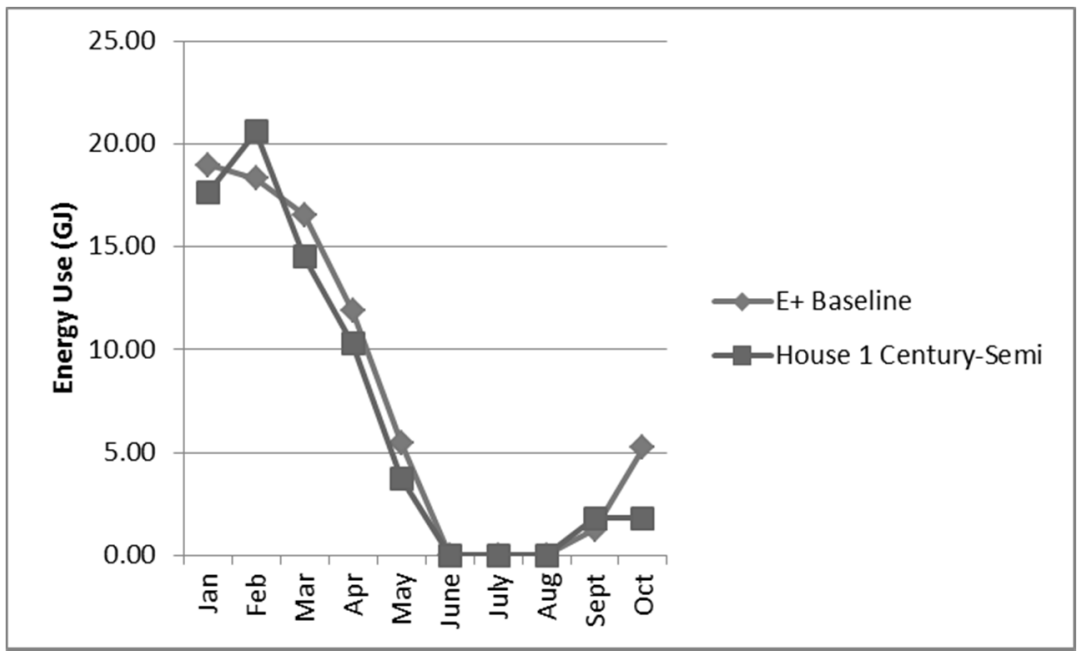

Century-Semi Home 1, 2013, monthly pre-calibration results

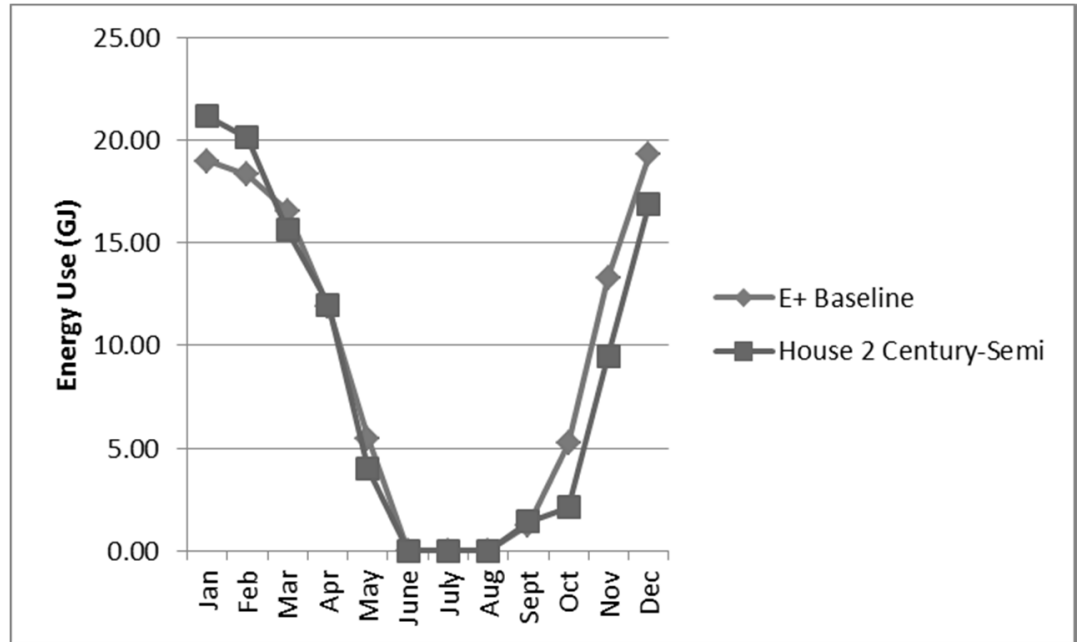

Century-Semi Home 2, 2013, monthly pre-calibration results

- In all cases, the energy model over-predicted energy use except January 2012 where the model under-predicted energy use

- Insulation was increased in walls from $25 \mathrm{~mm}$ to $75 \mathrm{~mm}$ and in roof from $100 \mathrm{~mm}$ to $200 \mathrm{~mm}$. This is still within the average ranges given by Blaszak (2010)

- For 2012, models were much closer to measured data, except:

- January under-predicts

- October and December over-predict

- For 2013, models were much closer to measured data, except:

- January and February under-predict

- October, November, December over-predict

- Air Tightness was increased within the tolerances of the LBL N-Factor

- Calibration could not be achieved 


\section{Normalizing Energy Bills to Degree Days:}

- Degree days sourced for Toronto Centre (Government of Canada, 2014)

- Dividing monthly E+ energy usage by degree days gives consistent value of GJ/DD

- Dividing energy bills by degree days gives varying values

- Taking average of GJ/DD for energy bills and multiplying monthly degree days by the average GJ/DD gives a smooth monthly curve similar to the $\mathrm{E}+$ curve

- This is to account for energy bill estimations, gaps in the energy bill data, and varying billing periods (monthly billing does not have a consistent number of days per month)

- Very consistent trend of energy models over-predicting energy use.

- Century Homes

- Increased ceiling insulation for both homes (100-200mm) within ranges given by Blaszak (2010)

- Century Home 1 Calibrated for 2012 and 2013

- Decreased ACH for Home 2 from 10.54 to 6.8

- Century Home 2 Calibrated for 2012 and 2013

- Century-Semi Homes

- Increased ceiling insulation for both homes (100-200mm) within ranges given by Blaszak (2010)

○ Century-Semi 2 Calibrated for 2012 and 2013

- Decreased ACH from 11.7 to 10.2

- Century-Semi Home 1 Calibrated for 2012 and 2013

- All scenarios were able to be calibrated keeping housing characteristics constant across data sets. For example Home 1 was calibrated in both 2012 and 2013 using the same envelope and air tightness parameters. 


\section{Appendix I: Normalized Energy Bill Data and Calibration Summary}

Century Home 1, 2012:

\begin{tabular}{|c|c|c|c|c|c|c|}
\hline & EnergyPlus & Energy Bill & Heating & E+ Baseline & Energy Bill & Normalized Energy Bill \\
\hline & (GJ) & $(G J)$ & Degree Days & (GJ/HDD) & $(G J / H D D)$ & (Avg Energy Bill GJ/HDD * HDD) \\
\hline January & 25.9830 & 0.0000 & 578.0000 & 0.0450 & & 21.1548 \\
\hline February & 21.1375 & 0.0000 & 478.0000 & 0.0442 & & 17.4948 \\
\hline March & 16.0586 & 15.3805 & 344.0000 & 0.0467 & 0.0447 & 12.5904 \\
\hline April & 12.8741 & 13.0849 & 315.0000 & 0.0409 & 0.0415 & 11.5290 \\
\hline May & 4.0482 & 0.0000 & 100.0000 & 0.0405 & & 3.6600 \\
\hline September & 1.4433 & 2.2956 & 73.0000 & 0.0198 & 0.0314 & 2.6718 \\
\hline October & 9.1774 & 4.7825 & 231.0000 & 0.0397 & & 8.4546 \\
\hline November & 15.5754 & 14.2710 & 396.0000 & 0.0393 & 0.0360 & 14.4936 \\
\hline \multirow{2}{*}{ December } & 21.8250 & 14.7301 & 503.0000 & 0.0434 & 0.0293 & 18.4098 \\
\hline & Sum & 64.5445 & Average & 0.0399 & 0.0366 & 110.4588 \\
\hline
\end{tabular}

\begin{tabular}{|l|r|r|r|r|r|}
\hline 2012 & E+ Baseline & Century Home 1 & AVG. & MBE & CVRMSE \\
\hline Jan & 23.35 & 21.15 & 21.15 & -2.19 & 4.81232 \\
\hline Feb & 18.99 & 17.49 & 17.49 & -1.49 & 2.233231 \\
\hline Mar & 14.38 & 12.59 & 12.59 & -1.79 & 3.216284 \\
\hline Apr & 11.52 & 11.53 & 11.53 & 0.01 & $3.84 E-05$ \\
\hline May & 3.63 & 3.66 & 3.66 & 0.03 & 0.001186 \\
\hline June & 0.00 & 0.00 & 0.00 & 0.00 & 0 \\
\hline July & 0.00 & 0.00 & 0.00 & 0.00 & 0 \\
\hline Aug & 0.00 & 0.00 & 0.00 & 0.00 & 0 \\
\hline Sept & 1.19 & 2.67 & 2.67 & 1.48 & 2.197362 \\
\hline Oct & 8.12 & 8.45 & 8.45 & 0.33 & 0.11049 \\
\hline Nov & 13.96 & 14.49 & 14.49 & 0.54 & 0.287082 \\
\hline Dec & 19.63 & 18.41 & 18.41 & -1.22 & 1.49891 \\
\hline & & & SUM & $-4 \%$ & $12 \%$ \\
\hline
\end{tabular}

Century Home 2, 2012:

\begin{tabular}{|c|c|c|c|c|c|c|}
\hline & EnergyPlus & Energy Bill & Heating & E+ Baseline & Energy Bill & Normalized Energy Bill \\
\hline & $(G J)$ & (GJ) & Degree Days & $(G J / H D D)$ & (GJ/HDD) & (Avg Energy Bill GJ/HDD * HDD) \\
\hline January & 25.9830 & 27.7767 & 578.0000 & 0.0450 & 0.0481 & 19.6173 \\
\hline February & 21.1375 & 15.9161 & 478.0000 & 0.0442 & 0.0333 & 16.2233 \\
\hline March & 16.0586 & 14.0797 & 344.0000 & 0.0467 & 0.0409 & 11.6754 \\
\hline April & 12.8741 & 7.7668 & 315.0000 & 0.0409 & 0.0247 & 10.6911 \\
\hline May & 4.0482 & 5.0503 & 100.0000 & 0.0405 & 0.0505 & 3.3940 \\
\hline September & 1.4433 & 1.7982 & 73.0000 & 0.0198 & 0.0246 & 2.4776 \\
\hline October & 9.1774 & 5.7007 & 231.0000 & 0.0397 & 0.0247 & 7.8401 \\
\hline November & 15.5754 & 12.7788 & 396.0000 & 0.0393 & 0.0323 & 13.4402 \\
\hline \multirow[t]{2}{*}{ December } & 21.8250 & 13.3145 & 503.0000 & 0.0434 & 0.0265 & 17.0718 \\
\hline & Sum & \multicolumn{2}{|c|}{ 104.1818 Average } & 0.0399 & 0.0339 & 102.4309 \\
\hline
\end{tabular}




\begin{tabular}{|l|r|r|r|r|r|}
\hline 2012 & E+ Baseline & Century Home 2 & AVG. & MBE & CVRMSE \\
\hline Jan & 21.71 & 19.62 & 19.62 & -2.10 & 4.391875 \\
\hline Feb & 17.67 & 16.22 & 16.22 & -1.44 & 2.082769 \\
\hline Mar & 13.34 & 11.68 & 11.68 & -1.66 & 2.771692 \\
\hline Apr & 10.68 & 10.69 & 10.69 & 0.01 & 0.00018 \\
\hline May & 3.37 & 3.39 & 3.39 & 0.02 & 0.000518 \\
\hline June & 0.00 & 0.00 & 0.00 & 0.00 & 0 \\
\hline July & 0.00 & 0.00 & 0.00 & 0.00 & 0 \\
\hline Aug & 0.00 & 0.00 & 0.00 & 0.00 & 0 \\
\hline Sept & 1.03 & 2.48 & 2.48 & 1.45 & 2.110105 \\
\hline Oct & 7.46 & 7.84 & 7.84 & 0.38 & 0.146169 \\
\hline Nov & 13.00 & 13.44 & 13.44 & 0.44 & 0.191967 \\
\hline Dec & 18.30 & 17.07 & 17.07 & -1.22 & 1.499596 \\
\hline & & & SUM & $-4 \%$ & $13 \%$ \\
\hline
\end{tabular}

Century Home 1, 2013:

\begin{tabular}{|c|c|c|c|c|c|c|}
\hline & EnergyPlus & Energy Bill & Heating & E+ Baseline & Energy Bill & Normalized Energy Bill \\
\hline & $(G J)$ & $(G J)$ & Degree Days & (GJ/HDD) & (GJ/HDD) & (Avg Energy Bill GJ/HDD * HDD) \\
\hline January & 26.3306 & 28.4271 & 596.0000 & 0.0442 & 0.0477 & 22.6927 \\
\hline February & 25.2432 & 29.0776 & 569.0000 & 0.0444 & & 21.6647 \\
\hline March & 22.4979 & 21.8082 & 525.0000 & 0.0429 & 0.0415 & 19.9894 \\
\hline April & 15.5978 & 19.7804 & 354.0000 & 0.0441 & 0.0559 & 13.4786 \\
\hline May & 6.3153 & 5.5860 & 140.0000 & 0.0451 & 0.0399 & 5.3305 \\
\hline September & 1.4396 & 2.7547 & 78.0000 & 0.0185 & 0.0353 & 2.9699 \\
\hline October & 6.8776 & 2.4486 & 191.0000 & 0.0360 & 0.0128 & 7.2723 \\
\hline November & 18.3991 & 14.3857 & 431.0000 & 0.0427 & 0.0334 & 16.4103 \\
\hline December & 27.0742 & 0.0000 & 644.0000 & 0.0420 & & 24.5203 \\
\hline \multicolumn{2}{|r|}{ Sum } & \multicolumn{2}{|c|}{ 124.2683 Average } & 0.0400 & 0.0381 & 134.3286 \\
\hline
\end{tabular}

\begin{tabular}{|l|r|r|r|r|r|}
\hline 2013 & E+ Baseline & Century Home 1 & AVG. & MBE & CVRMSE \\
\hline Jan & 23.67 & 22.69 & 22.69 & -0.97 & 0.948092 \\
\hline Feb & 22.66 & 21.66 & 21.66 & -1.00 & 0.993062 \\
\hline Mar & 20.25 & 19.99 & 19.99 & -0.26 & 0.068291 \\
\hline Apr & 13.94 & 13.48 & 13.48 & -0.46 & 0.212106 \\
\hline May & 5.60 & 5.33 & 5.33 & -0.27 & 0.07235 \\
\hline June & 0.00 & 0.00 & 0.00 & 0.00 & 0 \\
\hline July & 0.00 & 0.00 & 0.00 & 0.00 & 0 \\
\hline Aug & 0.00 & 0.00 & 0.00 & 0.00 & 0 \\
\hline Sept & 1.18 & 2.97 & 2.97 & 1.79 & 3.191154 \\
\hline Oct & 6.04 & 7.27 & 7.27 & 1.23 & 1.515004 \\
\hline Nov & 16.36 & 16.41 & 16.41 & 0.05 & 0.002696 \\
\hline Dec & 24.28 & 24.52 & 24.52 & 0.24 & 0.056122 \\
\hline & & & SUM & $0 \%$ & $7 \%$ \\
\hline
\end{tabular}


Century Home 2, 2013:

\begin{tabular}{|c|c|c|c|c|c|c|}
\hline & EnergyPlus & Energy Bill & Heating & E+ Baseline & Energy Bill & Normalized Energy Bill \\
\hline & $(G J)$ & $(G J)$ & Degree Days & $(G J / H D D)$ & $(G J / H D D)$ & (Avg Energy Bill GJ/HDD * HDD) \\
\hline January & 26.3306 & 27.5854 & 596.0000 & 0.0442 & 0.0463 & $\begin{array}{r}21.2057 \\
\end{array}$ \\
\hline February & 25.2432 & 28.5419 & 569.0000 & 0.0444 & 0.0502 & 20.2450 \\
\hline March & 22.4979 & 16.7961 & 525.0000 & 0.0429 & 0.0320 & 18.6795 \\
\hline April & 15.5978 & 18.9769 & 354.0000 & 0.0441 & 0.0536 & 12.5953 \\
\hline May & 6.3153 & 4.2851 & 140.0000 & 0.0451 & 0.0306 & 4.9812 \\
\hline September & 1.4396 & 2.4486 & 78.0000 & 0.0185 & 0.0314 & 2.7752 \\
\hline October & 6.8776 & 2.3339 & 191.0000 & 0.0360 & 0.0122 & 6.7958 \\
\hline November & 18.3991 & 12.9701 & 431.0000 & 0.0427 & 0.0301 & 15.3350 \\
\hline \multirow[t]{2}{*}{ December } & 27.0742 & 21.8082 & 644.0000 & 0.0420 & 0.0339 & 22.9135 \\
\hline & Sum & 135.7463 & Average & 0.0400 & 0.0356 & 125.5262 \\
\hline
\end{tabular}

\begin{tabular}{|l|r|r|r|r|r|}
\hline 2013 & E+ Baseline & Century Home 2 & AVG. & MBE & CVRMSE \\
\hline Jan & 22.04 & 21.21 & 21.21 & -0.83 & 0.69609 \\
\hline Feb & 21.07 & 20.25 & 20.25 & -0.82 & 0.673516 \\
\hline Mar & 18.89 & 18.68 & 18.68 & -0.22 & 0.046397 \\
\hline Apr & 12.87 & 12.60 & 12.60 & -0.28 & 0.077774 \\
\hline May & 5.14 & 4.98 & 4.98 & -0.16 & 0.025195 \\
\hline June & 0.00 & 0.00 & 0.00 & 0.00 & 0 \\
\hline July & 0.00 & 0.00 & 0.00 & 0.00 & 0 \\
\hline Aug & 0.00 & 0.00 & 0.00 & 0.00 & 0 \\
\hline Sept & 1.03 & 2.78 & 2.78 & 1.75 & 3.055084 \\
\hline Oct & 5.52 & 6.80 & 6.80 & 1.28 & 1.638963 \\
\hline Nov & 15.05 & 15.33 & 15.33 & 0.28 & 0.079626 \\
\hline Dec & 22.57 & 22.91 & 22.91 & 0.35 & 0.120701 \\
\hline & & & SUM & $1 \%$ & $7 \%$ \\
\hline
\end{tabular}

Century-Semi Home 1, 2012:

\begin{tabular}{|c|c|c|c|c|c|c|}
\hline & EnergyPlus & Energy Bill & Heating & E+ Baseline & Energy Bill & Normalized Energy Bill \\
\hline & (GJ) & (GJ) & Degree Days & (GJ/HDD) & (GJ/HDD) & (Avg Energy Bill GJ/HDD * HDD) \\
\hline January & 18.6883 & 26.5907 & 578.0000 & 0.0323 & 0.0460 & 15.3170 \\
\hline February & 15.4704 & 3.9400 & 478.0000 & 0.0324 & 0.0082 & 12.6670 \\
\hline March & 12.1793 & 12.8936 & 344.0000 & 0.0354 & 0.0375 & 9.1160 \\
\hline April & 10.0111 & 6.3511 & 315.0000 & 0.0318 & 0.0202 & 8.3475 \\
\hline May & 3.6788 & 4.0556 & 100.0000 & 0.0368 & 0.0406 & 2.6500 \\
\hline September & 1.2307 & 1.4539 & 73.0000 & 0.0169 & 0.0199 & 1.9345 \\
\hline October & 6.7844 & 2.2191 & 231.0000 & 0.0294 & & 6.1215 \\
\hline November & 11.2996 & 8.1876 & 396.0000 & 0.0285 & 0.0207 & 10.4940 \\
\hline \multirow[t]{2}{*}{ December } & 15.5884 & 9.4885 & 503.0000 & 0.0310 & 0.0189 & 13.3295 \\
\hline & Sum & 75.1800 & Average & 0.0305 & 0.0265 & 79.9770 \\
\hline
\end{tabular}




\begin{tabular}{|l|r|r|r|r|r|}
\hline 2012 & E+ Baseline & Century-Semi Home 1 & AVG. & MBE & CVRMSE \\
\hline Jan & 16.26 & 15.32 & 15.32 & -0.95 & 0.897377 \\
\hline Feb & 13.50 & 12.67 & 12.67 & -0.84 & 0.702076 \\
\hline Mar & 10.65 & 9.12 & 9.12 & -1.54 & 2.36114 \\
\hline Apr & 8.79 & 8.35 & 8.35 & -0.44 & 0.194093 \\
\hline May & 3.31 & 2.65 & 2.65 & -0.66 & 0.429392 \\
\hline June & 0.00 & 0.00 & 0.00 & 0.00 & 0 \\
\hline July & 0.00 & 0.00 & 0.00 & 0.00 & 0 \\
\hline Aug & 0.00 & 0.00 & 0.00 & 0.00 & 0 \\
\hline Sept & 0.98 & 1.93 & 1.93 & 0.96 & 0.917009 \\
\hline Oct & 5.82 & 6.12 & 6.12 & 0.30 & 0.089419 \\
\hline Nov & 9.85 & 10.49 & 10.49 & 0.65 & 0.418247 \\
\hline Dec & 13.59 & 13.33 & 13.33 & -0.26 & 0.067496 \\
\hline & & & SUM & $-4 \%$ & $11 \%$ \\
\hline
\end{tabular}

Century-Semi Home 2, 2012:

\begin{tabular}{|c|c|c|c|c|c|c|c|c|c|c|c|}
\hline & EnergyPlus & Energy Bill & & Heating & $\mathrm{E}+$ Base & eline & Energy & y Bill & \multicolumn{3}{|c|}{ Normalized Energy Bill } \\
\hline & (GJ) & \multicolumn{2}{|l|}{$(G J)$} & Degree Days 1 & \multicolumn{2}{|c|}{ (GJ/HDD) } & \multicolumn{2}{|c|}{ (GJ/HDD) } & \multicolumn{3}{|c|}{ (Avg Energy Bill GJ/HDD*HDD) } \\
\hline January & \multicolumn{2}{|c|}{18.6883} & 25.1750 & 578.0000 & \multicolumn{2}{|c|}{0.0323} & \multicolumn{2}{|r|}{0.0436} & \multicolumn{3}{|r|}{17.1088} \\
\hline February & \multicolumn{2}{|c|}{15.4704} & 11.5162 & 478.0000 & \multirow{2}{*}{\multicolumn{2}{|c|}{0.0324}} & \multicolumn{2}{|r|}{0.0241} & \multicolumn{3}{|r|}{14.1488} \\
\hline March & \multicolumn{2}{|c|}{12.1793} & 13.3910 & 344.0000 & \multirow{2}{*}{\multicolumn{2}{|c|}{$\begin{array}{l}0.0354 \\
0.0318\end{array}$}} & \multirow{2}{*}{\multicolumn{2}{|c|}{$\begin{array}{l}0.0389 \\
0.0256\end{array}$}} & \multirow{2}{*}{\multicolumn{3}{|c|}{$\begin{array}{r}10.1824 \\
9.3240\end{array}$}} \\
\hline April & \multirow{2}{*}{\multicolumn{2}{|c|}{$\begin{array}{r}1.0111 \\
3.6788\end{array}$}} & 8.0728 & 315.0000 & & & & & & & \\
\hline May & & & 4.1321 & 100.0000 & \multicolumn{2}{|c|}{0.0368} & \multicolumn{2}{|r|}{0.0413} & \multicolumn{3}{|r|}{2.9600} \\
\hline September & \multicolumn{2}{|c|}{1.2307} & 1.3391 & 73.0000 & & 0.0169 & \multirow{2}{*}{\multicolumn{2}{|c|}{0.0183}} & \multirow{2}{*}{\multicolumn{3}{|c|}{$\begin{array}{l}2.1608 \\
6.8376\end{array}$}} \\
\hline October & \multicolumn{2}{|c|}{6.7844} & 0.0000 & 231.0000 & \multicolumn{2}{|c|}{0.0294} & & & & & \\
\hline November & \multicolumn{2}{|c|}{11.2996} & 9.4502 & 396.0000 & & 0.0285 & \multicolumn{2}{|r|}{0.0239} & \multicolumn{3}{|r|}{11.7216} \\
\hline December & 15.588 & & 10.6745 & 503.0000 & & 0.0310 & & 0.0212 & & & 14.8888 \\
\hline & Sum & & 83.7510 & Average & & 0.0305 & & 0.0296 & & & 89.3328 \\
\hline & 2012 & $E+$ Baseline & Centur & $y$-Semi Home & ne 2 & AVG. & & MBE & & CVRMSE & \\
\hline & Jan & 16.75 & & & 17.11 & & 17.11 & & 0.36 & 0.127949 & \\
\hline & Feb & 13.90 & & & 14.15 & & 14.15 & & 0.25 & 0.0628 & \\
\hline & Mar & 10.96 & & & 10.18 & & 10.18 & & -0.78 & 0.608712 & \\
\hline & Apr & 9.04 & & & 9.32 & & 9.32 & & 0.29 & 0.081288 & \\
\hline & May & 3.39 & & & 2.96 & & 2.96 & & -0.43 & 0.181144 & \\
\hline & June & 0.00 & & & 0.00 & & 0.00 & & 0.00 & 0 & \\
\hline & July & 0.00 & & & 0.00 & & 0.00 & & 0.00 & 0 & \\
\hline & Aug & 0.00 & & & 0.00 & & 0.00 & & 0.00 & 0 & \\
\hline & Sept & 1.03 & & & 2.16 & & 2.16 & & 1.13 & 1.27993 & \\
\hline & Oct & 6.02 & & & 6.84 & & 6.84 & & 0.82 & 0.673893 & \\
\hline & Nov & 10.13 & & & 11.72 & & 11.72 & & 1.59 & 2.536693 & \\
\hline & Dec & 13.99 & & & 14.89 & & 14.89 & & 0.90 & 0.81577 & \\
\hline & & & & & & SUM & & & $5 \%$ & $10 \%$ & \\
\hline
\end{tabular}


Century-Semi Home 1, 2013:

\begin{tabular}{|c|c|c|c|c|c|c|}
\hline & EnergyPlus & Energy Bill & Heating & E+ Baseline & Energy Bill & Normalized Energy Bill \\
\hline & $(G J)$ & (GJ) & Degree Days & $(\mathrm{GJ} / \mathrm{HDD})$ & (GJ/HDD) & (Avg Energy Bill GJ/HDD * HDD) \\
\hline January & 18.9753 & 17.6378 & 596.0000 & 0.0318 & 0.0296 & 15.4722 \\
\hline February & 18.3077 & 20.5838 & 569.0000 & 0.0322 & 0.0362 & 14.7712 \\
\hline March & 16.5525 & 14.5005 & 525.0000 & 0.0315 & 0.0276 & 13.6290 \\
\hline April & 11.8670 & 10.2919 & 354.0000 & 0.0335 & 0.0291 & 9.1898 \\
\hline May & 5.4586 & 3.7495 & 140.0000 & 0.0390 & 0.0268 & 3.6344 \\
\hline September & 1.2665 & 1.7982 & 78.0000 & 0.0162 & 0.0231 & 2.0249 \\
\hline October & 5.2385 & 1.8000 & 191.0000 & 0.0274 & 0.0094 & 4.9584 \\
\hline November & 13.2976 & 0.0000 & 431.0000 & 0.0309 & & 11.1888 \\
\hline \multirow[t]{2}{*}{ December } & 19.2901 & 0.0000 & 644.0000 & 0.0300 & & 16.7182 \\
\hline & Sum & 70.3618 & Average & 0.0303 & 0.0260 & 91.5869 \\
\hline
\end{tabular}

\begin{tabular}{|l|r|r|r|r|r|}
\hline 2013 & E+ Baseline & Century-Semi Home 1 & AVG. & MBE & CVRMSE \\
\hline Jan & 16.54 & 15.47 & 15.47 & -1.07 & 1.134736 \\
\hline Feb & 15.93 & 14.77 & 14.77 & -1.16 & 1.350383 \\
\hline Mar & 14.51 & 13.63 & 13.63 & -0.88 & 0.779512 \\
\hline Apr & 10.34 & 9.19 & 9.19 & -1.15 & 1.31942 \\
\hline May & 4.81 & 3.63 & 3.63 & -1.18 & 1.391928 \\
\hline June & 0.00 & 0.00 & 0.00 & 0.00 & 0 \\
\hline July & 0.00 & 0.00 & 0.00 & 0.00 & 0 \\
\hline Aug & 0.00 & 0.00 & 0.00 & 0.00 & 0 \\
\hline Sept & 1.01 & 2.02 & 2.02 & 1.01 & 1.0299 \\
\hline Oct & 4.47 & 4.96 & 4.96 & 0.49 & 0.238789 \\
\hline Nov & 11.41 & 11.19 & 11.19 & -0.22 & 0.049569 \\
\hline Dec & 16.73 & 16.72 & 16.72 & -0.01 & $5.42 E-05$ \\
\hline & & & SUM & $-5 \%$ & $11 \%$ \\
\hline
\end{tabular}

Century-Semi Home 2, 2013:

\begin{tabular}{|l|r|r|r|r|r|r|}
\hline & $\begin{array}{r}\text { EnergyPlus } \\
\text { (GJ) }\end{array}$ & Energy Bill & Heating & E+ Baseline & \multicolumn{1}{c|}{$\begin{array}{c}\text { Energy Bill } \\
\text { (GJ/HDD) }\end{array}$} & $\begin{array}{r}\text { Normalized Energy Bill } \\
\text { (Avg Energy Bill GJ/HDD * HDD) }\end{array}$ \\
\hline January & 18.6883 & 21.1577 & 596.0000 & 0.0314 & 0.0355 & 15.9126 \\
\hline February & 15.4704 & 20.1247 & 569.0000 & 0.0272 & 0.0354 & 15.1917 \\
\hline March & 12.1793 & 15.6101 & 525.0000 & 0.0232 & 0.0297 & 14.0170 \\
\hline April & 10.0111 & 11.9754 & 354.0000 & 0.0283 & 0.0338 & 9.4514 \\
May & 3.6788 & 3.9790 & 140.0000 & 0.0263 & 0.0284 & 3.7379 \\
\hline September & 1.2307 & 1.4156 & 78.0000 & 0.0158 & 0.0181 & 2.0825 \\
\hline October & 6.7844 & 2.1043 & 191.0000 & 0.0355 & 0.0110 & 5.0995 \\
\hline November & 11.2996 & 9.4885 & 431.0000 & 0.0262 & 0.0220 & 11.5073 \\
\hline December & 15.5884 & 16.9109 & 644.0000 & 0.0242 & 0.0263 & 17.1942 \\
\hline
\end{tabular}




\begin{tabular}{|l|r|r|r|r|r|}
\hline 2013 & E+ Baseline & Century-Semi Home 2 & AVG. & MBE & CVRMSE \\
\hline Jan & 17.02 & 15.91 & 15.91 & -1.11 & 1.231203 \\
\hline Feb & 16.41 & 15.19 & 15.19 & -1.22 & 1.484423 \\
\hline Mar & 14.92 & 14.02 & 14.02 & -0.90 & 0.811486 \\
\hline Apr & 10.66 & 9.45 & 9.45 & -1.20 & 1.450228 \\
\hline May & 4.95 & 3.74 & 3.74 & -1.22 & 1.47744 \\
\hline June & 0.00 & 0.00 & 0.00 & 0.00 & 0 \\
\hline July & 0.00 & 0.00 & 0.00 & 0.00 & 0 \\
\hline Aug & 0.00 & 0.00 & 0.00 & 0.00 & 0 \\
\hline Sept & 1.06 & 2.08 & 2.08 & 1.02 & 1.038997 \\
\hline Oct & 4.62 & 5.10 & 5.10 & 0.48 & 0.225681 \\
\hline Nov & 11.80 & 11.51 & 11.51 & -0.29 & 0.084118 \\
\hline Dec & 17.24 & 17.19 & 17.19 & -0.04 & 0.001914 \\
\hline & & & SUM & $-5 \%$ & $11 \%$ \\
\hline
\end{tabular}




\section{Appendix J: Assemblies Updated Through Hygrothermal Analysis}

\section{Wood Frame Walls Level 1 - RSI 4 (R 22) - INITIAL}

Section

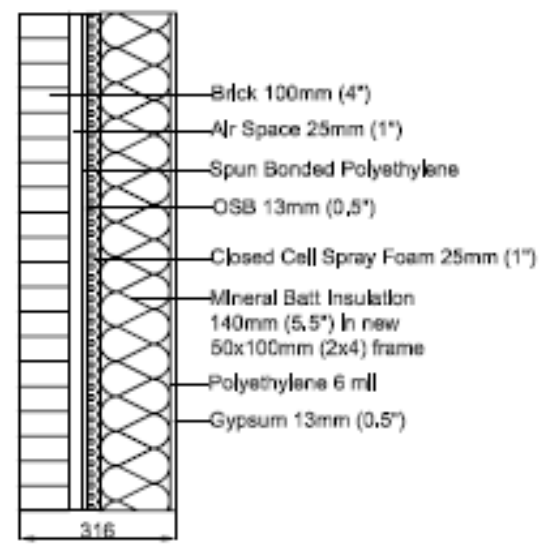

Plar

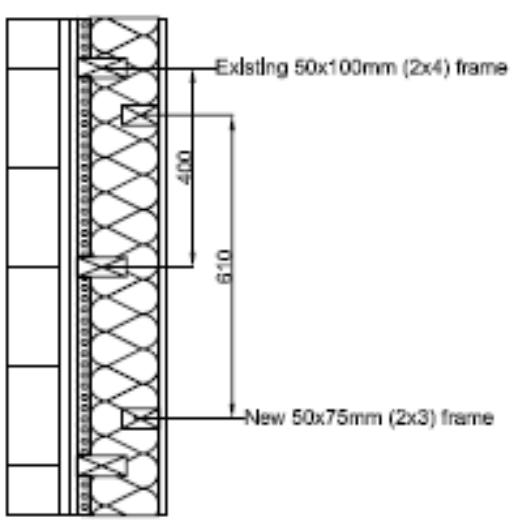

Wood Frame Walls Level 2 - RSI 6 (R 35) - INITIAL Secton

Plan
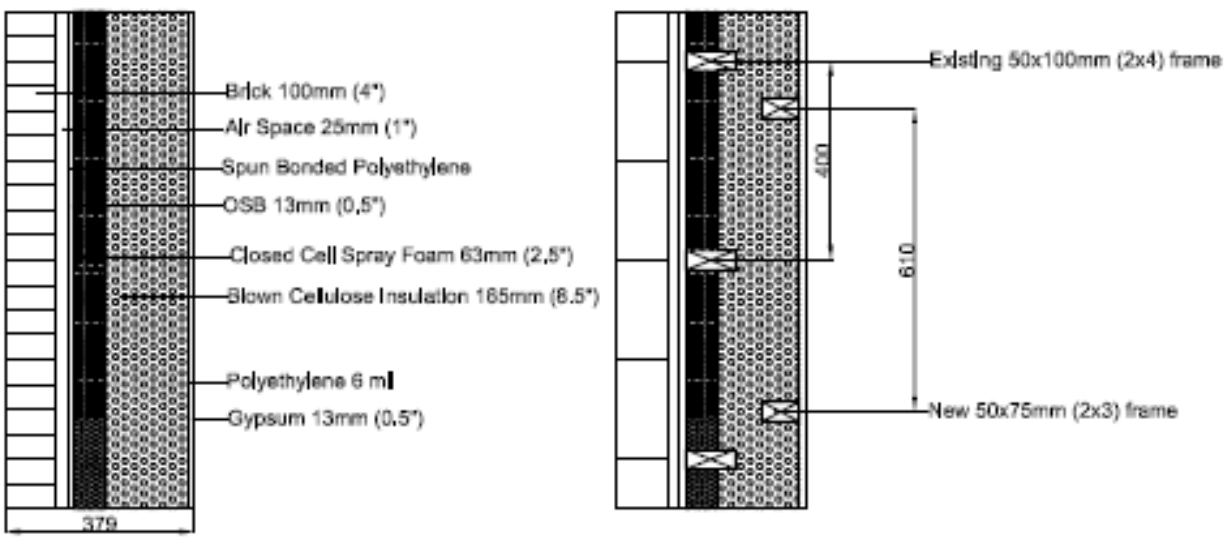


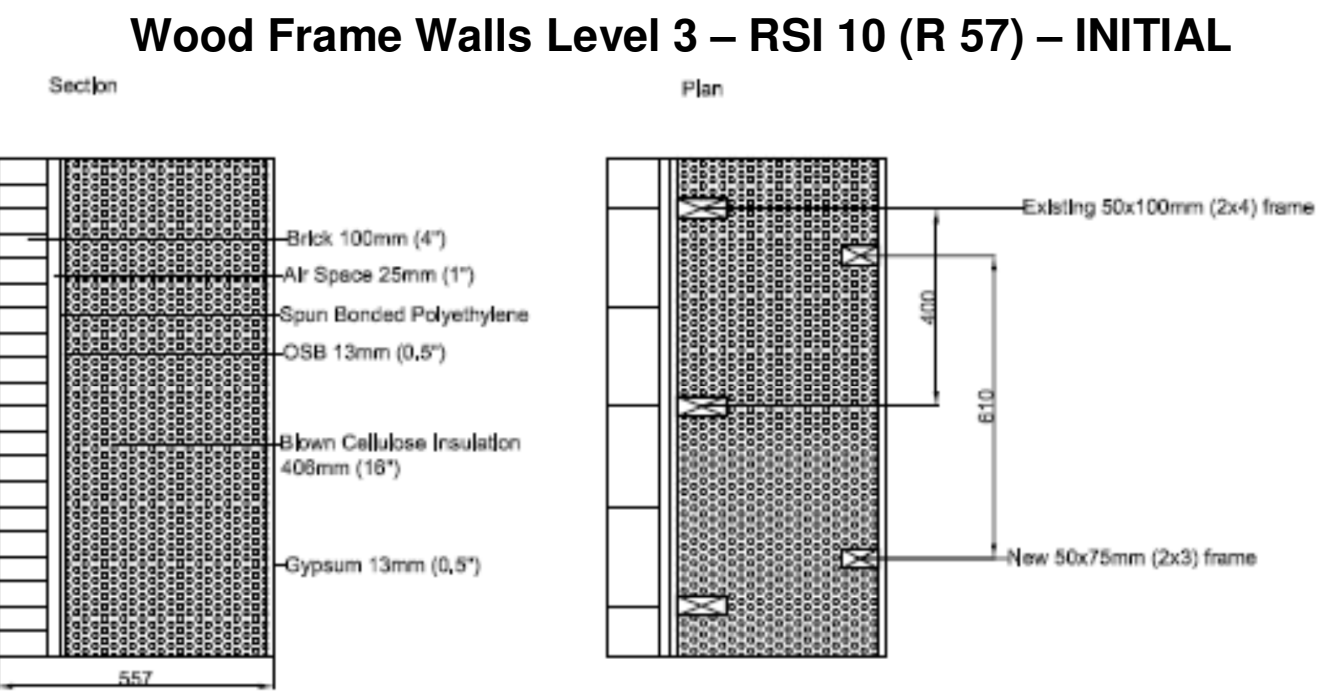

\section{Cathedral Roof Level 1 - RSI 9 (R 50) - INITIAL}
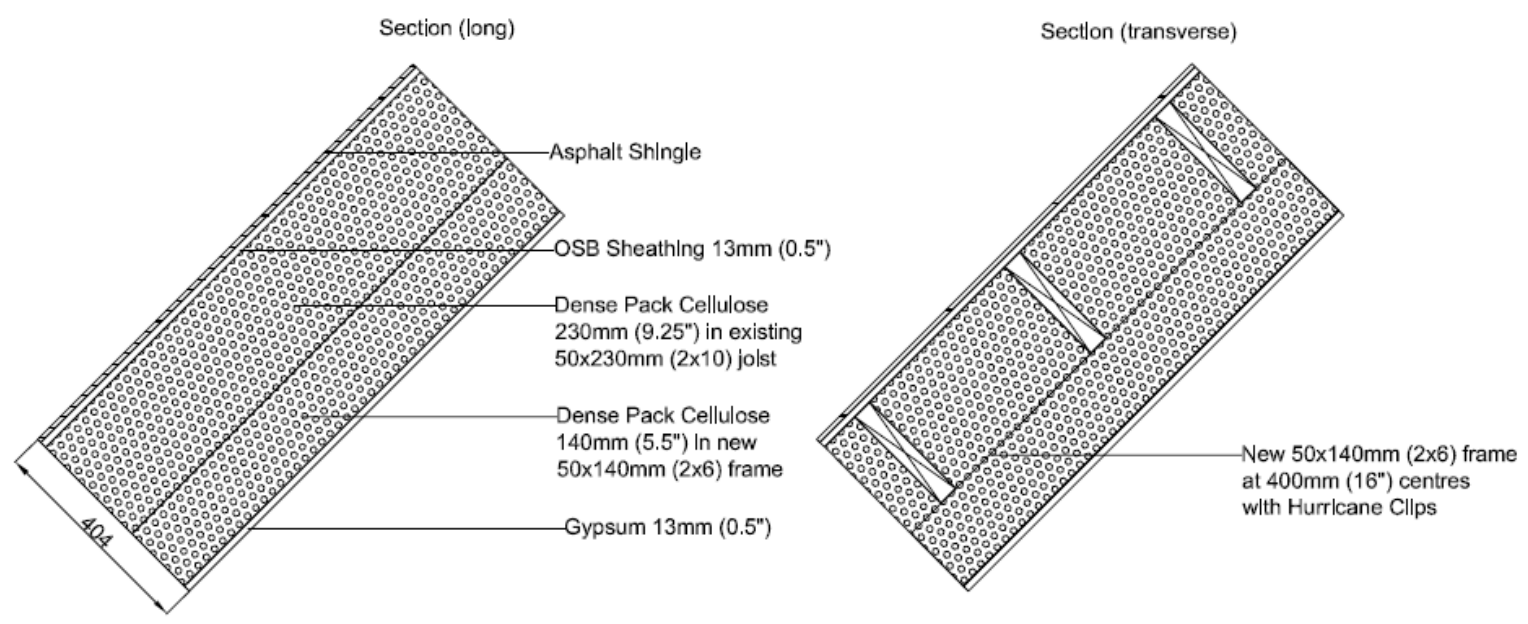


\section{Appendix K: Retrofit Strategy Cost Estimations}

\section{R.S. Means}

\begin{tabular}{|c|c|c|c|c|}
\hline \multicolumn{4}{|c|}{ Masonry Wall Level 1} & \multirow[b]{2}{*}{ Reference/Notes } \\
\hline Component & Unit & Uni & & \\
\hline Demolish Lath and Plaster & S.F. & $\$$ & 1.08 & 090505.303000 \\
\hline Framing $50 \times 100 \mathrm{~mm} 610 \mathrm{~mm}$ O.C. & L.F. & $\$$ & 9.75 & 061110.260305 \\
\hline Closed Cell Spray Foam 25mm & S.F. & $\$$ & 0.80 & 072129.100310 \\
\hline Mineral Batt Insulation 140mm & S.F. & $\$$ & 0.76 & 072116.201340 \\
\hline \multirow[t]{3}{*}{ Gypsum Board 13mm } & S.F. & $\$$ & 0.78 & 092910.300300 \\
\hline & Sum & $\$$ & 13.17 & \\
\hline & Toronto Cost & $\$$ & 14.79 & \\
\hline
\end{tabular}

\begin{tabular}{|c|c|c|c|c|}
\hline \multicolumn{4}{|c|}{ Masonry Wall Level 2} & \multirow[b]{3}{*}{090505.303000} \\
\hline Component & Unit & \multicolumn{2}{|c|}{ Unit Cost } & \\
\hline Demolish Lath and Plaster & S.F. & $\$$ & 1.08 & \\
\hline Framing $50 \times 100 \mathrm{~mm} 610 \mathrm{~mm}$ O.C. & L.F. & $\$$ & 9.75 & 061110.260305 \\
\hline XPS 76mm & S.F. & $\$$ & 1.66 & 072113.102140 \\
\hline Mineral Batt Insulation 140mm & S.F. & $\$$ & 0.76 & 072116.201340 \\
\hline \multirow[t]{3}{*}{ Gypsum Board 13mm } & S.F. & $\$$ & 0.78 & 092910.300300 \\
\hline & Sum & $\$$ & 14.03 & \\
\hline & Toronto Cost & $\$$ & 15.76 & \\
\hline
\end{tabular}

\begin{tabular}{|c|c|c|c|c|c|}
\hline \multicolumn{4}{|c|}{ Masonry Wall Level 3} & \multirow[b]{3}{*}{090505.303000} & \\
\hline Component & Unit & \multicolumn{2}{|c|}{ Unit Cost } & & \\
\hline Demolish Lath and Plaster & S.F. & $\$$ & 1.08 & & \\
\hline Framing $50 \times 75 \mathrm{~mm} 610 \mathrm{~mm}$ O.C. & L.F. & $\$$ & 9.75 & 061110.260305 & \\
\hline Spun Bonded Polyethylene & S.F. & $\$$ & 0.33 & 072510.103000 & \\
\hline Roxul Drain Board 50mm & S.F. & $\$$ & 0.99 & 072113.100080 & \\
\hline Blown Cellulose $356 \mathrm{~mm}$ & S.F. & $\$$ & 2.03 & 072126.100120 & Extrapolated \\
\hline \multirow[t]{3}{*}{ Gypsum Board 13mm } & S.F. & $\$$ & 0.78 & 092910.300300 & \\
\hline & Sum & $\$$ & 14.96 & & \\
\hline & Toronto Cost & $\$$ & 16.80 & & \\
\hline
\end{tabular}

\begin{tabular}{|c|c|c|c|c|}
\hline \multicolumn{4}{|c|}{ Wood Frame Wall Level 1} & \multirow[b]{3}{*}{090505.301000} \\
\hline Component & Unit & \multicolumn{2}{|c|}{ Unit Cost } & \\
\hline Demolish Gypsum and Fibreglass Insulation & S.F. & $\$$ & 0.43 & \\
\hline Framing $50 \times 75 \mathrm{~mm} 610 \mathrm{~mm}$ O.C. & L.F. & $\$$ & 9.75 & 061110.260305 \\
\hline Closed Cell Spray Foam 25mm & S.F. & $\$$ & 0.80 & 072129.100310 \\
\hline Mineral Batt Insulation 140mm & S.F. & $\$$ & 0.76 & 072116.201340 \\
\hline \multirow[t]{3}{*}{ Gypsum Board 13mm } & S.F. & $\$$ & 0.78 & 092910.300300 \\
\hline & Sum & $\$$ & 12.52 & \\
\hline & Toronto Cost & $\$$ & 14.06 & \\
\hline
\end{tabular}




\begin{tabular}{|c|c|c|c|c|c|}
\hline \multicolumn{4}{|c|}{ Wood Frame Wall Level 2} & \multirow[b]{3}{*}{090505.301000} & \\
\hline \multirow{2}{*}{$\begin{array}{l}\text { Component } \\
\text { Demolish Gypsum and Fibreglass Insulation }\end{array}$} & \multirow{2}{*}{\begin{tabular}{|l|} 
Unit \\
S.F. \\
\end{tabular}} & \multicolumn{2}{|c|}{ Unit Cost } & & \\
\hline & & $\$$ & 0.43 & & \\
\hline Framing $50 \times 75 \mathrm{~mm} 610 \mathrm{~mm}$ O.C. & L.F. & $\$$ & 9.75 & 061110.260305 & \\
\hline Closed Cell Spray Foam 63mm & S.F. & $\$$ & 2.99 & 072129.100330 & Interpolated \\
\hline Blown Cellulose $165 \mathrm{~mm}$ & S.F. & $\$$ & 1.17 & 072126.200100 & \\
\hline \multirow[t]{3}{*}{ Gypsum Board 13mm } & S.F. & $\$$ & 0.78 & 092910.300300 & \\
\hline & Sum & $\$$ & 15.12 & & \\
\hline & Toronto Cost & $\$$ & 16.98 & & \\
\hline
\end{tabular}

\begin{tabular}{|c|c|c|c|c|c|}
\hline \multicolumn{4}{|c|}{ Wood Frame Wall Level 3} & \multirow[b]{3}{*}{090505.301000} & \\
\hline Component & Unit & \multicolumn{2}{|c|}{ Unit Cost } & & \\
\hline Demolish Gypsum and Fibreglass Insulation & S.F. & $\$$ & 0.43 & & \\
\hline Framing 50x75mm 610mm O.C. & L.F. & $\$$ & 9.75 & 061110.260305 & \\
\hline Closed Cell Spray Foam 63mm & S.F. & $\$$ & 2.99 & 072129.100330 & Interpolated \\
\hline Blown Cellulose 261mm & S.F. & $\$$ & 2.33 & 072126.200120 & Extrapolated \\
\hline \multirow[t]{3}{*}{ Gypsum Board 13mm } & S.F. & $\$$ & 0.78 & 092910.300300 & \\
\hline & Sum & $\$$ & 16.28 & & \\
\hline & Toronto Cost & $\$$ & 18.28 & & \\
\hline
\end{tabular}

\begin{tabular}{|c|c|c|c|c|c|}
\hline \multicolumn{4}{|c|}{ Cathedral Roof Level 1} & \multirow[b]{3}{*}{090505.303000} & \\
\hline \multirow{2}{*}{$\begin{array}{l}\text { Component } \\
\text { Demolish Lath and Plaster } \\
\end{array}$} & \multirow{2}{*}{\begin{tabular}{|l|} 
Unit \\
S.F. \\
\end{tabular}} & \multicolumn{2}{|c|}{ Unit Cost } & & \\
\hline & & $\$$ & 1.08 & & \\
\hline Framing 50x140mm 610mm O.C. & L.F. & $\$$ & 1.93 & 061110.126500 & \\
\hline Closed Cell Spray Foam $25 \mathrm{~mm}$ & S.F. & $\$$ & 0.80 & 072129.100310 & \\
\hline Blown Cellulose $345 \mathrm{~mm}$ & S.F. & $\$$ & 2.04 & 072126.200120 & Extrapolated \\
\hline \multirow[t]{3}{*}{ Gypsum Board 13mm } & S.F. & $\$$ & 0.78 & 092910.300300 & \\
\hline & Sum & $\$$ & 6.63 & & \\
\hline & Toronto Cost & $\$$ & 7.45 & & \\
\hline
\end{tabular}

\begin{tabular}{|c|c|c|c|c|}
\hline \multicolumn{4}{|c|}{ Cathedral Roof Level 2} & \multirow[b]{3}{*}{090505.303000} \\
\hline Component & Unit & \multicolumn{2}{|c|}{ Unit Cost } & \\
\hline Demolish Lath and Plaster & S.F. & $\$$ & 1.08 & \\
\hline Framing $50 \times 140 \mathrm{~mm} 610 \mathrm{~mm}$ O.C. & L.F. & $\$$ & 1.93 & 061110.126500 \\
\hline Closed Cell Spray Foam 100mm & S.F. & $\$$ & 3.16 & 072129.100340 \\
\hline Blown Cellulose $270 \mathrm{~mm}$ & S.F. & $\$$ & 1.60 & 072126.200120 \\
\hline \multirow[t]{3}{*}{ Gypsum Board 13mm } & S.F. & $\$$ & 0.78 & 092910.300300 \\
\hline & Sum & $\$$ & 8.55 & \\
\hline & Toronto Cost & $\$$ & 9.60 & \\
\hline
\end{tabular}




\begin{tabular}{|c|c|c|c|c|c|}
\hline \multicolumn{4}{|c|}{ Cathedral Roof Level 3} & \multirow[b]{3}{*}{090505.303000} & \\
\hline Component & Unit & \multicolumn{2}{|c|}{ Unit Cost } & & \\
\hline Demolish Lath and Plaster & S.F. & $\$$ & 1.08 & & \\
\hline Demolish Shingles & S.F. & $\$$ & 0.62 & 070505.103170 & \\
\hline Polyisocyanurate $150 \mathrm{~mm}$ & S.F. & $\$$ & 3.70 & 072216.101745 & 3" Doubled \\
\hline Blown Cellulose $230 \mathrm{~mm}$ & S.F. & $\$$ & 1.17 & 072126.200100 & \\
\hline Shingles & S.F. & $\$$ & 1.74 & 073113.100150 & \\
\hline OSB Sheathing & S.F. & $\$$ & 1.09 & 061636.100846 & \\
\hline \multirow[t]{3}{*}{ Gypsum Board 13mm } & S.F. & $\$$ & 0.78 & 092910.300300 & \\
\hline & Sum & $\$$ & 10.18 & & \\
\hline & Toronto Cost & $\$$ & 11.43 & & \\
\hline
\end{tabular}

\begin{tabular}{|c|c|c|c|c|}
\hline \multicolumn{3}{|c|}{ Attic Roof Level 1} & \multirow[b]{3}{*}{072126.200120} & \multirow[b]{3}{*}{ Extrapolated } \\
\hline Component & Unit & Unit Cost & & \\
\hline Blown Cellulose $375 \mathrm{~mm}$ & S.F. & $\$ \quad 2.18$ & & \\
\hline & Sum & 2.18 & & \\
\hline & Toronto Cost & 2.45 & & \\
\hline
\end{tabular}

\begin{tabular}{|c|c|c|c|c|}
\hline \multicolumn{3}{|c|}{ Attic Roof Level 2} & \multirow[b]{3}{*}{072126.200120} & \multirow[b]{3}{*}{ Extrapolated } \\
\hline Component & Unit & Unit Cost & & \\
\hline \multirow[t]{3}{*}{ Blown Cellulose $450 \mathrm{~mm}$} & S.F. & $\$ \quad 2.62$ & & \\
\hline & Sum & 2.62 & & \\
\hline & Toronto Cost & 2.94 & & \\
\hline
\end{tabular}

\begin{tabular}{|c|c|c|c|c|}
\hline \multicolumn{3}{|c|}{ Attic Roof Level 3} & \multirow[b]{3}{*}{072126.200120} & \multirow[b]{3}{*}{ Extrapolated } \\
\hline Component & Unit & Unit Cost & & \\
\hline Blown Cellulose 563mm & S.F. & $\$ \quad 3.27$ & & \\
\hline & Sum & 3.27 & & \\
\hline & Toronto Cost & 3.67 & & \\
\hline
\end{tabular}

\begin{tabular}{|c|c|c|c|c|}
\hline \multicolumn{4}{|c|}{ Basement Wall Level 1} & \multirow[b]{3}{*}{061110.420012} \\
\hline Component & Unit & \multicolumn{2}{|c|}{ Unit Cost } & \\
\hline Framing $25 \times 50 \mathrm{~mm} 400 \mathrm{~mm}$ O.C. & L.F. & $\$$ & 1.27 & \\
\hline XPS 50mm & S.F. & $\$$ & 1.36 & 072113.102120 \\
\hline \multirow[t]{3}{*}{ Gypsum Board 13mm } & S.F. & $\$$ & 0.78 & 092910.300300 \\
\hline & Sum & $\$$ & 3.41 & \\
\hline & Toronto Cost & $\$$ & 3.83 & \\
\hline
\end{tabular}

\begin{tabular}{|c|c|c|c|c|c|}
\hline \multicolumn{4}{|c|}{ Basement Wall Level 2} & \multirow[b]{3}{*}{061110.420012} & \multirow[b]{4}{*}{ Interpolated } \\
\hline Component & Unit & \multicolumn{2}{|c|}{ Unit Cost } & & \\
\hline Framing $25 \times 50 \mathrm{~mm} 400 \mathrm{~mm}$ O.C. & L.F. & $\$$ & 1.27 & & \\
\hline XPS 63mm & S.F. & $\$$ & 1.51 & 072113.102140 & \\
\hline \multirow{3}{*}{ Gypsum Board 13mm } & S.F. & $\$$ & 0.78 & 092910.300300 & \\
\hline & Sum & $\$$ & 3.56 & & \\
\hline & Toronto Cost & $\$$ & 4.00 & & \\
\hline
\end{tabular}




\begin{tabular}{|c|c|c|c|c|}
\hline \multicolumn{4}{|c|}{ Basement Wall Level 3} & \multirow[b]{3}{*}{061110.420012} \\
\hline Component & Unit & \multicolumn{2}{|c|}{ Unit Cost } & \\
\hline Framing $25 \times 50 \mathrm{~mm} 400 \mathrm{~mm}$ O.C. & L.F. & $\$$ & 1.27 & \\
\hline XPS $76 \mathrm{~mm}$ & S.F. & $\$$ & 1.66 & 072113.102140 \\
\hline \multirow[t]{3}{*}{ Gypsum Board 13mm } & S.F. & $\$$ & 0.78 & 092910.300300 \\
\hline & Sum & $\$$ & 3.71 & \\
\hline & Toronto Cost & $\$$ & 4.17 & \\
\hline
\end{tabular}

\begin{tabular}{|c|c|c|c|c|}
\hline \multicolumn{4}{|c|}{ War Time Basement Wall Level 1} & \multirow[b]{3}{*}{090505.301000} \\
\hline Component & Unit & \multicolumn{2}{|c|}{ Unit Cost } & \\
\hline Demolish Gypsum and Fibreglass Insulation & S.F. & $\$$ & 0.43 & \\
\hline Framing $25 \times 50 \mathrm{~mm} 400 \mathrm{~mm}$ O.C. & L.F. & $\$$ & 1.27 & 061110.420012 \\
\hline XPS 50mm & S.F. & $\$$ & 1.36 & 072113.102120 \\
\hline \multirow[t]{3}{*}{ Gypsum Board 13mm } & S.F. & $\$$ & 0.78 & 092910.300300 \\
\hline & Sum & $\$$ & 3.84 & \\
\hline & Toronto Cost & $\$$ & 4.31 & \\
\hline
\end{tabular}

\begin{tabular}{|c|c|c|c|c|c|}
\hline \multicolumn{4}{|c|}{ War Time Basement Wall Level 2} & \multirow[b]{3}{*}{090505.301000} & \\
\hline Component & Unit & \multicolumn{2}{|c|}{ Unit Cost } & & \\
\hline Demolish Gypsum and Fibreglass Insulation & S.F. & $\$$ & 0.43 & & \\
\hline Framing $25 \times 50 \mathrm{~mm} 400 \mathrm{~mm}$ O.C. & L.F. & $\$$ & 1.27 & 061110.420012 & \\
\hline XPS $63 \mathrm{~mm}$ & S.F. & $\$$ & 1.51 & 072113.102140 & Interpolated \\
\hline \multirow[t]{3}{*}{ Gypsum Board 13mm } & S.F. & $\$$ & 0.78 & 092910.300300 & \\
\hline & Sum & $\$$ & 3.99 & & \\
\hline & Toronto Cost & $\$$ & 4.48 & & \\
\hline
\end{tabular}

\begin{tabular}{|c|c|c|c|c|}
\hline \multicolumn{4}{|c|}{ War Time Basement Wall Level 3} & \multirow[b]{3}{*}{090505.301000} \\
\hline Component & Unit & \multicolumn{2}{|c|}{ Unit Cost } & \\
\hline Demolish Gypsum and Fibreglass Insulation & S.F. & $\$$ & 0.43 & \\
\hline Framing $25 \times 50 \mathrm{~mm} 400 \mathrm{~mm}$ O.C. & L.F. & $\$$ & 1.27 & 061110.420012 \\
\hline XPS 76mm & S.F. & $\$$ & 1.66 & 072113.102140 \\
\hline \multirow[t]{3}{*}{ Gypsum Board 13mm } & S.F. & $\$$ & 0.78 & 092910.300300 \\
\hline & Sum & $\$$ & 4.14 & \\
\hline & Toronto Cost & $\$$ & 4.65 & \\
\hline
\end{tabular}

\begin{tabular}{|c|c|c|c|c|c|}
\hline \multicolumn{4}{|c|}{ Slab Level 1} & \multirow[b]{3}{*}{072113.102100} & \multirow[b]{3}{*}{ Extrapolated } \\
\hline Component & Unit & \multicolumn{2}{|c|}{ Unit Cost } & & \\
\hline XPS 19mm & S.F. & $\$$ & 0.74 & & \\
\hline \multirow[t]{3}{*}{ Concrete Slab 75mm } & S.F. & $\$$ & 1.97 & 033053.405001 & Extrapolated \\
\hline & Sum & $\$$ & 2.71 & & \\
\hline & Toronto Cost & $\$$ & 3.04 & & \\
\hline
\end{tabular}




\begin{tabular}{|c|c|c|c|c|}
\hline \multicolumn{3}{|c|}{ Slab Level 2} & \multirow[b]{3}{*}{072113.102100} & \multirow[b]{3}{*}{ Extrapolated } \\
\hline Component & Unit & Unit Cost & & \\
\hline XPS 25mm & S.F. & $\$ \quad 0.99$ & & \\
\hline \multirow[t]{3}{*}{ Concrete Slab 75mm } & S.F. & 1.97 & 033053.405001 & Extrapolated \\
\hline & Sum & 2.96 & & \\
\hline & Toronto Cost & 3.32 & & \\
\hline
\end{tabular}

\begin{tabular}{|c|c|c|c|c|}
\hline \multicolumn{3}{|c|}{ Slab Level 3} & \multirow[b]{3}{*}{072113.102120} & \multirow[b]{3}{*}{ Extrapolated } \\
\hline Component & Unit & Unit Cost & & \\
\hline XPS 40mm & S.F. & $\$ \quad 1.18$ & & \\
\hline \multirow[t]{3}{*}{ Concrete Slab 75mm } & S.F. & 1.97 & 033053.405001 & Extrapolated \\
\hline & Sum & 3.15 & & \\
\hline & Toronto Cost & 3.54 & & \\
\hline
\end{tabular}

\begin{tabular}{|c|c|c|c|c|}
\hline \multicolumn{4}{|c|}{ Windows Level 1} & \multirow[b]{3}{*}{080505.202000} \\
\hline Component & Unit & \multicolumn{2}{|c|}{ Unit Cost } & \\
\hline Demolish Existing Windows & S.F. & $\$$ & 19.65 & \\
\hline \multirow[t]{3}{*}{ Double, Low-E, Air Filled } & S.F. & $\$$ & 56.67 & 085210.400150 \\
\hline & Sum & $\$$ & 76.32 & \\
\hline & Toronto Cost & $\$$ & 85.71 & \\
\hline
\end{tabular}

\begin{tabular}{|c|c|c|c|c|}
\hline \multicolumn{4}{|c|}{ Windows Level 2} & \multirow[b]{3}{*}{080505.202000} \\
\hline Component & Unit & \multicolumn{2}{|c|}{ Unit Cost } & \\
\hline Demolish Existing Windows & S.F. & $\$$ & 19.65 & \\
\hline \multirow[t]{3}{*}{ Alpen 725} & S.F. & $\$$ & 65.00 & Manufacturer \\
\hline & Sum & $\$$ & 84.65 & \\
\hline & Toronto Cost & $\$$ & 95.06 & \\
\hline
\end{tabular}

\begin{tabular}{|c|c|c|c|c|}
\hline \multicolumn{4}{|c|}{ Windows Level 3} & \multirow[b]{3}{*}{080505.202000} \\
\hline Component & Unit & \multicolumn{2}{|c|}{ Unit Cost } & \\
\hline Demolish Existing Windows & S.F. & $\$$ & 19.65 & \\
\hline \multirow[t]{3}{*}{ Alpen 925} & S.F. & $\$$ & 80.00 & Manufacturer \\
\hline & Sum & $\$$ & 99.65 & \\
\hline & Toronto Cost & $\$$ & 111.91 & \\
\hline
\end{tabular}

\begin{tabular}{|c|c|c|c|}
\hline \multicolumn{3}{|c|}{ HVAC } & \\
\hline Component & Unit & Unit Cost & \\
\hline Level 1, 90\% Efficient & Ea. & $\$ 2,550.00$ & http://www.furnacepriceguides \\
\hline Level 2, 94\% Efficient & Ea. & $\$ 3,195.00$ & .com/gas-furnace/\#afue \\
\hline Level 3, 97\% Efficient & Ea. & $\$ 3,220.00$ & \\
\hline
\end{tabular}




\begin{tabular}{|l|l|l|l|}
\hline \multicolumn{2}{|c|}{ Ventilation } & \\
\cline { 1 - 3 } Component & Unit & Unit Cost & \\
\hline Level 1, HRV 60\% Efficient & Ea. & $\$ \quad 499.57$ & ecomfort.com \\
\hline Level 2, HRV 85\% Efficient & Ea. & $\$ 1,625.00$ & Plus 1500 Install \\
\hline Level 3, ERV 80\% Efficient & Ea. & $\$ 1,921.49$ & (Average) \\
\hline
\end{tabular}

\begin{tabular}{|c|c|c|c|}
\hline \multicolumn{3}{|c|}{ Air Sealing } & \\
\hline Component & Unit & Unit Cost & \\
\hline Level 1, 20\% Reduction & N/A & N/A & \\
\hline Level 2, ACH 2-3 & House & $\$ 1,500.00$ & Assumed \\
\hline Level 3, ACH 1 & House & $\$ \quad 1,500.00$ & Assumed \\
\hline
\end{tabular}

\section{Contractor 1}

Labour \$55/hour

\begin{tabular}{|c|c|c|c|}
\hline \multicolumn{3}{|c|}{ Masonry Wall Level 1} & \multirow[b]{2}{*}{ Reference/Notes } \\
\hline Component & Unit & Unit Cost & \\
\hline Demolish Lath and Plaster & Floor & $\$ 2,640.00$ & 3 people for 2 days per floor \\
\hline Framing $50 \times 100 \mathrm{~mm} 610 \mathrm{~mm}$ O.C. & L.F. & $\$ \quad 6.00$ & \\
\hline Closed Cell Spray Foam 25mm & S.F. & 2.50 & \\
\hline Mineral Batt Insulation $140 \mathrm{~mm}$ & S.F. & 1.43 & \\
\hline Gypsum Board 13mm & S.F. & 1.70 & \\
\hline
\end{tabular}

\begin{tabular}{|c|c|c|c|}
\hline \multicolumn{3}{|c|}{ Masonry Wall Level 2} & \\
\hline Component & Unit & Unit Cost & \\
\hline Demolish Lath and Plaster & Floor & $\$ 2,640.00$ & 3 people for 2 days per floor \\
\hline Framing $50 \times 100 \mathrm{~mm} 610 \mathrm{~mm}$ O.C. & L.F. & $\$ \quad 6.00$ & \\
\hline XPS $76 \mathrm{~mm}$ & S.F. & 1.87 & plus 880 ( 2 people/day/floor) \\
\hline Mineral Batt Insulation 140mm & S.F. & 1.43 & \\
\hline Gypsum Board 13mm & S.F. & 1.70 & \\
\hline
\end{tabular}

\begin{tabular}{|c|c|c|c|c|}
\hline \multicolumn{4}{|c|}{ Masonry Wall Level 3} & \\
\hline Component & Unit & Uni & Cost & \\
\hline Demolish Lath and Plaster & Floor & & 640.00 & 3 people for 2 days per floor \\
\hline Framing $50 \times 75 \mathrm{~mm} 610 \mathrm{~mm}$ O.C. & L.F. & $\$$ & 5.50 & \\
\hline Spun Bonded Polyethylene & S.F. & $\$$ & 0.11 & \\
\hline Roxul Drain Board 50mm & S.F. & $\$$ & 1.16 & \\
\hline Blown Cellulose 356mm & S.F. & $\$$ & 3.75 & \\
\hline Gypsum Board 13mm & S.F. & $\$$ & 1.70 & \\
\hline
\end{tabular}




\begin{tabular}{|l|l|lr|l|}
\hline \multicolumn{3}{|c|}{ Wood Frame Wall Level 1} & \multicolumn{1}{|l|}{} \\
\hline Component & Unit & Unit Cost & Reference/Notes \\
\hline Demolish Gypsum and Fibreglass Insulation & Floor & $\$ 2,640.00$ & Labour 3 people for 2 days per floor \\
\hline Framing 50x75mm 610mm O.C. & L.F. & $\$$ & 5.50 & \\
\hline Closed Cell Spray Foam $25 \mathrm{~mm}$ & S.F. & $\$$ & 2.50 & \\
\cline { 1 - 3 } Mineral Batt Insulation $140 \mathrm{~mm}$ & S.F. & $\$$ & 1.43 & \\
\cline { 1 - 3 } Gypsum Board 13mm & S.F. & $\$$ & 1.70 & \\
\hline
\end{tabular}

\begin{tabular}{|c|c|c|c|}
\hline \multicolumn{3}{|l|}{ Wood Frame Wall Level 2} & \\
\hline Component & Unit & Unit Cost & Reference/Notes \\
\hline Demolish Gypsum and Fibreglass Insulation & Floor & $\$ 2,640.00$ & Labour 3 people for 2 days per floor \\
\hline Framing $50 \times 75 \mathrm{~mm} 610 \mathrm{~mm}$ O.C. & L.F. & $\$ \quad 5.50$ & \\
\hline Closed Cell Spray Foam 63mm & S.F. & 3.60 & \\
\hline Blown Cellulose $165 \mathrm{~mm}$ & S.F. & 2.90 & \\
\hline Gypsum Board 13mm & S.F. & 1.70 & \\
\hline
\end{tabular}

\begin{tabular}{|c|c|c|c|}
\hline \multicolumn{3}{|l|}{ Wood Frame Wall Level 3} & \\
\hline Component & Unit & Unit Cost & Reference/Notes \\
\hline Demolish Gypsum and Fibreglass Insulation & Floor & $\$ 2,640.00$ & Labour 3 people for 2 days per floor \\
\hline Framing $50 \times 75 \mathrm{~mm} 610 \mathrm{~mm}$ O.C. & L.F. & $\$ \quad 5.50$ & \\
\hline Closed Cell Spray Foam 63mm & S.F. & 3.50 & \\
\hline Blown Cellulose $261 \mathrm{~mm}$ & S.F. & 3.40 & \\
\hline Gypsum Board 13mm & S.F. & 1.70 & \\
\hline
\end{tabular}

\begin{tabular}{|c|c|c|c|c|}
\hline \multicolumn{4}{|c|}{ Cathedral Roof Level 1} & \\
\hline Component & Unit & Un & Cost & \\
\hline Demolish Lath and Plaster & Floor & $\$$ & 660.00 & 3 people for 0.5 day / floor \\
\hline Framing 50x140mm 610mm O.C. & L.F. & $\$$ & 7.00 & \\
\hline Closed Cell Spray Foam $25 \mathrm{~mm}$ & S.F. & $\$$ & 2.50 & \\
\hline Dense Pack Cellulose 345mm & S.F. & $\$$ & 3.85 & \\
\hline Gypsum Board 13mm & S.F. & $\$$ & 1.70 & \\
\hline
\end{tabular}

\begin{tabular}{|c|c|c|c|c|}
\hline \multicolumn{4}{|c|}{ Cathedral Roof Level 2} & \multirow[b]{3}{*}{3 people for 0.5 day/ floor } \\
\hline Component & Unit & Un & Cost & \\
\hline Demolish Lath and Plaster & Floor & $\$$ & 660.00 & \\
\hline Framing $50 \times 140 \mathrm{~mm} 610 \mathrm{~mm}$ O.C. & L.F. & $\$$ & 7.00 & \\
\hline Closed Cell Spray Foam 100mm & S.F. & $\$$ & 5.00 & \\
\hline Dense Pack Cellulose 270mm & S.F. & $\$$ & 3.00 & \\
\hline Gypsum Board 13mm & S.F. & $\$$ & 1.70 & \\
\hline
\end{tabular}




\begin{tabular}{|c|c|c|c|c|}
\hline \multicolumn{4}{|c|}{ Cathedral Roof Level 3} & \multirow[b]{3}{*}{3 people for 0.5 day $/$ floo } \\
\hline Component & Unit & & Cost & \\
\hline Demolish Lath and Plaster & Floor & $\$$ & 660.00 & \\
\hline Demolish Shingles & S.F. & $\$$ & 0.62 & RS Means \\
\hline Polyisocyanurate $150 \mathrm{~mm}$ & S.F. & $\$$ & 2.24 & \\
\hline Dense Pack Cellulose $230 \mathrm{~mm}$ & S.F. & $\$$ & 3.00 & \\
\hline Shingles & S.F. & $\$$ & 1.74 & RS Means \\
\hline OSB Sheathing & S.F. & $\$$ & 1.09 & RS Means \\
\hline Gypsum Board 13mm & S.F. & $\$$ & 1.70 & \\
\hline
\end{tabular}

\begin{tabular}{|c|c|c|}
\hline \multicolumn{3}{|c|}{ Attic Roof Level 1} \\
\hline Component & Unit & Unit Cost \\
\hline Blown Cellulose $375 \mathrm{~mm}$ & S.F. & $\$ \quad 1.35$ \\
\hline
\end{tabular}

\begin{tabular}{|l|l|l|}
\hline \multicolumn{3}{|c|}{ Attic Roof Level 2 } \\
\hline Component & Unit & Unit Cost \\
\hline Blown Cellulose 450mm & S.F. & \$ 1.50 \\
\hline
\end{tabular}

\begin{tabular}{|c|c|c|}
\hline \multicolumn{3}{|c|}{ Attic Roof Level 3} \\
\hline Component & Unit & Unit Cost \\
\hline Blown Cellulose $563 \mathrm{~mm}$ & S.F. & $\$ \quad 1.75$ \\
\hline
\end{tabular}

\begin{tabular}{|c|c|c|c|c|}
\hline \multicolumn{4}{|c|}{ Basement Wall Level 1} & \\
\hline Component & Unit & Un & & \\
\hline Framing $25 \times 50 \mathrm{~mm} 400 \mathrm{~mm}$ O.C. & L.F. & $\$$ & 4.50 & \\
\hline XPS 50mm & S.F. & $\$$ & 1.87 & plus 880 for labour \\
\hline Gypsum Board 13mm & S.F. & $\$$ & 1.70 & \\
\hline
\end{tabular}

\begin{tabular}{|l|l|lr|}
\hline \multicolumn{3}{|c|}{ Basement Wall Level 2} \\
\hline Component & Unit & Unit Cost & \\
\hline Framing 25x50mm 400mm O.C. & L.F. & $\$$ & 4.50 \\
\hline XPS 63mm & S.F. & $\$$ & 2.02 \\
\hline Gypsum Board 13mm & S.F. & $\$$ & 1.70 \\
\hline
\end{tabular}

\begin{tabular}{|c|c|c|c|c|}
\hline \multicolumn{4}{|c|}{ Basement Wall Level 3} & \\
\hline Component & Unit & Un & & \\
\hline Framing $25 \times 50 \mathrm{~mm} 400 \mathrm{~mm}$ O.C. & L.F. & $\$$ & 4.50 & \\
\hline XPS 76mm & S.F. & $\$$ & 2.17 & plus 880 for labour \\
\hline Gypsum Board 13mm & S.F. & $\$$ & 1.70 & \\
\hline
\end{tabular}




\begin{tabular}{|l|l|lr|}
\hline \multicolumn{3}{|c|}{ War Time Basement Wall Level 1} \\
\hline Component & Unit & Unit Cost \\
\hline Demolish Gypsum and Fibreglass Insulation & Floor & $\$$ & $2,640.00$ \\
\hline Framing 25x50mm 400mm O.C. & L.F. & $\$$ & 4.50 \\
\hline XPS 50mm & S.F. & $\$$ & 1.87 \\
\cline { 1 - 3 } Gypsum Board 13mm & S.F. & $\$$ & 1.70 \\
\hline
\end{tabular}

\begin{tabular}{|l|l|lr|}
\hline \multicolumn{3}{|c|}{ War Time Basement Wall Level 2} \\
\hline Component & Unit & Unit Cost & \\
\hline Demolish Gypsum and Fibreglass Insulation & Floor & $\$$ & $2,640.00$ \\
\hline Framing 25x50mm 400mm O.C. & L.F. & $\$$ & 4.50 \\
\hline XPS 63mm & S.F. & $\$$ & 2.02 \\
\hline Gypsum Board 13mm & S.F. & $\$$ & 1.70 \\
\hline
\end{tabular}

\begin{tabular}{|l|l|lr|}
\hline \multicolumn{3}{|c|}{ War Time Basement Wall Level 3} \\
\hline Component & Unit & Unit Cost \\
\hline Demolish Gypsum and Fibreglass Insulation & Floor & $\$ 2,640.00$ \\
\hline Framing 25x50mm 400mm O.C. & L.F. & $\$$ & 4.50 \\
\hline XPS 76mm & S.F. & $\$$ & 2.17 \\
\hline Gypsum Board 13mm & S.F. & $\$$ & 1.70 \\
\hline
\end{tabular}

\begin{tabular}{|l|l|lr|}
\hline \multicolumn{3}{|c|}{ Slab Level 1 } & \multicolumn{3}{c|}{} \\
\hline Component & Unit & Unit Cost \\
\hline XPS 19mm & S.F. & $\$$ & 1.42 \\
\hline Concrete Slab 75mm & S.F. & $\$$ & 5.00 \\
\hline
\end{tabular}

\begin{tabular}{|l|l|lr|}
\hline \multicolumn{3}{|c|}{ Slab Level 2 } & \multicolumn{3}{c|}{} \\
\hline Component & Unit & Unit Cost \\
\hline XPS 25mm & S.F. & \$ & 1.57 \\
\hline Concrete Slab 75mm & S.F. & \$ & 5.00 \\
\hline
\end{tabular}

\begin{tabular}{|l|l|ll|}
\hline \multicolumn{3}{|c|}{ Slab Level 3 } & \multicolumn{2}{l|}{} \\
\hline Component & Unit & Unit Cost \\
\hline XPS 40mm & S.F. & $\$$ & 1.72 \\
\hline Concrete Slab 75mm & S.F. & $\$$ & 5.00 \\
\hline
\end{tabular}

\begin{tabular}{|l|l|l|}
\hline \multicolumn{3}{|c|}{ Windows Level 1} \\
\hline Component & Unit & Unit Cost \\
\hline Double, Low-E, Air Filled & S.F. & $\$ \quad 56.67$ \\
\hline
\end{tabular}

*330 per window for labour

\begin{tabular}{|c|c|c|c|c|}
\hline \multicolumn{4}{|c|}{ Windows Level 2} & \\
\hline Component & Unit & & Cost & \\
\hline Alpen 725 & S.F. & $\$$ & 65.00 & *330 per window for labour \\
\hline
\end{tabular}




\begin{tabular}{|c|c|c|c|}
\hline \multicolumn{3}{|c|}{ Windows Level 3} & \\
\hline Component & Unit & Unit Cost & \\
\hline Alpen 925 & S.F. & $\$ \quad 80.00$ & *330 per window for labour \\
\hline
\end{tabular}

\begin{tabular}{|l|l|l|}
\hline \multicolumn{3}{|c|}{ HVAC } \\
\hline Component & Unit & Unit Cost \\
\hline Level 1, 90\% Efficient & Ea. & $\$ 1,200.00$ \\
\hline Level 2, 94\% Efficient & Ea. & $\$ 1,650.00$ \\
\hline Level 3, 97\% Efficient & Ea. & $\$ 2,640.00$ \\
\hline
\end{tabular}

\begin{tabular}{|c|c|c|c|}
\hline \multicolumn{3}{|c|}{ Ventilation } & \\
\hline Component & Unit & Unit Cost & \\
\hline Level 1, HRV 60\% Efficient & Ea. & $\$ \quad 499.57$ & *install 1000 \\
\hline Level 2, HRV 85\% Efficient & Ea. & $\$ 1,625.00$ & \\
\hline Level 3, ERV 80\% Efficient & Ea. & $\$ 1,921.49$ & \\
\hline
\end{tabular}

\begin{tabular}{|c|c|c|c|}
\hline \multicolumn{3}{|c|}{ Air Sealing } & \\
\hline Component & Unit & Unit Cost & \\
\hline Level 1, 20\% Reduction & House & $1375-2200$ & \\
\hline Level 2, 40\% Reduction & House & $\$ 11,000.00$ & \\
\hline Level 2, ACH 2-3 & House & $\$ 1,500.00$ & Assumed \\
\hline Level 3, ACH 1 & House & $\$ 1,500.00$ & Assumed \\
\hline
\end{tabular}

\section{Contractor 2}

Labour: Lead \$65/hr, Apprentice \$45/hr

\begin{tabular}{|c|c|c|c|c|}
\hline \multicolumn{4}{|c|}{ Masonry Wall Level 1} & \multirow[b]{2}{*}{ Reference/Notes } \\
\hline Component & Unit & Uni & & \\
\hline Demolish Lath and Plaster & S.F. & $\$$ & 2.40 & \\
\hline Framing $50 \times 100 \mathrm{~mm} 610 \mathrm{~mm}$ O.C. & L.F. & $\$$ & 6.00 & Average \\
\hline Closed Cell Spray Foam 25mm & S.F. & $\$$ & 2.50 & \\
\hline Mineral Batt Insulation 140mm & S.F. & $\$$ & 1.43 & Manufacturer \\
\hline Gypsum Board 13mm & S.F. & $\$$ & 0.74 & \\
\hline
\end{tabular}

\begin{tabular}{|c|c|c|c|c|}
\hline \multicolumn{4}{|c|}{ Masonry Wall Level 2} & \\
\hline Component & Unit & Uni & & \\
\hline Demolish Lath and Plaster & S.F. & $\$$ & 2.40 & \\
\hline Framing $50 \times 100 \mathrm{~mm} 610 \mathrm{~mm}$ O.C. & L.F. & $\$$ & 6.00 & \\
\hline XPS 76mm & S.F. & $\$$ & 1.87 & Manufacturer \\
\hline Mineral Batt Insulation 140mm & S.F. & $\$$ & 1.43 & Manufacturer \\
\hline Gypsum Board 13mm & S.F. & $\$$ & 0.74 & \\
\hline
\end{tabular}




\begin{tabular}{|c|c|c|c|c|}
\hline \multicolumn{4}{|c|}{ Masonry Wall Level 3} & \\
\hline Component & Unit & Uni & & \\
\hline Demolish Lath and Plaster & S.F. & $\$$ & 2.40 & \\
\hline Framing $50 \times 75 \mathrm{~mm} 610 \mathrm{~mm}$ O.C. & L.F. & $\$$ & 5.50 & Average \\
\hline Spun Bonded Polyethylene & S.F. & $\$$ & 0.11 & 775 in labour for house \\
\hline Roxul Drain Board 50mm & S.F. & $\$$ & 0.57 & \\
\hline Blown Cellulose $356 \mathrm{~mm}$ & S.F. & $\$$ & 3.75 & Manufacturer \\
\hline Gypsum Board 13mm & S.F. & $\$$ & 0.74 & \\
\hline
\end{tabular}

\begin{tabular}{|c|c|c|c|c|}
\hline \multicolumn{4}{|l|}{ Wood Frame Wall Level 1} & \\
\hline Component & Unit & Uni & & \\
\hline Demolish Gypsum and Fibreglass Insulation & S.F. & $\$$ & 2.40 & \\
\hline Framing $50 \times 75 \mathrm{~mm} 610 \mathrm{~mm}$ O.C. & L.F. & $\$$ & 5.50 & Average \\
\hline Closed Cell Spray Foam 25mm & S.F. & $\$$ & 2.50 & \\
\hline Mineral Batt Insulation 140mm & S.F. & $\$$ & 1.43 & Manufacturer \\
\hline Gypsum Board 13mm & S.F. & $\$$ & 0.74 & \\
\hline
\end{tabular}

\begin{tabular}{|c|c|c|c|c|}
\hline \multicolumn{4}{|l|}{ Wood Frame Wall Level 2} & \\
\hline Component & Unit & & & \\
\hline Demolish Gypsum and Fibreglass Insulation & S.F. & $\$$ & 2.40 & \\
\hline Framing 50x75mm 610mm O.C. & L.F. & $\$$ & 5.50 & Average \\
\hline Closed Cell Spray Foam 63mm & S.F. & $\$$ & 3.60 & \\
\hline Blown Cellulose $165 \mathrm{~mm}$ & S.F. & $\$$ & 2.90 & Manufacturer \\
\hline Gypsum Board 13mm & S.F. & $\$$ & 0.74 & \\
\hline
\end{tabular}

\begin{tabular}{|c|c|c|c|c|}
\hline \multicolumn{4}{|l|}{ Wood Frame Wall Level 3} & \\
\hline \multirow{2}{*}{$\begin{array}{l}\text { Component } \\
\text { Demolish Gypsum and Fibreglass Insulation }\end{array}$} & \multirow{2}{*}{\begin{tabular}{|l} 
Unit \\
S.F.
\end{tabular}} & \multicolumn{2}{|c|}{ Unit Cost } & \\
\hline & & $\$$ & 2.40 & \\
\hline Framing $50 \times 75 \mathrm{~mm} 610 \mathrm{~mm}$ O.C. & L.F. & $\$$ & 5.50 & Average \\
\hline Closed Cell Spray Foam 63mm & S.F. & $\$$ & 3.60 & \\
\hline Blown Cellulose $261 \mathrm{~mm}$ & S.F. & $\$$ & 3.40 & Manufacturer \\
\hline Gypsum Board 13mm & S.F. & $\$$ & 0.74 & \\
\hline
\end{tabular}

\begin{tabular}{|c|c|c|c|c|}
\hline \multicolumn{4}{|c|}{ Cathedral Roof Level 1} & \\
\hline Component & Unit & Uni & & \\
\hline Demolish Lath and Plaster & S.F. & $\$$ & 2.40 & \\
\hline Framing $50 \times 140 \mathrm{~mm} 610 \mathrm{~mm}$ O.C. & L.F. & $\$$ & 4.33 & \\
\hline Closed Cell Spray Foam $25 \mathrm{~mm}$ & S.F. & $\$$ & 2.50 & \\
\hline Blown Cellulose $345 \mathrm{~mm}$ & S.F. & $\$$ & 3.85 & Manufacture \\
\hline Gypsum Board 13mm & S.F. & $\$$ & 0.74 & \\
\hline
\end{tabular}




\begin{tabular}{|l|l|lr|}
\hline \multicolumn{3}{|c|}{ Cathedral Roof Level 2} \\
\hline Component & Unit & Unit Cost \\
\hline Demolish Lath and Plaster & S.F. & $\$$ & 2.40 \\
\hline Framing 50x140mm 610mm O.C. & L.F. & $\$$ & 4.33 \\
\hline Closed Cell Spray Foam 100mm & S.F. & $\$$ & 4.00 \\
\hline Blown Cellulose $270 \mathrm{~mm}$ & S.F. & $\$$ & 3.00 \\
\hline Gypsum Board 13mm & S.F. & $\$$ & 0.74 \\
\hline
\end{tabular}

\begin{tabular}{|c|c|c|c|c|}
\hline \multicolumn{4}{|c|}{ Cathedral Roof Level 3} & \\
\hline Component & Unit & Uni & & \\
\hline Demolish Lath and Plaster & S.F. & $\$$ & 2.40 & \\
\hline Demolish Shingles & S.F. & $\$$ & 0.62 & RS Means \\
\hline Polyisocyanurate $150 \mathrm{~mm}$ & S.F. & $\$$ & 2.24 & Manufacturer \\
\hline Blown Cellulose $230 \mathrm{~mm}$ & S.F. & $\$$ & 3.00 & Manufacturer \\
\hline Shingles & S.F. & $\$$ & 4.00 & \\
\hline OSB Sheathing & S.F. & $\$$ & 0.72 & Plus 3700 labour \\
\hline Gypsum Board 13mm & S.F. & $\$$ & 0.74 & \\
\hline
\end{tabular}

\begin{tabular}{|l|l|l|l|}
\hline \multicolumn{3}{|c|}{ Attic Roof Level 1 } \\
\hline Component & Unit & Unit Cost & \\
\cline { 1 - 3 } Blown Cellulose $375 \mathrm{~mm}$ & S.F. & $\$ \quad 1.35$ & Manufacturer \\
\hline
\end{tabular}

\begin{tabular}{|l|l|l||}
\hline \multicolumn{3}{|c|}{ Attic Roof Level 2 } \\
\hline Component & Unit & Unit Cost \\
\hline Blown Cellulose 450mm & S.F. & $\$ \quad 1.50$ \\
Manufacturer
\end{tabular}

\begin{tabular}{|l|l|l||}
\hline \multicolumn{3}{|c|}{ Attic Roof Level 3 } \\
\hline Component & Unit & Unit Cost \\
\hline Blown Cellulose $563 \mathrm{~mm}$ & S.F. & $\$ \quad 1.75$ \\
Manufacturer
\end{tabular}

\begin{tabular}{|c|c|c|c|c|}
\hline \multicolumn{4}{|c|}{ Basement Wall Level 1} & \multirow[b]{3}{*}{1765 for labour for all } \\
\hline Component & Unit & \multicolumn{2}{|c|}{ Unit Cost } & \\
\hline Framing $25 \times 50 \mathrm{~mm} 400 \mathrm{~mm}$ O.C. & L.F. & $\$$ & 2.00 & \\
\hline XPS 50mm & S.F. & $\$$ & 1.63 & \\
\hline Gypsum Board 13mm & S.F. & $\$$ & 0.74 & \\
\hline
\end{tabular}

\begin{tabular}{|c|c|c|c|c|}
\hline \multicolumn{4}{|c|}{ Basement Wall Level 2} & \multirow[b]{3}{*}{1765 for labour for all } \\
\hline Component & Unit & Un & ost & \\
\hline Framing $25 \times 50 \mathrm{~mm} 400 \mathrm{~mm}$ O.C. & L.F. & $\$$ & 2.00 & \\
\hline XPS 63mm & S.F. & $\$$ & 2.02 & Manufacturer \\
\hline Gypsum Board 13mm & S.F. & $\$$ & 0.74 & \\
\hline
\end{tabular}




\begin{tabular}{|c|c|c|c|}
\hline \multicolumn{3}{|c|}{ Basement Wall Level 3} & \\
\hline Component & Unit & Unit Cost & \\
\hline Framing $25 \times 50 \mathrm{~mm} 400 \mathrm{~mm}$ O.C. & L.F. & $\$ \quad 2.00$ & 1765 for labour for all \\
\hline XPS 76mm & S.F. & 2.17 & Manufacturer \\
\hline Gypsum Board 13mm & S.F. & 0.74 & \\
\hline
\end{tabular}

\begin{tabular}{|l|l|ll|}
\hline \multicolumn{3}{|c|}{ War Time Basement Wall Level 1} \\
\hline Component & Unit & Unit Cost \\
\hline Demolish Gypsum and Fibreglass Insulation & S.F. & $\$$ & 2.40 \\
\hline Framing 25x50mm 400mm O.C. & L.F. & $\$$ & 2.00 \\
\hline XPS 50mm & S.F. & $\$$ & 1.63 \\
\hline Gypsum Board 13mm & S.F. & $\$$ & 0.74 \\
\hline
\end{tabular}

\begin{tabular}{|l|l|ll|}
\hline \multicolumn{3}{|c|}{ War Time Basement Wall Level 2} \\
\hline Component & Unit & Unit Cost & \\
\hline Demolish Gypsum and Fibreglass Insulation & S.F. & $\$$ & 2.40 \\
\hline Framing $25 \times 50 \mathrm{~mm} 400 \mathrm{~mm}$ O.C. & L.F. & $\$$ & 2.00 \\
\hline XPS $63 \mathrm{~mm}$ & S.F. & $\$$ & 2.02 \\
\cline { 1 - 2 } Gypsum Board $13 \mathrm{~mm}$ & S.F. & $\$$ & 0.74 \\
\hline
\end{tabular}

\begin{tabular}{|c|c|c|c|c|}
\hline \multicolumn{4}{|c|}{ War Time Basement Wall Level 3} & \\
\hline Component & Unit & Un & ost & \\
\hline Demolish Gypsum and Fibreglass Insulation & S.F. & $\$$ & 2.40 & \\
\hline Framing $25 \times 50 \mathrm{~mm} 400 \mathrm{~mm}$ O.C. & L.F. & $\$$ & 2.00 & \\
\hline XPS 76mm & S.F. & $\$$ & 2.17 & Manufacture \\
\hline Gypsum Board 13mm & S.F. & $\$$ & 0.74 & \\
\hline
\end{tabular}

\begin{tabular}{|c|c|c|c|}
\hline \multicolumn{3}{|c|}{ Slab Level 1} & \\
\hline Component & Unit & Unit Cost & \\
\hline XPS 19mm & S.F. & $\$ \quad 0.63$ & \\
\hline Concrete Slab 75mm & S.F. & N/A & 1200 for the pour \\
\hline
\end{tabular}

\begin{tabular}{|l|l|l|l|}
\hline \multicolumn{2}{|c|}{ Slab Level 2 } & \multicolumn{1}{|c|}{} \\
\cline { 1 - 3 } Component & Unit & Unit Cost & \\
\cline { 1 - 3 } $25 \mathrm{~mm}$ & S.F. & \$ $\quad 1.57$ & Manufacturer \\
\hline Concrete Slab $75 \mathrm{~mm}$ & S.F. & N/A & 1200 for the pour \\
\hline
\end{tabular}

\begin{tabular}{|l|l|l|l|}
\hline \multicolumn{2}{|c|}{ Slab Level 3 } & \multicolumn{1}{|c|}{} \\
\cline { 1 - 3 } Component & Unit & Unit Cost & \\
\cline { 1 - 3 } XPS 40mm & S.F. & \$ 1.72 & Manufacturer \\
\hline Concrete Slab 75mm & S.F. & N/A & 1200 for the pour \\
\hline
\end{tabular}




\begin{tabular}{|c|c|c|c|}
\hline \multicolumn{3}{|c|}{ Windows Level 1} & \\
\hline Component & Unit & Unit Cost & \\
\hline Demolish Existing Windows & S.F. & $\mathrm{N} / \mathrm{A}$ & 200 per window \\
\hline Double, Low-E, Air Filled & S.F. & $\$ \quad 56.67$ & Manufacturer \\
\hline
\end{tabular}

\begin{tabular}{|l|l|l|l|}
\hline \multicolumn{3}{|c|}{ Windows Level 2 } & \\
\cline { 1 - 3 } Component & Unit & Unit Cost & \\
\cline { 1 - 3 } Demolish Existing Windows & S.F. & N/A & \\
\cline { 1 - 3 } Alpen 725 & S.F. & $\$ \quad 65.00$ & Manufacturer \\
\hline
\end{tabular}

\begin{tabular}{|l|l|l|l|}
\hline \multicolumn{2}{|c|}{ Windows Level 3 } & \\
\cline { 1 - 3 } Component & Unit & Unit Cost & \\
\cline { 1 - 3 } Demolish Existing Windows & S.F. & N/A & 200 per window \\
\cline { 1 - 3 } Alpen 925 & S.F. & $\$ \quad 80.00$ & Manufacturer \\
\hline
\end{tabular}

\begin{tabular}{|l|l|l|}
\hline \multicolumn{3}{|c|}{ HVAC } \\
\hline Component & Unit & Unit Cost \\
\hline Level 1, 90\% Efficient & Ea. & N/A \\
\hline Level 2, 94\% Efficient & Ea. & N/A \\
\hline Level 3, 97\% Efficient & Ea. & N/A \\
\hline
\end{tabular}

\begin{tabular}{|l|l|l|l|}
\hline \multicolumn{3}{|c|}{ Ventilation } & \multicolumn{1}{|c|}{} \\
\hline Component & Unit & Unit Cost & \\
\hline Level 1, HRV 60\% Efficient & Ea. & $\$ 499.57$ & ecomfort.com \\
\hline Level 2, HRV 85\% Efficient & Ea. & $\$ 1,625.00$ & 500 each to install \\
\hline Level 3, ERV 80\% Efficient & Ea. & $\$ 1,921.49$ & \\
\hline
\end{tabular}

\begin{tabular}{|l|l|l|l|}
\hline \multicolumn{2}{|c|}{ Air Sealing } & \\
\cline { 1 - 3 } Component & Unit & Unit Cost & \\
\cline { 1 - 3 } Level 1, 20\% Reduction & & $\$ 520.00$ & 1 person for a day \\
\hline Level 2, ACH 2-3 & House & $\$ 1,500.00$ & Assumed \\
\hline Level 3, ACH 1 & House & $\$ 1,500.00$ & Assumed \\
\hline
\end{tabular}

\section{Contractor 3}

\begin{tabular}{|c|c|c|c|}
\hline \multicolumn{3}{|c|}{ Masonry Wall Level 1} & \multirow[b]{2}{*}{ Reference/Notes } \\
\hline Component & Unit & Unit Cost & \\
\hline Demolish Lath and Plaster & S.F. & $\$ \quad 3.50$ & \\
\hline Framing 50x100mm 610mm O.C. & L.F. & 2.00 & \\
\hline Closed Cell Spray Foam 25mm & S.F. & 1.30 & \\
\hline Mineral Batt Insulation 140mm & S.F. & 1.33 & \\
\hline Gypsum Board 13mm & S.F. & 2.18 & \\
\hline
\end{tabular}




\begin{tabular}{|l|l|lr|}
\hline \multicolumn{4}{|c|}{ Masonry Wall Level 2} \\
\hline Component & Unit & Unit Cost \\
\hline Demolish Lath and Plaster & S.F. & $\$$ & 3.50 \\
\hline Framing 50x100mm 610mm O.C. & L.F. & $\$$ & 2.00 \\
\hline XPS 76mm & S.F. & $\$$ & 2.10 \\
\hline Mineral Batt Insulation 140mm & S.F. & $\$$ & 1.33 \\
\hline Gypsum Board 13mm & S.F. & $\$$ & 2.18 \\
\hline
\end{tabular}

\begin{tabular}{|l|l|lr|}
\hline \multicolumn{4}{|c|}{ Masonry Wall Level 3 } \\
\hline Component & Unit & Unit Cost \\
\hline Demolish Lath and Plaster & S.F. & $\$$ & 3.50 \\
\hline Framing 50x75mm 610mm O.C. & L.F. & $\$$ & 1.95 \\
\hline Spun Bonded Polyethylene & S.F. & $\$$ & 0.60 \\
\hline Roxul Drain Board 50mm & S.F. & $\$$ & 1.70 \\
\hline Blown Cellulose 356mm & S.F. & $\$$ & 1.10 \\
\hline Gypsum Board 13mm & S.F. & $\$$ & 2.18 \\
\hline
\end{tabular}

\begin{tabular}{|l|l|lr|}
\hline \multicolumn{4}{|c|}{ Wood Frame Wall Level 1} \\
\hline Component & Unit & Unit Cost \\
\hline Demolish Gypsum and Fibreglass Insulation & S.F. & $\$$ & 3.50 \\
\hline Framing 50x75mm 610mm O.C. & L.F. & $\$$ & 1.95 \\
\hline Closed Cell Spray Foam $25 \mathrm{~mm}$ & S.F. & $\$$ & 1.30 \\
\hline Mineral Batt Insulation $140 \mathrm{~mm}$ & S.F. & $\$$ & 1.33 \\
\hline Gypsum Board $13 \mathrm{~mm}$ & S.F. & $\$$ & 2.18 \\
\hline
\end{tabular}

\begin{tabular}{|l|l|lr|}
\hline \multicolumn{3}{|c|}{ Wood Frame Wall Level 2} \\
\hline Component & Unit & Unit Cost \\
\hline Demolish Gypsum and Fibreglass Insulation & S.F. & $\$$ & 3.50 \\
\hline Framing 50x75mm 610mm O.C. & L.F. & $\$$ & 1.95 \\
\hline Closed Cell Spray Foam 63mm & S.F. & $\$$ & 2.21 \\
\hline Blown Cellulose $165 \mathrm{~mm}$ & S.F. & $\$$ & 0.80 \\
\hline Gypsum Board 13mm & S.F. & $\$$ & 2.18 \\
\hline
\end{tabular}

\begin{tabular}{|l|l|lr|}
\hline \multicolumn{4}{|c|}{ Wood Frame Wall Level 3} \\
\hline Component & Unit & Unit Cost \\
\hline Demolish Gypsum and Fibreglass Insulation & S.F. & $\$$ & 3.50 \\
\hline Framing 50x75mm 610mm O.C. & L.F. & $\$$ & 1.95 \\
\hline Closed Cell Spray Foam 63mm & S.F. & $\$$ & 2.21 \\
\hline Blown Cellulose $261 \mathrm{~mm}$ & S.F. & $\$$ & 1.20 \\
\hline Gypsum Board 13mm & S.F. & $\$$ & 2.18 \\
\hline
\end{tabular}




\begin{tabular}{|l|l|lr|}
\hline \multicolumn{3}{|c|}{ Cathedral Roof Level 1} \\
\hline Component & Unit & Unit Cost \\
\hline Demolish Lath and Plaster & S.F. & $\$$ & 3.50 \\
\hline Framing 50x140mm 610mm O.C. & L.F. & $\$$ & 2.47 \\
\hline Closed Cell Spray Foam 25mm & S.F. & $\$$ & 1.30 \\
\hline Blown Cellulose 345mm & S.F. & $\$$ & 3.85 \\
\hline Gypsum Board $13 \mathrm{~mm}$ & S.F. & $\$$ & 2.18 \\
\hline
\end{tabular}

\begin{tabular}{|l|l|lr|}
\hline \multicolumn{3}{|c|}{ Cathedral Roof Level 2} \\
\hline Component & Unit & Unit Cost \\
\hline Demolish Lath and Plaster & S.F. & $\$$ & 3.50 \\
\hline Framing 50x140mm 610mm O.C. & L.F. & $\$$ & 2.47 \\
\hline Closed Cell Spray Foam 100mm & S.F. & $\$$ & 3.30 \\
\hline Blown Cellulose $270 \mathrm{~mm}$ & S.F. & $\$$ & 3.00 \\
\hline Gypsum Board $13 \mathrm{~mm}$ & S.F. & $\$$ & 2.18 \\
\hline
\end{tabular}

\begin{tabular}{|c|c|c|c|c|}
\hline \multicolumn{4}{|c|}{ Cathedral Roof Level 3} & \\
\hline Component & Unit & Uni & Cost & \\
\hline Demolish Lath and Plaster & S.F. & $\$$ & 3.50 & \\
\hline Demolish Shingles & S.F. & $\$$ & 2.00 & \\
\hline Polyisocyanurate $150 \mathrm{~mm}$ & S.F. & $\$$ & 4.40 & \\
\hline Blown Cellulose 230mm & S.F. & $\$$ & 3.00 & Manufacturer \\
\hline Shingles & S.F. & $\$$ & 4.00 & \\
\hline OSB Sheathing & S.F. & $\$$ & 1.80 & \\
\hline Gypsum Board 13mm & S.F. & $\$$ & 2.18 & \\
\hline
\end{tabular}

\begin{tabular}{|l|l|l|}
\hline \multicolumn{3}{|c|}{ Attic Roof Level 1 } \\
\hline Component & Unit & Unit Cost \\
\hline Blown Cellulose 375mm & S.F. & \$ 1.20 \\
\hline
\end{tabular}

\begin{tabular}{|l|l|l|}
\hline \multicolumn{3}{|c|}{ Attic Roof Level 2 } \\
\hline Component & Unit & Unit Cost \\
\hline Blown Cellulose 450mm & S.F. & \$ 1.30 \\
\hline
\end{tabular}

\begin{tabular}{|c|c|c|}
\hline \multicolumn{3}{|c|}{ Attic Roof Level 3} \\
\hline Component & Unit & Unit Cost \\
\hline Blown Cellulose $563 \mathrm{~mm}$ & S.F. & 1.60 \\
\hline
\end{tabular}

\begin{tabular}{|l|l|ll|}
\hline \multicolumn{3}{|c|}{ Basement Wall Level 1 } \\
\hline Component & Unit & Unit Cost \\
\hline Framing 25x50mm 400mm O.C. & L.F. & $\$$ & 0.70 \\
\hline XPS 50mm & S.F. & $\$$ & 1.50 \\
\hline Gypsum Board 13mm & S.F. & $\$$ & 2.18 \\
\hline
\end{tabular}




\begin{tabular}{|l|l|ll|}
\hline \multicolumn{3}{|c|}{ Basement Wall Level 2} \\
\hline Component & Unit & Unit Cost \\
\hline Framing 25x50mm 400mm O.C. & L.F. & $\$$ & 0.70 \\
\hline XPS 63mm & S.F. & $\$$ & 1.80 \\
\hline Gypsum Board 13mm & S.F. & $\$$ & 2.18 \\
\hline
\end{tabular}

\begin{tabular}{|l|l|lr|}
\hline \multicolumn{3}{|c|}{ Basement Wall Level 3 } \\
\hline Component & Unit & Unit Cost \\
\hline Framing $25 \times 50 \mathrm{~mm} 400 \mathrm{~mm}$ O.C. & L.F. & $\$$ & 0.70 \\
\hline XPS $76 \mathrm{~mm}$ & S.F. & $\$$ & 2.10 \\
\hline Gypsum Board $13 \mathrm{~mm}$ & S.F. & $\$$ & 2.18 \\
\hline
\end{tabular}

\begin{tabular}{|l|l|lr|}
\hline \multicolumn{4}{|c|}{ War Time Basement Wall Level 1} \\
\hline Component & Unit & Unit Cost \\
\hline Demolish Gypsum and Fibreglass Insulation & S.F. & $\$$ & 3.50 \\
\hline Framing 25x50mm 400mm O.C. & L.F. & $\$$ & 0.70 \\
\hline XPS 50mm & S.F. & $\$$ & 1.50 \\
\hline Gypsum Board 13mm & S.F. & $\$$ & 2.18 \\
\hline
\end{tabular}

\begin{tabular}{|l|l|lr|}
\hline \multicolumn{4}{|c|}{ War Time Basement Wall Level 2} \\
\hline Component & Unit & Unit Cost \\
\hline Demolish Gypsum and Fibreglass Insulation & S.F. & $\$$ & 3.50 \\
\hline Framing $25 \times 50 \mathrm{~mm} 400 \mathrm{~mm}$ O.C. & L.F. & $\$$ & 0.70 \\
\hline XPS 63mm & S.F. & $\$$ & 1.80 \\
\hline Gypsum Board $13 \mathrm{~mm}$ & S.F. & $\$$ & 2.18 \\
\hline
\end{tabular}

\begin{tabular}{|l|l|lr|}
\hline \multicolumn{4}{|c|}{ War Time Basement Wall Level 3} \\
\hline Component & Unit & Unit Cost \\
\hline Demolish Gypsum and Fibreglass Insulation & S.F. & $\$$ & 3.50 \\
\hline Framing $25 \times 50 \mathrm{~mm} 400 \mathrm{~mm}$ O.C. & L.F. & $\$$ & 0.70 \\
\hline XPS $76 \mathrm{~mm}$ & S.F. & $\$$ & 2.10 \\
\hline Gypsum Board $13 \mathrm{~mm}$ & S.F. & $\$$ & 2.18 \\
\hline
\end{tabular}

\begin{tabular}{|c|c|c|}
\hline \multicolumn{3}{|c|}{ Slab Level 1} \\
\hline Component & Unit & Unit Cost \\
\hline XPS 19mm & S.F. & $\$ \quad 0.70$ \\
\hline Concrete Slab $75 \mathrm{~mm}$ & S.F. & 12.00 \\
\hline
\end{tabular}

\begin{tabular}{|c|c|c|}
\hline \multicolumn{3}{|c|}{ Slab Level 2} \\
\hline Component & Unit & Unit Cost \\
\hline XPS 25mm & S.F. & 0.75 \\
\hline Concrete Slab $75 \mathrm{~mm}$ & S.F. & 12.00 \\
\hline
\end{tabular}




\begin{tabular}{|c|c|c|}
\hline \multicolumn{3}{|c|}{ Slab Level 3} \\
\hline Component & Unit & Unit Cost \\
\hline XPS 40mm & S.F. & 1.20 \\
\hline Concrete Slab $75 \mathrm{~mm}$ & S.F. & 12.00 \\
\hline
\end{tabular}

\begin{tabular}{|c|c|c|c|}
\hline \multicolumn{3}{|c|}{ Windows Level 1} & \\
\hline Component & Unit & Unit Cost & \\
\hline Demolish Existing Windows & S.F. & N/A & 300 per window \\
\hline Double, Low-E, Air Filled & S.F. & 56.67 & \\
\hline
\end{tabular}

\begin{tabular}{|l|l|l|l|}
\hline \multicolumn{2}{|c|}{ Windows Level 2 } & \\
\cline { 1 - 3 } Component & Unit & Unit Cost & \\
\cline { 1 - 3 } Demolish Existing Windows & S.F. & N/A & \\
\cline { 1 - 3 } Alpen 725 & S.F. & $\$ \quad 65.00$ & Manufacturer \\
\hline
\end{tabular}

\begin{tabular}{|l|l|l|l|}
\hline \multicolumn{2}{|c|}{ Windows Level 3 } & \\
\cline { 1 - 3 } Component & Unit & Unit Cost & \\
\cline { 1 - 3 } Demolish Existing Windows & S.F. & N/A & \multirow{3}{*}{300 per window } \\
\hline Alpen 925 & S.F. & $\$ \quad 80.00$ & Manufacturer \\
\hline
\end{tabular}

\begin{tabular}{|l|l|l|}
\hline \multicolumn{2}{|c|}{ HVAC } \\
\hline Component & Unit & Unit Cost \\
\hline Level 1, 90\% Efficient & Ea. & $\$ 1,200.00$ \\
\hline Level 2, 94\% Efficient & Ea. & $\$ 1,650.00$ \\
\hline Level 3, 97\% Efficient & Ea. & $\$ 2,640.00$ \\
\hline
\end{tabular}

\begin{tabular}{|c|c|c|c|}
\hline \multicolumn{3}{|c|}{ Ventilation } & \\
\hline Component & Unit & Unit Cost & \\
\hline Level 1, HRV 60\% Efficient & Ea. & $\$ 499.57$ & ecomfort.com \\
\hline Level 2, HRV 85\% Efficient & Ea. & $\$ 1,625.00$ & Plus 3500 for install \\
\hline Level 3, ERV 80\% Efficient & Ea. & $\$ 1,921.49$ & \\
\hline
\end{tabular}

\begin{tabular}{|c|c|c|c|}
\hline \multicolumn{3}{|c|}{ Air Sealing } & \\
\hline Component & Unit & Unit Cost & \\
\hline Level 1, 20\% Reduction & S.F. & $\$ \quad 0.36$ & \\
\hline Level 2, ACH 2-3 & House & $\$ 1,500.00$ & Assumed \\
\hline Level 3, ACH 1 & House & $\$ 1,500.00$ & Assumed \\
\hline
\end{tabular}




\section{Appendix L: Retrofit Strategy Cost Estimation Summary by Archetype}

\begin{tabular}{|c|c|c|c|c|c|c|c|c|c|c|c|c|c|c|c|c|c|c|c|c|c|}
\hline & & \multicolumn{4}{|c|}{ RS Means } & \multicolumn{4}{|c|}{ Contractor 1 (Steve) } & \multicolumn{4}{|c|}{ Contractor 2 (Ken) } & \multicolumn{4}{|c|}{ Contractor 3 (Paul) } & \multicolumn{4}{|c|}{ Average } \\
\hline & & Century & Cent & ry-Semi & War Time & Century & Cer & ry-Semi & War Time & Century & Cer & Iry-Semi & War Time & Century & Cen & ry-Semi & War Time & Century & & ury-Semi & War Time \\
\hline \multirow{3}{*}{ Walls } & Level 1 & $\$ 17,693$ & $\$$ & 12,868 & $\$ 6,883$ & $\$ 25,517$ & $\$$ & 19,287 & $\$ 9,920$ & $\$ 20,824$ & $\$$ & 14,989 & $\$ 8,633$ & $\$ 20,283$ & $\$$ & 14,512 & $\$ 8,514$ & $\$ 21,079$ & $\$$ & 15,414 & $\$ 8,488$ \\
\hline & Level 2 & $\$ 19,867$ & $\$$ & 14,419 & $\$ 9,627$ & $\$ 24,985$ & $\$$ & 19,160 & $\$ 12,335$ & $\$ 19,412$ & $\$$ & 13,982 & $\$ 11,048$ & $\$ 22,076$ & $\$$ & 15,791 & $\$ 8,871$ & $\$ 21,585$ & $\$$ & 15,838 & $\$ 10,470$ \\
\hline & Level 3 & $\$ 22,198$ & $\$$ & 16,081 & $\$ 10,848$ & $\$ 27,544$ & $\$$ & 20,722 & $\$ 12,711$ & $\$ 21,184$ & $\$$ & 15,456 & $\$ 11,988$ & $\$ 21,976$ & $\$$ & 15,712 & $\$ 9,247$ & $\$ 23,226$ & $\$$ & 16,993 & $\$ 11,199$ \\
\hline \multirow{3}{*}{ Ceiling } & Level 1 & $\$ \quad 6,047$ & $\$$ & 4,224 & $\$ 2,917$ & $\$ 10,413$ & $\$$ & 7,645 & $\$ 1,607$ & $\$ 10,931$ & $\$$ & 7,656 & $\$ 1,607$ & $\$ 12,119$ & $\$$ & 8,373 & $\$ 1,429$ & $\$ \quad 9,878$ & $\$$ & 6,975 & $\$ 1,890$ \\
\hline & Level 2 & $\$ 8,383$ & $\$$ & 5,814 & $\$ 3,500$ & $\$ 12,205$ & $\$$ & 8,865 & $\$ 1,786$ & $\$ 11,637$ & $\$$ & 8,137 & $\$ 1,786$ & $\$ 13,368$ & $\$$ & 9,223 & $\$ 1,548$ & $\$ 11,398$ & $\$$ & 8,010 & $\$ 2,155$ \\
\hline & Level 3 & $\$ 12,414$ & $\$$ & 8,452 & $\$ 4,369$ & $\$ 11,944$ & $\$$ & 8,343 & $\$ 2,083$ & $\$ 19,226$ & $\$$ & 14,484 & $\$ 2,083$ & $\$ 22,667$ & $\$$ & 15,440 & $\$ 1,905$ & $\$ 16,563$ & $\$$ & 11,680 & $\$ 2,610$ \\
\hline \multirow{3}{*}{$\begin{array}{c}\text { Basement } \\
\text { Walls }\end{array}$} & Level 1 & $\$ 2,816$ & $\$$ & 1,593 & $\$ 3,258$ & $\$ 6,038$ & $\$$ & 3,838 & $\$ 8,653$ & $\$ 4,788$ & $\$$ & 3,485 & $\$ 7,003$ & $\$ 3,718$ & $\$$ & 2,078 & $\$ 6,952$ & $\$ 4,340$ & $\$$ & 2,749 & $\$ 6,467$ \\
\hline & Level 2 & $\$ \quad 2,975$ & $\$$ & 1,681 & $\$ 3,406$ & $\$ 6,178$ & $\$$ & 3,915 & $\$ 8,792$ & $\$ 5,152$ & $\$$ & 3,687 & $\$ 7,365$ & $\$ 3,998$ & $\$$ & 2,233 & $\$ 7,231$ & $\$ \quad 4,576$ & $\$$ & 2,879 & $\$ 6,699$ \\
\hline & Level 3 & $\$ \quad 3,133$ & $\$$ & 1,769 & $\$ 3,564$ & $\$ 6,318$ & $\$$ & 3,993 & $\$ 8,931$ & $\$ 5,292$ & $\$$ & 3,765 & $\$ 7,505$ & $\$ 4,278$ & $\$$ & 2,389 & $\$ 7,510$ & $\$ 4,755$ & $\$$ & 2,979 & $\$ 6,878$ \\
\hline \multirow{3}{*}{ Slab } & Level 1 & $\$ \quad 2,543$ & $\$$ & 2,068 & $\$ 2,722$ & $\$ 5,369$ & $\$$ & 4,367 & $\$ 5,749$ & $\$ 1,727$ & $\$$ & 1,629 & $\$ 1,764$ & $\$ 10,622$ & $\$$ & 8,640 & $\$ 11,374$ & $\$ \quad 5,065$ & $\$$ & 4,176 & $\$ 5,402$ \\
\hline & Level 2 & 2,777 & $\$$ & 2,259 & $\$ 2,973$ & $\$ 5,495$ & $\$$ & 4,469 & $\$ 5,884$ & $\$ 2,513$ & $\$$ & 2,268 & $\$ 2,606$ & $\$ 10,664$ & $\$$ & 8,674 & $\$ 11,418$ & $\$ 5,362$ & $\$$ & 4,418 & $\$ 5,720$ \\
\hline & Level 3 & $\$ \quad 2,961$ & $\$$ & 2,408 & $\$ 3,170$ & $\$ 5,620$ & $\$$ & 4,571 & $\$ 6,018$ & $\$ 2,639$ & $\$$ & 2,370 & $\$ 2,740$ & $\$ 11,040$ & $\$$ & 8,980 & $\$ 11,821$ & $\$ \quad 5,565$ & $\$$ & 4,582 & $\$ 5,937$ \\
\hline \multirow{3}{*}{ Windows } & Level 1 & $\$ 20,850$ & $\$$ & 12,455 & $\$ 14,392$ & $\$ 19,113$ & $\$$ & 11,417 & $\$ 13,193$ & $\$ 16,386$ & $\$$ & 10,635 & $\$ 11,716$ & $\$ 17,686$ & $\$$ & 11,835 & $\$ 12,816$ & $\$ 18,509$ & $\$$ & 11,586 & $\$ 13,029$ \\
\hline & Level 2 & $\$ 23,125$ & $\$$ & 13,813 & $\$ 15,962$ & $\$ 21,139$ & $\$$ & 12,628 & $\$ 14,592$ & $\$ 18,412$ & $\$$ & 11,845 & $\$ 13,115$ & $\$ 19,712$ & $\$$ & 13,045 & $\$ 14,215$ & $\$ 20,597$ & $\$$ & 12,833 & $\$ 14,471$ \\
\hline & Level 3 & $\$ 27,224$ & $\$$ & 16,262 & $\$ 18,792$ & $\$ 24,788$ & $\$$ & 14,807 & $\$ 17,111$ & $\$ 22,061$ & $\$$ & 14,025 & $\$ 15,633$ & $\$ 23,361$ & $\$$ & 15,225 & $\$ 16,733$ & $\$ 24,359$ & $\$$ & 15,080 & $\$ 17,067$ \\
\hline \multirow{3}{*}{ Air Sealing } & Level 1 & N/A & $\mathrm{N} / \mathrm{A}$ & & N/A & $\$ 2,200$ & $\$$ & 2,200 & $\$ 2,200$ & $\$ \quad 520$ & $\$$ & 520 & 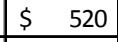 & $\$ 1,285$ & $\$$ & 894 & \begin{tabular}{|l|}
$\$ \quad 827$ \\
\end{tabular} & $\$ 1,335$ & $\$$ & 1,205 & $\$ 1,182$ \\
\hline & Level 2 & $\$ 1,500$ & $\$$ & 1,500 & $\$ 1,500$ & $\$ 1,500$ & $\$$ & 1,500 & $\$ 1,500$ & $\$ 1,500$ & $\$$ & 1,500 & $\$ 1,500$ & $\$ 1,500$ & $\$$ & 1,500 & $\$ 1,500$ & $\$ 1,500$ & $\$$ & 1,500 & $\$ 1,500$ \\
\hline & Level 3 & $\$ 1,500$ & $\$$ & 1,500 & $\$ 1,500$ & $\$ 1,500$ & $\$$ & 1,500 & $\$ 1,500$ & $\$ 1,500$ & $\$$ & 1,500 & $\$ 1,500$ & $\$ 1,500$ & $\$$ & 1,500 & $\$ 1,500$ & $\$ 1,500$ & $\$$ & 1,500 & $\$ 1,500$ \\
\hline \multirow{3}{*}{ Furnace } & Level 1 & $\$ 2,550$ & $\$$ & 2,550 & $\$ 2,550$ & $\$ 2,200$ & $\$$ & 2,200 & $\$ 2,200$ & N/A & $\mathrm{N} /$ & & N/A & $\$ 4,700$ & $\$$ & 4,700 & $\$ 4,700$ & $\$ 3,150$ & $\$$ & 3,150 & $\$ 3,150$ \\
\hline & Level 2 & $\$ 3,195$ & $\$$ & 3,195 & $\$ 3,195$ & $\$ 2,650$ & $\$$ & 2,650 & $\$ 2,650$ & N/A & $\mathrm{N} /$ & & N/A & $\$ 5,150$ & $\$$ & 5,150 & $\$ 5,150$ & $\$ 3,665$ & $\$$ & 3,665 & $\$ 3,665$ \\
\hline & Level 3 & $\$ 3,220$ & $\$$ & 3,220 & $\$ 3,220$ & $\$ 3,640$ & $\$$ & 3,640 & $\$ 3,640$ & $\mathrm{~N} / \mathrm{A}$ & $\mathrm{N} /$ & & $\mathrm{N} / \mathrm{A}$ & $\$ 6,140$ & $\$$ & 6,140 & $\$ 6,140$ & $\$ 4,333$ & $\$$ & 4,333 & $\$ 4,333$ \\
\hline \multirow{3}{*}{ HRV/ERV } & Level 1 & $\$ 2,000$ & $\$$ & 2,000 & $\$ 2,000$ & $\$ 1,499$ & $\$$ & 1,499 & $\$ 1,499$ & $\$ 1,000$ & $\$$ & 1,000 & $\$ 1,000$ & $\$ 4,000$ & $\$$ & 4,000 & $\$ 4,000$ & $\$ 2,125$ & $\$$ & 2,125 & $\$ 2,125$ \\
\hline & Level 2 & $\$ 3,125$ & $\$$ & 3,125 & $\$ 3,125$ & $\$ 2,625$ & $\$$ & 2,625 & $\$ 2,625$ & $\$ 2,125$ & $\$$ & 2,125 & $\$ 2,125$ & $\$ 5,150$ & $\$$ & 5,150 & $\$ 5,150$ & 3,256 & $\$$ & 3,256 & $\$ 3,256$ \\
\hline & Level 3 & $\$ \quad 3,421$ & $\$$ & 3,421 & $\$ 3,421$ & $\$ 2,921$ & $\$$ & 2,921 & $\$ 2,921$ & $\$ 2,422$ & $\$$ & 2,422 & $\$ 2,422$ & $\$ 6,140$ & $\$$ & 6,140 & $\$ 6,140$ & $\$ 3,726$ & $\$$ & 3,726 & $\$ 3,726$ \\
\hline
\end{tabular}




\section{Appendix M: Energy Modelling Results Century Home}

\begin{tabular}{|c|c|c|c|c|c|c|c|c|c|c|c|c|c|c|c|c|c|c|c|c|}
\hline Baseline: $\mathbf{2 1 1}$ & \multicolumn{4}{|c|}{ Round 1} & \multicolumn{4}{|c|}{ Round 2} & \multicolumn{4}{|c|}{ Round 3} & \multicolumn{4}{|c|}{ Round 4} & \multicolumn{4}{|c|}{ Round 5} \\
\hline Retrofit & Intensity & Saved & Cost & $\$ /$ Saved & Intensity & Saved & Cost & $\$ /$ Saved & Intensity & Saved & Cost & $\$ /$ Saved & Intensity & Saved & Cost & $\$ /$ Saved & Intensity & Saved & Cost & \$/Saved \\
\hline Walls & 169 & 42 & $\$ 21,079$ & 502 & \begin{tabular}{|l|}
150 \\
\end{tabular} & 38 & $\$ 21,079$ & 555 & 143 & 38 & $\$ 21,079$ & 555 & 131 & 38 & $\$ 21,079$ & 555 & 108 & 36 & $\$ 21,079$ & 586 \\
\hline Roof & 199 & 12 & $\$ 9,878$ & 823 & 177 & 11 & $\$ 9,878$ & 898 & 170 & 11 & $\$ 9,878$ & 898 & 159 & 10 & $\$ 9,878$ & 988 & 134 & 10 & $\$ 9,878$ & 988 \\
\hline Basement Walls & 198 & 13 & $\$ 4,340$ & 334 & 176 & 12 & $\$ 4,340$ & 362 & 169 & 12 & $\$ 4,340$ & 362 & 168 & 1 & $\$ 4,576$ & 4576 & 142 & 2 & $\$ 4,576$ & 2288 \\
\hline Slab & 196 & 15 & $\$ 5,065$ & 338 & 175 & 13 & $\$ 5,065$ & 390 & 168 & 13 & $\$ 5,065$ & 390 & 144 & 25 & $\$ 5,065$ & 203 & 141 & 3 & $\$ 5,362$ & 1787 \\
\hline Windows & 203 & & $\$ 18,509$ & 2314 & 180 & 8 & $\$ 18,509$ & 2314 & 174 & & $\$ 18,509$ & 2644 & 163 & 6 & $\$ 18,509$ & 3085 & 137 & 7 & $\$ 18,509$ & 2644 \\
\hline Air Sealing & 203 & & $\$ 1,335$ & 167 & 181 & 7 & $\$ 1,335$ & 191 & & & & & & & & & & & & \\
\hline \begin{tabular}{|l|} 
Heating/Cooling \\
\end{tabular} & 188 & 23 & $\$ 3,150$ & 137 & 180 & 8 & $\$ 3,665$ & 458 & 173 & 8 & $\$ 3,665$ & 458 & 162 & 7 & $\$ 3,665$ & 524 & 138 & 6 & $\$ 3,665$ & 611 \\
\hline Ventilation & 208 & 3 & $\$ 2,125$ & 708 & 185 & 3 & $\$ 2,125$ & 708 & 178 & 3 & $\$ 2,125$ & 708 & 167 & 2 & $\$ 2,125$ & 1062 & 141 & & $\$ 2,125$ & 708 \\
\hline
\end{tabular}

\begin{tabular}{|c|c|c|c|c|c|c|c|c|c|c|c|c|c|c|c|c|c|c|c|}
\hline \multicolumn{4}{|c|}{ Round 6} & \multicolumn{4}{|c|}{ Round 7} & \multicolumn{4}{|c|}{ Round 8} & \multicolumn{4}{|c|}{ Round 9} & \multicolumn{4}{|c|}{ Round 10} \\
\hline Intensity & Saved & Cost & \$/Saved & Intensity & Saved & Cost & \$/Saved & Intensity & Saved & Cost & $\$ /$ Saved & Intensity & Saved & Cost & $\$ /$ Saved & Intensity & Saved & Cost & \$/Saved \\
\hline 83 & 25 & $\$ 21,585$ & 863 & 77 & 6 & $\$ 23,226$ & \begin{tabular}{|r|}
3871 \\
\end{tabular} & 67 & 7 & $\$ 23,226$ & 3318 & 48 & 9 & $\$ 23,226$ & 2581 & 46 & 9 & $\$ 23,226$ & 2581 \\
\hline 98 & 10 & $\$ 9,878$ & 988 & 74 & 9 & $\$ 9,878$ & 1098 & 57 & 17 & $\$ 12,898$ & 759 & 56 & 1 & $\$ 16,563$ & 16563 & 54 & 1 & $\$ 16,563$ & 16563 \\
\hline 106 & 2 & $\$ 4,576$ & 2288 & 82 & 1 & $\$ 4,576$ & 4576 & 72 & 2 & $\$ 4,576$ & 2288 & 56 & 1 & $\$ 4,576$ & 4576 & 54 & 1 & $\$ 4,576$ & 4576 \\
\hline 106 & 2 & $\$ 5,362$ & 2681 & 82 & 1 & $\$ 5,362$ & 5362 & 73 & 1 & $\$ 5,362$ & 5362 & 56 & 1 & $\$ 5,362$ & 5362 & 54 & 1 & $\$ 5,362$ & 5362 \\
\hline 101 & 7 & $\$ 18,509$ & 2644 & 76 & 7 & $\$ 18,509$ & 2644 & 65 & 9 & $\$ 18,509$ & 2057 & 51 & 6 & $\$ 18,509$ & 3085 & 49 & 6 & $\$ 18,509$ & 3085 \\
\hline & & & & & & & & & & & & & & & & & & & \\
\hline 104 & 4 & $\$ 3,665$ & 916 & 81 & 2 & $\$ 3,665$ & 1833 & 71 & 3 & $\$ 3,665$ & 1222 & 55 & 2 & $\$ 3,665$ & 1833 & 53 & 2 & $\$ 4,333$ & 2167 \\
\hline 107 & 1 & $\$ 2,125$ & 2125 & 82 & 1 & $\$ 2,125$ & 2125 & 73 & 1 & $\$ 2,125$ & 2125 & 56 & 1 & $\$ 2,125$ & 2125 & 54 & 1 & $\$ 2,125$ & 2125 \\
\hline & & & & First Targe & Met at $\mathrm{Rc}$ & ound 7 & & Air Tightn & ess gets re & duced to 3 & $3 \mathrm{ACH}$ & & & & & & & & \\
\hline & & & & & & & & Level 2 wa & Ils and roo & of were en & nployed & & & & & & & & \\
\hline
\end{tabular}

\begin{tabular}{|c|c|c|c|c|c|c|c|c|c|c|c|c|c|c|c|c|}
\hline \multirow{2}{*}{\begin{tabular}{|l} 
Baseline: 38 \\
Retrofit \\
\end{tabular}} & \multicolumn{4}{|c|}{ Round 11} & \multicolumn{4}{|c|}{ Round 12} & \multicolumn{4}{|c|}{ Round 13} & \multicolumn{4}{|c|}{ Round 14} \\
\hline & Intensity & Saved & Cost & \$/Saved & Intensity & Saved & Cost & $\$ /$ Saved & Intensity & Saved & Cost & \$/Saved & Intensity & Saved & Cost & \$/Saved \\
\hline Walls & 46 & 8 & $\$ 23,226$ & 2903 & & & & & & & & & & & & \\
\hline Roof & 53 & 1 & $\$ 16,563$ & 16563 & 38 & 15 & $\$ 18,063$ & 1204 & & & & & & & & \\
\hline Basement Walls & 53 & 1 & $\$ 4,576$ & 4576 & 44 & 2 & $\$ 4,576$ & 2288 & 37 & 1 & $\$ 4,576$ & 4576 & 30 & 1 & $\$ 4,576$ & 4576 \\
\hline Slab & 53 & 1 & $\$ 5,362$ & 5362 & 44 & 2 & $\$ 5,362$ & 2681 & 37 & 1 & $\$ 5,362$ & 5362 & 30 & 1 & $\$ 5,362$ & 5362 \\
\hline Windows & 48 & 6 & $\$ 18,509$ & 3085 & 38 & 15 & $\$ 18,509$ & 1234 & 31 & 7 & $\$ 18,509$ & 2644 & 22 & 9 & $\$ 20,597$ & 2289 \\
\hline \multicolumn{17}{|l|}{ Air Sealing } \\
\hline Heating/Cooling & 53 & 1 & $\$ 4,333$ & 4333 & 44 & 2 & $\$ 4,333$ & 2167 & 37 & 1 & $\$ 4,333$ & 4333 & 30 & 1 & $\$ 4,333$ & 4333 \\
\hline \multirow[t]{3}{*}{ Ventilation } & 53 & 1 & $\$ 3,256$ & 3256 & 45 & 1 & $\$ 3,256$ & 3256 & 37 & 1 & $\$ 3,256$ & 3256 & 30 & 1 & $\$ 3,256$ & 3256 \\
\hline & & & & & Air Tightn & ss gets re & duced to & $1 \mathrm{ACH}$ & & & & & \multirow{2}{*}{\multicolumn{4}{|c|}{ With TFA Intensity is 25: Final target met }} \\
\hline & & & & & Level 3 wa & Ils and roc & of were e & mployed & & & & & & & & \\
\hline
\end{tabular}




\section{Century-Semi Home}

\begin{tabular}{|c|c|c|c|c|c|c|c|c|c|c|c|c|c|c|c|c|c|c|c|c|}
\hline Baseline: $\mathbf{2 2 8}$ & \multicolumn{4}{|c|}{ Round 1} & \multicolumn{4}{|c|}{ Round 2} & \multicolumn{4}{|c|}{ Round 3} & \multicolumn{4}{|c|}{ Round 4} & \multicolumn{4}{|c|}{ Round 5} \\
\hline Retrofit & Intensity & Saved & Cost & $\$ /$ Saved & Intensity & Saved & Cost & $\$ /$ Saved & Intensity & Saved & Cost & $\$ /$ Saved & Intensity & Saved & Cost & $\$ /$ Saved & Intensity & Saved & Cost & $\$ /$ Saved \\
\hline Walls & \begin{tabular}{|r|}
192 \\
\end{tabular} & 36 & $\$ 15,414$ & 428 & 171 & 32 & $\$ 15,414$ & 482 & 162 & 32 & $\$ 15,414$ & \begin{tabular}{|r|}
482 \\
\end{tabular} & 141 & $\begin{array}{l}1 \\
11 \\
\end{array}$ & $\$ 15,414$ & 497 & 119 & 31 & $\$ 15,414$ & 497 \\
\hline Roof & 219 & 9 & $\$ 6,975$ & 775 & 194 & 9 & $\$ 6,975$ & 775 & 186 & 8 & $\$ 6,975$ & 872 & 165 & 7 & $\$ 6,975$ & 996 & 143 & 7 & $\$ 6,975$ & 996 \\
\hline Basement Walls & 216 & 12 & $\$ 2,749$ & 229 & 192 & 11 & $\$ 2,749$ & 250 & 184 & 10 & $\$ 2,749$ & 275 & 150 & 22 & $\$ 2,749$ & 125 & 148 & 2 & $\$ 2,879$ & 1440 \\
\hline Slab & 202 & 26 & $\$ 4,176$ & 161 & 180 & 23 & $\$ 4,176$ & 182 & 172 & 22 & $\$ 4,176$ & 190 & 170 & 2 & $\$ 4,176$ & 2088 & 146 & 4 & $\$ 4,176$ & 1044 \\
\hline Windows & 219 & 9 & $\$ 11,586$ & 1287 & 195 & 8 & $\$ 11,586$ & 1448 & 187 & 7 & $\$ 11,586$ & 1655 & 165 & 7 & $\$ 11,586$ & 1655 & 143 & 7 & $\$ 11,586$ & 1655 \\
\hline Air Sealing & 219 & 9 & $\$ 1,205$ & 134 & 194 & 9 & $\$ 1,205$ & 134 & & & & & & & & & & & & \\
\hline Heating/Cooling & 203 & 25 & $\$ 3,150$ & 126 & 194 & 9 & $\$ 3,665$ & 407 & 186 & 8 & $\$ 3,665$ & 458 & 165 & & $\$ 3,665$ & 524 & 143 & 7 & $\$ 3,665$ & 524 \\
\hline Ventilation & 225 & 3 & $\$ 2,125$ & 708 & 200 & 3 & $\$ 2,125$ & 708 & 192 & 2 & $\$ 2,125$ & 1063 & 170 & 2 & $\$ 2,125$ & 1063 & 148 & 2 & $\$ 2,125$ & 1063 \\
\hline
\end{tabular}

\begin{tabular}{|c|c|c|c|c|c|c|c|c|c|c|c|c|c|c|c|c|c|c|c|}
\hline \multicolumn{4}{|c|}{ Round 6} & \multicolumn{4}{|c|}{ Round 7} & \multicolumn{4}{|c|}{ Round 8} & \multicolumn{4}{|c|}{ Round 9} & \multicolumn{4}{|c|}{ Round 10} \\
\hline Intensity & Saved & Cost & $\$ /$ Saved & Intensity & Saved & Cost & $\$ /$ Saved & Intensity & Saved & Cost & \$/Saved & Intensity & Saved & Cost & $\$ /$ Saved & Intensity & Saved & Cost & $\$$ /Saved \\
\hline 97 & 22 & $\$ 15,838$ & 720 & 94 & 3 & $\$ 16,993$ & 5664 & $\begin{array}{r}82 \\
\end{array}$ & 4 & $\$ 16,993$ & 4248 & \begin{tabular}{|r|}
55 \\
\end{tabular} & 8 & $\$ 16,993$ & 2124 & 53 & 7 & $\$ 16,993$ & 2428 \\
\hline 110 & 9 & $\$ 6,975$ & 775 & 86 & 11 & $\$ 6,975$ & 634 & 63 & 23 & $\$ 9,510$ & 413 & 62 & 1 & $\$ 11,680$ & 11680 & 59 & 1 & $\$ 11,680$ & 11680 \\
\hline 117 & 2 & $\$ 2,879$ & 1440 & 95 & 2 & $\$ 2,879$ & 1440 & 85 & 1 & $\$ 2,879$ & 2879 & 62 & 1 & $\$ 2,879$ & 2879 & 59 & 1 & $\$ 2,879$ & 2879 \\
\hline 116 & 3 & $\$ 4,176$ & 1392 & 94 & 3 & $\$ 4,176$ & 1392 & 84 & 2 & $\$ 4,176$ & 2088 & 61 & 2 & $\$ 4,176$ & 2088 & 58 & 2 & $\$ 4,176$ & 2088 \\
\hline 111 & 8 & $\$ 11,586$ & 1448 & 88 & 9 & $\$ 11,586$ & 1287 & 77 & 9 & $\$ 11,586$ & 1287 & 57 & 6 & $\$ 11,586$ & 1931 & 55 & 5 & $\$ 11,586$ & 2317 \\
\hline & & & & & & & & & & & & & & & & & & & \\
\hline 114 & 5 & $\$ 3,665$ & 733 & 93 & 4 & $\$ 3,665$ & 916 & 83 & 3 & $\$ 3,665$ & 1222 & 60 & 3 & $\$ 3,665$ & 1222 & 59 & 1 & $\$ 4,333$ & 4333 \\
\hline 117 & 2 & $\$ 2,125$ & 1063 & 95 & 2 & $\$ 2,125$ & 1063 & 85 & 1 & $\$ 2,125$ & 2125 & 62 & 1 & $\$ 2,125$ & 2125 & 59 & 1 & $\$ 2,125$ & 2125 \\
\hline & & & & & & & & First Targe & Met at $\mathrm{Rc}$ & ound 8 & & & & & & & & & \\
\hline & & & & & & & & Air Tightne & ss gets re & duced to 3 & $3 \mathrm{ACH}$ & & & & & & & & \\
\hline & & & & & & & & Level 2 wa & Is and roo & f were en & nployed & & & & & & & & \\
\hline
\end{tabular}

\begin{tabular}{|c|c|c|c|c|c|c|c|c|c|c|c|c|c|c|c|c|c|c|c|}
\hline \multicolumn{4}{|c|}{ Round 11} & \multicolumn{4}{|c|}{$\begin{array}{l}\text { Round } 12 \\
\end{array}$} & \multicolumn{4}{|c|}{ Round 13} & \multicolumn{4}{|c|}{ Round 14} & \multicolumn{4}{|c|}{ Round 15} \\
\hline Intensity & Saved & Cost & \$/Saved I & Intensity & Saved & Cost & $\$ /$ Saved & Intensity & Saved & Cost & $\$ /$ Saved & Intensity & Saved & Cost & $\$ /$ Saved & Intensity & Saved & Cost & $\$ /$ Saved \\
\hline 51 & 7 & $\$ 16,993$ & 2428 & 47 & 8 & $\$ 16,993$ & 2124 & 46 & 7 & $\$ 16,993$ & 2428 & 45 & 7 & $\$ 16,993$ & 2428 & 38 & 9 & $\$ 16,993$ & 1888 \\
\hline 56 & 2 & $\$ 11,680$ & 5840 & 54 & 1 & $\$ 11,680$ & 11680 & 52 & 1 & $\$ 11,680$ & 11680 & 51 & 1 & $\$ 11,680$ & 11680 & 46 & 1 & $\$ 11,680$ & 11680 \\
\hline 57 & 1 & $\$ 2,879$ & 2879 & 53 & 2 & $\$ 2,879$ & 1440 & 52 & 1 & $\$ 2,979$ & 2979 & 52 & 1 & $\$ 2,979$ & 2979 & 46 & 1 & $\$ 2,979$ & 2979 \\
\hline 55 & 3 & $\$ 4,582$ & 1527 & & & & & & & & & & & & & & & & \\
\hline 52 & 6 & $\$ 11,586$ & 1931 & 49 & 6 & $\$ 11,586$ & 1931 & 48 & 5 & $\$ 11,586$ & 2317 & 47 & 5 & $\$ 11,586$ & 2317 & 39 & 8 & $\$ 12,833$ & 1604 \\
\hline & & & & & & & & & & & & & & & & & & & \\
\hline 57 & 1 & $\$ 4,333$ & 4333 & 53 & 2 & $\$ 4,333$ & 2167 & 52 & 1 & $\$ 4,333$ & 4333 & 51 & 1 & $\$ 4,333$ & 4333 & 46 & & $\$ 4,333$ & 4333 \\
\hline 57 & 1 & $\$ 2,125$ & 2125 & 54 & 1 & $\$ 2,125$ & 2125 & 52 & 1 & $\$ 2,125$ & 2125 & 51 & 1 & $\$ 3,256$ & 3256 & 46 & & $\$ 3,256$ & 3256 \\
\hline
\end{tabular}




\begin{tabular}{|r|r|r|r|r|r|r|r|}
\hline \multicolumn{5}{|c|}{ Round 16 } & \multicolumn{5}{|c|}{ Round 17 } \\
\hline Intensity & Saved & Cost & \$/Saved & Intensity & Saved & Cost & $\$ /$ Saved \\
\hline 30 & 9 & $\$ 16,993$ & 1888 & & & & \\
\hline 38 & 1 & $\$ 11,680$ & 11680 & 22 & 8 & $\$ 13,180$ & 1648 \\
\hline 38 & 1 & $\$ 2,979$ & 2979 & 29 & 1 & $\$ 2,979$ & 2979 \\
\hline & & & & & & & \\
\hline 38 & 1 & $\$ 15,080$ & 15080 & 29 & 1 & $\$ 15,080$ & 15080 \\
\hline & & & & & & & \\
\hline 38 & 1 & $\$ 4,333$ & 4333 & 29 & 1 & $\$ 4,333$ & 4333 \\
\hline 38 & 1 & $\$ 3,256$ & 3256 & 29 & 1 & $\$ 3,256$ & 3256 \\
\hline \multicolumn{7}{|c|}{ With TFA Intensity is 25: Final target met }
\end{tabular}

\section{War Time Home}

\begin{tabular}{|c|c|c|c|c|c|c|c|c|c|c|c|c|c|c|c|c|c|c|c|c|}
\hline Baseline: 209 & & Rou & ind 1 & & & Rour & nd 2 & & & Rour & nd 3 & & & Rour & nd 4 & & & Rour & nd 5 & \\
\hline Retrofit & Intensity & Saved & Cost & $\$$ /Saved & Intensity & Saved & Cost & $\$ /$ Saved & Intensity & Saved & Cost & $\$ /$ Saved & Intensity & Saved & Cost & $\$ /$ Saved & Intensity & Saved & Cost & $\$ /$ Saved \\
\hline Walls & 192 & 17 & $\$ 8,488$ & 499 & 174 & 19 & $\$ 8,488$ & 447 & 155 & 16 & $\$ 8,488$ & 530 & 132 & 16 & $\$ 8,488$ & 530 & 96 & 16 & $\$ 8,488$ & 530 \\
\hline Roof & 193 & 16 & $\$ 1,890$ & 118 & 191 & 2 & $\$ 2,155$ & 1078 & 170 & 1 & $\$ 2,155$ & 2155 & 147 & 1 & $\$ 2,155$ & 2155 & 111 & 1 & $\$ 2,155$ & 2155 \\
\hline Basement Walls & 187 & 22 & $\$ 6,467$ & 294 & 171 & 22 & $\$ 6,467$ & 294 & 153 & 18 & $\$ 6,467$ & 359 & 112 & 36 & $\$ 6,467$ & 180 & 109 & 3 & $\$ 6,699$ & 2233 \\
\hline Slab & 181 & 28 & $\$ 5,402$ & 193 & 166 & 27 & $\$ 5,402$ & 200 & 148 & 23 & $\$ 5,402$ & 235 & 146 & 2 & $\$ 5,720$ & 2860 & 109 & 3 & $\$ 5,720$ & 1907 \\
\hline Windows & 200 & 9 & $\$ 13,029$ & 1448 & 184 & 9 & $\$ 13,029$ & 1448 & 163 & 8 & $\$ 13,029$ & 1629 & 140 & 8 & $\$ 13,029$ & 1629 & 104 & 8 & $\$ 13,029$ & 1629 \\
\hline Air Sealing & 206 & 3 & $\$ 1,182$ & 394 & 190 & 3 & $\$ 1,182$ & 394 & 169 & 2 & $\$ 1,182$ & 591 & 146 & 2 & $\$ 1,182$ & 591 & 110 & & $\$ 1,182$ & 591 \\
\hline Heating/Cooling & 186 & 23 & $\$ 3,150$ & 137 & 171 & 22 & $\$ 3,150$ & 143 & 164 & 7 & $\$ 3,665$ & 524 & 142 & 6 & $\$ 3,665$ & 611 & 108 & & $\$ 3,665$ & 916 \\
\hline \begin{tabular}{|l|} 
Ventilation \\
\end{tabular} & 201 & 8 & $\$ 2,125$ & 266 & 186 & 7 & $\$ 2,125$ & 304 & 166 & 5 & $\$ 2,125$ & 425 & 141 & 7 & $\$ 2,125$ & 304 & 106 & 6 & $\$ 2,125$ & 354 \\
\hline
\end{tabular}

\begin{tabular}{|c|c|c|c|c|c|c|c|c|c|c|c|c|c|c|c|c|c|c|c|}
\hline \multicolumn{4}{|c|}{ Round 6} & \multicolumn{4}{|c|}{ Round 7} & \multicolumn{4}{|c|}{ Round 8} & \multicolumn{4}{|c|}{ Round 9} & \multicolumn{4}{|c|}{ Round 10} \\
\hline Intensity & Saved & Cost & $\$ /$ Saved & Intensity & Saved & Cost & \$/Saved & Intensity & Saved & Cost & \$/Saved & Intensity & Saved & Cost & $\$ /$ Saved & Intensity & Saved & Cost & \$/Saved \\
\hline 91 & 15 & $\$ 8,488$ & 566 & 69 & 22 & $\$ 10,470$ & 476 & 68 & 1 & $\$ 11,199$ & 11199 & 66 & 1 & $\$ 11,199$ & 11199 & 63 & 1 & $\$ 11,199$ & 11199 \\
\hline 105 & 1 & $\$ 2,155$ & 2155 & 90 & 1 & $\$ 2,155$ & 2155 & 68 & 1 & $\$ 2,155$ & 2155 & 66 & 1 & $\$ 2,155$ & 2155 & 63 & 1 & $\$ 2,155$ & 2155 \\
\hline 102 & 4 & $\$ 6,699$ & 1675 & 88 & 3 & $\$ 6,699$ & 2233 & 65 & 4 & $\$ 6,699$ & 1675 & 64 & 3 & $\$ 6,699$ & 2233 & 61 & 3 & $\$ 6,699$ & 2233 \\
\hline 102 & 4 & $\$ 5,720$ & 1430 & 88 & 3 & $\$ 5,720$ & 1907 & 66 & 3 & $\$ 5,720$ & 1907 & 64 & 3 & $\$ 5,720$ & 1907 & 61 & 3 & $\$ 5,720$ & 1907 \\
\hline 98 & 8 & $\$ 13,029$ & 1629 & 83 & 8 & $\$ 13,029$ & 1629 & 60 & 9 & $\$ 13,029$ & 1448 & 58 & 9 & $\$ 13,029$ & 1448 & 56 & 8 & $\$ 13,029$ & 1629 \\
\hline 104 & 2 & $\$ 1,182$ & 591 & 89 & 2 & $\$ 1,182$ & 591 & 67 & 2 & $\$ 1,182$ & 591 & & & & & & & & \\
\hline 101 & 5 & $\$ 3,665$ & 733 & 87 & 4 & $\$ 3,665$ & 916 & 66 & 3 & $\$ 3,665$ & 1222 & 64 & 3 & $\$ 3,665$ & 1222 & 62 & 2 & $\$ 4,333$ & 2167 \\
\hline 104 & 2 & $\$ 3,256$ & 1628 & 89 & 2 & $\$ 3,256$ & 1628 & 67 & 2 & $\$ 3,256$ & 1628 & 66 & 1 & $\$ 3,256$ & 3256 & 63 & 1 & $\$ 3,256$ & 3256 \\
\hline
\end{tabular}




\begin{tabular}{|c|c|c|c|c|c|c|c|c|c|c|c|c|c|c|c|c|c|c|c|}
\hline \multicolumn{4}{|c|}{ Round 11} & \multicolumn{4}{|c|}{ Round 12} & \multicolumn{4}{|c|}{ Round 13} & \multicolumn{4}{|c|}{ Round 14} & \multicolumn{4}{|c|}{ Round 15} \\
\hline Intensity & Saved & Cost & $\$ /$ Saved & Intensity & Saved & Cost & \$/Saved & Intensity & Saved & Cost & \$/Saved & Intensity & Saved & Cost & $\$$ /Saved & Intensity & Saved & Cost & \$/Saved \\
\hline 55 & 1 & $\$ 11,199$ & 11199 & 46 & 1 & $\$ 11,199$ & 11199 & 40 & 2 & $\$ 11,199$ & 5599 & 37 & 3 & $\$ 11,199$ & 3733 & 35 & 2 & $\$ 11,199$ & 5599 \\
\hline 55 & 1 & $\$ 2,155$ & 2155 & 42 & 5 & $\$ 3,655$ & 731 & 40 & 2 & $\$ 2,610$ & 1305 & & & & & & & & \\
\hline 54 & 2 & $\$ 6,699$ & 3349 & 45 & 2 & $\$ 6,699$ & 3349 & 38 & 4 & $\$ 6,699$ & 1675 & 37 & 3 & $\$ 6,699$ & 2233 & 35 & 2 & $\$ 6,699$ & 3349 \\
\hline 54 & 2 & $\$ 5,720$ & 2860 & 46 & 1 & $\$ 5,720$ & 5720 & 38 & 4 & $\$ 5,720$ & 1430 & 37 & 3 & $\$ 5,720$ & 1907 & 34 & 3 & $\$ 5,937$ & 1979 \\
\hline 47 & 9 & $\$ 14,471$ & 1608 & 44 & 3 & $\$ 17,067$ & 5689 & 37 & 5 & $\$ 17,067$ & 3413 & 37 & 3 & $\$ 17,067$ & 5689 & 34 & 3 & $\$ 17,067$ & 5689 \\
\hline & & & & & & & & & & & & & & & & & & & \\
\hline 55 & 1 & $\$ 4,333$ & 4333 & 46 & 1 & $\$ 4,333$ & 4333 & 40 & 2 & $\$ 4,333$ & 2167 & 39 & 1 & $\$ 4,333$ & 4333 & 36 & 1 & $\$ 4,333$ & 4333 \\
\hline 55 & 1 & $\$ 3,256$ & 3256 & 46 & 1 & $\$ 3,256$ & 3256 & 40 & 2 & $\$ 3,256$ & 1628 & 39 & 1 & $\$ 3,256$ & 3256 & 36 & & $\$ 3,256$ & 3256 \\
\hline & & & & Air Tightne & ess gets re & duced to 2 & $2 \mathrm{ACH}$ & & & & & & & & & & & & \\
\hline & & & & Level 2 wa & IIs and roo & f were en & mployed & & & & & & & & & & & & \\
\hline
\end{tabular}

\begin{tabular}{|c|c|c|c|c|c|c|c|c|c|c|c|c|c|c|c|c|c|c|c|}
\hline \multicolumn{4}{|c|}{ Round 16} & \multicolumn{4}{|c|}{ Round 17} & \multicolumn{4}{|c|}{ Round 18} & \multicolumn{4}{|c|}{ Round 19} & \multicolumn{4}{|c|}{ Round 20} \\
\hline Intensity & Saved & \begin{tabular}{|l|} 
Cost \\
\end{tabular} & $\$$ /Saved & \begin{tabular}{|l|} 
Intensity \\
\end{tabular} & Saved & \begin{tabular}{|l|} 
Cost \\
\end{tabular} & $\$ /$ Saved & \begin{tabular}{|l|} 
Intensity \\
\end{tabular} & Saved & Cost & $\$$ /Saved & Intensity & Saved & \begin{tabular}{|l|} 
Cost \\
\end{tabular} & $\$ /$ Saved & Intensity & Saved & Cost & $\$$ Saved \\
\hline 31 & 3 & $\$ 11,199$ & 3733 & 29 & 2 & $\$ 11,199$ & 5599 & 28 & 2 & $\$ 11,199$ & 5599 & 28 & & $\$ 11,199$ & 11199 & 27 & 1 & $\$ 11,199$ & 11199 \\
\hline & & & & & & & & & & & & & & & & & & & \\
\hline 31 & 3 & $\$ 6,699$ & 2233 & 30 & 1 & $\$ 6,878$ & 6878 & 29 & 1 & $\$ 6,878$ & 6878 & 28 & & $\$ 6,878$ & 6878 & 27 & 1 & $\$ 6,878$ & 6878 \\
\hline & & & & & & & & & & & & & & & & & & & \\
\hline 31 & 3 & $\$ 17,067$ & 5689 & 28 & 3 & $\$ 17,067$ & 5689 & 28 & 2 & $\$ 17,067$ & 8534 & 28 & & $\$ 17,067$ & 17067 & 27 & 1 & $\$ 17,067$ & 17067 \\
\hline & & & & & & & & & & & & & & & & & & & \\
\hline 33 & & $\$ 4,333$ & 4333 & 30 & 1 & $\$ 4,333$ & 4333 & 29 & & $\$ 4,333$ & 4333 & 28 & & $\$ 4,333$ & 4333 & & & & \\
\hline 33 & 1 & $\$ 3,256$ & 3256 & 30 & 1 & $\$ 3,256$ & 3256 & 29 & 1 & $\$ 3,726$ & 3726 & & & & & & & & \\
\hline
\end{tabular}

\begin{tabular}{|c|c|c|c|c|c|c|c|}
\hline \multicolumn{4}{|c|}{ Round 21} & \multicolumn{4}{|c|}{ Round 22} \\
\hline Intensity & Saved & Cost & $\$ /$ Saved & Intensity & Saved & Cost & $\$ /$ Saved \\
\hline 26 & 1 & $\$ 11,199$ & 11199 & 22 & 3 & $\$ 12,699$ & 4233 \\
\hline & & & & & & & \\
\hline & & & & & & & \\
\hline 25 & 2 & $\$ 17.067$ & 8534 & & & & \\
\hline & & & & & & & \\
\hline & & & & & & & \\
\hline & & & & & & & \\
\hline
\end{tabular}

With TFA Intensity is 23: Final Target Met 


\section{References}

Allinson, D., \& Hall, M. (2010) Hygrothermal analysis of a stabilised rammed earth test building in the UK. Energy and Buildings, 42(6), 845-852.

Asadi, E., da Silva, M. G., Antunes, C. H., \& Dias, L. (2012). Multi-objective optimization for building retrofit strategies: A model and an application. Energy \& Buildings, $44,81-87$.

ASHRAE. (1997). ASHRAE Handbook: Fundamentals. Atlanta, GA: American Society of Heating, Refrigeration and Air Conditioning Engineers.

ASHRAE. (2007). ASHRAE Guideline 14-2002R. Atlanta, GA: American Society of Heating, Refrigeration and Air Conditioning Engineers.

ASHRAE. (2009a). Standard 160-2009: criteria for moisture control design analysis in buildings. GA: American Society of Heating, Refrigeration and Air Conditioning Engineers.

ASHRAE. (2009b). Fundamentals. American Society of Heating, Refrigerating, and AirConditioning Engineers, Inc., Atlanta.

Aste, N., \& Del Pero, C. (2013). Energy retrofit of commercial buildings: case study and applied methodology. Energy Efficiency, 6, 407-423.

Aydinalp, M., Ferguson, A., Fung, A., Ugursal, I.V. (2001). Energuide for houses database analysis. Novia Scotia: Canadian Residential Energy End-use Data and Analysis Centre.

Badescu, V., \& Sicre, B. (2003). Renewable energy for passive house heating: building description. Energy and Buildings, 35, 1077-1084.

Bassett, E., \& Shandas, V. (2010). Innovation and climate action planning: perspectives from municipal plans. Journal of the American Planning Association, 76(4), 435450.

Bin, G., Parker, P. (2012). Measuring buildings for sustainability: Comparing the initial and retrofit ecological footprint of a century home - The REEP House. Applied Energy, 93, 24-32.

Blaszak, K. M. (2010). Towards sustainability: Prioritizing retrofit options for Toronto's single-family homes. Unpublished master dissertation, Ryerson University, Toronto, Canada. Available at:

http://digital.library.ryerson.ca/islandora/object/RULA\%3A1452 
Blaszak, K. M., \& Richman, R. (2013). Prioritizing method for retrofitting Toronto's single family housing stock to reduce heating and cooling loads. Journal of Architectural Engineering, 19(4), 229-224.

Burleton, D., Petramala, D. (2014). Housing in the greater Toronto area - several markets, several tales. Retrieved July 17, 2017, from the Toronto Dominion Bank Web site: http://www.td.com/document/PDF/economics/special/GTAHousing.pdf

Cameron, G. (1999). Trades council wants building retrofit plan: Energy and water consumption would be reduced. Daily Commercial News and Construction Record, 72(173), A1-A1, A7.

Canada Mortgage and Housing Corporation. (1947). 67 homes for Canadians. Central Mortgage and Housing, Ottawa, Canada. Available at: ftp://ftp.cmhcschl.gc.ca/chic-ccdh/HousePlans/CA1\%20MH\%2047S37_w.pdf

Canada Mortgage and Housing Corporation. (2008). Approaching net-zero energy in existing housing. Retrieved February 15, 2013, from the Canada Mortgage and Housing Corporation Web site: http://www.cmhcschl.gc.ca/odpub/pdf/66060.pdf?fr=1303770799406

Canadian Bankers Association. (2013). Changes to canada's mortgage market. Retrieved July 20, 2014, from the Canadian Bankers Association Web site: http://www.cba.ca/en/media-room/50-backgrounders-on-banking-issues/657changes-to-canadas-mortgage-market

Carll, C., TenWolde, A., \& Munson, R. (2007). Moisture performance of a contemporary wood-frame house operated at design indoor humidity levels. Retrieved June 10, 2013 from: http://www.ornl.gov/sci/buildings/2012/Session\%20PDFs/72_New.pdf

Centre for Energy. (2013). Heating and cooling. Retrieved February 15, 2013, from the Centre for Energy Web site: http://www.centreforenergy.com/Consumer/Resident ial/HeatingAndCooling/About.asp?page $=2$

City of Toronto. (2007). Energy efficiency and beyond: Toronto's sustainable energy plan. Retrieved February 15, 2013, from the City of Toronto Web site: http://www.toronto.ca/legdocs/mmis/2007/pe/bgrd/backgroundfile-4989.pdf

City of Toronto. (2013). Toronto neighbourhood profiles. Retrieved July 8, 2013, from the City of Toronto Web site: http://www.toronto.ca/demographics/neighbourhoods.htm

Cooperman, A., Dieckmann, J., \& Brodrick, J. (2011). Home envelope retrofits. ASHRAE Journal, 53(6), 82-85. 
Crawley, D., et al. (2004). EnergyPlus: New, capable, and linked. Journal of Architecture and Planning Research 21(4), 292 - 302.

Dembo, A. (2011). Least cost analysis of canadian new housing - identifying the most cost-effective specifications to achieve improved energy efficiency standards. Unpublished master dissertation, Ryerson University, Toronto, Canada. Available at: http://digital.library.ryerson.ca/islandora/object/RULA\%3A1016

Diakaki, C., Grigoroudis, E., \& Kolokotsa, D. (2008). Towards a multi-objective optimization approach for improving energy efficiency in buildings. Energy \& Buildings, 40(9), 1747-1754.

Efficiency Valuation Organisation. (2007). International Performance Measurement and Verification Protocol.

Eisenhower, B., O’Neill, Z., Narayanan, S., Fonoberov, V. A., Mezić, I. (2012). A methodology for meta-model based optimization in building energy models. Energy and Buildings, 47, 292-30

Enbridge Gas Distribution Inc. (2014). Is your bill high? Retrieved May 26, 2014 from the Enbridge Gas Distribution Inc. Web site: https://www.enbridgegas.com/homes/accounts-billing/is-your-bill-high.aspx

EnergyPlus, 2013. EnergyPlus Input Output Reference.

Entrop, A. G., Brouwers, H. J. H., \& Reinders, A. H. M. E. (2010). Evaluation of energy performance indicators and financial aspects of energy saving techniques in residential real estate. Energy \& Buildings, 42(5), 618-629.

Environmental Protection Agency. (2014). Product finder. Retrieved April 2, 2014, from the Energy Star Web site: http://www.energystar.gov/certified-products/certifiedproducts?c=products.pr_find_es_products

Flourentzou, F., \& Roulet, C. (2002). Elaboration of retrofit scenarios. Energy and Buildings, 34(2), 185-192.

Foley, H. C. (2012). Challenges and opportunities in engineered retrofits of buildings for improved energy efficiency and habitability. AIChE Journal, 58(3), 658-677.

Government of Canada. (2014). Monthly climate summaries. Retrieved May 26, 2014, from the Government of Canada Web site: http://climate.weather.gc.ca/prods_servs/cdn_climate_summary_e.html

Gowri, K., Winiarski, D., Jarnagin, R. (2009). Infiltration modeling guidelines for commercial building energy analysis. Retrieved October 17, 2013, from the 
California Energy Commission Web site:

http://www.energy.ca.gov/title24/2013standards/rulemaking/documents/public_co mments/45-day/2012-05-15_Infiltration_Modeling_Guidelines_for_Commercial_ Building_Energy_Analysis_TN-65229.pdf

Hamada, Y., Nakamura, M., Ochifuji, K., Yokoyama, S., \& Nagano, K. (2003).

Development of a database of low energy homes around the world and analysis of their trends. Renewable Energy, 28, 321-328.

Hannu, A., \& Viitanen, H. A. (1997). Modelling the time factor in the development of mould fungi - the effect of critical humidity and temperature conditions on pine and spruce sapwood. Holzforschung, 51, 6-14.

Harvey, L., D. (2009). Reducing energy use in the buildings sector: measures, costs, and examples. Energy Efficiency, 2(2), 139-163.

Henninger, R. and Witte, M. (2013). EnergyPlus testing with building thermal envelope and fabric load tests from ANSI/ASHRAE standard 140-2011. Ernest Orlando Lawrence Berkeley National Laboratory. Retrieved October 2013 from: http://apps1.eere.energy.gov/buildings/energyplus/pdfs/energyplus_ashrae_140_ envelope.pdf

Hoicka, C. E., \& Parker, P. (2011). Residential energy efficiency programs retrofit choices and greenhouse gas emissions savings: A decade of energy efficiency improvements in waterloo region, canada. International Journal of Energy Research, 35(15), 1312-1324.

Hubler, D., Tupper, K., Greensfelder, E. (2010). Pulling the levers on existing buildings: a simple method for calibrating hourly energy models. ASHRAE Transactions, 16(2), 2-8).

Hukka, A., \& Viitanen, H. A. (1999). A mathematical model of mould growth on wooden material. Wood Science and Technology, 33(6), 475-485.

Johansson, P., Ekstrand-Tobin, A., Svensson, T., \& Bok, G. (2012) Laboratory study to determine the critical moisture level for mould growth on building materials. International Biodeterioration and Biodegradation, 73, 23-32.

Krus, M., Sedlbauer, K., Zillig, W., \& Kunzel, H. M. (2001). A new model for mould prediction and its application on a test roof. Paper presented at II International Scientific Conference: The Current Problems of Building-Physics in the Rural Building, Cracow, Poland. 
LBNL. (2014). Window. Retrieved April 2, 2014, from the Lawrence Berkeley National Laboratory Web site: http://windows.lbl.gov/software/window/window.html

Lstiburek, J. (2002). Moisture control for buildings. ASHRAE Journal, 44(2), 36.

Lstiburek, J., Schumacher, C. (2011). Hygrothermal analysis of california attics. Retrieved April 11, 2014, from the Building Science Corporation Web site: http://www.buildingscience.com/documents/reports/rr-1110-hygrothermalanalysis-california-attics/view?searchterm=california\%20roofs

Ma, Z., Cooper, P., Daly, D., \& Ledo, L. (2012). Existing building retrofits: Methodology and state-of-the-art. Energy and Buildings, 55(2012), 889-902.

Markiel, I. (2011). Energy performance of sustainable renovation index retrofits in Toronto's residential housing stock. Unpublished master dissertation, Ryerson University, Toronto, Canada.

McNulty, M. (2003). Give durability a chance. Professional Builder, 68(10), 55-56.

Meldem, R. Winkelmann, F. (1995). Comparison of DOE-2 with Measurements in the Pala Test Houses. Energy and Buildings, (27)1. 69-81.

Menassa, C. C. (2011). Evaluating sustainable retrofits in existing buildings under uncertainty. Energy and Buildings, 43(12), 3576-3583.

Mucciarone, A. (2011). Towards a proposed framework for analyzing sustainable renovation building envelope assemblies. Unpublished master dissertation, Ryerson University, Toronto, Canada.

Munro, M. (2009). Former PMs want stimulus to be green; why should canada be left behind? The Province, pp. A.26.

National Renewable Energy Laboratory. (2010). Opt-e-plus software for commercial building optimization. Retrieved July 14, 2014, from the National Renewable Energy Laboratory Web site: http://www.nrel.gov/tech_deployment/pdfs/45620.pdf

National Renewable Energy Laboratory. (2014). Beopt. Retrieved July 14, 2014, from the National Renewable Energy Laboratory Web site: https://beopt.nrel.gov/

Natural Resources Canada - CanmetENERGY. (2009). The urban archetypes project: the city of Ottawa. Retrieved on April 1, 2013 from: http://canmetenergy.nrcan.gc.ca/sites/canmetenergy.nrcan.gc.ca/files/files/pubs/ ottawa_e.pdf 
Norman, J., MacLean, H., \& Kennedy, C. (2006). Comparing high and low residential density: life-cycle analysis of energy use and greenhouse gas emissions. Journal of Urban Planning and Development, 132(1), 10-21.

NRC IRC. 2011. National Energy Code of Canada for Buildings. Ottawa, ON: Government of Canada.

Olgyay, V., \& Seruto, C. (2010). Whole-building retrofits: A gateway to climate stabilization. ASHRAE Transactions, 116, 244-251.

Ontario Building Code (OBC). (2012). Ontario Ministry of Municipal Affairs and Housing, Building and Development Branch.

Ontario Energy Board. (2014). Natural gas rate updates. Retrieved July 20, 2014, from the Ontario Energy Board Web site: http://www.ontarioenergyboard.ca/OEB/Con sumers/Natural+Gas/Natural+Gas+Rates

Pappas, A., PE, \& Reilly, S., PE. (2011). Streamlining energy simulation to identify building retrofits. ASHRAE Journal, 53(11), 32-42.

Parker, P., Rowlands, I.H. \& Scott, D. (2003). Innovations to reduce residential energy use and carbon emissions: an integrated approach. The Canadian Geographer, 47(2), 169-84.

Passive House Institute. (2012). Enerphit and enerphit+i. Retrieved May 30, 2013 from: http://www.passiv.de/downloads/03_enerphit_criteria_en.pdf

Passive House Institute. (2013a). What is a passive house. Retrieved May 30, 2013 from: http://passipedia.passiv.de/passipedia_en/basics/what_is_a_passive_house

Passive House Institute. (2013b). Energy balances - background. Retrieved May 30, 2013 from: http://passipedia.passiv.de/passipedia_en/planning/calculating_energ y_efficiency/energy_balances_-_background?s[]=treated\&s[]=floor\&s[]=area

Pitt, D., Randolph, J., St Jean, D., \& Chang, M. (2012). Estimating potential communitywide energy and greenhouse gas emissions savings from residential energy retrofits. Energy and Environment Research, 2(1), 44-61.

Procter, D. (2011). Green loan innovation. Daily Commercial News and Construction Record, 84(35), N_A.

Qasass, R., Gorgolewski, M., Ge, H. (2014). Timber framing factors in toronto residential house construction. Architectural Science Review, 57(3), 1-10. 
Raftery, P., Keane, M., O'Donnell, J. (2011). Calibrating whole building energy models: an evidence-based methodology. Energy and Buildings, 43(2011), 2356-2364.

Rysanek, A. M., \& Choudhary, R. (2012). A decoupled whole-building simulation engine for rapid exhaustive search of low-carbon and low-energy building refurbishment options. Building and Environment, 50(0), 21-33.

Rysanek, A. M., \& Choudhary, R. (2013). Optimum building energy retrofits under technical and economic uncertainty. Energy \& Buildings, 57, 324-337.

Sharp, B. (2012). Ontario electricity price increase forecast: december 2011 to december 2016. Retrieved July 20, 2014, from the Ontario Energy Board Web site: http://www.ontarioenergyboard.ca/oeb/_Documents/EB-2010-0337/CME _SUB_Ontario\%20Elec\%20Price\%20Increase\%20Forecast\%202012.pdf

Shonder, J. A., \& Im, P. (2012). Bayesian analysis of savings from retrofit projects. ASHRAE Transactions, 118, 367-379.

Smulski, S. (1999). Durability of energy-efficient wood-frame houses. Forest Products Journal, 49(5), 8-15.

Straube, J. (2011). Building america special research project: high R-value enclosures for high performance residential buildings in all climate zones. Retrieved April 2, 2014, from the Building Science Corporation Web site:

http://www.buildingscience.com/documents/bareports/ba-1005-building-americahigh-r-value-high-performance-residential-buildings-all-climate-zones/view? Searchterm=Research\%20Project:\%20High\%20R-value\%20Enclosures\%20for\% 20High\%20Performance\%20Residential\%20Buildings\%20in\%20All\%20Climate $\% 20 Z$ Znes

Straube, J., Grin, A. (2010). Building america special research project: high-R roofs case study analysis. Retrieved April 2, 2014, from the Building Science Corporation Web site: http://www.buildingscience.com/documents/bareports/ba1006-ba-high-r-roofs-case-studyanalysis/view?searchterm=Research\%20Project: $\% 20 H i g h \% 20 \mathrm{R}$-Value\%20Enclosures\%20for\%20High\%20Performance\%20 Residential\%20Buildings\%20in\%20All\%20Climate\%20Zones

Straube, J., Finch, G. (2009). Ventilated wall claddings: review, field performance, and hygrothermal modeling. Retrieved April 11, 2014, from the Building Science Corporation Web site: http://www.buildingscience.com/documents/reports/rr0907-ventilated-wall-claddings-review-performancemodeling/view?searchterm=ventilated\%20wall\%20claddings 
Sustainable Buildings Canada, (2012). Cost/benefit analysis of proposed energy efficiency requirements for the toronto green standard: final report. Retrieved July 20, 2014, from the Toronto Atmospheric Fund, TowerWise Web site: http://www.towerwise.ca/wp-content/uploads/2013/07/TGS-Phase-II-CostBenefit-Analysis.pdf

TenWolde, A. (2008). ASHRAE standard 160P-criteria for moisture control design analysis in buildings. ASHRAE Transactions, 114, 167-171.

Timothy C Wagner. (2012). The current state of energy retrofits for small and medium buildings. ASHRAE Transactions, 118, 333-340.

Toronto City Directory. (2010). General information guide for toronto. Retrieved May 22, 2013 from: http://www.toronto-city.info/

Toronto Hydro. (2014). Summer time's in bloom: new rates, new hours, starting may 1, 2014. Retrieved July 20, 2014, from the Toronto Hydro Web site: http://www.torontohydro.com/sites/electricsystem/residential/yourbilloverview/pag es/tourates.aspx

Trading Economics, (2014). Canada inflation rate. Retrieved July 20, 2014, from the Trading Economics Web site: http://www.tradingeconomics.com/canada/inflationcpi

US Department Of Energy. (2008). M\&V guidelines: measurement and verification for federal energy projects version 3.0. Retrieved May 6, 2014 from the Lawrence Berkeley National Laboratory Web site: http://mnv.lbl.gov/keyMnVDocs/femp

VandeWeghe, J. R., \& Kennedy, C. (2007). A spatial analysis of residential greenhouse gas emissions in the toronto census metropolitan area. Journal of Industrial Ecology, 11(2), 133-144.

Waier, P. R., Babbitt, C., Balboni, B., Charest, A. C. (2012). RS Means building construction cost data 2012. R. S. Means Company Incorporated.

Yoon, J., Lee, E. J., Claridge, D. E. (2003). Calibration procedure for energy performance simulation of a commercial building. ASME Journal of Solar Energy, 125(3), 251-257.

Zirnhelt, H. (2013). Using calibrated simulation to quantify the energy savings from residential passive solar design in canada. Unpublished master dissertation, Ryerson University, Toronto, Canada. Available at: http://digital.library.ryerson.ca/islandora/object/RULA\%3A195 